\title{
UNIVERSAL PROGRAMMABLE BATTERY CHARGER WITH OPTIONAL BATTERY MANAGEMENT SYSTEM
}

\author{
A Thesis \\ presented to \\ the Faculty of California Polytechnic State University, \\ San Luis Obispo
}

In Partial Fulfillment

of the Requirements for the Degree

Master of Science in Electrical Engineering

By

Michael DeSando

June 2015 
(C) 2015

Michael DeSando

ALL RIGHTS RESERVED 


\section{COMMITTEE MEMBERSHIP}

TITLE:

AUTHOR:

DATE SUBMITTED:

COMMITTEE CHAIR:

COMMITTEE MEMBER:

COMMITTEE MEMBER:
Universal Programmable Battery Charger with Optional Battery Management System

Michael DeSando

June 2015

David B. Braun, Ph.D.

Professor in Electrical Engineering

Dale Dolan, Ph.D.

Associate Professor in Electrical Engineering

John S. Dunning, Ph.D.

Research Scholar in Residence - Cal Poly 


\begin{abstract}
Universal Programmable Battery Charger with Optional Battery Management System
\end{abstract}

Michael DeSando

In today's world, nearly everyone owns some electronic device whether a phone, laptop, tablet, or any other device that uses a rechargeable battery. A problem arises when each device uses different batteries with different chemistry or power requirements meaning they each require a different charger. To create a more sustainable future, we need to reduce the number of battery chargers created, and thus disposed of when outdated, by reducing the number of battery chargers required to charge all the devices in everyday life. This project aims to reduce the number of battery chargers by creating a programmable system that encompasses functionality and features found in a variety of battery chargers currently on the market. Non-programmable chargers offer multi-cell operation but are limited by single types of cells rather than cells of varying voltage, current requirements, or chemistries. Programmable battery chargers currently on the market are limited to single cell or single chemistry operation. The "universal" chargers that charge a variety of cells of different chemistries use asynchronous topologies, which result in lower efficiency than a synchronous topology. These chargers also fail to offer multiple charge modes per chemistry allowing the tradeoff between faster charging or extending the lifetime of the battery. This project combines the capability of many battery chargers into a single programmable system that allows ultimate flexibility in terms of charge profiles and adding features as battery technology improves in the future.

This report demonstrates improvements made in battery charging and battery management technology through the design of a universal programmable battery charger with optional battery management system attachment. This charger offers improvements in charge efficiency and unique battery charging algorithms to charge a variety of battery chemistries with variety of power requirements. Improvements in efficiency result from a synchronous Buck Controller topology as compared to previous universal chargers that use asynchronous BuckBoost Converter topologies. This battery charger also surpasses current universal battery chargers by offering different charge modes for different battery chemistries. Charge modes provide the user an option between extending the life of the battery by selecting a mode with a slower, less stressful charge rate or a shorter charge time with a fast, more stressful charging mode. The user can also choose a charge mode in which the battery charges to full capacity, resulting in maximum runtime or a less than full capacity, which puts less stress on the battery thus extending the lifetime. Ultimately, this system permits weighing the performance tradeoff of battery lifetime and charge time. The optional BMS attachment offers more precise monitoring of each cell and cell balancing for Li-Ion batteries. This further enhances the performance of the charger when integrated, but is not necessary for charger operation.

The universal programmable battery charger consists of three subcircuits: A microcontroller unit, a power stage, and a current sensing circuit. A C2000 Piccolo F28069 microcontroller controls a LM5117 Buck Controller by injecting a pulse-width modulated signal into the feedback node controlling the output of the buck to set a constant current or constant voltage thus creating a programmable battery charger. The pulse-width modulated signal changes 
according to charge algorithms created in software for specific battery chemistries and charge requirements. An analog-to-digital converter on the microcontroller monitors battery voltage by using a voltage divider and an INA169 current shunt monitor, which outputs a voltage corresponding to the charge current to another analog-to-digital converter on the microcontroller, monitors the charge current. This allows the charger program to maintain correct and safe charging conditions for each charge mode in addition to measuring output power. Lights on the microcontroller display a real-time status to the user of which portion of the charge profile the charger is in. A solid red light means the charger is in the constant current portion of the charge profile. A blinking red light means the charger is in the constant voltage portion. No red light means the battery charger finished and the battery is currently charged above nominal voltage. The battery charger works with the battery management system in the next section to provide ultimate battery charging and managing capabilities.

The battery management system consists of two subcircuits: A microcontroller and a battery monitoring circuit. The MSP430FR5969 microcontroller unit communicates with BQ76PL536 battery management integrated circuits to create a battery management system that monitors data such as cell voltage, pack voltage, pack temperature, state of charge, fault statuses, alert statuses, and a variety of other useful cell parameters. This data displays on a liquid crystal display screen through different menu options. The user scrolls through the menus using a capacitive touch slider on the microcontroller unit and selects a given option using the option select button. A cell balance mode allows the user to check the balance of the cells and allows cell balancing if the cells differ by more than a set threshold. 


\section{ACKNOWLEDGMENTS}

Thank you to my advisor, David Braun, for advice, guidance, and support throughout the project. A special thank you goes to John Dunning for his guidance and insight throughout the project specifically relating to batteries and charger testing. Also thank you to Dale Dolan for being on my Thesis committee. Thank you to Texas Instruments for hardware and software assistance, component and battery related documentation, and for making this project possible. Thank you to Isidor Buchman, the Founder, President, and CEO of Cadex Electronics Inc., for providing free battery knowledge on the Battery University website. Also thank you to Barrie Lawson, the writer and website maintainer for Electropaedia. He provides free material relating to batteries for educational purposes copyright by Woodbank Communications Ltd, a battery consultancy based in Chester, UK. The most important acknowledgement goes to Bob Sheehan and Hrag Kasparian for guiding me throughout this project from conception to completion. I thank you for the lessons and knowledge you provided me along with the time you dedicated to answering all my questions 


\section{TABLE OF CONTENTS}

Page

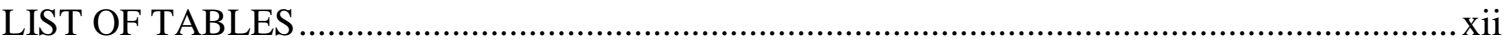

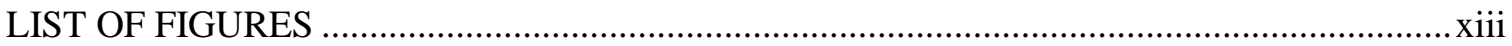

\section{CHAPTERS}

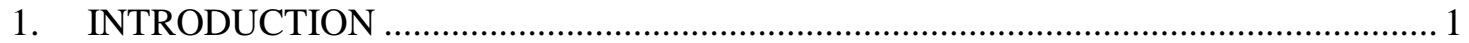

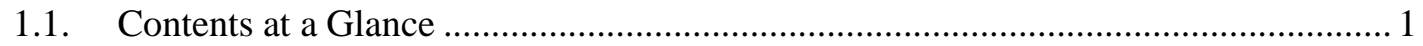

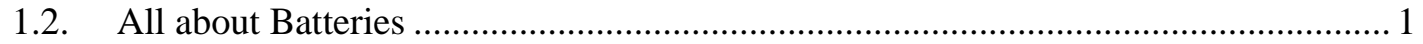

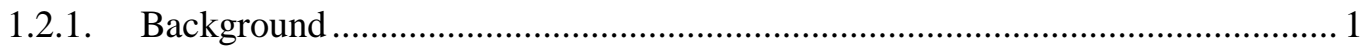

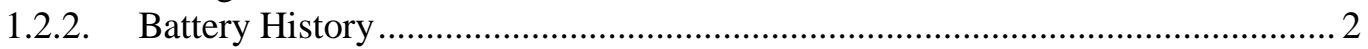

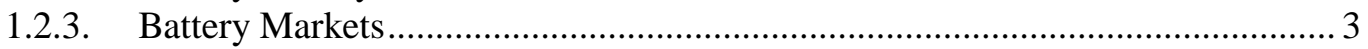

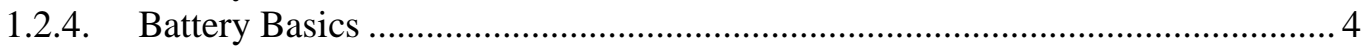

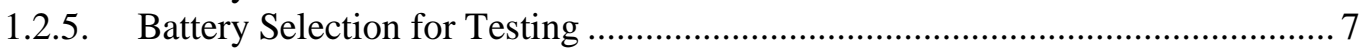

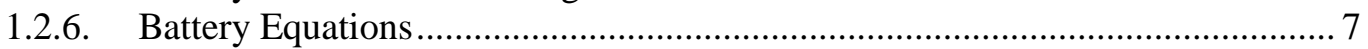

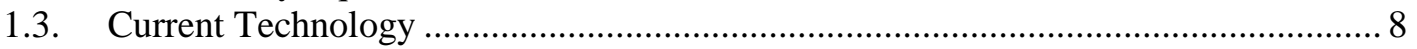

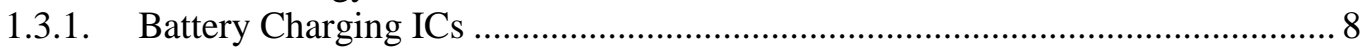

1.3.2. Battery Management ICs ......................................................................... 9

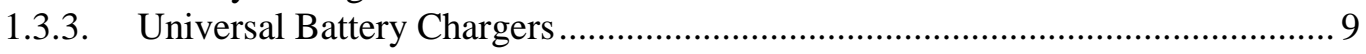

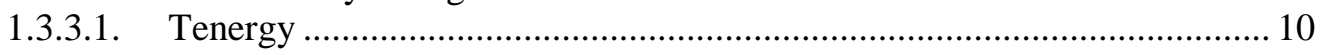

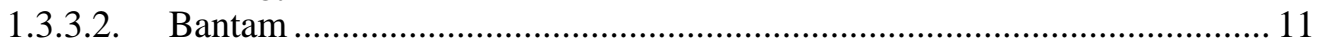

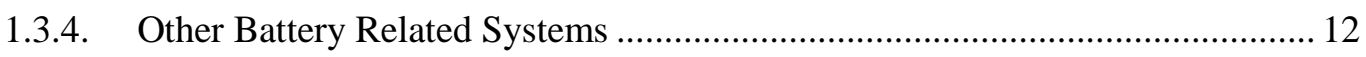

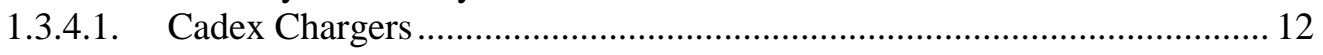

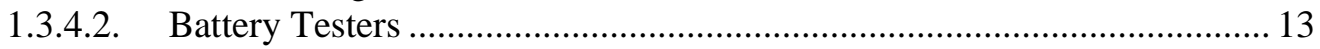

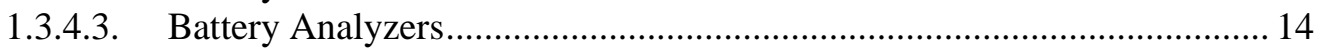

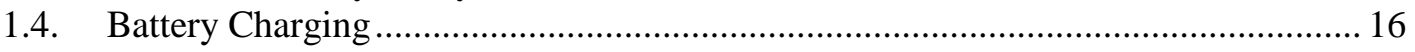

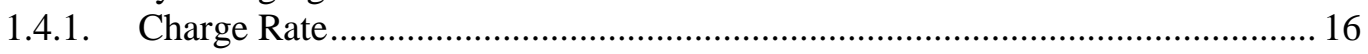

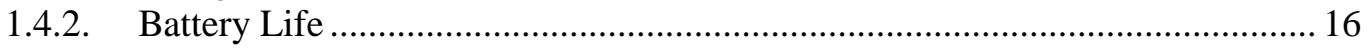

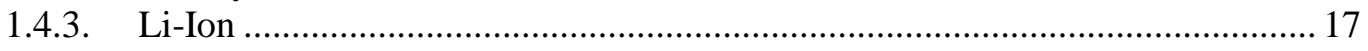

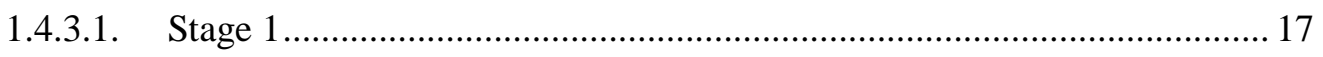

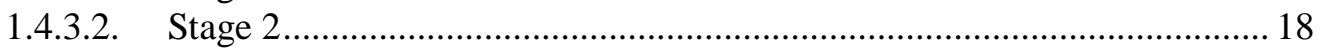

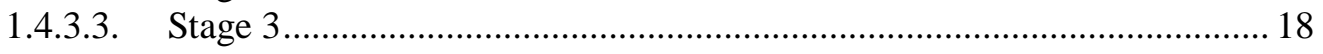

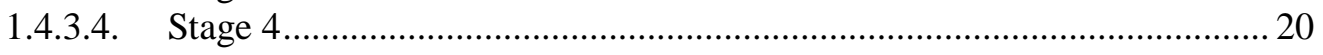

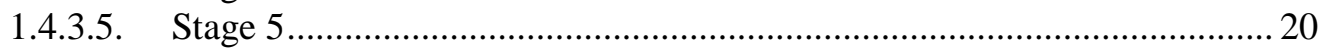

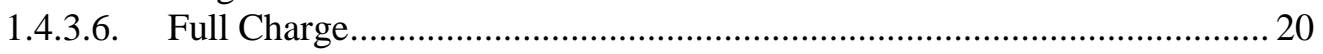

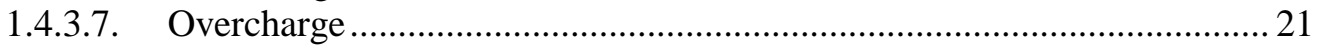

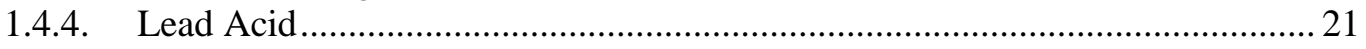

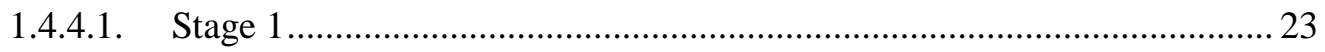

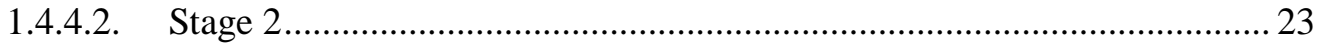

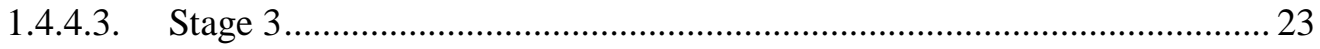

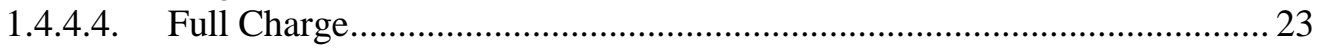




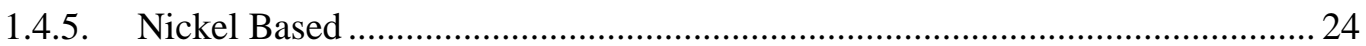

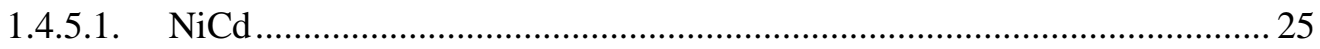

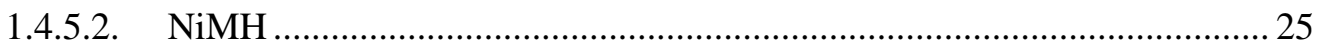

1.4.5.3. Full Charge Detection by Temperature .................................................... 26

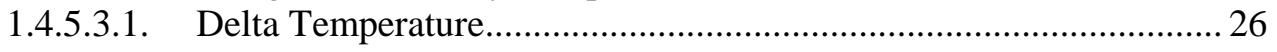

1.4.5.3.2. Delta Temperature over Delta Time (Slope Detection) ......................2 26

1.4.5.3.3. Fixed Temperature ...…………………………………………... 26

1.4.5.4. Full Charge Detection by Voltage …………………………………..... 26

1.4.5.4.1. Negative Delta Voltage (NDV) ....................................................2 26

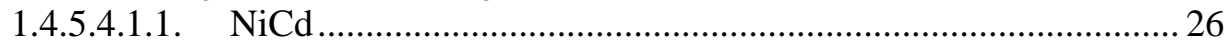

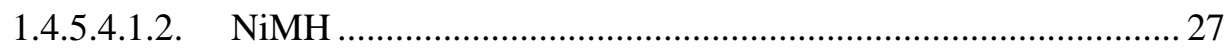

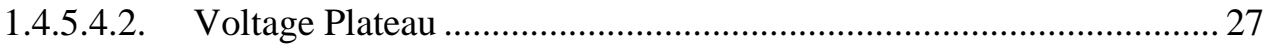

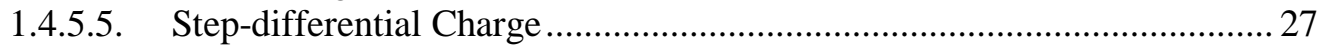

1.4.5.6. Trickle Charge ………………………………………………….... 27

1.4.5.7. Charging Flooded NiCd .................................................................... 28

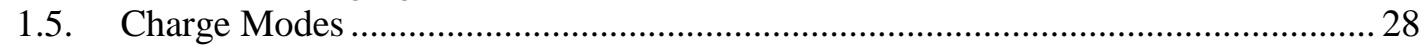

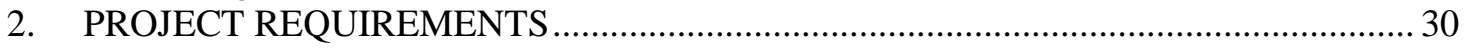

2.1. Design Requirements ............................................................................. 30

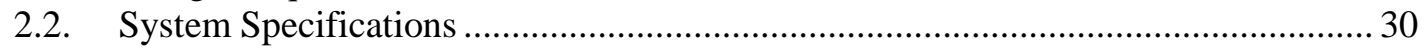

2.2.1. Universal Battery Charger …………………………………………….... 30

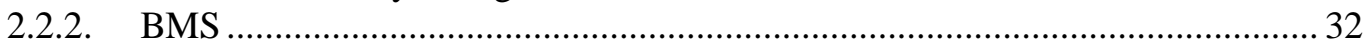

2.2.3. User Interface \& Protection ............................................................................ 33

2.3. Primary Constraints …………………………………………………………..... 33

2.4. System Decomposition ..................................................................................... 37

3. UNIVERSAL PROGRAMMABLE BATTERY CHARGER ........................................ 38

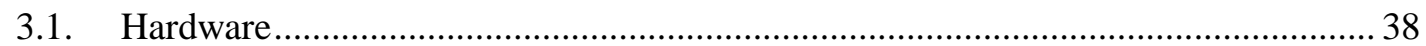

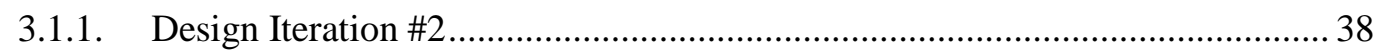

3.1.1.1. LM5117 Wide-Vin Syncronous Buck Controller [10] .............................. 39

3.1.1.2. Buck Converter .................................................................................... 39

3.1.1.3. MCU (host device) .............................................................................. 41

3.1.1.3.1. Design Iteration \#2 - C2000 LAUNCHXL-F28069M [11,12]........ 41

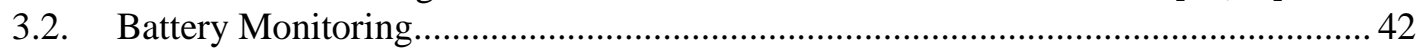

3.2.1. Measuring Battery Voltage ……………………………………………….... 43

3.2.1.1. Design Iteration \#2 ......................................................................... 43

3.2.2. Current Sense ……………………………………………………….... 43

3.2.2.1. Design Iteration \#2: INA169 Current Shunt Monitor ................................ 43

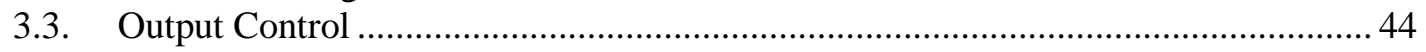

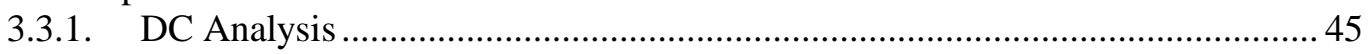

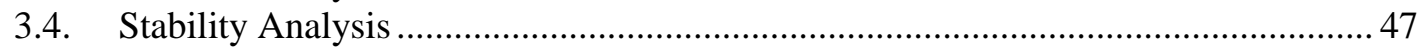

3.4.1. LM5117 Controller with Buck Converter......................................................... 48

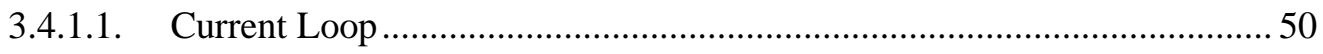

3.4.1.2. Voltage Loop ………………………………….............................. 52

3.4.2. INA169 Current Shunt Monitor ...................................................................... 53

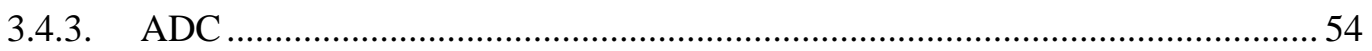

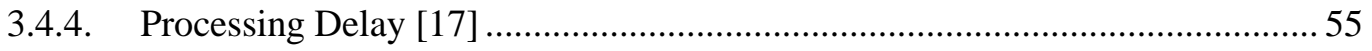

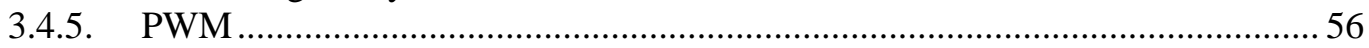

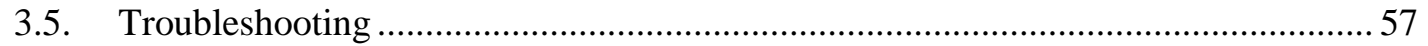

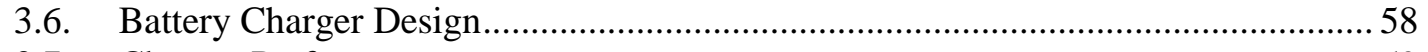

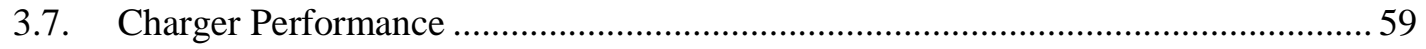

3.7.1. Charger Profiles ……………………………………………………….... 60

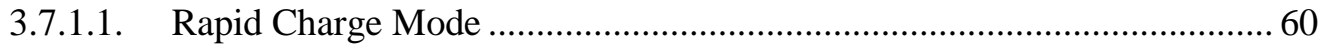




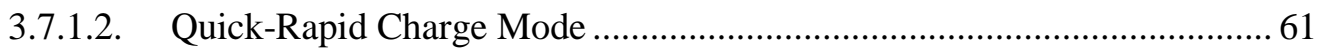

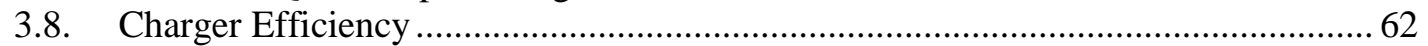

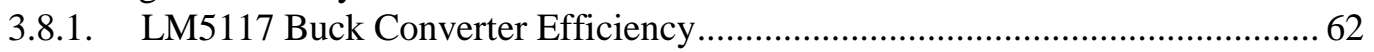

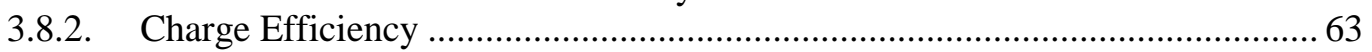

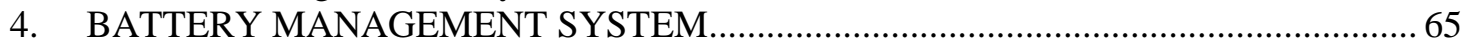

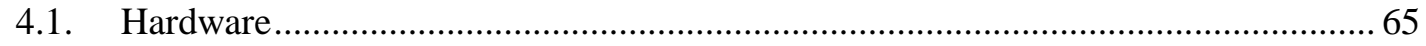

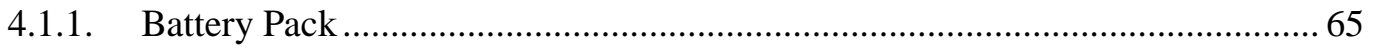

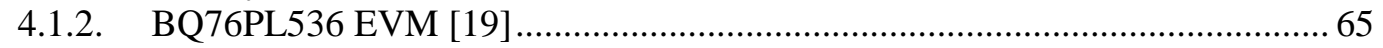

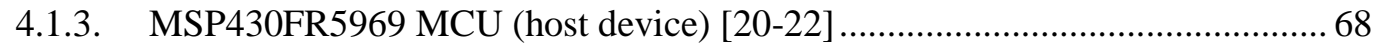

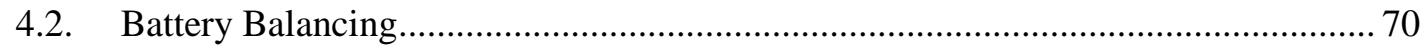

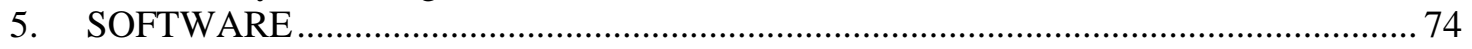

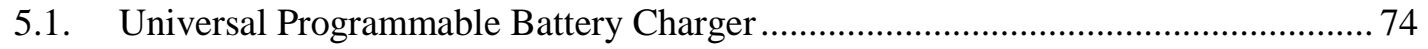

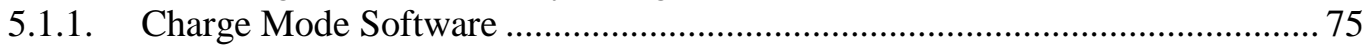

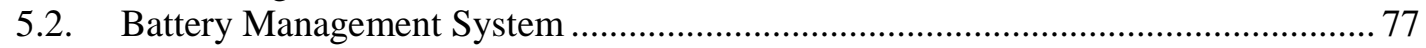

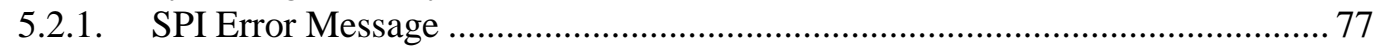

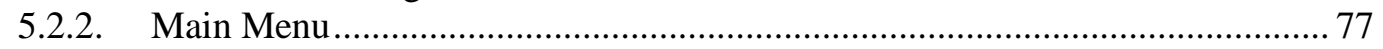

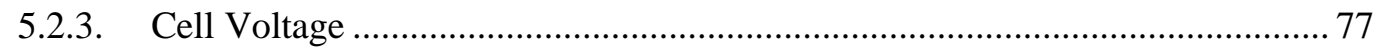

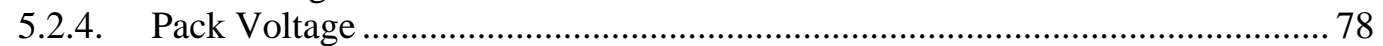

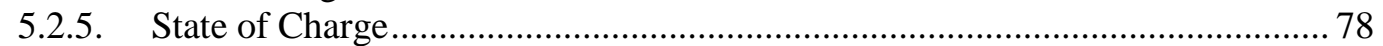

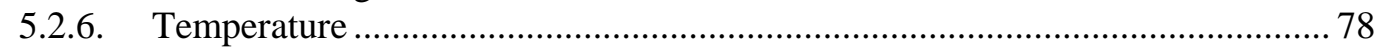

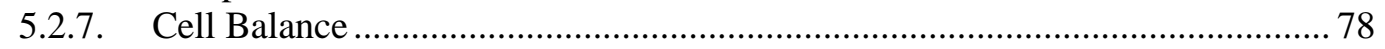

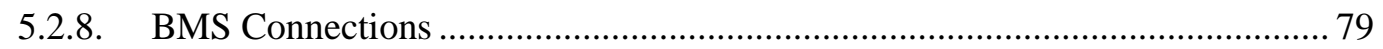

5.2.8.1. Between battery pack and EVM ............................................................. 79

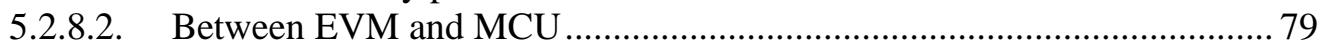

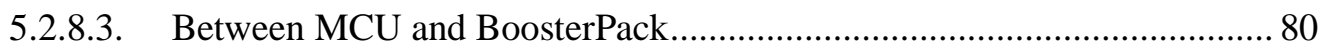

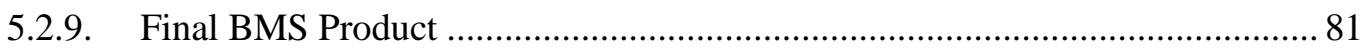

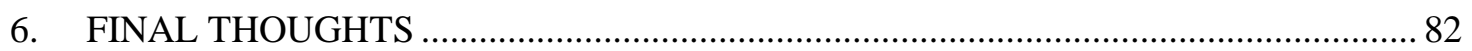

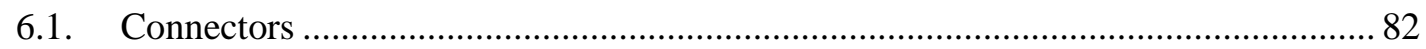

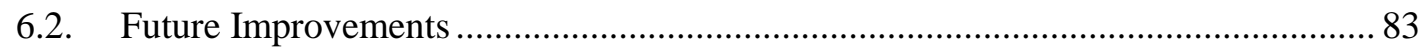

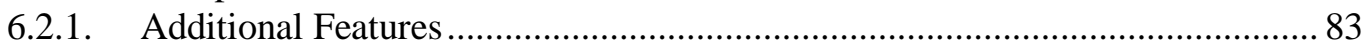

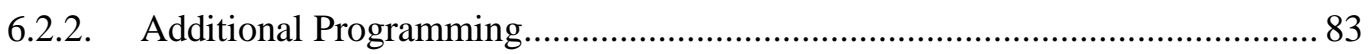

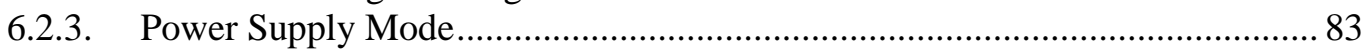

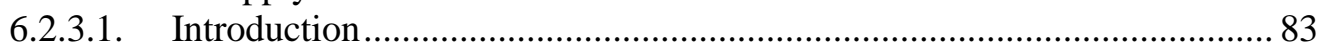

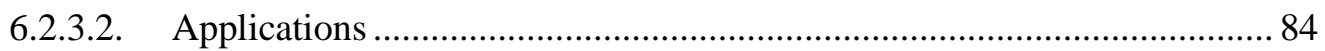

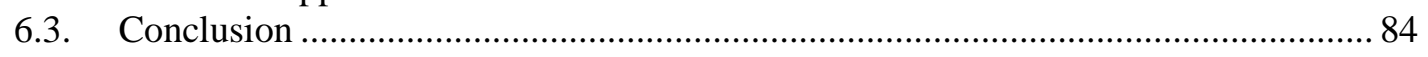

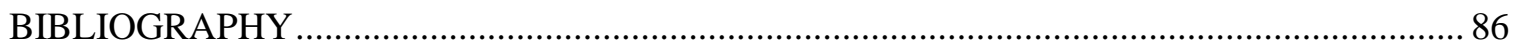

\section{APPENDICES}

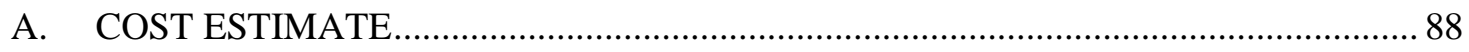

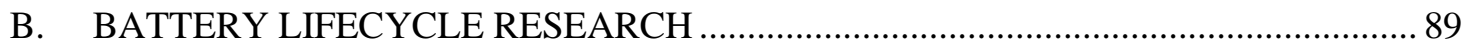

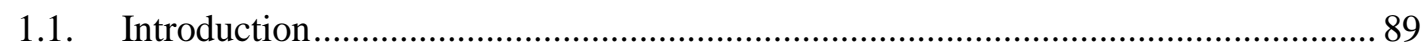

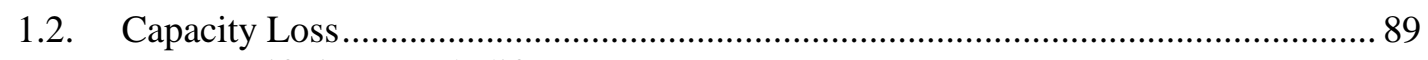

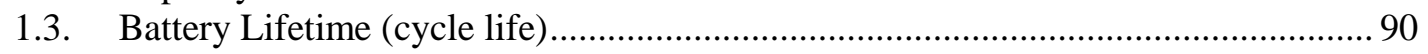

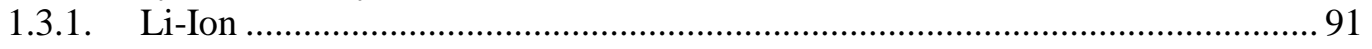

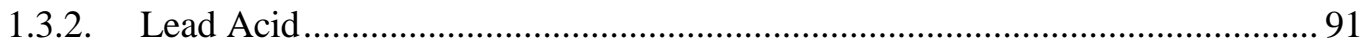

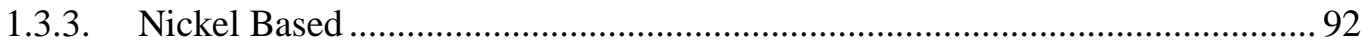

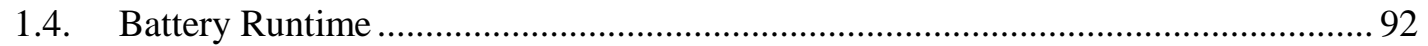

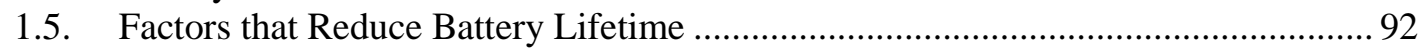

1.5.1. Number of Charge \& Discharge Cycles............................................................. 92

1.5.2. Charge \& Discharge Rate ................................................................................. 93 


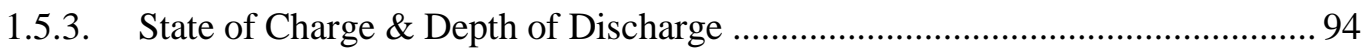

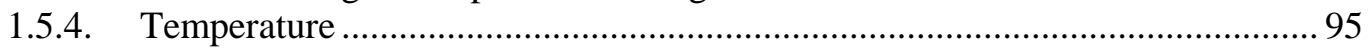

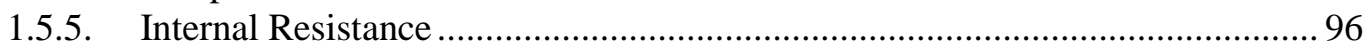

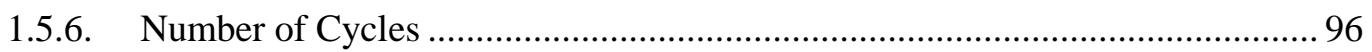

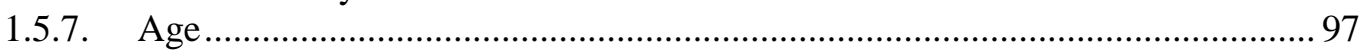

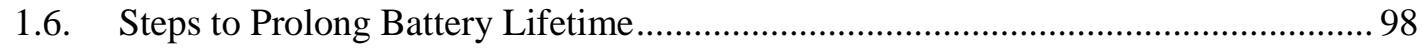

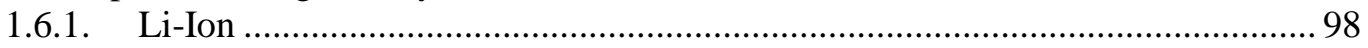

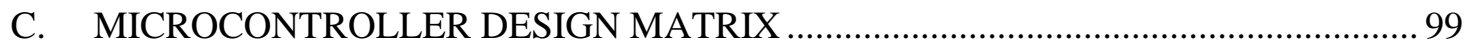

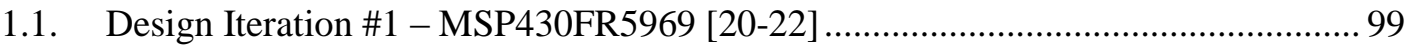

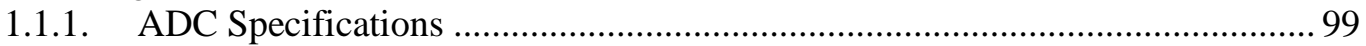

1.2. Design Iteration \#2 - C2000 LAUNCHXL-F28069M [11-14] ................................ 100

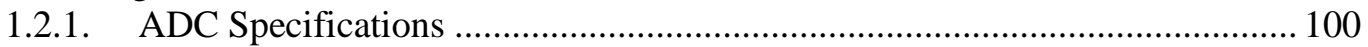

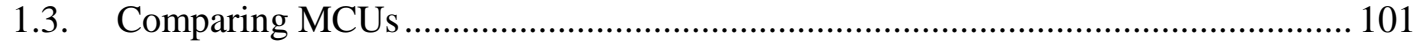

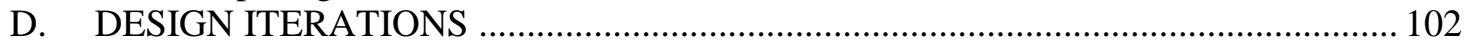

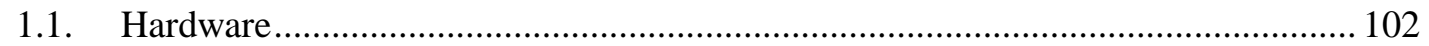

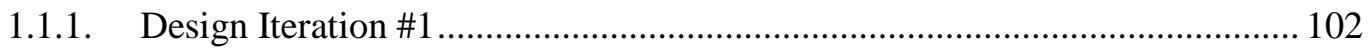

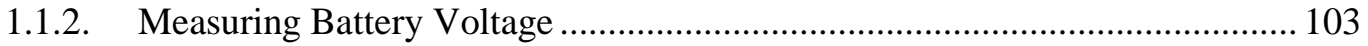

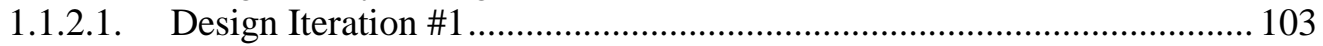

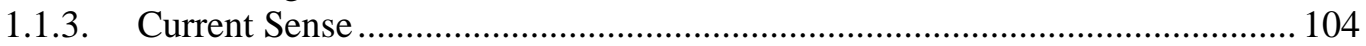

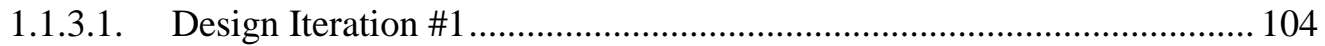

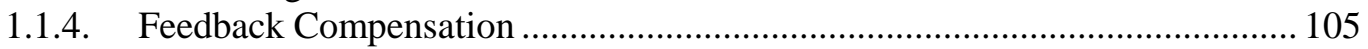

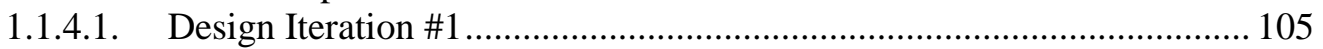

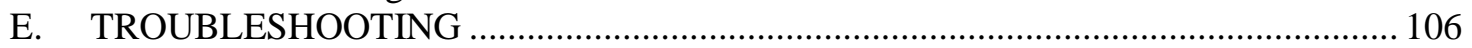

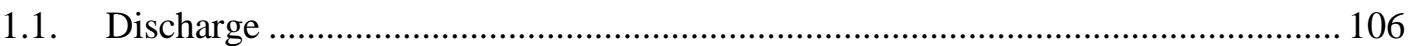

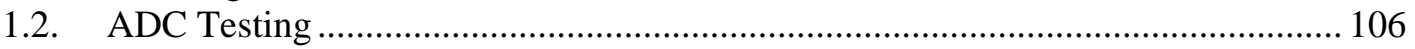

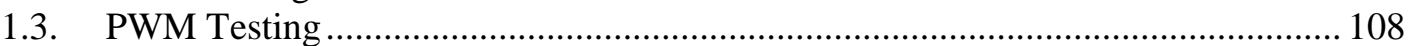

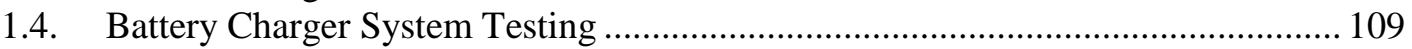

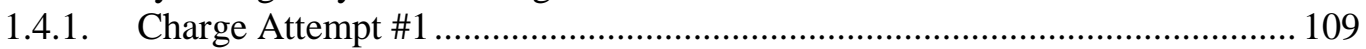

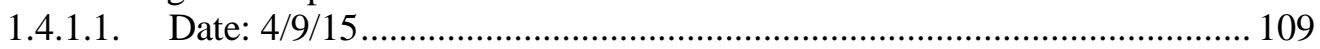

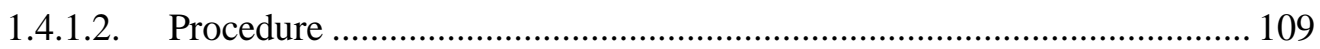

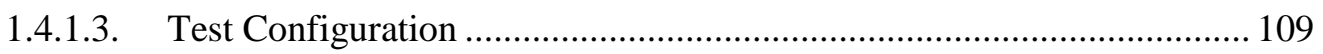

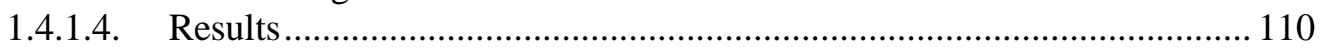

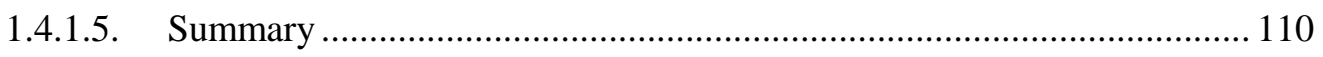

1.4.1.6. Things to Check before Next Charge ................................................. 110

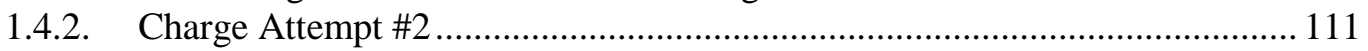

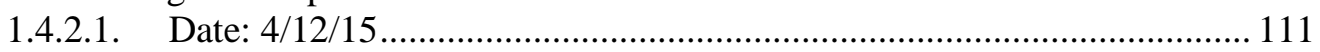

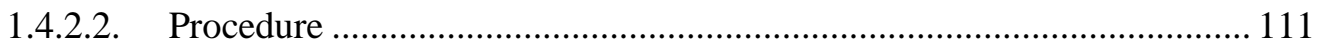

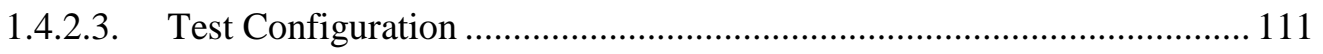

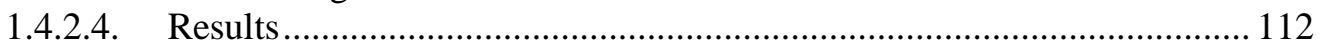

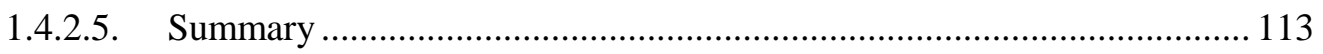

1.4.2.6. Things to Check Before Next Charge .................................................... 113

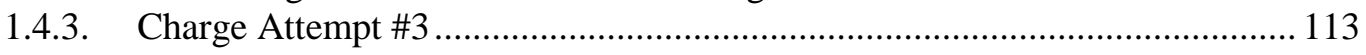

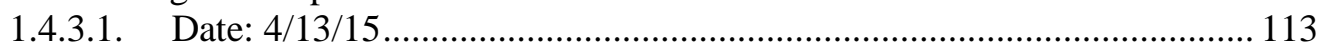

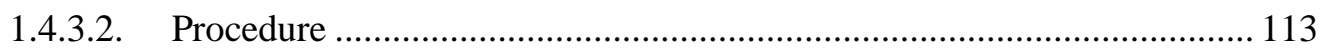

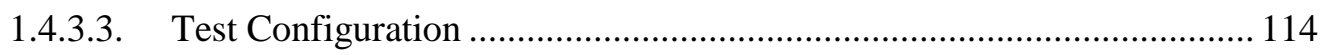

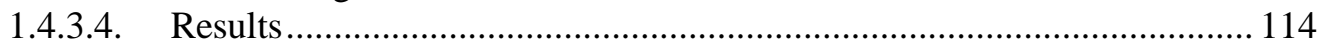

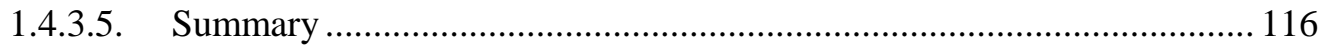

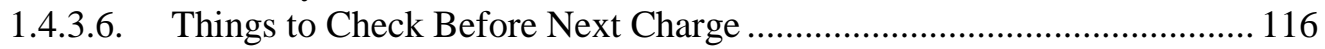

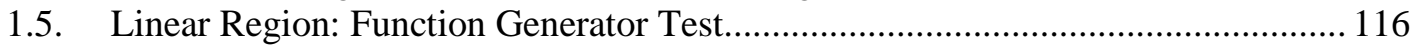

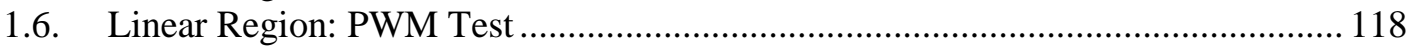

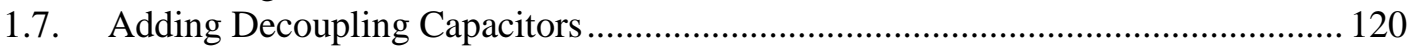




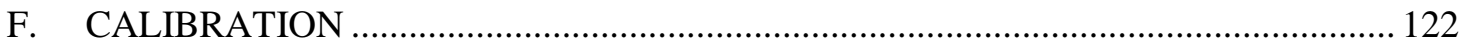

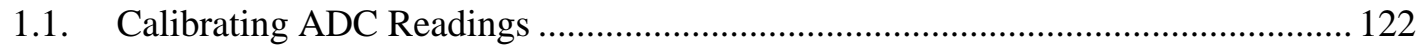

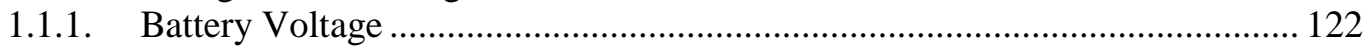

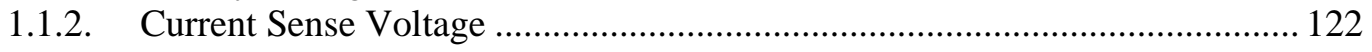

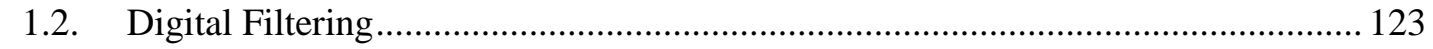

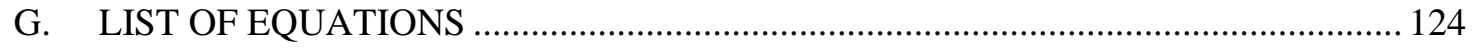

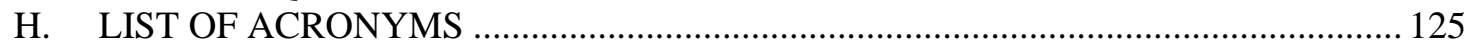




\section{LIST OF TABLES}

Table

Page

I. $\quad$ Battery developments over the years provided by Battery University ......................... 3

II. Secondary battery specifications provided by Battery University ................................ 6

III. Lithium Ion 18650 specifications provided by Panasonic Datasheet ............................ 7

IV. Typical charge characteristics of li-ion provided by Battery University ...................... 18

V. Effects of charge voltage on a lead acid battery provided by Battery University ......... 22

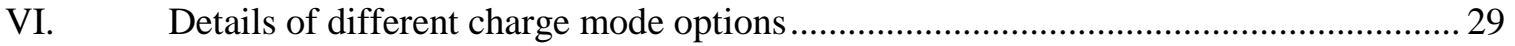

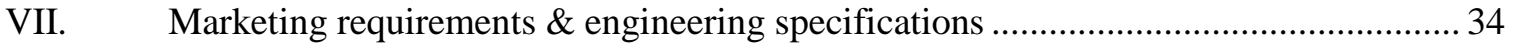

VIII. Recommended Charge Modes and Charge Terminations.............................................. 35

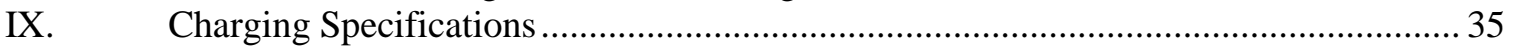

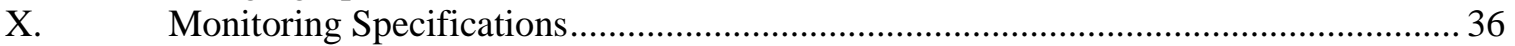

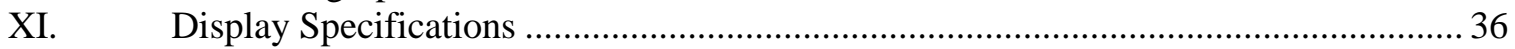

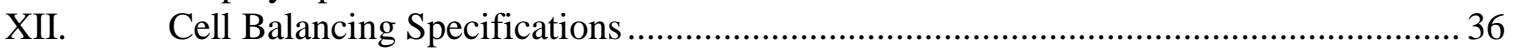

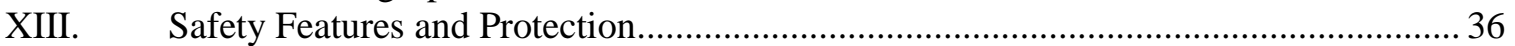

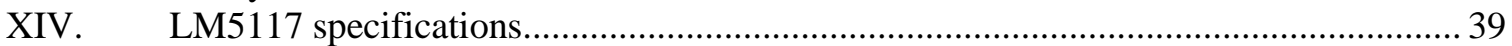

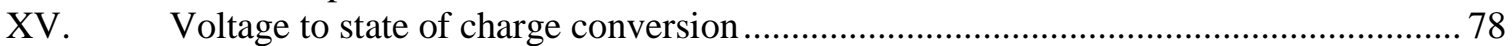

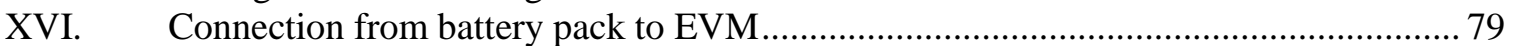

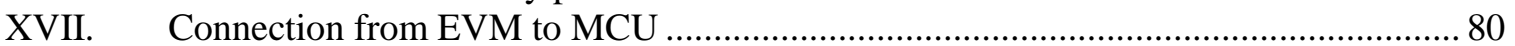

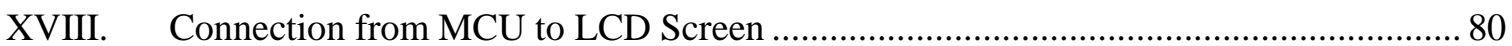

XIX. Power requirements to charge (or power) various electronic devices ........................... 84

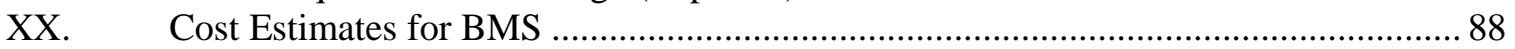

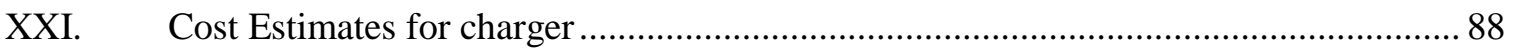

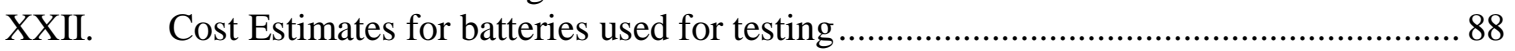

XXIII. State of charge compared to Li-Ion cycle lifetime courtesy of Cadex........................... 94

XXIV. Depth of discharge vs discharge cycles for Li-Ion courtesy of Cadex ......................... 94

XXV. Temperature and state of charge compared to capacity courtesy of Cadex .................. 95

XXVI. Self-discharge over time for different battery types courtesy of Cadex .......................98

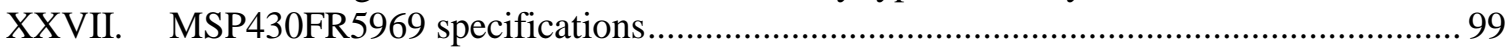

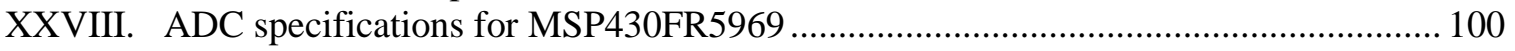

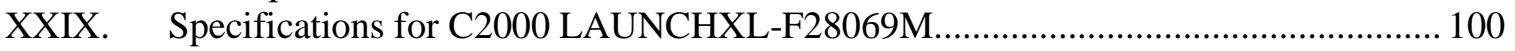

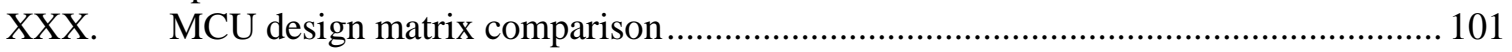

XXXI. Expected and measured ADC values for battery voltage calibration .......................... 122

XXXII. Expected and measured ADC values for current sense voltage calibration................ 123 


\section{LIST OF FIGURES}

Figure

Page

1. Revenue contributions by different battery chemistries courtesy of Frost \& Sullivan (2009)

2. Relative energy density of some common secondary cell chemistries provided by

Electropaedia

3. Specific energy and specific power of rechargeable batteries provided by Battery University.....

4. Tenergy TB6AC Multifunctional Balance Charger................................................................. 10

5. Tenergy TB6B Multifunctional Balance Charger Supported Battery Packs .............................. 10

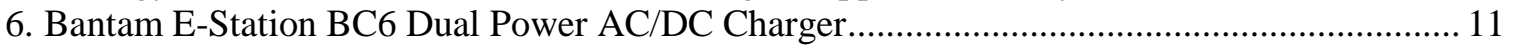

7. Bantam E-Station BC6 Dual Power AC/DC Charger Specifications ........................................ 11

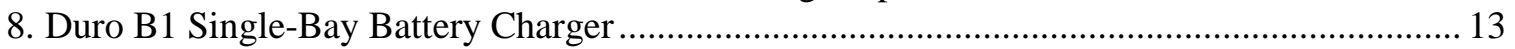

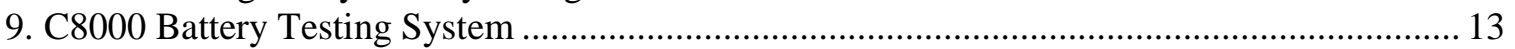

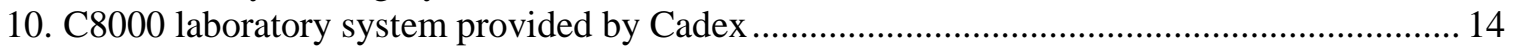

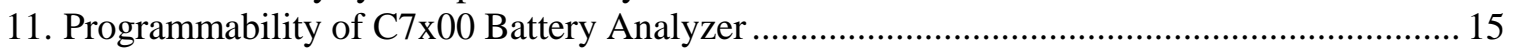

12. C7400ER Battery Analyzer (a), battery adapters (b), and RIGIDARM Universal

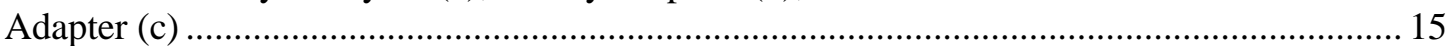

13. Charge profile for Li-Ion (Courtesy of Cadex) provided by Battery University ..................... 17

14. Capacity with respect to charge current and voltage provided by Battery

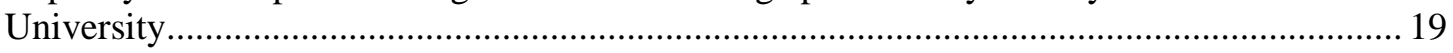

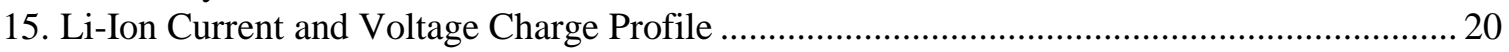

16. Charge profile for a lead acid battery provided by Battery University .................................. 22

17. Charge profile for NiMH provided by Battery University .................................................. 24

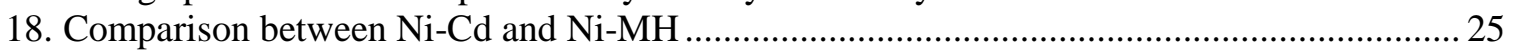

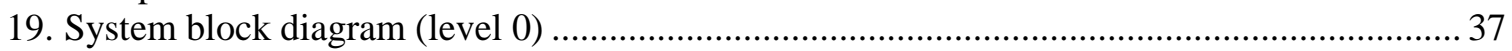

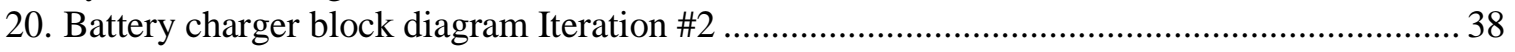

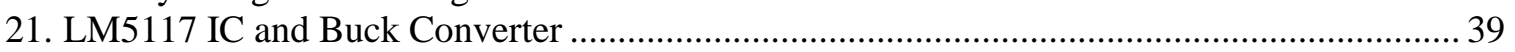

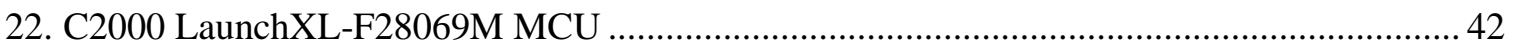

23. INA169 high-side measurement current shunt monitors (a) and INA169 circuit (b) .............. 44

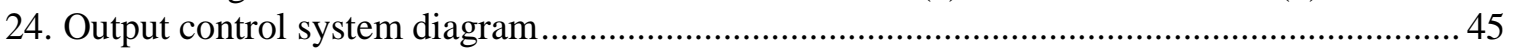

25. SIMPLIS switching model used to simulate DC analysis of PWM to LM5117

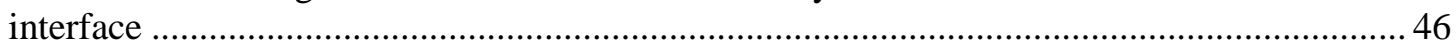

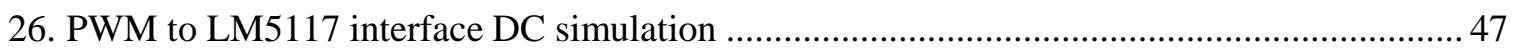

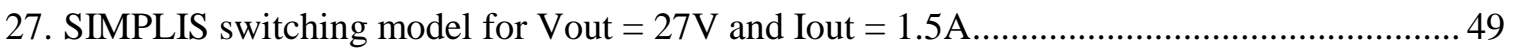

28. SIMPLIS average linear model based on switching model for Vout $=27 \mathrm{~V}$

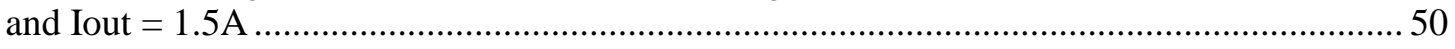

29. Current control loop magnitude and phase Bode plot from SIMPLIS linear model simulation

30. Voltage control loop magnitude and phase Bode plot with battery disconnected $(\mathrm{Ro}=1 \mathrm{k} \Omega)$ and single battery connected $(\mathrm{Ro}=100 \mathrm{~m} \Omega)$ from SIMPLIS linear model simulation.

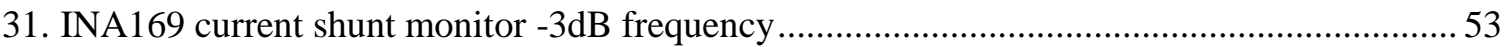




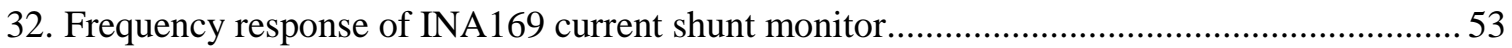

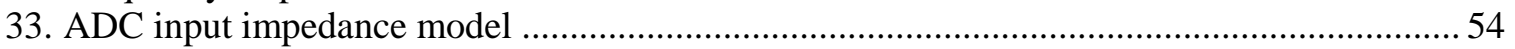

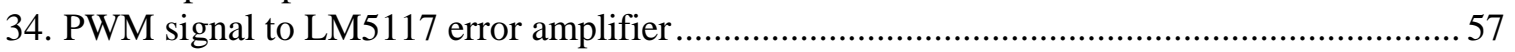

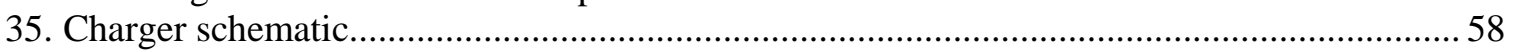

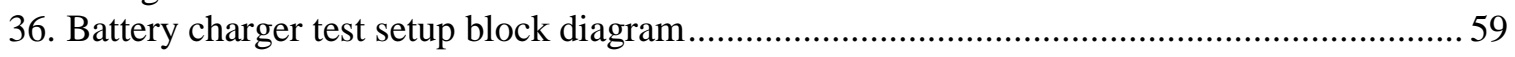

37. Picture of battery charger test setup consisting of the power stage LM5117 (a),

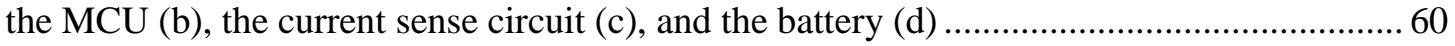

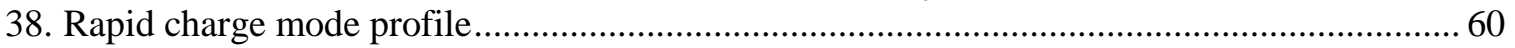

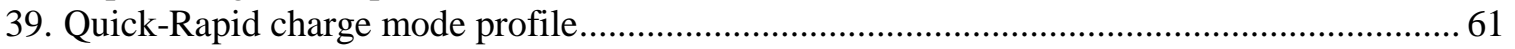

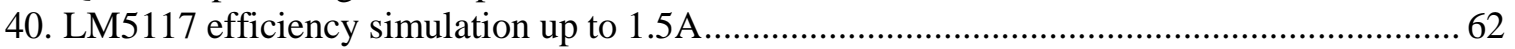

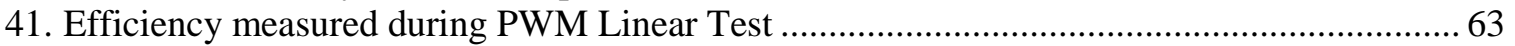

42. Efficiency measured during rapid charge mode with $\mathrm{Vin}=15.05 \mathrm{~V}$ and $\mathrm{Iin}=0.49 \mathrm{~A}$ to $0.52 \mathrm{~A}$

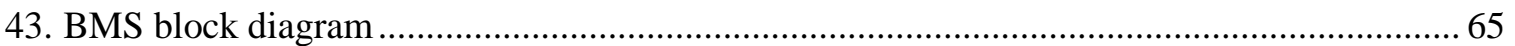

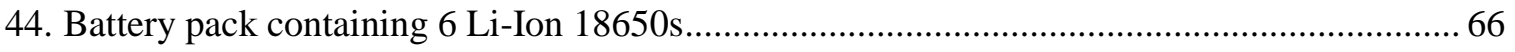

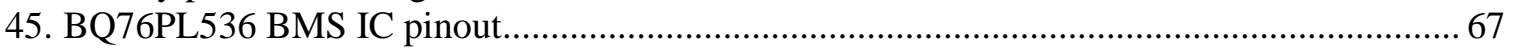

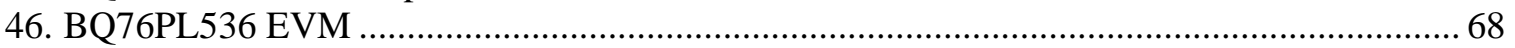

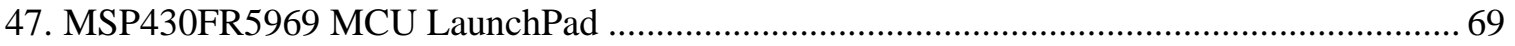

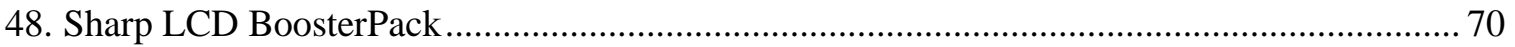

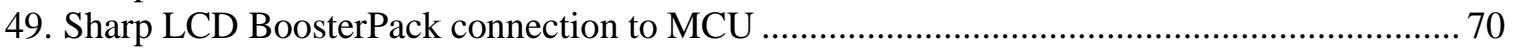

50. Balance circuity from BQ76PL536 EVM developed by Texas Instruments ........................... 72

51. Cell balance schematic from BQ76PL536 EVM developed by Texas Instruments ................. 73

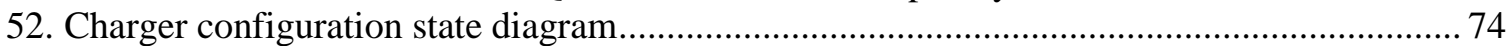

53. Lithium Ion chemistry Rapid charge mode designed for a Panasonic 18650 .......................... 75

54. Lithium Ion chemistry Quick Rapid charge mode designed for a Panasonic

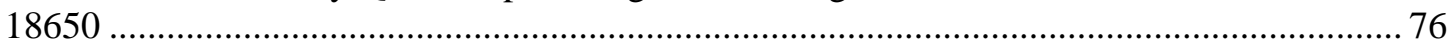

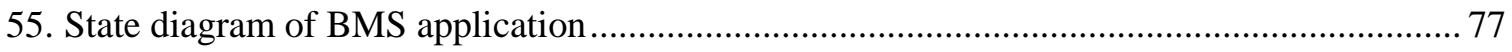

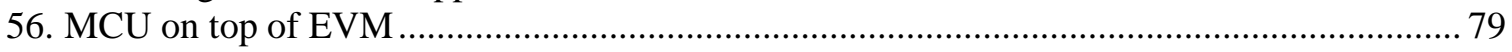

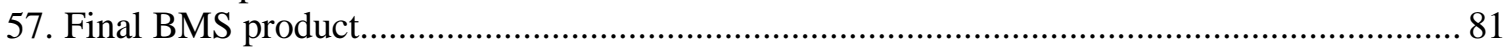

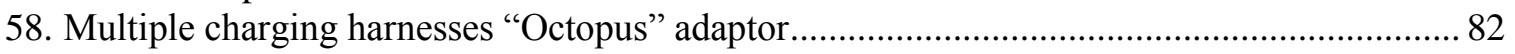

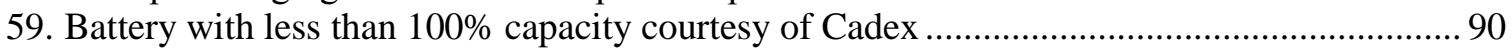

60. Three stages of lead acid cycle lifetime courtesy of Cadex .................................................. 91

61. Capacity compared to the number of cycles ........................................................................ 93

62. Charge and discharge rate for Li-Ion battery vs number of cycles courtesy of Cadex

63. State of charge and capacity compared to Li-ion cycle lifetime courtesy of Cadex . .95

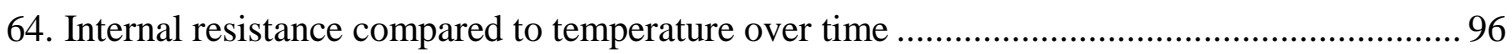

65. Capacity of 11 Li-polymer batteries during cycling courtesy of Cadex ................................. 97

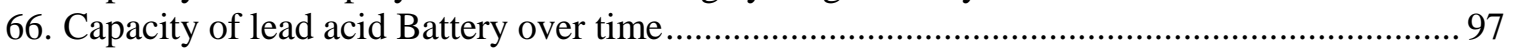

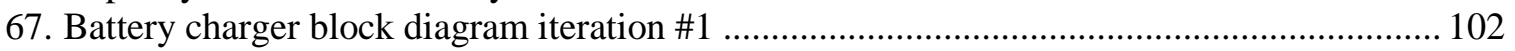

68. Output voltage divider for ADC monitoring of battery pack voltage ................................. 103

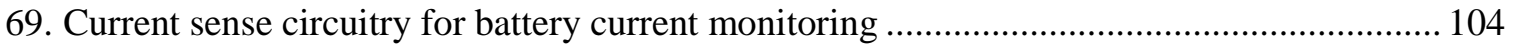

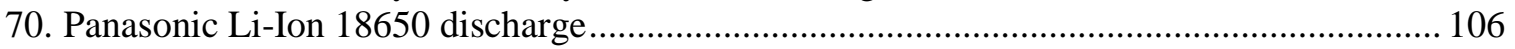

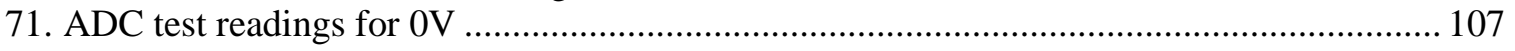

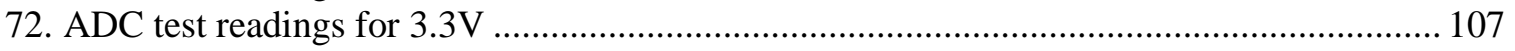

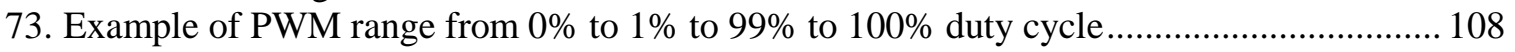

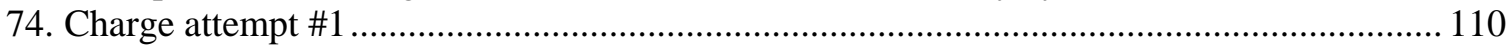

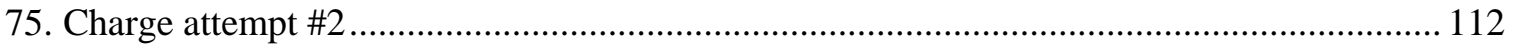

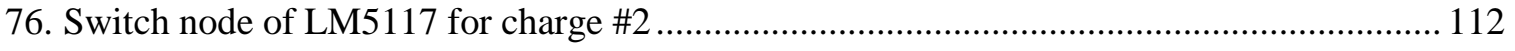

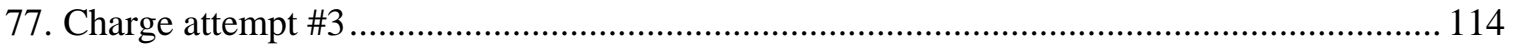




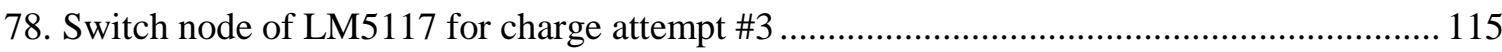

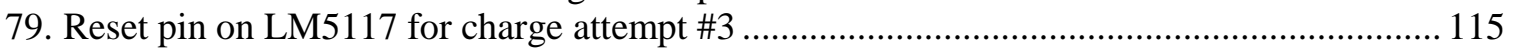

80. Switch node with function generator set to $73.9 \%$ and applied at feedback node of LM5117

81. Switch node with function generator set to $74.0 \%$ and applied at feedback node of LM5117.

82. PWM value and corresponding charge current.

83. AC-coupled output voltage spikes of $300 \mathrm{~mA}$ while charging battery

84. AC-coupled output voltage spikes reduced to $100 \mathrm{mV}$ with decoupling capacitors 


\subsection{Contents at a Glance}

\section{INTRODUCTION}

This report gives the reader insight into batteries, battery chargers, and battery management systems. Chapter 1 explains the popularity and importance of batteries in today's times. After convincing the reader that battery related technology is only going to grow over time, it gives the reader an overview of batteries and their history. This helps the reader see the progress batteries have made over the years and what trends to expect for the future. Chapter 1 provides the battery knowledge basics required to understand how to charge and manage batteries thus allowing the reader to make comparisons between different battery chargers and battery management systems. Then, Chapter 1 provides a snapshot of current battery charger and BMS technology, which allows the reader to understand how the system described in Chapter 2 compares to options currently on the market. Chapter 3 explains the design of the battery charger and Chapter 4 describes the design of the optional BMS to show the reader the design differences compared to other systems. By the end of this report, the reader should have a clear understanding of the technological advancements this design achieves with regard to battery charging and battery management. Specifically, the reader should understand the improvements made in charger efficiency along with the unique programmable algorithms this system offers to allow the user to make tradeoffs between charge speed, state of charge, and battery lifetime. Appendix B contains research supporting this tradeoff.

\subsection{All about Batteries}

\subsubsection{Background}

Batteries exist in nearly every portable device, and charging batteries occurs every day by almost everyone. The global revenue from batteries reached $\$ 47.5$ billion in 2009 , and this market expects to grow to $\$ 74$ billion by 2015 [1]. Proper management of batteries is essential to their performance and life along with the performance of the system and the user's safety. A battery management system (BMS) is any system that monitors and manages batteries. Since 
batteries exist in nearly all portable systems that require power, the need for battery management systems is tremendous.

The requirement of a BMS is to monitor cell voltage, pack voltage, and pack temperature. The BMS keeps each cell within a desired voltage range through cell balancing. The cells need protection from cell overvoltage (COV) and cell undervoltage (CUV) by alerting the user if these conditions exist. This system also needs to prevent gas leakage or fires by shutting the system down if thermal excursions occur beyond the set temperature limits.

A programmable battery charger differs from other battery chargers because of the extreme charge flexibility, which allows charging batteries of different voltages and chemistries with different charge currents, charge schemes and profiles, charge voltage set points, and charge terminations. This project focuses on the design, build, and test of a programmable battery charger along with a BMS that allows interfacing between the two. A microcontroller programs the battery charger to a specific charge profile dependent on the battery's chemistry and charge capabilities. It features a wide input voltage range current mode synchronous buck controller with analog current monitor, which provides the charge current with cycle-by-cycle overcurrent protection to help protect the batteries. The BMS monitors the batteries for cell voltage, pack voltage, temperature, and state of charge. It also provides cell balancing to maintain even cell charge for the entire battery pack. The BMS displays the measurements to a LCD screen for the user to see using a MSP430FR5969 microcontroller unit (MCU) with a Sharp LCD BoosterPack. The user navigates with the capacitive touch slider and the option select button on the MCU to access the cell parameters. The system has set COV and CUV trip points as well as overtemperature and under-temperature trip points so the system can alert the user or shut down completely to protect the batteries and the overall system.

\subsubsection{Battery History}

Batteries have existed since the 1800s with Alessandro Volta making discoveries that led to the invention of the first voltaic cell. Some believe batteries existed even before this with 
discoveries of ancient devices referred to as Parthian batteries dating back to 2,000 years ago [1].

Table I shows the inventor and approximate time for many key inventions that led up to the battery technology of today.

Table I: Battery developments over the years provided by Battery University [1]

\begin{tabular}{|c|c|c|}
\hline Year & Inventor & Activity \\
\hline 1600 & William Gilbert (UK) & Establishment of electrochemistry study \\
\hline 1791 & Luigi Galvani (Italy) & Discovery of "animal electricity" \\
\hline 1800 & Alessandro Volta (Italy) & Invention of the voltaic cell (zinc, copper disks) \\
\hline 1802 & William Cruickshank (UK) & First electric battery capable of mass production \\
\hline 1820 & André-Marie Ampère (France) & Electricity through magnetism \\
\hline 1833 & Michael Faraday (UK) & Announcement of Faraday's law \\
\hline 1836 & John F. Daniell (UK) & Invention of the Daniell cell \\
\hline 1839 & William Robert Grove (UK) & Invention of the fuel cell $\left(\mathrm{H}_{2} / \mathrm{O}_{2}\right)$ \\
\hline 1859 & Gaston Planté (France) & Invention of the lead acid battery \\
\hline 1868 & Georges Leclanché (France) & Invention of the Leclanche cell (carbon-zinc) \\
\hline 1899 & Waldmar Jungner (Sweden) & Invention of the nickel-cadmium battery \\
\hline 1901 & Thomas A. Edison (USA) & Invention of the nickel-iron battery \\
\hline 1932 & Shlecht \& Ackermann (D) & Invention of the sintered pole plate \\
\hline 1947 & Georg Neumann (Germany) & Successfully sealing the nickel-cadmium battery \\
\hline 1949 & Lew Urry, Eveready Battery & Invention of the alkaline-manganese battery \\
\hline 1970 s & Group effort & Development of valve-regulated lead acid battery \\
\hline 1990 & Group effort & Commercialization of nickel-metal-hydride battery \\
\hline 1991 & Sony (Japan) & Commercialization of lithium-ion battery \\
\hline 1994 & Bellcore (USA) & Commercialization of lithium-ion polymer \\
\hline 1996 & Moli Energy (Canada) & Introduction of Li-ion with manganese cathode \\
\hline 1996 & University of Texas (USA) & Identification of Li-phosphate ( $\mathrm{LiFePO}{ }_{4}$ ) \\
\hline 2002 & $\begin{array}{l}\text { University of Montreal, Quebec } \\
\text { Hydro, MIT, others }\end{array}$ & $\begin{array}{l}\text { Improvement of Li-phosphate, nanotechnology, } \\
\text { commercialization }\end{array}$ \\
\hline
\end{tabular}

\subsubsection{Battery Markets}

According to battery data analysis from Frost \& Sullivan, Primary batteries made up 23.6 percent of the global market in 2009. By 2015, the analysis estimates a 7.4 percent decline in battery revenue for non-rechargeable batteries. Secondary, or "rechargeable", batteries make up 
76.4 percent of the global market and expect to increase to 82.6 percent in 2015 [1]. Batteries are also categorized by the chemistry or chemical make-up with lithium being the most common. See Figure 1 for revenue distributions by different battery chemistries.

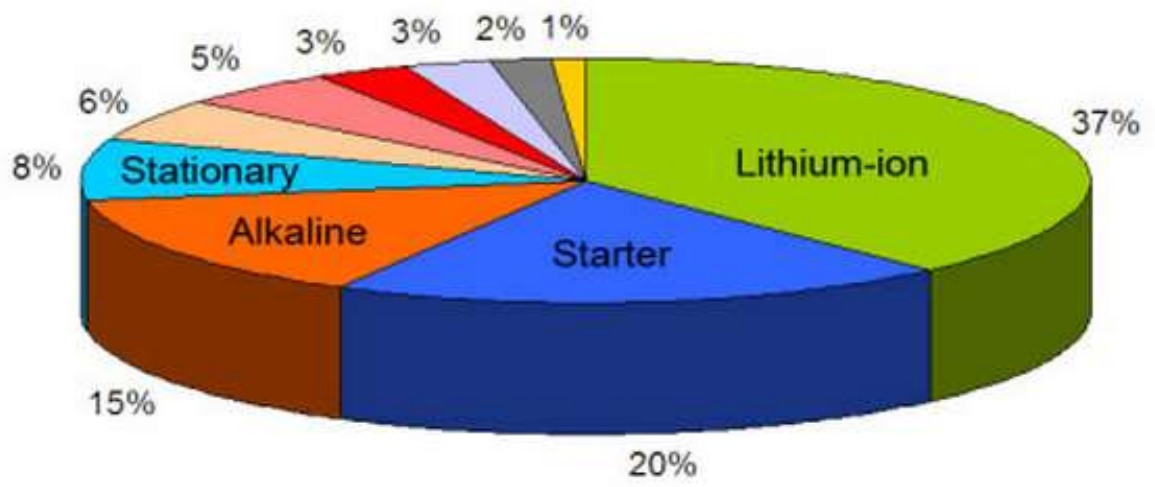

Lithium-ion (37\%)

SLI (Starter Battery) (20\%) $\square$ Alkaline (15\%)

Stationary Lead Acid (8\%) $\square$ Primary Carbon Zinc (6\%) $\square$ Deep Cycle Lead Acid (5\%)

Nickel Metal Hydride (3\%) 口Primary Lithium (3\%) D Nickel Cadmium (2\%) Other $(1 \%)$

Figure 1: Revenue contributions by different battery chemistries Courtesy of Frost \& Sullivan (2009)

\subsubsection{Battery Basics}

Batteries store electrical energy in chemical form, which then provides power to a device or circuit. Batteries are primary (non-rechargeable) or secondary (rechargeable) and this project focuses on the charging and managing of secondary cells of a variety of chemistries. The different chemistries provide the cells with different performance because of the resulting energy and power densities. Specific energy is the capacity a battery can hold in watt-hours per kilogram $(\mathrm{Wh} / \mathrm{kg}$ ) and specific power is the battery's ability to deliver power in watts per kilogram $(\mathrm{W} / \mathrm{kg})$. A higher specific energy means a longer use or runtime for a given battery whereas a higher specific power means the battery can deliver more power or current. Figure 2 and Figure 3 compares different chemistries of batteries to help the reader understand that batteries of different chemistries perform (discharge) differently, which also means they charging differently. This 
chapter also discusses how to charge the different types of batteries so the reader understands the requirements of a universal battery charger.

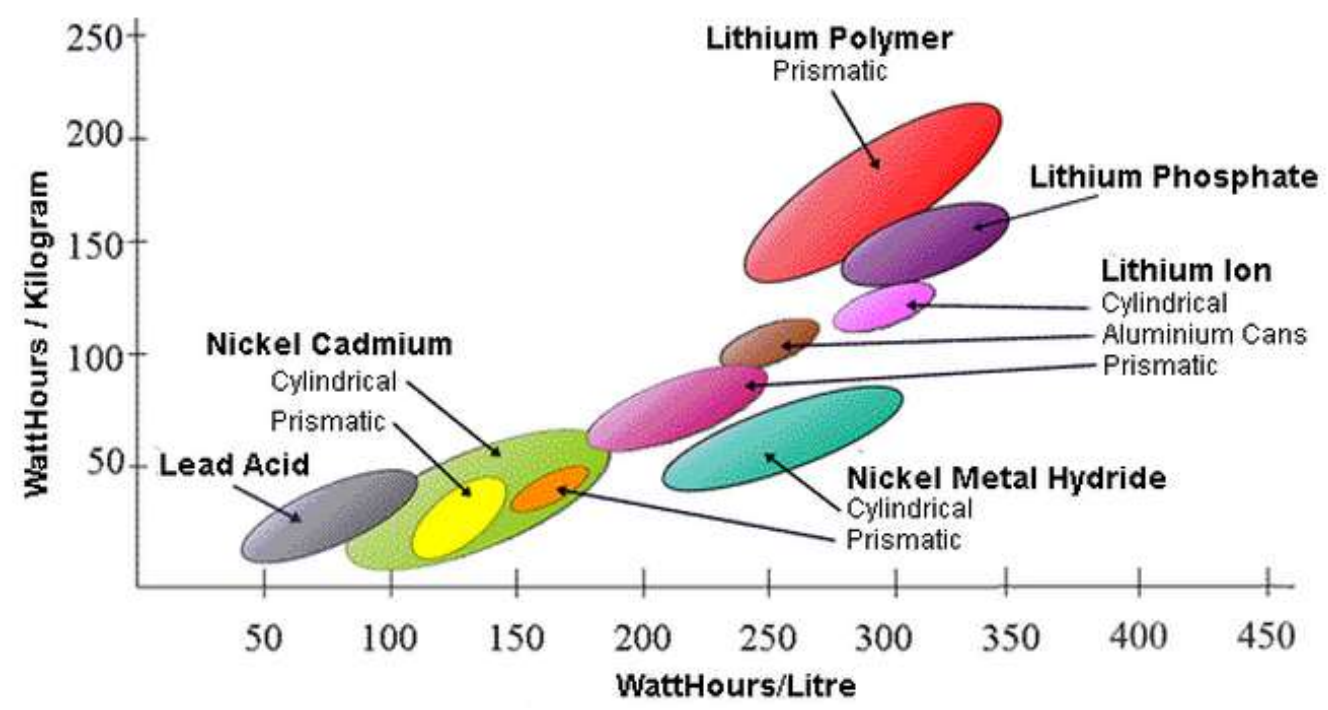

Figure 2: Relative energy density of some common secondary cell chemistries provided by

\section{Electropaedia [2]}

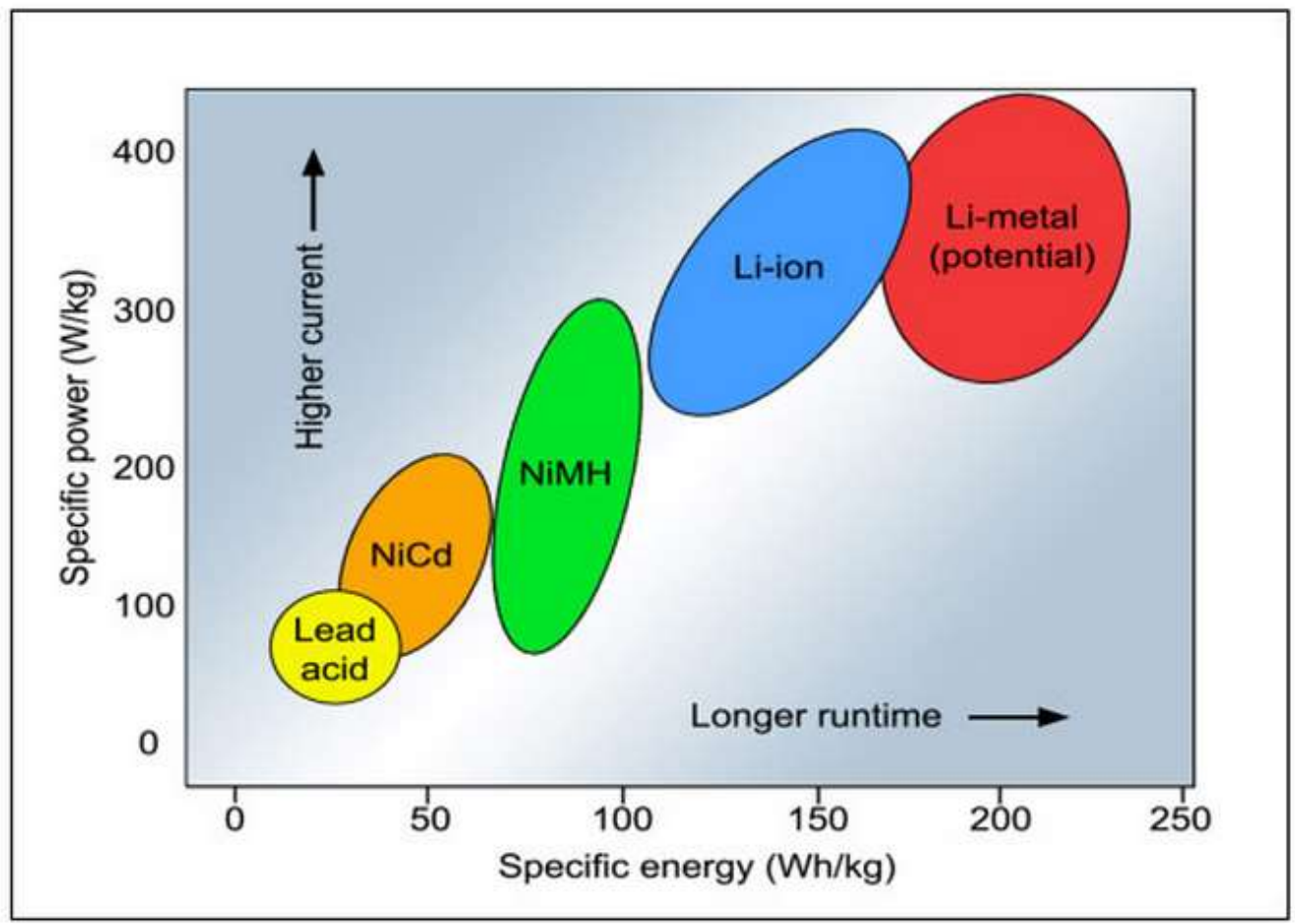

Figure 3: Specific energy and specific power of rechargeable batteries provided by Battery University [1] 
Table II below shows how different battery specifications compare and differ between different battery chemistries. Note that these differences explain why most battery chargers are limited in the types of batteries they can charge, because they are designed to charge a specific battery. This makes programmable chargers, if correctly designed, far superior in the terms of flexibility and usability.

Table II: Secondary battery specifications provided by Battery University [1]

\begin{tabular}{|c|c|c|c|c|c|c|}
\hline Specifications & Lead Acid & $\mathrm{NiCd}$ & $\mathrm{NiMH}$ & Cobalt & $\begin{array}{c}\text { Li-ion } \\
\text { Manganese }\end{array}$ & Phosphate \\
\hline $\begin{array}{l}\text { Specific energy } \\
\text { density (Wh/kg) }\end{array}$ & $30-50$ & $45-80$ & $60-120$ & $150-190$ & $100-135$ & $90-120$ \\
\hline $\begin{array}{l}\text { Internal resistance }{ }^{1} \\
(\mathrm{~m} \Omega)\end{array}$ & $\begin{array}{c}<100 \\
12 V \text { pack }\end{array}$ & $\begin{array}{l}100-200 \\
6 \mathrm{~V} \text { pack }\end{array}$ & $\begin{array}{l}200-300 \\
6 \mathrm{~V} \text { pack }\end{array}$ & $\begin{array}{c}150-300 \\
7.2 \mathrm{~V}\end{array}$ & $\begin{array}{l}25-75^{2} \\
\text { per cell }\end{array}$ & $\begin{array}{l}25-50^{2} \\
\text { per cell }\end{array}$ \\
\hline $\begin{array}{l}\text { Cycle life } \\
\text { (80\% discharge) }\end{array}$ & $200-300$ & $1000^{3}$ & $300-500^{3}$ & $\begin{array}{l}500- \\
1,000\end{array}$ & $500-1,000$ & $\begin{array}{l}1,000- \\
2,000\end{array}$ \\
\hline Fast-charge time & $8-16 h$ & 1h typical & $2-4 h$ & $2-4 h$ & 1h or less & $1 \mathrm{~h}$ or less \\
\hline $\begin{array}{l}\text { Overcharge } \\
\text { tolerance }\end{array}$ & High & Moderate & Low & \multicolumn{3}{|c|}{ Low. Cannot tolerate trickle charge } \\
\hline $\begin{array}{l}\text { Self-discharge/ } \\
\text { month (room temp) }\end{array}$ & $5 \%$ & $20 \% 5$ & $30 \% 5$ & \multicolumn{3}{|c|}{$<10 \%^{6}$} \\
\hline $\begin{array}{l}\text { Cell voltage } \\
\text { (nominal) }\end{array}$ & $2 \mathrm{~V}$ & $1.2 \mathrm{~V}^{7}$ & $1.2 \mathrm{~V}^{7}$ & $3.6 V^{8}$ & $3.8 \mathrm{~V}^{8}$ & $3.3 \mathrm{~V}$ \\
\hline $\begin{array}{l}\text { Charge cutoff } \\
\text { voltage (V/cell) }\end{array}$ & $\begin{array}{l}2.40 \\
\text { Float } 2.25\end{array}$ & \multicolumn{2}{|c|}{$\begin{array}{l}\text { Full charge detection } \\
\text { by voltage signature }\end{array}$} & \multicolumn{2}{|c|}{4.20} & 3.60 \\
\hline $\begin{array}{l}\text { Discharge cutoff } \\
\text { voltage }(\mathrm{V} / \text { cell, } \mathrm{C})\end{array}$ & 1.75 & \multicolumn{2}{|c|}{1.00} & \multicolumn{2}{|c|}{$2.50-3.00$} & 2.80 \\
\hline $\begin{array}{l}\text { Peak load current } \\
\text { Best result }\end{array}$ & $\begin{array}{l}5 C^{9} \\
0.2 C\end{array}$ & $\begin{array}{l}20 \mathrm{C} \\
1 \mathrm{C}\end{array}$ & $\begin{array}{l}5 \mathrm{C} \\
0.5 \mathrm{C}\end{array}$ & $\begin{array}{l}>3 \mathrm{C} \\
<1 \mathrm{C}\end{array}$ & $\begin{array}{l}>30 \mathrm{C} \\
<10 \mathrm{C}\end{array}$ & $\begin{array}{l}>30 \mathrm{C} \\
<10 \mathrm{C}\end{array}$ \\
\hline Charge temperature & -20 to $50^{\circ} \mathrm{C}$ & \multicolumn{2}{|c|}{0 to $45^{\circ} \mathrm{C}$} & \multicolumn{3}{|c|}{0 to $45^{\circ} \mathrm{C}^{10}$} \\
\hline $\begin{array}{l}\text { Discharge } \\
\text { temperature }\end{array}$ & -20 to $50^{\circ} \mathrm{C}$ & \multicolumn{2}{|c|}{-20 to $65^{\circ} \mathrm{C}$} & \multicolumn{3}{|c|}{-20 to $60^{\circ} \mathrm{C}$} \\
\hline $\begin{array}{l}\text { Maintenance } \\
\text { requirement }\end{array}$ & $\begin{array}{l}3-6 \text { months }{ }^{11} \\
\text { (topping chg.) }\end{array}$ & $\begin{array}{l}30-60 \text { days } \\
\text { (discharge) }\end{array}$ & $\begin{array}{l}60-90 \text { days } \\
\text { (discharge) }\end{array}$ & \multicolumn{3}{|c|}{ Not required } \\
\hline Safety requirements & $\begin{array}{l}\text { Thermally } \\
\text { stable }\end{array}$ & \multicolumn{2}{|c|}{$\begin{array}{l}\text { Thermally stable, fuse } \\
\text { protection common }\end{array}$} & \multicolumn{3}{|c|}{ Protection circuit mandatory ${ }^{12}$} \\
\hline In use since & Late $1800 \mathrm{~s}$ & 1950 & 1990 & 1991 & 1996 & 1999 \\
\hline
\end{tabular}


1. Internal resistance of a battery pack varies with milliampere-hour (mAh) rating, wiring and number of cells. Protection circuit of lithium-ion adds about $100 \mathrm{~m} \Omega$.

2. Based on 18650 cell size. Cell size and design determines internal resistance.

3. Cycle life is based on battery receiving regular maintenance.

4. Cycle life is based on the depth of discharge (DoD). Shallow DoD improves cycle life.

5. Self-discharge is highest immediately after charge. NiCd loses $10 \%$ in the first 24 hours, then declines to $10 \%$ every 30 days. High temperature increases self-discharge.

6. Internal protection circuits typically consume $3 \%$ of the stored energy per month.

7. The traditional voltage is $1.25 \mathrm{~V} ; 1.2 \mathrm{~V}$ is more commonly used.

8. Low internal resistance reduces the voltage drop under load and Li-ion is often rated higher than 3.6V/cell. Cells marked $3.7 \mathrm{~V}$ and $3.8 \mathrm{~V}$ are fully compatible with $3.6 \mathrm{~V}$.

9. $\quad$ Capable of high current pulses; needs time to recuperate.

10. Do not charge regular Li-ion below freezing. See Charging at High and Low Temperatures.

11. Maintenance may be in the form of equalizing or topping charge to prevent sulfation.

12. Cut-off if less than $2.20 \mathrm{~V}$ or more than $4.30 \mathrm{~V}$ for most Li-ion; different voltage settings apply for lithium-iron-phosphate.

\subsubsection{Battery Selection for Testing}

The Li-Ion cell used in this project is the Panasonic Lithium Ion NCR18650 shown in

Table III. These batteries are reasonably priced at approximately $\$ 10.00$ per cell and also very popular and used in various systems including the battery packs in Tesla cars.

Table III: Lithium Ion 18650 specifications provided by Panasonic Datasheet [6]

\begin{tabular}{|c|c|c|}
\hline \multicolumn{2}{|c|}{ Nominal Voltage } & $3.6 \mathrm{~V}$ \\
\hline \multirow{2}{*}{$\begin{array}{l}\text { Nominal } \\
\text { Capacity }^{* 1}\end{array}$} & Minimum & $2,750 \mathrm{mAh}$ \\
\hline & Typical & $2,900 \mathrm{mAh}$ \\
\hline \multirow{2}{*}{ Dimensions } & Diameter & Max. $18.6 \mathrm{~mm}$ \\
\hline & Height & Max. $65.2 \mathrm{~mm}$ \\
\hline \multicolumn{2}{|c|}{ Approx. Weight } & $45 \mathrm{~g}$ \\
\hline
\end{tabular}

\subsubsection{Battery Equations}

Capacity measures the amount of charge a battery can store. Calculate the maximum

battery capacity by integrating the total charge current over the amount of time to fully charge the

battery.

Capacity $=\int_{0}^{t} I d t[\mathrm{Ah}]$ 
The energy of the battery measures its ability to do work and is calculated by integrating the amount of power provided over a given period of time.

Energy $=\int_{0}^{t} P d t=\int_{0}^{t} I V d t[\mathrm{Wh}]$

The voltage of the battery equals the open circuit voltage minus the voltage drop across its internal resistance.

$V_{\text {battery }}=V_{o c}-I * R_{\text {int }}[V]$

$\mathrm{C}$ rate measures charging or discharging from maximum capacity in a specific amount of time.

$1 C$ rate $=\frac{\text { Full Capacity }}{1 \mathrm{~h}}=$ charge current to fully discharge the battery in 1 hour.

The time it takes to discharge a battery is inversely proportional to its $\mathrm{C}$ rate.

time $=1 /($ C rate $)[$ hrs $]$

\subsection{Current Technology}

This section provides the reader a snapshot of the battery charger and BMS technology currently on the market to allow later comparison to the system designed in this report. In today's times, numerous different battery charging and battery management solutions exist in all shapes and sizes. Solutions range from ICs that integrate into a system or complete charger systems. This section explores different battery charging and management solutions.

\subsubsection{Battery Charging ICs}

Battery charger ICs charge batteries of a fixed voltage and chemistry of either single cell or multiple cells. Texas Instruments offers over 200 parts that charge different Li-Ion cells, lead acid, NiCd, or NiMH batteries. These chargers take supply voltages between $4.2 \mathrm{~V}$ to $40 \mathrm{~V}$ and provide fixed battery charge voltages between $3.5 \mathrm{~V}$ and $8.4 \mathrm{~V}$. Changing hardware values makes some of these parts adjustable. Others charger ICs allow programming by a host controller to different chemistries and different charge voltages and currents but charge single cells only. The charge currents range from $15 \mathrm{~mA}$ to $10 \mathrm{~A}$ and have different charging control topologies. Other 
companies such as Linear Technology, STMicroelectronics, Semtech, Maxim, and Toshiba offer other charger ICs similar to those sold by Texas Instruments. Visit their websites to see all of their battery related products.

\subsubsection{Battery Management ICs}

Battery management ICs monitor cell voltage and/or temperature and a variety of other cell characteristics. They monitor charge statuses such as low charge or fully charged, battery absent, charge faults and can act as capacity or charge gauges. Some management ICs can also provide cell balancing which can passively or actively balance up to six cells in a series configuration.

\subsubsection{Universal Battery Chargers}

Universal battery chargers can charge multiple chemistries at a variety of charge voltages. These systems resemble the closest products to the project designed in this report. Key differences include specifications, performance parameters, charge modes, charge and balance algorithms, converter topology, and user interaction and display. See Figure 4 through Figure 7 for pictures and specifications of current universal chargers on the market. By providing pictures and specifications of other universal battery chargers, it permits the reader to make comparisons to the project designed in Chapter 3.

Both the Tenergy and Bantam chargers mentioned in this report use an asynchronous Buck-Boost topology, which limits the charger efficiency to $80 \%$. They also both have a minimum charge current limit of 100mA preventing the charge of low current batteries. They are pre-programmed to allow the user to choose different battery charging options but do not allow the user to create their own unique charge profiles. The charger designed in Chapter 3 solves all of these limitations. 


\subsubsection{Tenergy}

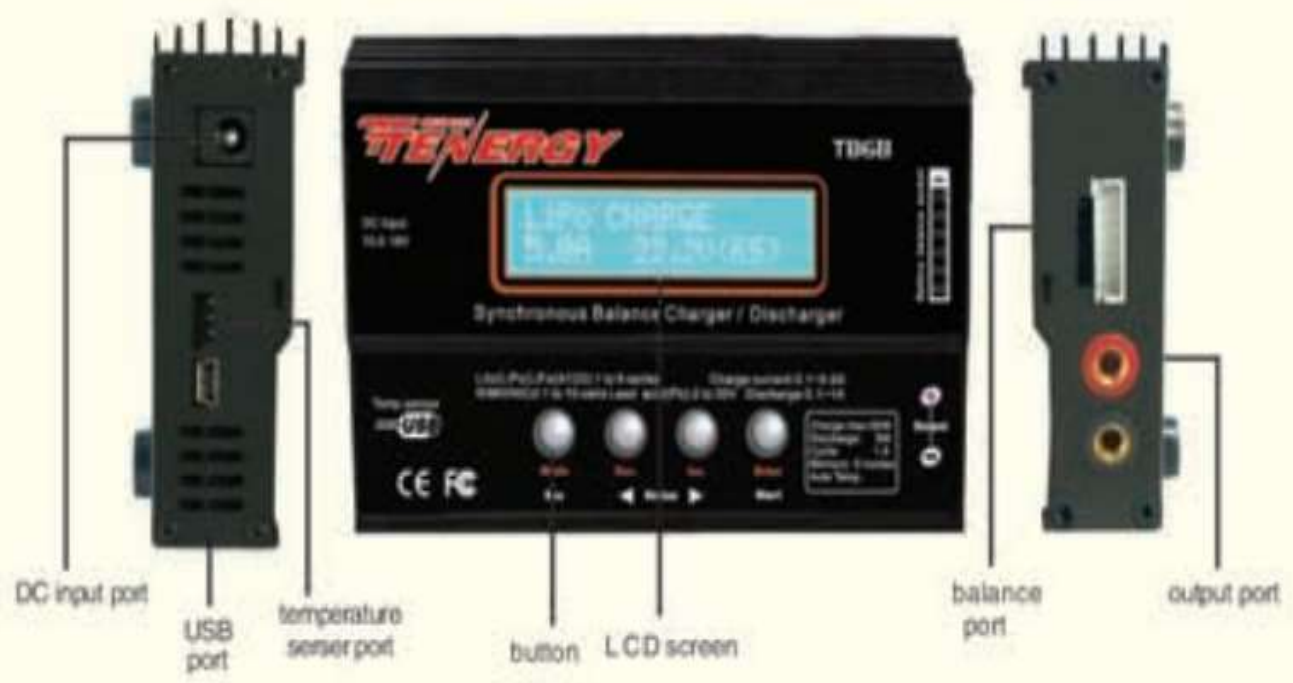

Figure 4: Tenergy TB6AC Multifunctional Balance Charger [7]

Figure 4 shows the size and user features for a Tenergy universal battery charger. The system offers buttons and LCD display for user interaction and a variety of ports to operate the system.

\begin{tabular}{|lll|}
\hline \multicolumn{3}{|c|}{ Supported Battery Packs } \\
\hline Battery Type & (In Voltages) & (Series) \\
\hline NiMH/NiCD & $1.2 \mathrm{v}$ to $18 \mathrm{v}$ & $1 \mathrm{~S}-15 \mathrm{~S}$ \\
\hline $\mathrm{LiPO} / \mathrm{Li}$-lon & $3.7 \mathrm{v}$ to $22.2 \mathrm{v}$ & $1 \mathrm{~S}-6 \mathrm{~S}$ \\
\hline $\mathrm{LiFe}$ & $3.2 \mathrm{v}$ to $19.2 \mathrm{v}$ & $1 \mathrm{~S}-6 \mathrm{~S}$ \\
\hline $\mathrm{SLA}$ & $2 \mathrm{v}-20 \mathrm{~V}$ \\
\hline
\end{tabular}

Figure 5: Tenergy TB6B Multifunctional Balance Charger Supported Battery Packs [7]

Figure 5 shows the various battery packs supported by the Tenergy charger. It charges a variety of battery chemistries at a variety of voltages but does not offer charge modes for the different chemistries to allow the user to determine the charge speed or state of charge, which ultimately affects the battery's lifetime. 


\subsubsection{Bantam}

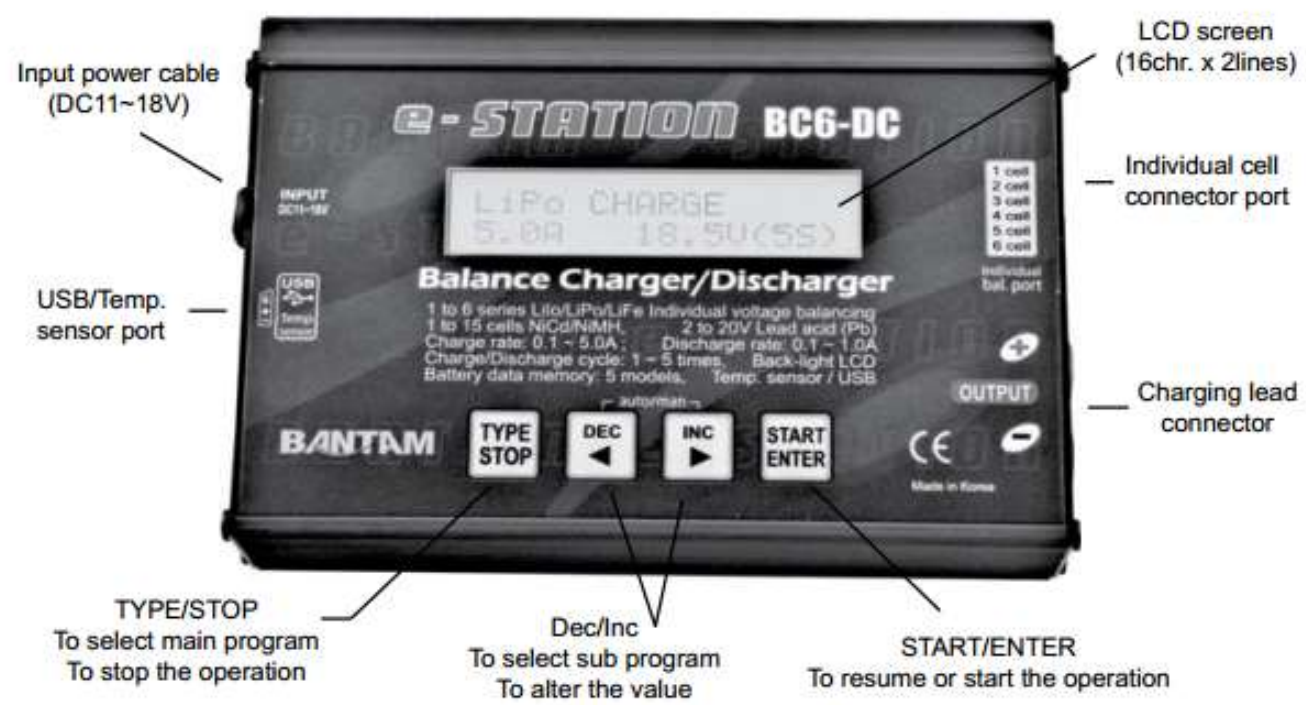

Figure 6: Bantam E-Station BC6 Dual Power AC/DC Charger [8]

Figure 6 shows the size and user features for a Bantam universal battery charger, which looks and performs very similar to the Tenergy brand charger.

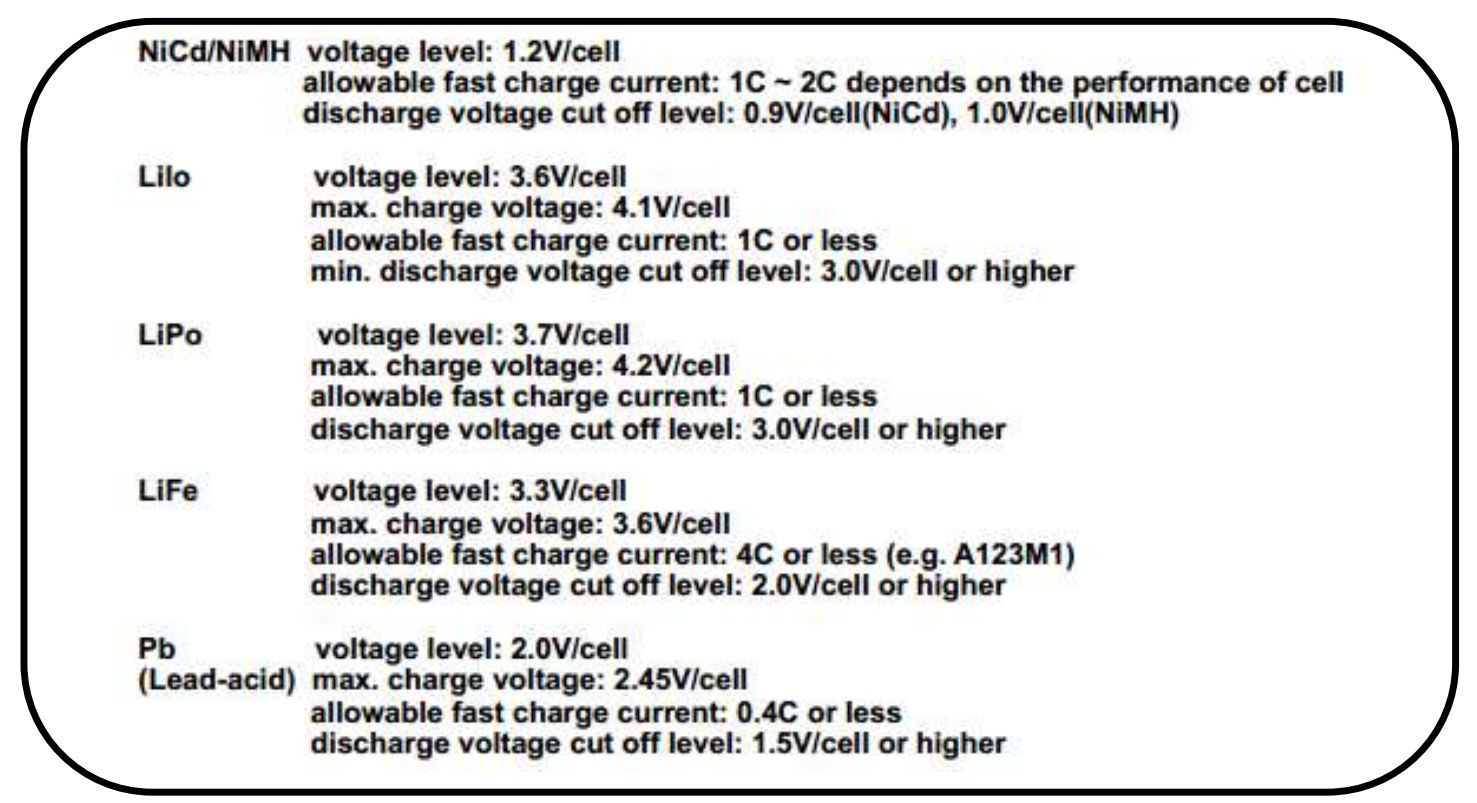

Figure 7: Bantam E-Station BC6 Dual Power AC/DC Charger Specifications [8]

Figure 7 shows that the Bantam charger allows changing the charge current or voltage to one of the available options, which resembles the system in this report but the does not allow the user to 
program any charge mode or charge algorithm. The Bantam charger limits the user to choosing the pre-programmed options. The charger designed in Chapter 3 allows full control over the charge current, charge voltage, and the termination taper current in addition to lower than $100 \mathrm{~mA}$ charge applications and improvements in charge efficiency.

\subsubsection{Other Battery Related Systems}

A company called Cadex offers different battery related devices that include battery chargers, battery testers and analyzers, battery maintenance systems, even custom products for special requests. Other unique features include a sorting option that can test single Li-Ion cells in seconds to check the performance of the battery and a boost mode that can revive dead packs. For nickel based batteries, setting a capacity level permits triggering a deep discharge in attempt to recondition the battery to restore the capacity. These special devices can also estimate the capacity of the battery and determine the lifetime or the remaining cycle life.

\subsubsection{Cadex Chargers}

These chargers range in functionality and specifications. They can support battery voltage ranging from $1.2 \mathrm{~V}$ to $36 \mathrm{~V}$, with a charge current up to $6 \mathrm{~A}$ per station. They have special charging algorithms and detection systems to charge batteries safely in hot or cold temperatures. Unique discharge algorithms can calibrate the cells in addition to conditioning cells that have lost performance over time. These chargers differ in their charge algorithms in that they use a reversepulse-charge technique, which helps improve charge acceptance, speed up charge times, and better battery performance. Figure 8 shows an example of a Cadex charger for comparison to the charger designed in Chapter 3. 


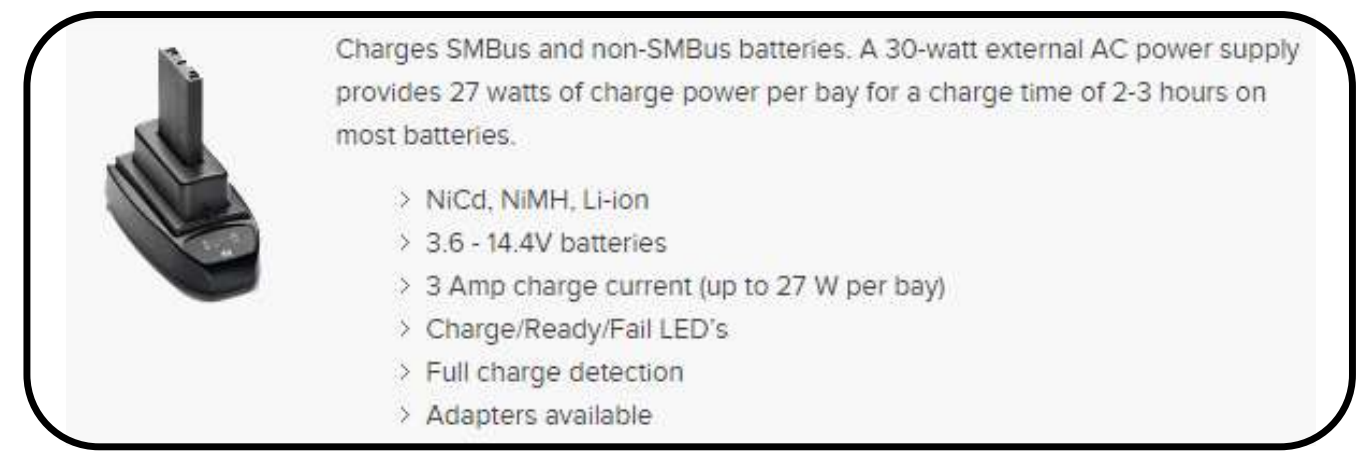

Figure 8: Duro B1 Single-Bay Battery Charger [9]

\subsubsection{Battery Testers}

A battery tester enables device simulation to choose the right battery and lifecycle testing to help characterize the battery. Custom programs allow users to monitor the battery quality and performance and service programs to maintain the battery. These devices have load testing available to determine how the batteries preform under different load conditions in addition to other attachments that allow a user to create an entire battery laboratory system that includes temperature and pressure monitoring, individual cell monitoring, and safety circuit testing. Although battery testers have much more functionality that the system designed in this report, they cost more and are much larger as Figure 9 shows.

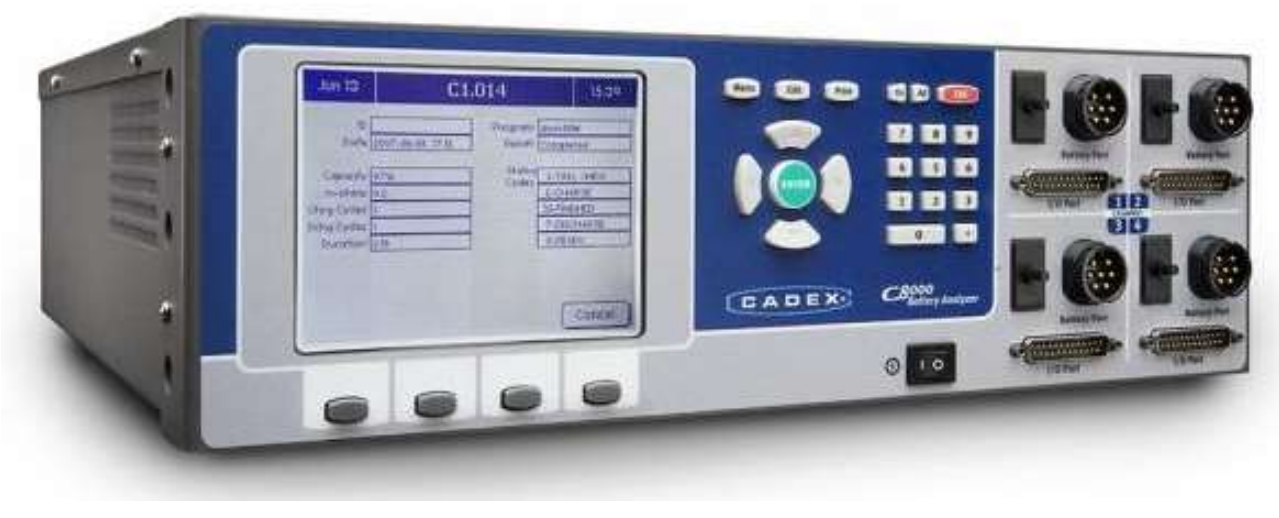

Figure 9: C8000 Battery Testing System [9] 
Figure 10 shows an example of a battery laboratory system. This is the best system in terms of battery charging and managing capability but requires many subcircuits working together, which increases the size and cost of the system.

The $\mathrm{C} 8000$ can be configured as a command center

to control accessories as follows:

Thermal chamber

$>$ External charger

Digital load bank

Heating element

Pressure gauge

Cell monitoring

Safety circuit

$>$ Alarms*

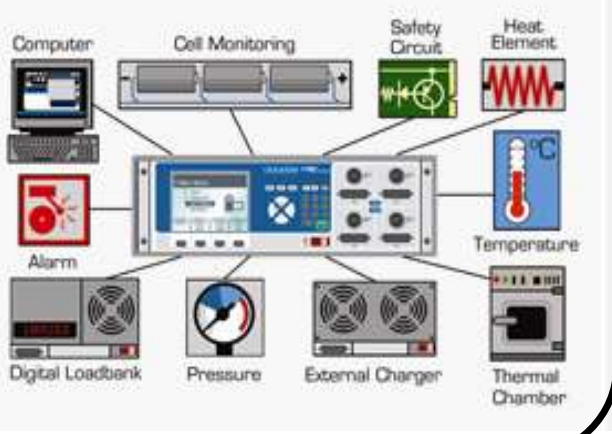

Figure 10: C8000 laboratory system provided by Cadex [9]

\subsubsection{Battery Analyzers}

Cadex produces battery analyzers can handle virtually all battery testing and conditioning needs. They offer over 1500 custom battery adaptors, 18 automated battery testing programs, sorting tests that determine the performance of Li-Ion cells in as little as 30 seconds, a boost mode that restores batteries that have deeply discharged, and can work with online software that can further characterize the batteries. Setting a target capacity automatically reconditions the battery if the capacity drops below the set point. Figure 11 shows the programming capabilities of a battery analyzer, which permits comparison with the system designed in this report. Battery analyzers have more battery parameters to program but also cost more and require more battery knowledge by the user. 


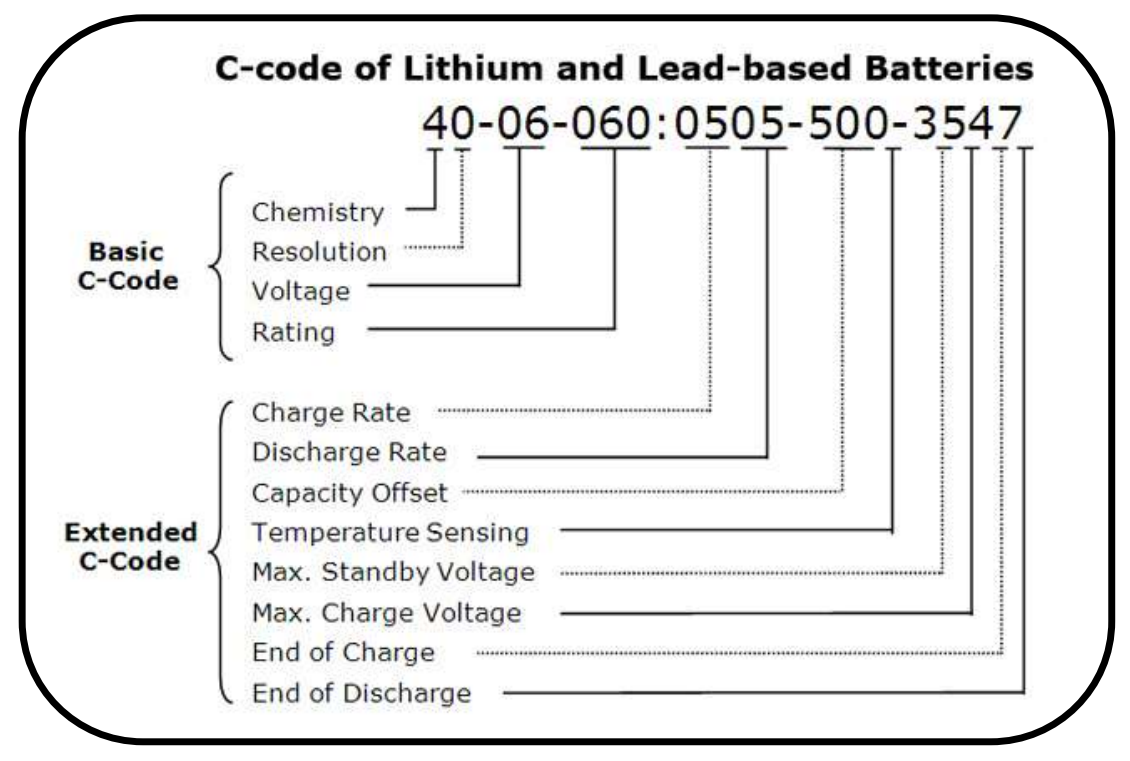

Figure 11: Programmability of C7x00 Battery Analyzer [9]

Custom programs allow the user to define the settings for charging, discharging, and conditioning to make everything automatic. Lifecycle testing gives accurate estimations of the current state of the battery and the approximate cycle life remaining. Dynamic stress tests provide information of how the batteries perform under a variety of output and load conditions. These systems analyze batteries of all shapes and sizes using special platform adaptors as seen in Figure 12. Special charging platforms to charge different types of batteries increases the size and cost of the charger but provides much more flexibility in terms of charging applications.

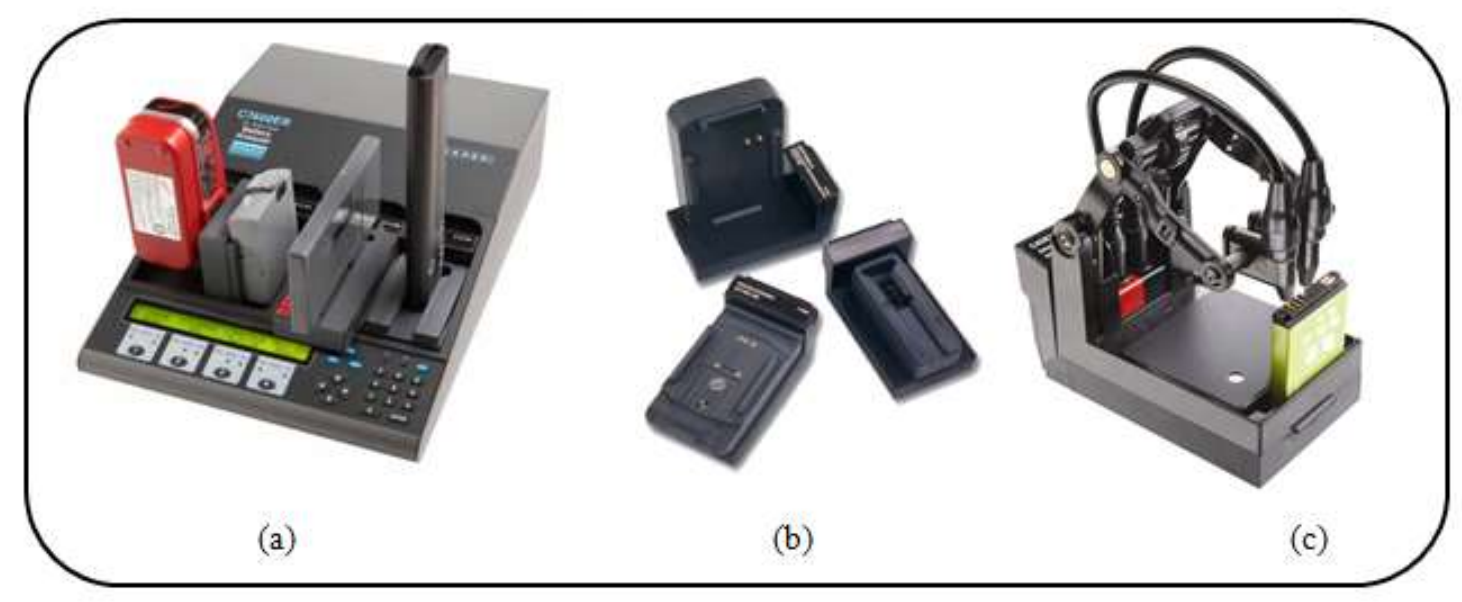

Figure 12: C7400ER Battery Analyzer (a), battery adapters (b), and RIGIDARM Universal Adapter (c) [9] 
Chapter 6 mentions possible connectors to connect the battery charger designed in this report to the various batteries on the market. The platforms in Figure 12 offer other connector options and provide superior connectivity but require more customization.

\subsection{Battery Charging}

This section describes how to charge various batteries to provide the fundamental requirements of a universal battery charger. Although this report describes the generalities for charging different batteries, the user should verify the correct battery specifications in the battery's data sheet before charging any battery.

\subsubsection{Charge Rate}

The charge rate or "C-rate" defines the rate the battery charges or discharges compared to the capacity of the battery. It determines how long a battery takes to charge or discharge at a given current. For example, a $1 \mathrm{C}$ discharge of a battery rated at a capacity of $1 \mathrm{Ah}$ produces $1 \mathrm{~A}$ for 1 hour. Discharging that same battery at $0.5 \mathrm{C}$ would produce half as much current, $0.5 \mathrm{~A}$, for twice as long, 2 hours. Discharging that same battery at $2 \mathrm{C}$ would produce twice as much current, 2A, for half as long, 30 minutes. Charging works the same way in that the C-rate determines the time it takes to reach a full charge at the specified current. For example, the battery with rated capacity of $1 \mathrm{Ah}$ requires a charge of $1 \mathrm{~A}$ for 1 hour for $1 \mathrm{C}, 0.5 \mathrm{~A}$ for 2 hours for $0.5 \mathrm{C}$, and $2 \mathrm{~A}$ for 30 minutes for $2 \mathrm{C}$. A rule of thumb to use states a battery charges or discharges in one hour at full capacity or 1C. Each battery has a unique charge profile depending on the chemistry, voltage, and capacity.

\subsubsection{Battery Life}

The life of a battery decreases when the battery charges with higher charge rates. This reduction of service life results from the decrease in capacity of the battery after a given number of cycles. See Appendix B for more details on battery cycle lifetime. 


\subsubsection{Li-Ion}

Li-Ion cells have a nominal voltage of 3.60V/cell for Li-cobalt, 3.80V/cell for Limanganese, and 3.30V/cell for Li-phosphate. Some Li-ion cells advertise with a nominal voltage of $3.70 \mathrm{~V} / \mathrm{cell}$ but this comes from a slightly lower internal resistance than the standard $3.60 \mathrm{~V} / \mathrm{cell}$. All li-ion cells have the same charge profile. Li-ion cells with nominal voltage between $3.60 \mathrm{~V} / \mathrm{cell}$ and $3.80 \mathrm{~V} / \mathrm{cell}$ charge to $4.20 \mathrm{~V} / \mathrm{cell}$ with a tolerance of $+/-50 \mathrm{mV} / \mathrm{cell}$ while $\mathrm{Li}$ phosphate charges to 3.6V/cell [1-5]. See the voltage and current charge profile in Figure 13 to understand how Li-Ion batteries behave while charging.

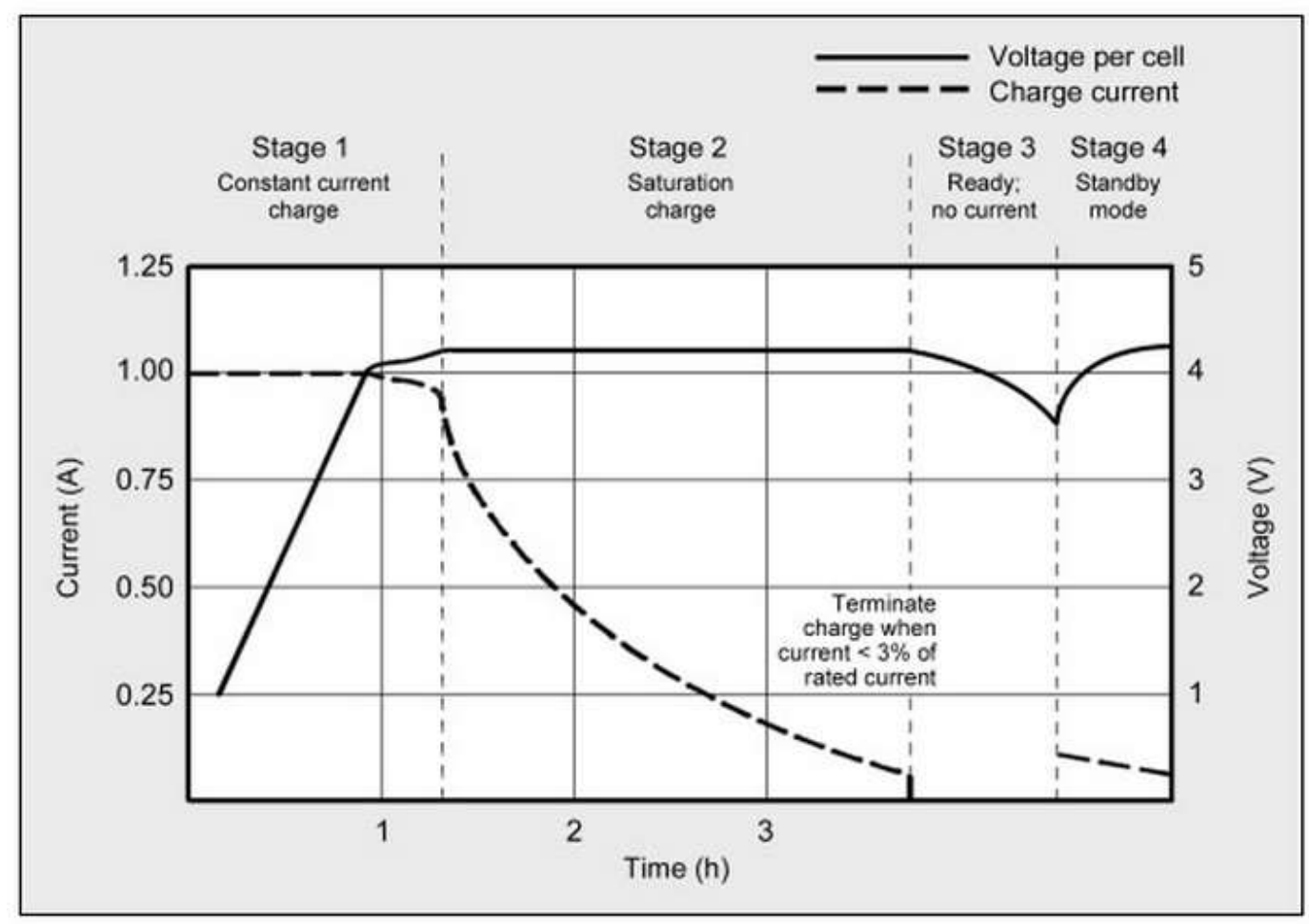

Figure 13: Charge profile for Li-Ion (Courtesy of Cadex) provided by Battery University [1]

\subsubsection{Stage 1}

In the first stage, known as the precharge stage, the battery charges with a small charge current $(0.1 \mathrm{C})$ if the battery voltage measures below its cutoff voltage of $2.5 \mathrm{~V}$ until the battery reaches its cutoff voltage in which the charger transitions to stage $2[2,5]$. 


\subsubsection{Stage 2}

In this stage, known as the constant current charge stage, the voltage rises at constant current. For a typical consumer Li-Ion battery, this charge rate is between $0.5 \mathrm{C}$ and $1 \mathrm{C}$. The charge time for this stage lasts approximately 3 hours $[1,2]$. The peak voltage threshold should never exceed more than 4.20V/cell [1-5]. The life of the battery extends by charging to a lower voltage threshold [1]. See Table IV below for approximate capacity of the battery after charging to different peak voltages with and without constant voltage saturation.

Table IV: Typical charge characteristics of li-ion provided by Battery University [1]

\begin{tabular}{|c|c|c|c|}
\hline Charge V/cell & $\begin{array}{c}\text { Capacity at } \\
\text { cut-off voltage }\end{array}$ & Charge time & $\begin{array}{c}\text { Capacity with full } \\
\text { saturation }\end{array}$ \\
\hline 3.80 & $60 \%$ & $120 \mathrm{~min}$ & $\sim 65 \%$ \\
3.90 & $70 \%$ & $135 \mathrm{~min}$ & $\sim 75 \%$ \\
4.00 & $75 \%$ & $150 \mathrm{~min}$ & $\sim 80 \%$ \\
4.10 & $80 \%$ & $165 \mathrm{~min}$ & $\sim 90 \%$ \\
4.20 & $85 \%$ & $180 \mathrm{~min}$ & $100 \%$ \\
\hline
\end{tabular}

Table IV shows the difference in capacity and thus runtime for a charged battery when using a charge mode that completes the constant voltage saturation portion of the charge process and a quick charge mode that stops the charger quicker at a lower capacity by skipping the constant voltage saturation portion. Although runtime decreases for the quick mode, the total time of charge reduces and the lifetime of the battery increases due to less stress on the battery. This chapter also describes different charge mode options in more detail in the charge mode section.

\subsubsection{Stage 3}

In this stage, known as the saturation stage, the voltage peaks, and current decreases. When the current measures less than $10 \%$ to $3 \%$ of the rated current $(0.1 \mathrm{C}$ to $0.03 \mathrm{C})$, the charge terminates $[1-3,5]$. Notice that the voltage remains nearly constant yet the additional charge provides more capacity. Figure 18 shows the capacity as a function of charge voltage, which 
emphasizes the need for the constant voltage saturation portion of the charge process to charge a battery to maximum capacity.

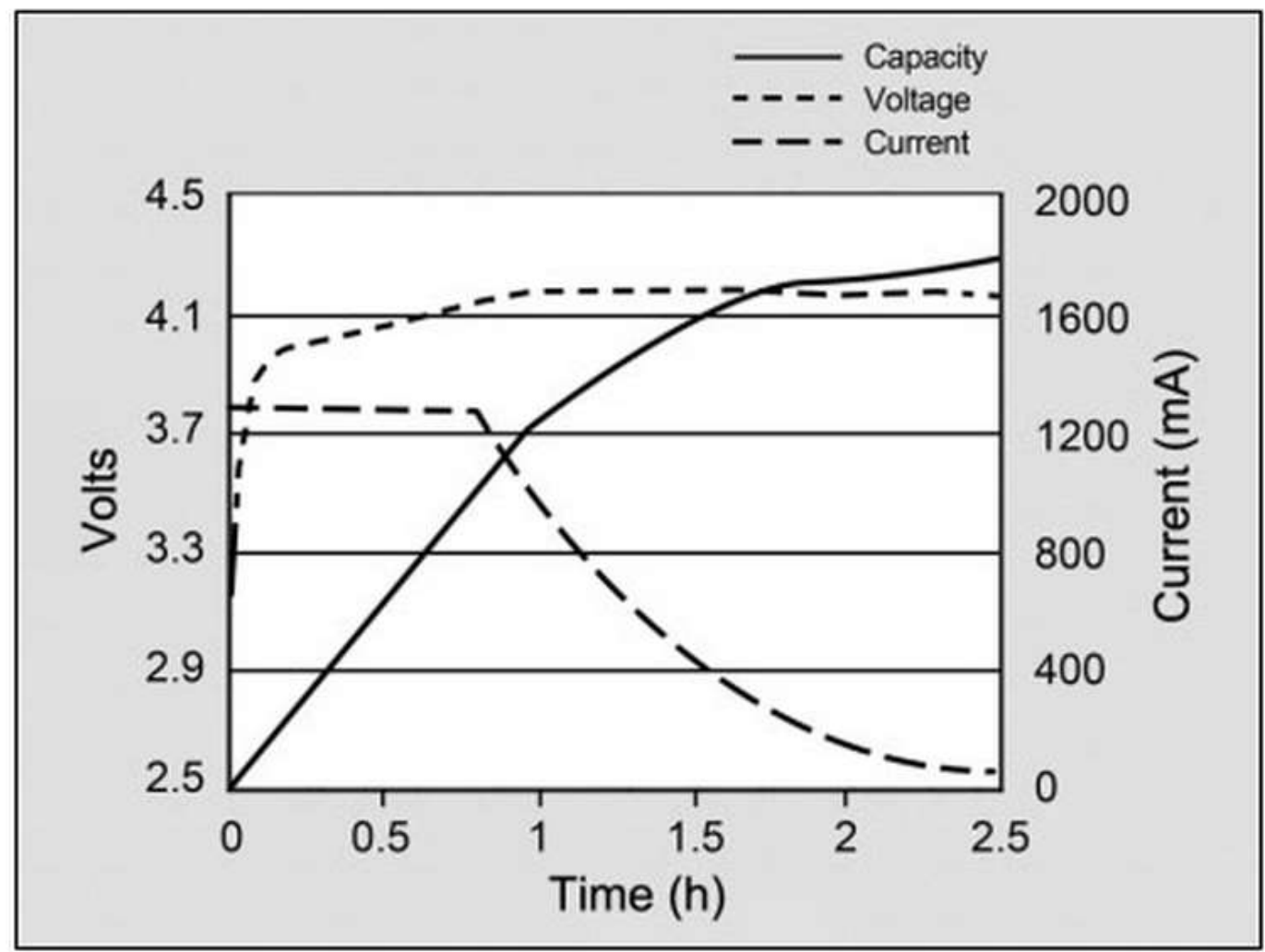

Figure 14: Capacity with respect to charge current and voltage provided by Battery University [1]

Figure 15 shows Li-Ion charge profile with current, voltage, and capacity on separate axes. When the charge voltage reaches $4.2 \mathrm{~V}$ on the cell voltage axis, the charger switches to the constant voltage saturation portion of the charge process, and the charge rate begins to taper. After the voltage remains at the charge voltage while the charge rate reduces to $0.1 \mathrm{C}$, the battery achieves $100 \%$ charge [3]. 


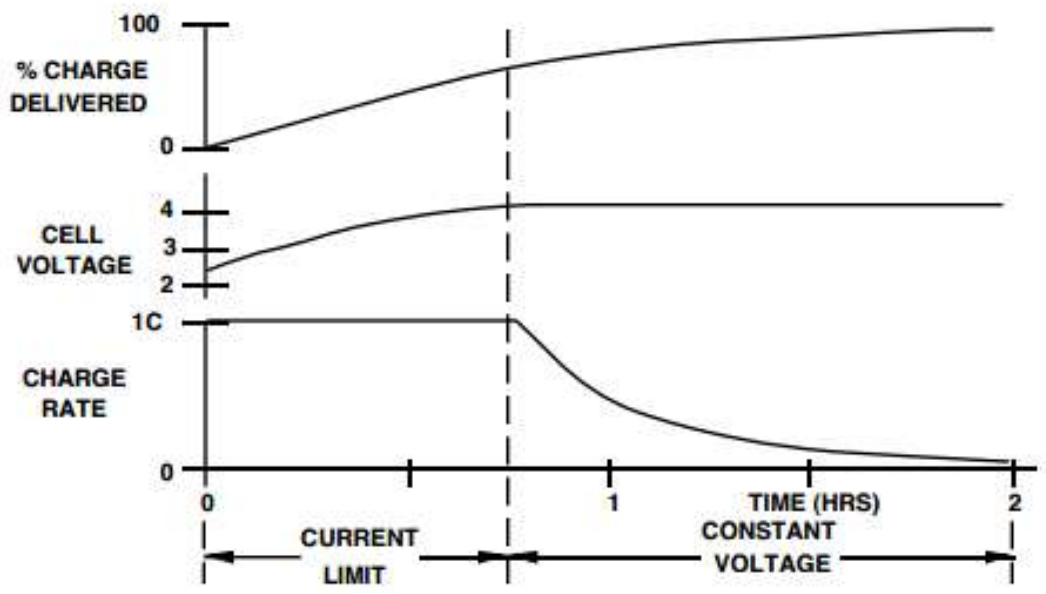

Figure 15: Li-Ion Current and Voltage Charge Profile [3]

\subsubsection{Stage 4}

In this stage, the charge current measures zero as charge has already terminated. The battery voltage eventually drops to between 3.60 and 3.90V/cell. Skipping stage 2 causes the battery voltage to drop quicker [1].

\subsubsection{Stage 5}

In this stage, the charger can provide occasional "top off" charge. This accounts for the voltage drop that occurs over time after charge has terminated in stage 3. In this "stand-by" mode, the battery charges up to $4.05 \mathrm{~V} /$ cell after dropping lower than $4.0 \mathrm{~V} /$ cell $[1,2]$.

\subsubsection{Full Charge}

Full charge occurs when the battery reaches the voltage threshold ( $4.2 \mathrm{~V}$ for most Li-Ion) and the current drops to the desired termination taper current $(0.03 \mathrm{C}$ to $0.1 \mathrm{C}$ for most $\mathrm{Li}$-Ion) or when the current can't decrease anymore $[1,5]$. Battery manufactures recommend that users do not fully charge Li-Ion cells, because higher voltages put larger stresses on the battery. Charging to lower voltage threshold prolongs battery life but reduces runtime. The temperature can rise about $5^{\circ} \mathrm{C}\left(9^{\circ} \mathrm{F}\right)$ when reaching full charge [1]. 


\subsubsection{Overcharge}

Overcharging Li-Ion cells is very dangerous, because the cell can explode. After the cell fully charges, the current must terminate! The cell should only remain at $4.20 \mathrm{~V} /$ cell for as short a time as possible to minimize stress. If a cell has stayed at or below $1.5 \mathrm{~V}$ for more than a week, experts recommend that users do not recharge the battery. The cell might become unstable if charged, which results in excessive heating or other problems. Experts at Battery University describe what happens in detail when Li-ion cells overcharge:

Prolonged charging above $4.30 \mathrm{~V}$ forms plating of metallic lithium on the anode, while the cathode material becomes an oxidizing agent, loses stability and produces carbon dioxide (CO2). The cell pressure rises, and if charging continues, the current interrupt device (CID) responsible for cell safety disconnects the current at $1,380 \mathrm{kPa}(200 \mathrm{psi})$. Should the pressure rise further, a safety membrane bursts open at 3,450kPa (500psi) and the cell might eventually vent with flame.

\subsubsection{Lead Acid}

Lead acid cells have nominal cell voltage of $2.0 \mathrm{~V} /$ cell and $12 \mathrm{~V}$ lead acid batteries consist of six cells placed in a series configuration. The charge voltage ranges from $2.30 \mathrm{~V} /$ cell to $2.45 \mathrm{~V} /$ cell. Selecting a voltage threshold too low causes sulfation on the negative plate but setting the voltage threshold too high causes grid corrosion on the positive plate, which can induce gassing. See the Table V below for the advantages and disadvantages for charging to the low and high voltage thresholds [1]. By choosing different charge modes, the user picks the voltage threshold and thus picks the desired tradeoff. 
Table V: Effects of charge voltage on a lead acid battery provided by Battery University [1]

\begin{tabular}{|c|l|l|}
\hline \multicolumn{1}{|c|}{$2.30 \mathrm{~V}$ to $2.35 \mathrm{~V} / \mathrm{cell}$} & \multicolumn{1}{c|}{$2.40 \mathrm{~V}$ to $2.45 \mathrm{~V} / \mathrm{cell}$} \\
\hline Advantages & $\begin{array}{l}\text { Maximum service life; battery stays } \\
\mathrm{cool} ; \text { charge temperature can exceed } \\
30^{\circ} \mathrm{C}\left(86^{\circ} \mathrm{F}\right)\end{array}$ & $\begin{array}{l}\text { Higher and more consistent capacity } \\
\text { readings; less sulfation. }\end{array}$ \\
\hline Disadvantages & $\begin{array}{l}\text { Slow charge time; capacity readings } \\
\text { may be inconsistent and declining } \\
\text { with each cycle. Sulfation may occur } \\
\text { without equalizing charge. }\end{array}$ & $\begin{array}{l}\text { Subject to corrosion and gassing. } \\
\text { Needs constant water. Not suitable } \\
\text { for charging at high room } \\
\text { temperatures, causing severe } \\
\text { overcharge. }\end{array}$ \\
\hline
\end{tabular}

Lead acid charging consists of three main stages as shown in the charge profile in Figure 16 below.

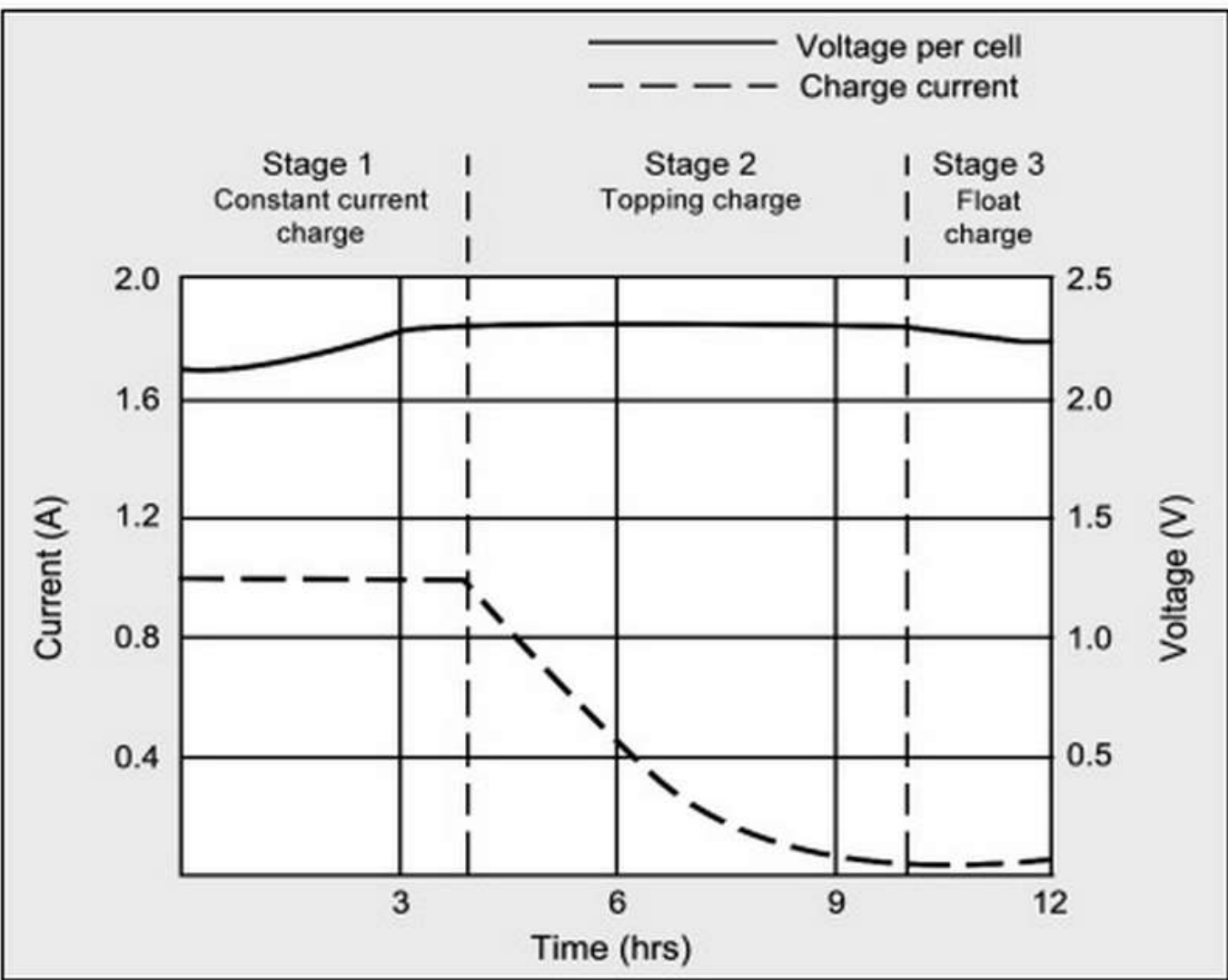

Figure 16: Charge profile for a lead acid battery provided by Battery University [1] 


\subsubsection{Stage 1}

In this stage, known as the constant current charge stage, the voltage rises at a constant current. This stage applies the majority of the actual charge to the battery. In this stage, the battery charges to $70 \%$ in about 5 to 8 hours. When the battery reaches a pre-determined voltage threshold, stage 2 beings [1].

\subsubsection{Stage 2}

In this stage, known as the topping or saturation stage, the current decreases after the voltage reaches the charge voltage threshold. This stage charges the battery the remaining $30 \%$ in about 7 to 10 hours. If the charger skips this stage, the battery can eventually lose the ability to fully charge due to sulfation, which hinders the performance and life of the battery. Once fully charged after stage 2 , the battery must not remain at the topping voltage for more than 48 hours to prevent damage to the battery. The battery voltage eventually reduces to the float voltage level of stage 3 [1].

\subsubsection{Stage 3}

In this stage, known as the trickle charge or float charge stage, a trickle charge compensates for self-discharge as the battery voltage decreases slightly over time. This stage helps keep the battery at full charge. The recommended float voltage for most low-pressure lead acid batteries is $2.25 \mathrm{~V} /$ cell to $2.27 \mathrm{~V} /$ cell. Manufactures recommend lowering the float charge at ambient temperatures above $29^{\circ} \mathrm{C}\left(85^{\circ} \mathrm{F}\right)[1]$.

\subsubsection{Full Charge}

The battery reaches full charge when the current drops to a pre-determined level or when the current reaches $3 \%$ of the rated current of the battery. Stage 3 keeps the battery at full charge after already reaching full charge. Lead acid batteries should always be stored with charge and the charger should apply a topping charge to prevent the voltage from dropping below $2.10 \mathrm{~V} /$ cell [1]. 


\subsubsection{Nickel Based}

Nickel based batteries have a unique charge profile in that they don't have specific stages of constant current or constant voltage that Li-Ion or Lead acid batteries have. Nickel bases batteries also require a certain amount of charge/discharge cycles before reaching optimal performance. The number of cycles depends on the quality of the battery. After reaching peak capacity usually between 100 and 300 cycles, the performance begins to degrade with each charge/discharge cycle after that [1]. See Figure 17 and Figure 18 to see the relationship of cell voltage, pressure, and temperature for charging $\mathrm{NiCd}$ and $\mathrm{NiMH}$.

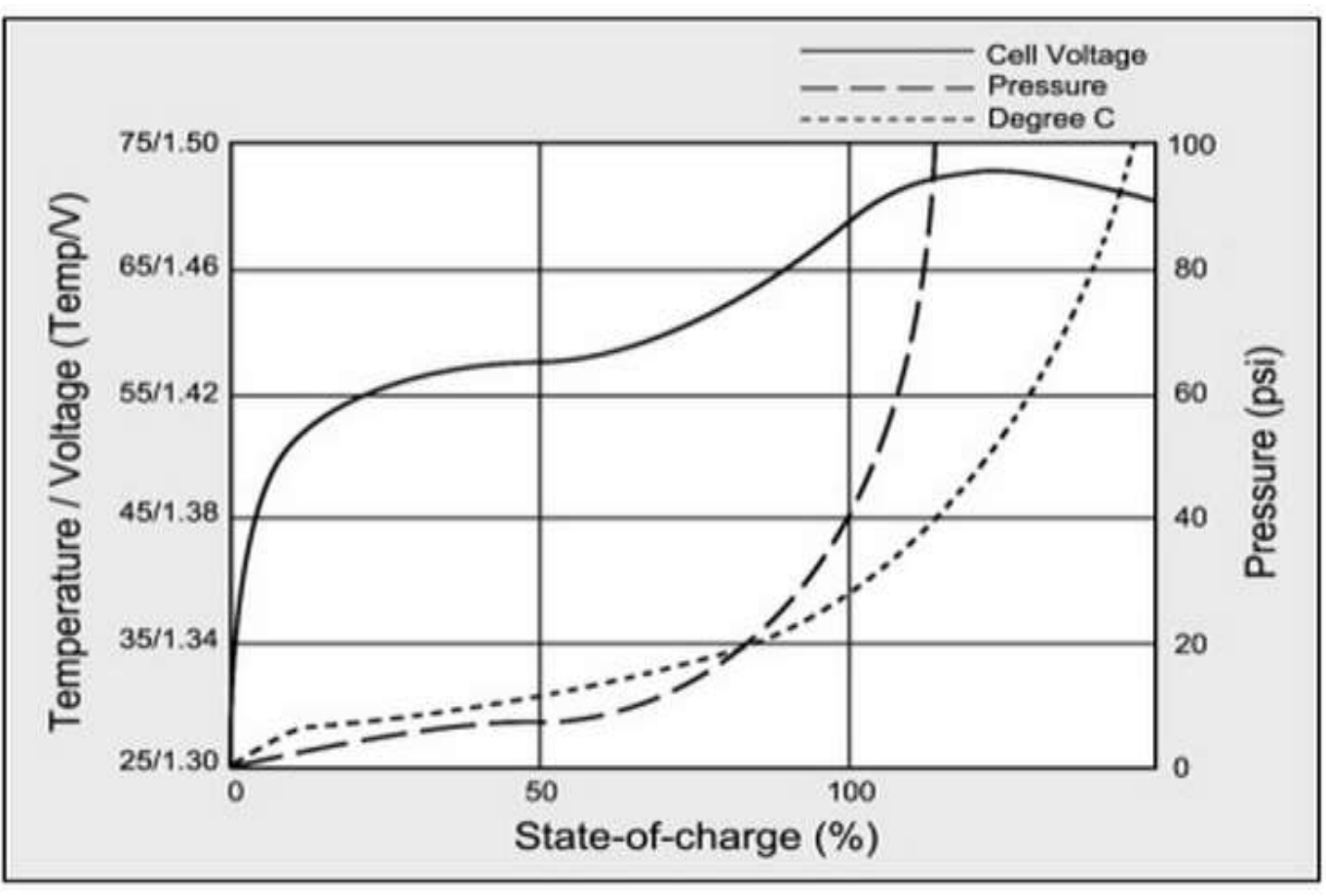

Figure 17: Charge profile for NiMH provided by Battery University [1] 

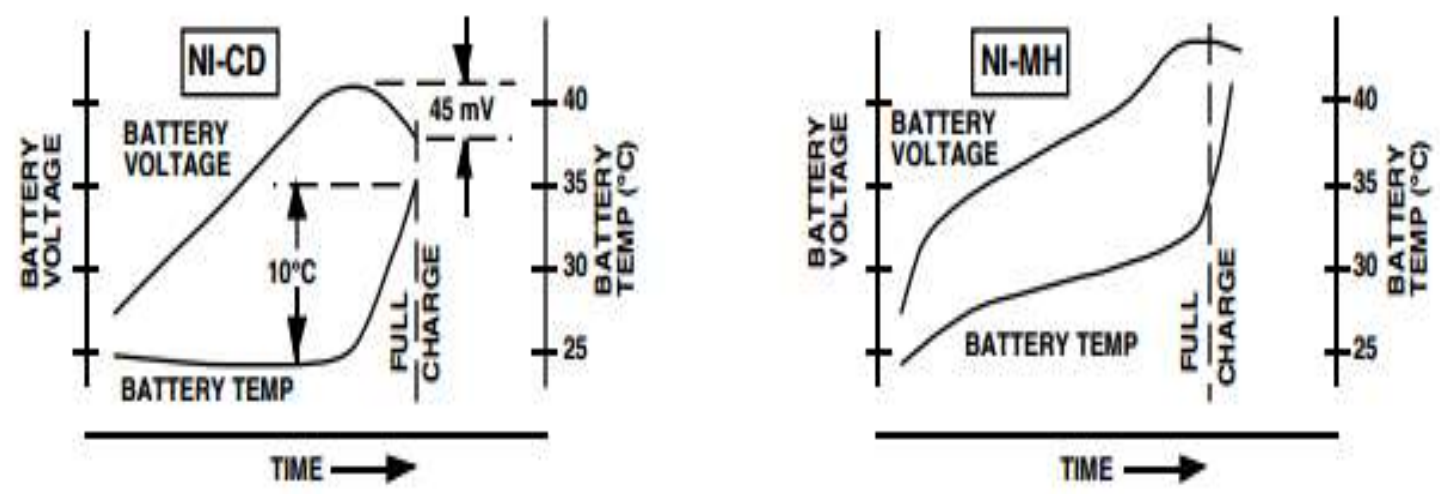

Figure 18: Comparison between Ni-Cd and Ni-MH [3]

\subsubsection{1 $\mathrm{NiCd}$}

New batteries should charge slowly, around $0.1 \mathrm{C}$, for 16 to 24 hours before use in order to bring all cells in the battery pack to an equal charge level. When batteries are stored for long periods of time, the cells could self-discharge at different rates resulting in the electrolyte moving towards the bottom of the cell. Giving them an initial slow charge helps redistribute the electrolyte to eliminate dry spots on the separator. Many rechargeable NiCd cells have a safety vent that opens at $1,000-1,400 \mathrm{kPa}(150-200 \mathrm{psi})$ to release excess pressure if incorrectly charged. This pressure releases through a resealable vent causing no damage, but some electrolyte escapes, and the seal can begin leaking, which creates a white powder at the vent opening. After multiple ventings, the cell dries out and no longer stores charge. Note that venting is a last resort safety feature and should never occur with proper charging [1].

\subsubsection{NiMH}

Difficulties arise when slow charging NiMH batteries. When charging below $0.3 \mathrm{C}$, the voltage and temperature profiles don't allow for accurate full-charge state measurements. At a low charge rate, $\mathrm{NiMH}$ can still overcharge without heating up, which causes problems if relying solely on temperature detection [1]. 


\subsubsection{Full Charge Detection by Temperature}

Note that chargers relying only on temperature detection to trigger charge cut-off can damage the cell. For example, if the user removes a fully charged battery that has cooled down and reinserts it back into the charger, the charge required to raise the temperature to the given threshold could cause harmful overcharge [1].

\subsection{Delta Temperature}

For both Ni-Cd and Ni-MH batteries, the full charge temperature is approximately $10{ }^{\circ} \mathrm{C}$ above ambient temperature, so use a delta of $10{ }^{\circ} \mathrm{C}$ to detect a full charge [3].

\subsection{Delta Temperature over Delta Time (Slope Detection)}

This method senses a rapid temperature increase that occurs towards the end of charge to trigger charge cut-off rather than waiting for the battery to reach a fixed temperature threshold, thus keeping the cells cooler. This method, however, requires a fast charge around $1 \mathrm{C}$. Charge cut-off triggers when the temperature rises $1^{\circ} \mathrm{C}\left(1.8^{\circ} \mathrm{F}\right)$ per minute [1].

\subsection{Fixed Temperature}

Charger manufactures recommend $50^{\circ} \mathrm{C}\left(122^{\circ} \mathrm{F}\right)$ skin temperature of the cell to trigger charge cut-off. Any prolonged temperature above $45^{\circ} \mathrm{C}\left(113^{\circ} \mathrm{F}\right)$ on the skin of the cell causes harm to the battery. A brief overshoot is acceptable if the battery temperature quickly drops after the overshoot [1].

\subsubsection{Full Charge Detection by Voltage}

Both of the following voltage detections used together provide a better charge termination than either one by itself [3].

\subsection{Negative Delta Voltage (NDV)}

\subsection{1 $\mathrm{NiCd}$}

This method triggers charge cut-off when a $10 \mathrm{mV} /$ cell voltage drop occurs signifying the battery is fully charged. Experts recommend this method for "open-lead" nickel based batteries, 
which are batteries without a thermistor. The charge rate must be $0.5 \mathrm{C}$ or higher to obtain the $10 \mathrm{mV} /$ cell voltage drop when the battery is fully charged [1-3].

\subsection{NiMH}

This method triggers charge cut-off, when a $5 \mathrm{mV} /$ cell voltage drop occurs. This low voltage change requires additional detections for accurate charge termination [1]. Detecting the voltage drop in NiMH batteries typically require more accurate circuitry than for NiCd batteries [3].

\subsection{Voltage Plateau}

If the voltage does not drop enough to reach the 5-10mV/cell threshold, the charge still needs to eventually terminate to prevent damage to the cell. This method terminates charge after the voltage remains in a steady state for one minute [1].

\subsubsection{Step-differential Charge}

This charge starts with a fast charge of $1 \mathrm{C}$, until the battery reaches a certain voltage threshold, which depends on the battery selected. Then the charge terminates for a few minutes to allow the battery to cool down before charging at a lower current of $0.1 \mathrm{C}$. The current gradually reduces as the charge progresses. This method can cause slight overstress on the battery, which can increase capacity by about $6 \%$ but reduces battery life by about 50 to 100 cycles [1].

\subsubsection{Trickle Charge}

After reaching full charge, the charger should use a trickle charge of $0.05 \mathrm{C}$ to compensate for self-discharge. For NiCd batteries, the trickle charge can be as high as $0.1 \mathrm{C}$, but anything higher results in overcharge. This trickle charge should not last for more than 30 minutes [1]. NiMH cells are not as tolerant of trickle charging, and the trickle charge is typically between $0.025 \mathrm{C}$ and $0.1 \mathrm{C}$ depending on the battery manufacturer [3]. 


\subsubsection{Charging Flooded NiCd}

Flooded NiCd batteries should charge with constant voltage to approximately $1.55 \mathrm{~V} /$ cell. Then, current reduces to $0.1 \mathrm{C}$ until the cell reaches $1.55 \mathrm{~V} /$ cell again. Finally, the charger should apply a trickle charge of $0.05 \mathrm{C}$ to compensate for self-discharge [1]

The next section describes different charge modes as a guide to help the user understand the possibilities. Ideally, the user can program any unique and original charge mode into my system depending on the tradeoffs desired.

\subsection{Charge Modes}

The battery charger in this project has different charge mode options, which changes how fast the batteries charge and the state of charge they charge to. The user should keep in mind the faster the batteries charge, the shorter the battery lasts in terms of battery lifetime measured in number of charge and discharge cycles. Also, charging to maximum state of charge gives maximum runtime but puts more stress on the battery and can reduce the battery's lifetime. See Appendix B for more information on battery cycle lifetime. Table VI provides a table of recommended charge modes for user reference. 
Table VI: Details of different charge mode options

\begin{tabular}{|c|c|c|c|c|c|}
\hline Type & Chemistry & C rate & Time & Temperatures & Charge Information \\
\hline $\begin{array}{c}\text { Slow } \\
\text { (trickle } \\
\text { charge) }\end{array}$ & $\begin{array}{l}\mathrm{NiCd} \\
\text { lead acid }\end{array}$ & $0.1 \mathrm{C}$ & 14 hours & $\begin{array}{c}0 \mathrm{C} \text { to } 45 \mathrm{C} \\
\left(32^{\circ} \mathrm{F} \text { to } 113^{\circ} \mathrm{F}\right)\end{array}$ & $\begin{array}{l}\text { Low charge for } \\
\text { extended period of } \\
\text { time. Reduces stress on } \\
\text { battery and prevents } \\
\text { overcharge. Remove } \\
\text { battery when charged. }\end{array}$ \\
\hline Rapid & $\begin{array}{l}\text { Li-Ion } \\
\text { NiCd, } \\
\text { NiMH }\end{array}$ & $\begin{array}{c}0.3 \mathrm{C} \text { to } \\
0.5 \mathrm{C}\end{array}$ & 3-6 hours & $\begin{array}{c}10 \mathrm{C} \text { to } 45 \mathrm{C} \\
\left(50^{\circ} \mathrm{F} \text { to } 113^{\circ} \mathrm{F}\right)\end{array}$ & $\begin{array}{l}\text { Slightly quicker charge } \\
\text { by rapid charging } \\
\text { battery to } 70 \% \text { SOC } \\
\text { then switching to } \\
\text { trickle charge for } \\
\text { remaining } 30 \% \text {. }\end{array}$ \\
\hline Fast & $\begin{array}{l}\text { Li-Ion } \\
\text { NiCd, } \\
\text { NiMH }\end{array}$ & $1 \mathrm{C}$ & 1 hour+ & $\begin{array}{c}10 \mathrm{C} \text { to } 45 \mathrm{C} \\
\left(50^{\circ} \mathrm{F} \text { to } 113^{\circ} \mathrm{F}\right)\end{array}$ & $\begin{array}{l}\text { Faster charge by fast } \\
\text { charging to } 70 \% \text { SOC } \\
\text { then switching to } \\
\text { trickle charge for } \\
\text { remaining } 30 \% .\end{array}$ \\
\hline Ultra-fast* & $\begin{array}{l}\text { Li-Ion } \\
\text { NiCd, } \\
\text { NiMH }\end{array}$ & $\begin{array}{l}1 \mathrm{C} \text { to } \\
10 \mathrm{C}\end{array}$ & $\begin{array}{c}10-60 \\
\text { minutes }\end{array}$ & $\begin{array}{c}10 \mathrm{C} \text { to } 45 \mathrm{C} \\
\left(50^{\circ} \mathrm{F} \text { to } 113^{\circ} \mathrm{F}\right)\end{array}$ & $\begin{array}{l}\text { Fastest full charge by } \\
\text { ultra-fast charging to } \\
70 \% \text { SOC then } \\
\text { switching to trickle } \\
\text { charge for remaining } \\
\text { 30\%. Not all batteries } \\
\text { can handle ultra-fast } \\
\text { charging. }\end{array}$ \\
\hline Quick Rapid & $\begin{array}{l}\text { Li-Ion } \\
\text { lead acid }\end{array}$ & $0.5 \mathrm{C}$ & $\begin{array}{c}90 \\
\text { minutes }\end{array}$ & $\begin{array}{c}10 \mathrm{C} \text { to } 45 \mathrm{C} \\
\left(50^{\circ} \mathrm{F} \text { to } 113^{\circ} \mathrm{F}\right)\end{array}$ & $\begin{array}{l}\text { Quick Rapid mode } \\
\text { charges using rapid } \\
\text { charge to } 70 \% \text { SOC } \\
\text { then terminates. Note } \\
\text { that battery is not fully } \\
\text { charged but is ready } \\
\text { sooner. Extends life of } \\
\text { battery by reducing } \\
\text { stress resulting from } \\
\text { complete full charging. }\end{array}$ \\
\hline Equalization & lead acid & $1.1 \mathrm{C}$ & $\begin{array}{l}2-16 \\
\text { hours }\end{array}$ & $\begin{array}{c}10 \mathrm{C} \text { to } 45 \mathrm{C} \\
\left(50^{\circ} \mathrm{F} \text { to } 113^{\circ} \mathrm{F}\right)\end{array}$ & $\begin{array}{c}\text { Equalizes slightly } \\
\text { unbalanced cells in a } \\
\text { lead acid battery pack } \\
\text { by slightly } \\
\text { overcharging them to } \\
2.5 \mathrm{~V} / \text { cell or } 10 \% \text { more } \\
\text { than the battery pack } \\
\text { voltage. This removes } \\
\text { sulfation that may have } \\
\text { formed during low } \\
\text { voltage conditions. }\end{array}$ \\
\hline
\end{tabular}

*Only special types of batteries can handle Ultra-Fast charge mode. Check datasheet of battery. 


\section{PROJECT REQUIREMENTS}

This chapter discusses the design requirements for the system as a whole. These provide the structure for what the system needs to accomplish. Then, this chapter discusses the details of how the system accomplishes the design requirements by providing the specifications of each of the subsystems. Finally, this chapter discusses the primary constraints considered throughout the design process with justification.

\subsection{Design Requirements}

The design requirements for the overall system are as follows:

1. Capable of constant current or constant voltage output

2. Feedback to determine correct output at any given time

3. Programmable if user desires unique charge profiles
a. Charge current
b. Charge voltage
c. Termination taper current

4. No additional hardware or replacement parts necessary

5. Status indicator to alert user when charger is charging or finished

6. Display BMS cell parameters on LCD screen

\subsection{System Specifications}

\subsubsection{Universal Battery Charger}

The requirements for the Universal Battery Charger are as follows:

1. Ability to charge batteries of different chemistries

a. Lithium Ion
i. Li-Cobalt
ii. Li-Manganese
iii. Li-Phosphate

b. Lead Acid 
c. Nickel based
i. $\mathrm{NiCd}$
ii. $\mathrm{NiMH}$

2. Ability to charge batteries of different voltages and current requirements
a. Max pack voltage: $20 \mathrm{~V}$
b. Max charge current: $1.8 \mathrm{~A}$
c. Cell voltage for Li-Ion: 1 to $4.5 \mathrm{~V}$
d. Cell voltage for $\mathrm{Pb}: 1$ to $20 \mathrm{~V}$
e. Cell voltage for Ni: 1 to $20 \mathrm{~V}$

3. Synchronous Buck Converter with maximum efficiency above $90 \%$
a. PWM controlled

4. Input power is $40 \mathrm{~W}$ maximum

a. Maximum input voltage: $65 \mathrm{~V}$

b. Minimum input voltage allowed: $12 \mathrm{~V}$

5. Variety of charge modes (varies with chemistry, see battery information section)

a. Slow charge

i. Overnight charging at a low charge rate to prolong battery life

ii. Doesn't require end-of-charge detection for lead acid and nickel based $[1-3]$

iii. Charging at $0.1 \mathrm{C}$ rate $[2,3]$

iv. 14-16 hours (lead acid) [2]

v. 12 hours (nickel based) [3]

b. Rapid charge

i. Complete full charge at a moderate charge rate

ii. 3-6 Hours charging at $0.3 \mathrm{C}$ rate [2] 
c. Fast charge

i. Complete full charge at a high charge rate

ii. Less than 1 hour charging at $1.0 \mathrm{C}$ rate [2]

iii. 1 hour at $1.2 \mathrm{C}$ for nickel based [3]

d. Quick charge

i. Charges to approximately $70 \%$ regardless of charge rate

ii. Prolongs battery life since battery is never stressed to maximum charge

e. Equalization charge (lead acid only)

i. Charges to $10 \%$ over recommended to remove sulfation that may have formed during low-charge conditions [1]

ii. Recommended every 6 months or after 20 cycles to bring all cells to similar levels [1]

6. Ability to act as programmable Power Supply
a. Constant current
b. Constant voltage
c. Timer or user controlled

\subsubsection{BMS}

The requirements for the Battery Management System are as follows:

1. Able to monitor battery characteristics for Li-Ion, nickel, lead acid
a. Cell voltage
b. Pack voltage
c. State of charge
d. Temperature

2. Monitors multiple cells

a. Maximum pack voltage: $27 \mathrm{~V}$ 
3. High accuracy
a. Measuring within $\pm 3 \mathrm{mV}$
b. 14-bit resolution ADC

4. Cell balancing capability
a. Imbalance detection
b. Passive cell balancing
c. Timer based balancing

\subsubsection{User Interface \& Protection}

The requirements for the user interface are as follows:

1. Safety features that protect the user and the system
a. Overcurrent
b. Overvoltage
c. Over-temperature
d. Automatic charge termination

2. User friendly interface on LCD screen
a. 1.3-inch screen with $96 \times 96$ resolution
b. Capacitive touch for option scrolling
c. Buttons for option selection

\subsection{Primary Constraints}

The primary constraints for this project are as follows:

1. The system charges and monitors the batteries without any damage to the batteries, system, or user.

2. Safety features prevent incorrect user operation.

3. Voltage, current, and power levels never exceed maximum ratings for any component anywhere in the system. 
Table VII: Marketing requirements \& engineering specifications

\begin{tabular}{|c|c|c|}
\hline $\begin{array}{l}\text { Marketing } \\
\text { Requirements }\end{array}$ & $\begin{array}{l}\text { Engineering } \\
\text { Specifications }\end{array}$ & Justification \\
\hline \multirow[t]{4}{*}{ Monitor } & $\begin{array}{l}\text { Monitors Li-Ion cells (Cobalt, } \\
\text { Manganese, Phosphate) from } 1 \mathrm{~V} \text { to } \\
4.5 \mathrm{~V} \\
\text { Monitors three to six cells per } \\
\text { BQ76PL536 chip. The EVM has } \\
\text { three BQ76PL536 chips providing } \\
\text { cell monitoring for up to } 18 \text { cells. }\end{array}$ & $\begin{array}{l}\text { This is a very common Li-Ion voltage } \\
\text { range making this BMS relevant. } \\
\text { The supply voltage for the } \\
\text { BQ76PL536 chip is } 7.2 \mathrm{~V} \text { to } 27 \mathrm{~V} \\
\text { which determines the minimum and } \\
\text { maximum number of cells per chip. }\end{array}$ \\
\hline & $\begin{array}{l}\text { Monitors nickel cells (Cadmium, } \\
\text { Metal Hydride) from } 1 \mathrm{~V} \text { to } 20 \mathrm{~V}\end{array}$ & $\begin{array}{l}\text { Almost all nickel based cells are in } \\
\text { this voltage range. }\end{array}$ \\
\hline & $\begin{array}{l}\text { Monitors lead acid cells from } 1 \mathrm{~V} \text { to } \\
20 \mathrm{~V}\end{array}$ & $\begin{array}{l}\text { Almost all lead acid cells are in this } \\
\text { voltage range. }\end{array}$ \\
\hline & $\begin{array}{l}\text { Monitors individual cell voltage, } \\
\text { pack voltage, state of charge, and } \\
\text { pack temperature. }\end{array}$ & $\begin{array}{l}\text { These are key characteristics to } \\
\text { monitor in any BMS. These values } \\
\text { determine the status of the cells and } \\
\text { the overall BMS. }\end{array}$ \\
\hline \multirow[t]{2}{*}{$\begin{array}{l}\text { Cell } \\
\text { Balancing }\end{array}$} & $\begin{array}{l}\text { Cells that differ in voltage balance to } \\
\text { the lowest cell through external cell } \\
\text { balancing circuitry. The user chooses } \\
\text { this option in the main menu. }\end{array}$ & $\begin{array}{l}\text { Cell balancing is essential in a BMS } \\
\text { to make sure all of the cells are at the } \\
\text { same voltage. }\end{array}$ \\
\hline & $\begin{array}{l}\text { When the user chooses cell balance, } \\
\text { the system detects any out of balance } \\
\text { cells and balances them. }\end{array}$ & $\begin{array}{l}\text { The cells only balance if detected by } \\
\text { the system to be out of balance to } \\
\text { prevent user error. }\end{array}$ \\
\hline \multirow[t]{2}{*}{$\begin{array}{l}\text { Safety } \\
\text { Features }\end{array}$} & $\begin{array}{l}\text { The BMS has cell overvoltage, cell } \\
\text { undervoltage, cell over-temperature, } \\
\text { and cell under-temperature trip } \\
\text { points that set Alert and Fault flags if } \\
\text { reached. }\end{array}$ & $\begin{array}{l}\text { These are the main issues with } \\
\text { batteries so this provides the most } \\
\text { essential battery protection. }\end{array}$ \\
\hline & $\begin{array}{l}\text { The BMS requires additional } \\
\text { programming to perform tasks when } \\
\text { an Alert or Fault is set. } \\
\text { Recommended tasks include blinking } \\
\text { an LED or shutting down the system. }\end{array}$ & $\begin{array}{l}\text { The BMS provides Alert and Fault } \\
\text { statuses to help protect the system and } \\
\text { the user. The user has control over the } \\
\text { Alert and Fault flags via } \\
\text { programming. }\end{array}$ \\
\hline \multirow[t]{4}{*}{ User Interface } & $\begin{array}{l}\text { The BMS displays the menus for the } \\
\text { user on a LCD screen. The user } \\
\text { navigates through the menus using } \\
\text { the LEFT Capacitive Touch Sensor } \\
\text { and the Option Select Button. }\end{array}$ & $\begin{array}{l}\text { The user needs to be able to choose } \\
\text { what mode they want to execute. This } \\
\text { includes all of the monitoring and cell } \\
\text { balancing. }\end{array}$ \\
\hline & $\begin{array}{l}\text { The user can return to the main menu } \\
\text { by clicking the Menu Button. }\end{array}$ & $\begin{array}{l}\text { This allows the user to change the } \\
\text { current mode. }\end{array}$ \\
\hline & $\begin{array}{l}\text { The user must select battery } \\
\text { chemistry, number of cells, battery } \\
\text { capacity, and type of charge. }\end{array}$ & $\begin{array}{l}\text { These are the essential characteristics } \\
\text { of the battery that allows the charger } \\
\text { to operate correctly. }\end{array}$ \\
\hline & $\begin{array}{l}\text { No maintenance is required. The user } \\
\text { has the ability to change trip points } \\
\text { and system tasks by changing the } \\
\text { software. }\end{array}$ & \\
\hline
\end{tabular}


Table VIII: Recommended Charge Modes and Charge Terminations

\begin{tabular}{|l|l|l|}
\hline $\begin{array}{l}\text { Battery } \\
\text { chemistry }\end{array}$ & $\begin{array}{l}\text { Recommended } \\
\text { charge modes }\end{array}$ & $\begin{array}{l}\text { Recommended } \\
\text { charge } \\
\text { termination }\end{array}$ \\
\hline Li-Ion & $\begin{array}{l}\text { Rapid } \\
\text { Fast } \\
\text { Quick }\end{array}$ & $\begin{array}{l}\text { Voltage threshold } \\
\text { Minimum current } \\
\text { threshold } \\
\text { Temperature } \\
\text { threshold } \\
\text { Timer }\end{array}$ \\
\hline lead acid & $\begin{array}{l}\text { Slow } \\
\text { Fast } \\
\text { Equalization }\end{array}$ & $\begin{array}{l}\text { Voltage threshold } \\
\text { Minimum current } \\
\text { threshold } \\
\text { Timer }\end{array}$ \\
\hline nickel & $\begin{array}{l}\text { Slow (new cells) } \\
\text { Rapid }\end{array}$ & $\begin{array}{l}\text { NDV } \\
\text { Voltage plateau } \\
\text { dT/dt } \\
\text { Temperature } \\
\text { threshold } \\
\text { timer }\end{array}$ \\
\hline
\end{tabular}

Table IX to Table XIII below display the actual specifications related to charging, monitoring, displaying, balancing, and safety features for my system. These specifications directly result from testing or from datasheet specifications provided by the manufactures.

Table IX: Charging Specifications

\begin{tabular}{|c|c|c|c|c|c|}
\hline $\begin{array}{c}\text { Max charge } \\
\text { current [A] }\end{array}$ & $\begin{array}{c}\text { Min charge } \\
\text { current [mA] }\end{array}$ & $\begin{array}{c}\text { PWM } \\
\text { steps }\end{array}$ & $\begin{array}{c}\text { Charge } \\
\text { current } \\
\text { resolution } \\
{[\mathrm{mA}]}\end{array}$ & $\begin{array}{c}\text { Charge } \\
\text { voltage } \\
\text { resolution } \\
{[\mathrm{mV}]}\end{array}$ & $\begin{array}{c}\text { Max charge } \\
\text { efficiency }\end{array}$ \\
\hline 1.816 & 9.91 & 112 & $\approx 16.12$ & $\approx 5$ & $>90 \%$ \\
\hline
\end{tabular}


Table X: Monitoring Specifications

\begin{tabular}{|c|c|c|c|c|c|c|c|c|c|}
\hline $\begin{array}{c}\text { Battery } \\
\text { chemistry }\end{array}$ & $\begin{array}{c}\text { Cell } \\
\text { voltage } \\
{[\mathrm{V}]}\end{array}$ & $\begin{array}{c}\text { Cell } \\
\text { voltage } \\
\text { resolution } \\
{[\mathrm{mV}]}\end{array}$ & $\begin{array}{c}\text { Cell } \\
\text { voltage } \\
\text { accuracy }\end{array}$ & $\begin{array}{c}\text { Pack } \\
\text { voltage } \\
{[\mathrm{V}]}\end{array}$ & $\begin{array}{c}\text { Pack } \\
\text { voltage } \\
\text { resolution } \\
{[\mathrm{mV}]}\end{array}$ & $\begin{array}{c}\text { Pack } \\
\text { voltage } \\
\text { accuracy }\end{array}$ & $\begin{array}{c}\text { Temperature } \\
{[\mathrm{C}]}\end{array}$ & $\begin{array}{c}\text { Temperature } \\
\text { resolution } \\
{[\mathrm{C}]}\end{array}$ & $\begin{array}{c}\text { Temperature } \\
\text { accuracy } \\
{[\mathrm{C}]}\end{array}$ \\
\hline Li-Ion & $\begin{array}{c}0 \text { to } \\
4.5\end{array}$ & $\begin{array}{c}0.378 \\
{[18]}\end{array}$ & $\begin{array}{c} \pm 0.1 \% \\
\text { or } \pm 3 \\
\mathrm{mV} \\
{[18]}\end{array}$ & $\begin{array}{c}0 \\
0 \text { to } \\
30\end{array}$ & $\begin{array}{c}1.831 \\
{[18]}\end{array}$ & $\begin{array}{c} \pm 0.2 \% \\
\text { or } \pm 6 \\
\mathrm{mV} \\
{[18]}\end{array}$ & 40 to 90 & $\begin{array}{c}0.003 \\
{[18]}\end{array}$ & $\pm 3[18]$ \\
\hline $\begin{array}{c}\text { lead } \\
\text { acid }\end{array}$ & $\begin{array}{c}1 \text { to } \\
20\end{array}$ & 5 & $\begin{array}{c} \pm 10 \\
\mathrm{mV}\end{array}$ & $\begin{array}{c}1 \text { to } \\
20\end{array}$ & 5 & $\begin{array}{c} \pm 10 \\
\mathrm{mV}\end{array}$ & 30 to 80 & N/A & N/A \\
\hline nickel & $\begin{array}{c}1 \text { to } \\
20\end{array}$ & 5 & $\begin{array}{c} \pm 10 \\
\mathrm{mV}\end{array}$ & $\begin{array}{c}1 \text { to } \\
20\end{array}$ & 5 & $\begin{array}{c} \pm 10 \\
\mathrm{mV}\end{array}$ & 30 to 80 & N/A & N/A \\
\hline
\end{tabular}

Table XI: Display Specifications [23]

\begin{tabular}{|c|c|c|c|c|c|c|}
\hline $\begin{array}{c}\text { Screen } \\
\text { type }\end{array}$ & $\begin{array}{c}\text { Screen } \\
\text { size } \\
\text { [inch] }\end{array}$ & $\begin{array}{c}\text { Pixel } \\
\text { resolution }\end{array}$ & $\begin{array}{c}\text { Measurement } \\
\text { resolution }\end{array}$ & Reflectance & $\begin{array}{c}\text { Power } \\
\text { consumption }\end{array}$ & $\begin{array}{c}\text { Minimum } \\
\text { environment } \\
\text { lighting }\end{array}$ \\
\hline LCD & $\begin{array}{c}1.3 \times \\
1.3\end{array}$ & $96 \times 96$ & 2 sig figs & $50 \%$ & $10 \mu \mathrm{W}$ & 0.5 lux \\
\hline
\end{tabular}

Table XII: Cell Balancing Specifications [18]

\begin{tabular}{|c|c|c|c|c|c|c|c|}
\hline $\begin{array}{c}\text { Battery } \\
\text { chemistry }\end{array}$ & $\begin{array}{c}\text { Output } \\
\text { impedance } \\
{[\mathrm{k} \Omega]}\end{array}$ & $\begin{array}{c}\text { Output } \\
\text { voltage } \\
{[\mathrm{V}]}\end{array}$ & $\begin{array}{c}\text { Balance } \\
\text { current } \\
{[\mu \mathrm{A}]}\end{array}$ & $\begin{array}{c}\text { Max } \\
\text { number } \\
\text { of cells }\end{array}$ & $\begin{array}{c}\text { Safety } \\
\text { Timer }[\mathrm{s} \\
\text { or min] }\end{array}$ & $\begin{array}{c}\text { Timer } \\
\text { accuracy }\end{array}$ & $\begin{array}{c}\text { Type } \\
\text { of } \\
\text { balance }\end{array}$ \\
\hline Li-Ion & $\begin{array}{c}80100 \\
120\end{array}$ & 1 to 4.5 & 46 to 60 & 6 & 0 to 63 & $10 \%$ & passive \\
\hline
\end{tabular}

Table XIII: Safety Features and Protection [18]

\begin{tabular}{|c|c|c|c|c|c|c|c|c|c|}
\hline $\begin{array}{c}\text { Battery } \\
\text { chemistry }\end{array}$ & $\begin{array}{c}\text { CUV } \\
\text { detection } \\
\text { range } \\
{[\mathrm{mV}]}\end{array}$ & $\begin{array}{c}\text { CUV } \\
\text { program } \\
\text { step } \\
{[\mathrm{mV}]}\end{array}$ & $\begin{array}{c}\text { CUV } \\
\text { detection } \\
\text { accuracy } \\
{[\mathrm{mV}]}\end{array}$ & $\begin{array}{c}\text { COV } \\
\text { detection } \\
\text { range } \\
{[\mathrm{V}]}\end{array}$ & $\begin{array}{c}\text { COV } \\
\text { program } \\
\text { step } \\
{[\mathrm{mV}]}\end{array}$ & $\begin{array}{c}\text { COV } \\
\text { detection } \\
\text { accuracy } \\
{[\mathrm{mV}]}\end{array}$ & $\begin{array}{c}\text { OT set } \\
\text { point } \\
{[\mathrm{C}]}\end{array}$ & $\begin{array}{c}\text { OT } \\
\text { program } \\
\text { step }[\mathrm{C}]\end{array}$ & $\begin{array}{c}\text { OT } \\
\text { accuracy } \\
{[\mathrm{C}]}\end{array}$ \\
\hline Li-Ion & $\begin{array}{c}700 \text { to } \\
3300\end{array}$ & 100 & \pm 100 & 2 to 5 & 50 & \pm 70 & $\begin{array}{c}40 \text { to } \\
90\end{array}$ & 5 & $2 \%$ \\
\hline
\end{tabular}

Note: COV and CUV thresholds must be set such that COV - CUV $\geq 300 \mathrm{mV}$ 


\subsection{System Decomposition}

This project consists of two main systems that the user interacts with to both charge and manage batteries. Figure 19 shows the system block diagram.

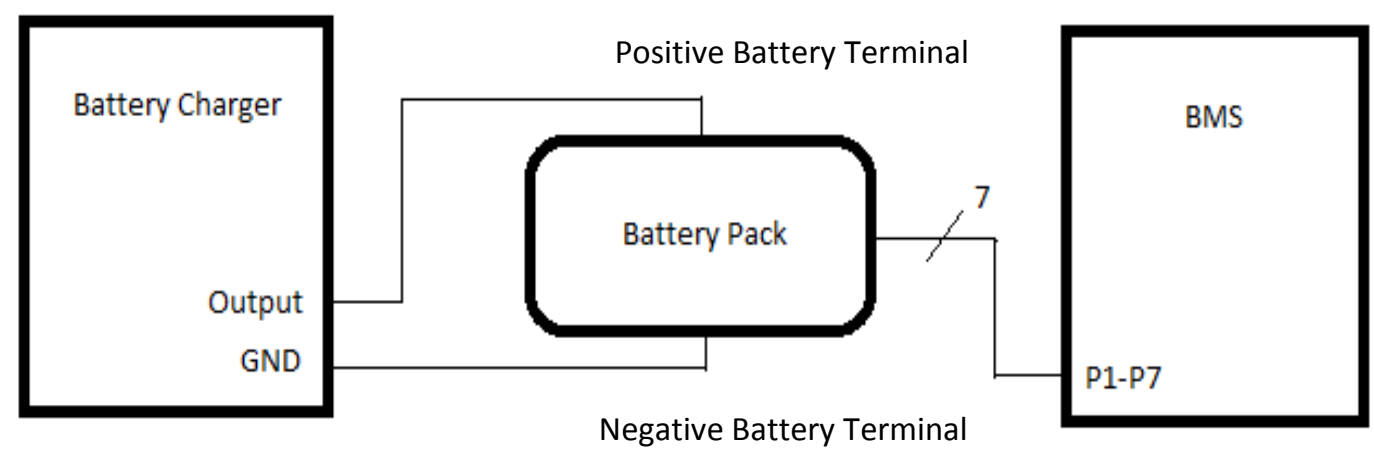

Figure 19: System block diagram (level 0)

The battery charger programs via a computer and the BMS has its own microcontroller controlling it. Both the battery charger and BMS require separate power sources. The power stage of the battery charger also requires a power source while the BMS uses the power provided by the battery pack. The battery charger output connects to the positive and negative terminals of the battery pack while the BMS has more wires to connect to each individual cell. Chapter 3 describes the design of the battery charger and Chapter 4 describes the design of the BMS. 


\section{UNIVERSAL PROGRAMMABLE BATTERY CHARGER}

\subsection{Hardware}

This chapter describes the design of the system along with the reasoning for the design choices. To see the previous design iterations, see Appendix D. The Battery Charger consists of separate subsystems working together. These include a controller to control the Buck converter that provides the output voltage or current to charge the batteries, a microcontroller unit (MCU) that controls the controller and allows the user to interact with the charger, and a current shunt monitor to provide charge current feedback to the MCU. The Battery Charger consists of the modules shown below in Figure 20.

\subsubsection{Design Iteration \#2}

Design iteration \#2 uses an external INA169 current shunt monitor, instead of using the current monitor internal to the LM5117, and the C2000 LaunchXL-F28069M, instead of the MSP430FR5969. Each section in this chapter explains the reasoning for the final design decisions.

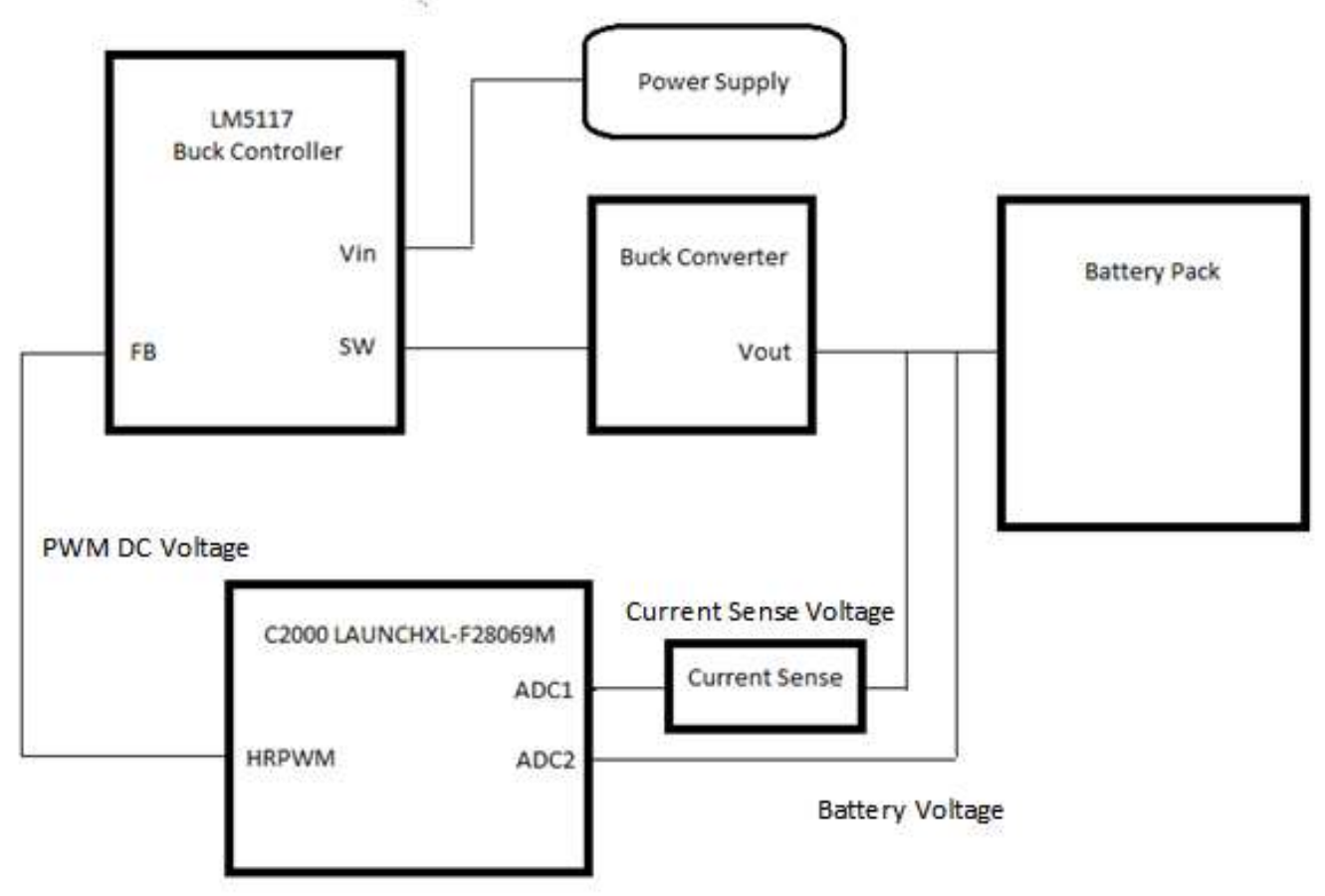

Figure 20: Battery charger block diagram iteration \#2 


\subsubsection{LM5117 Wide-Vin Synchronous Buck Controller [10]}

The circuit responsible for battery charging uses the LM5117 IC, shown in Figure 21, from Texas Instruments. This features a $5.5 \mathrm{~V}-65 \mathrm{~V}$ wide input voltage current mode synchronous Buck controller with analog current monitoring capability.

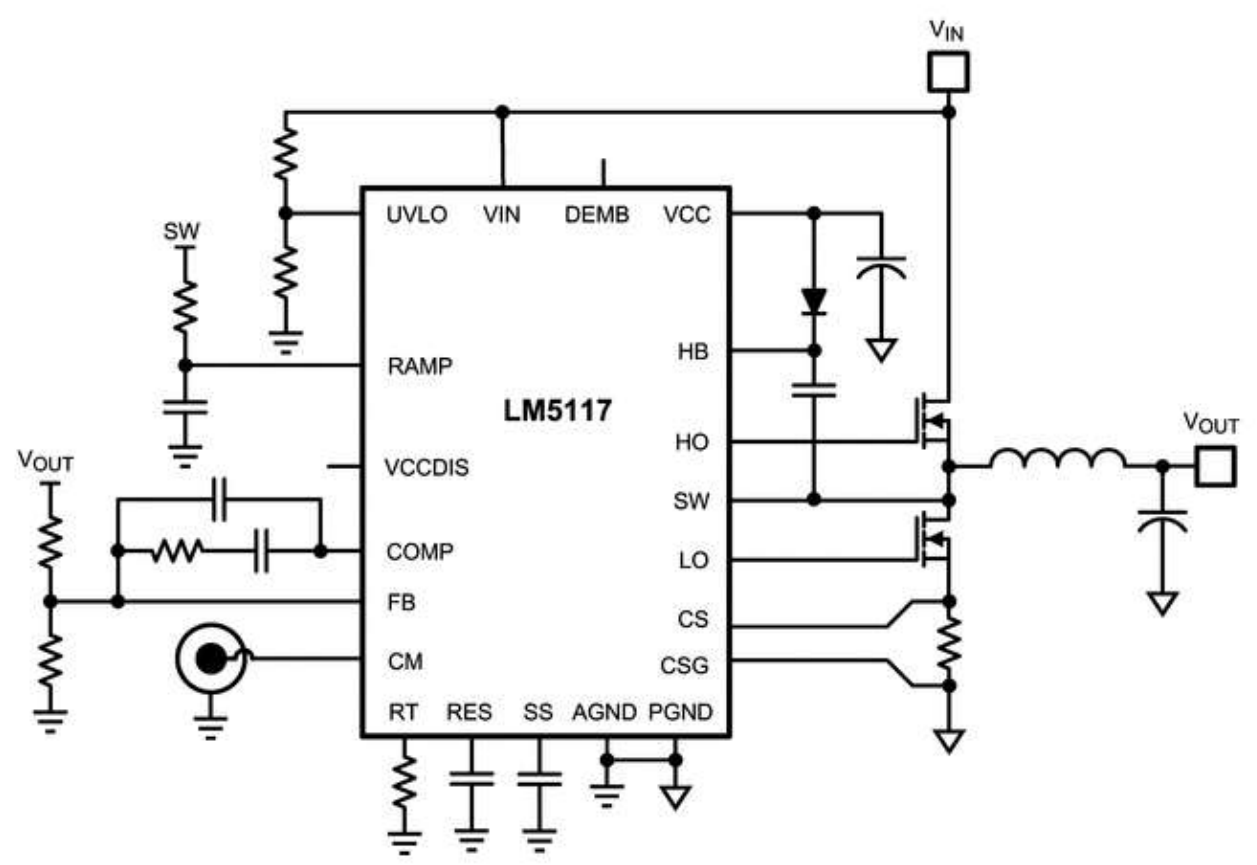

Figure 21: LM5117 IC and Buck Converter [10]

Table XIV: LM5117 specifications [10]

\begin{tabular}{|l|l|}
\hline Vin (Min) (V) & LM5117 \\
\hline Vin (Max) (V) & 5.5 \\
\hline Vout (Min) (V) & 65 \\
\hline Vout (Max) (V) & 0.8 \\
\hline Iout (Max) (A) & 62 \\
\hline Switching Frequency (Min) (kHz) & 50 \\
\hline Switching Frequency (Max) (kHz) & 750 \\
\hline Iq (Typ) (mA) & 4.8 \\
\hline Duty Cycle (Max) (\%) & 98 \\
\hline Regulated Outputs (\#) & 1 \\
\hline Topology & Buck \\
\hline
\end{tabular}




\subsubsection{Buck Converter}

This project uses a Synchronous Buck converter that maximizes power efficiency. The LM5117 Buck Controller controls the converter by varying the Buck converter's duty cycle providing the necessary output to charge various batteries by either constant voltage or constant current. The value of the inductor determines the maximum output current and output current ripple. The maximum current ripple happens at the maximum input voltage. The output current ripple reduces further by increasing the size of the inductor or using larger output capacitors to smooth the output ripple voltage. A good compromise between core loss and copper loss of the inductor current ripple is around $20 \%$ to $40 \%$ of the full load current. Equation 6 shows the calculation of the inductor value.

$$
\begin{aligned}
L_{o} & =\frac{V_{\text {out }}}{I_{p p(\max )} \times \text { Ripple } \% \times f_{\text {sw }}} \times\left(1-\frac{V_{\text {out }}}{V_{\text {in }(\max )}}\right) \\
& =\frac{27}{1.5 \times 25 \times 200 k} \times\left(1-\frac{27}{48}\right)=158 u \mathrm{H} \\
& \approx 154 \mu \mathrm{H}
\end{aligned}
$$

The output capacitors consist of eight $4.7 \mu \mathrm{F}$ ceramic XR7 50V rated capacitors to provide a $37.6 \mu \mathrm{F}$ effective output capacitance. These capacitors provide low ESR while help reduce the output voltage ripple. The capacitance must not be too large since adding a battery at the load increases the output capacitance significantly. Equation 7 calculates the cutoff frequency of the output LC network.

$$
\begin{aligned}
f_{\text {LC cutoff }} & =\frac{1}{2 \pi \sqrt{L C}} \\
& =\frac{1}{2 \pi \sqrt{154 u H \times 37.6 u F}}=2091 \mathrm{~Hz}
\end{aligned}
$$


Since the cutoff frequency is much lower than the $200 \mathrm{kHz}$ operating frequency of the PWM, the output capacitors effectively reduce the output voltage ripple to maintain a steady output voltage.

\subsubsection{MCU (host device)}

The MCU provides the user with charger configuration and controls charger operation. The user programs the charge current, charge voltage, and termination taper current to create nearly any desired charge profile. Future possibilities involve the user configuring the charger by selecting the cell chemistry, charge mode, and number of cells using the capacitive touch slider and option select button. The MCU uses ADCs to read battery voltage and charge current and then outputs a PWM signal that lowpass filters before feeding into the feedback node of the LM5117 buck controller. The PWM signal essentially varies the duty cycle of the buck converter to follow the required charging algorithm programmed in the MCU. Each chemistry of battery has unique charge algorithms that vary for the charge mode selected. Chapter 1 describes various charge modes, and Chapter 5 shows the corresponding charge algorithms created in software to execute the charge modes. To see the design matrix for MCU selection, see Appendix C.

\subsection{Design Iteration \#2 - C2000 LAUNCHXL-F28069M [11, 12]}

The C2000 LaunchXL-F28069M, shown in Figure 22, features the TMS320F28069m microcontroller, which offers a 90MHz operating frequency providing "real time control" and ADCs for sampling the charge current and battery voltage $[13,14]$. The C2000 also provides high-resolution pulse width modulation (HRPWM) and at $200 \mathrm{kHz}$ PWM switching frequency, chosen to match the switching frequency of the LM5117 Buck Controller, the HRPWM resolution is approximately 14.8 bits providing accuracy of $0.004 \%$. Even the regular PWM offers 8.8 bit resolution at $200 \mathrm{kHz}$ [10]. The C2000 LaunchXL-F28069M offers improved performance in ADC sampling, higher operating frequency for processing, and improved PWM output accuracy and resolution over the original design that uses the MSP430FR5969. Appendix $\mathrm{C}$ provides more details on the comparison between the MCU options. Using the $\mathrm{C} 2000$ provides a shorter delay in the control loop with better accuracy for optimum real-time control of battery 
current and voltage. The C2000 also has many unused pins allowing the user to add features in the future.

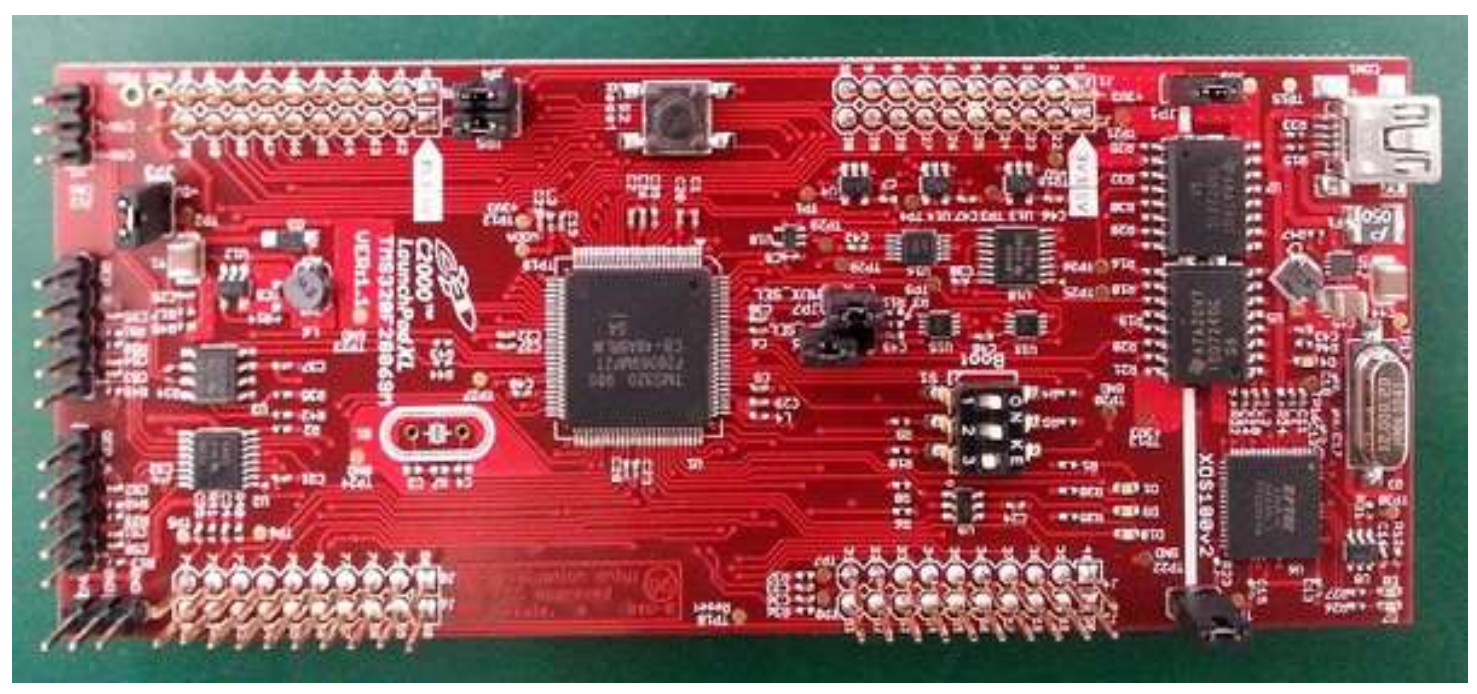

Figure 22: C2000 LaunchXL-F28069M MCU

Note that the PWM signal coming from the MCU that feeds into the feedback node of the LM5117 Buck Controller requires a RC lowpass filter to smooth out the signal. Another option could use a MCU with a DAC output, which doesn't require the additional RC lowpass filter but may require level shifting.

Battery Pack

The battery pack consists of up to six Li-Ion cells, up to 12 lead acid cells, or up to 15 nickel based cells. The maximum pack voltage must not exceed $20 \mathrm{~V}$ since this maximizes the input voltage to the battery voltage measuring ADC that comes from the voltage divider at the output node.

\subsection{Battery Monitoring}

Monitoring the battery voltage and charge current allows correct battery charger operation. Depending on what battery voltage the ADC measures, the charger changes the charge current accordingly to charge the batteries safely. The BMS measures temperature for Li-Ion cells to provide additional safety precaution but the charger does not measure temperature. If the temperature becomes too high, the batteries become damaged and may result in damage to the 
charger and/or the user. Temperature measurements for all chemistries could be incorporated into the battery charger by using the built in temperature sensor ADC provided by the C2000

\section{LAUNCHXL-F28069M.}

\subsubsection{Measuring Battery Voltage}

\subsubsection{Design Iteration \#2}

The C2000 LaunchXL-F28069M monitors the battery voltage by voltage dividing the output voltage into an ADC. The divider is set with $\mathrm{Rbottom}=4.99 \mathrm{k} \Omega$ and $\mathrm{Rtop}=24.9 \mathrm{k} \Omega$ to allow a $20 \mathrm{~V}$ pack voltage at the output to represent $3.3 \mathrm{~V}$ for the ADC input voltage reading, which maximizes the ADC's input voltage range. Ideally, this provides a digital value of 4096 for a 12-bit resolution. Thus, the resolution of the battery voltage measurement is $4.88 \mathrm{mV}$. The output voltage determines the accuracy and resolution of the ADC battery voltage measurement. By increasing the allowed pack voltage, the accuracy and resolution of the ADC measurement decrease. Note that when using the BMS to measure Li-Ion cell voltage, the resolution improves to $0.378 \mathrm{mV}$ due to a 14-bit ADC.

\subsubsection{Current Sense}

\subsubsection{Design Iteration \#2: INA169 Current Shunt Monitor [15]}

The INA169 high-side measurement current shunt monitor, shown in Figure 23, measures a voltage drop across a current sense resistor to provide the current sensing ADC a voltage proportional to the charge current. The external current monitor accurately measures battery current even when the LM5117 operates in discontinuous conduction mode, which is a limitation for Design Iteration \#1 that uses the current monitor in the LM5117. Another advantage of using the INA169 is that the gain can be set with an external resistor allowing more design flexibility. Having a current monitor allows monitoring the battery current for feedback control of the battery charger while also providing output power efficiency measurement. 


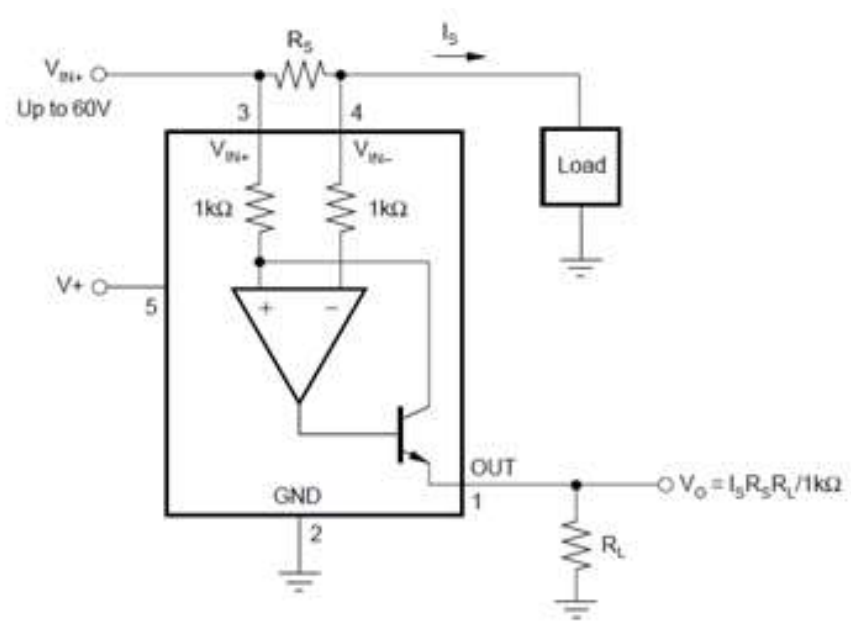

(a)

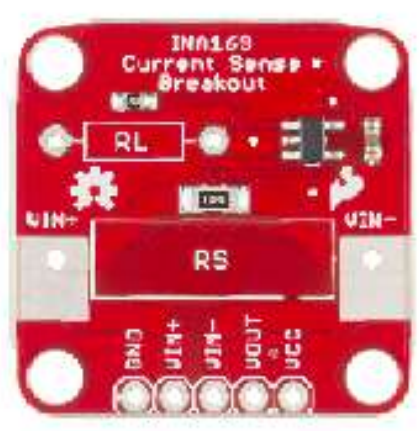

(b)

Figure 23: INA169 high-side measurement current shunt monitors [15] (a) and INA169 circuit (b)

The design sets the current sense resistor, Rs to $39 \mathrm{~m} \Omega$ and $\mathrm{RL}$ to $56.2 \mathrm{k} \Omega$ to provide a gain of 56.2. This means at a current of $1.5 \mathrm{~A}$, the voltage range of the current sense resistor is $58.5 \mathrm{mV}$, which results in the output voltage range of $0 \mathrm{~V}$ to $3.2877 \mathrm{~V}$. This output feeds into the ADCINA2 on the MCU, which gives current feedback to the charge algorithm in software.

\subsection{Output Control}

Controlling the output of the Buck Converter essentially controls the battery charger as a whole. By varying the duty cycle of the PWM output from the MCU that feeds into the feedback node of the LM5117 Buck Controller, the controller changes the duty cycle of the Buck Converter, which changes the output. The PWM output is a $0 \mathrm{~V}$ to $3 \mathrm{~V}$ digital signal that switches at a rate set by the MCU to produce a DC voltage when low-pass filtered. For example when the PWM has a $50 \%$ duty cycle, the DC voltage is $1.5 \mathrm{~V}$ since the output is only $3 \mathrm{~V}$ for $50 \%$ of the time. This filtered voltage feeds into the feedback pin of the LM5117 Buck Controller, which uses negative feedback to regulate the output of the internal error amplifier, which regulates the Buck converter. Figure 24 shows the output control system diagram. Refer to the complete system schematic in Figure 35 for component values. 


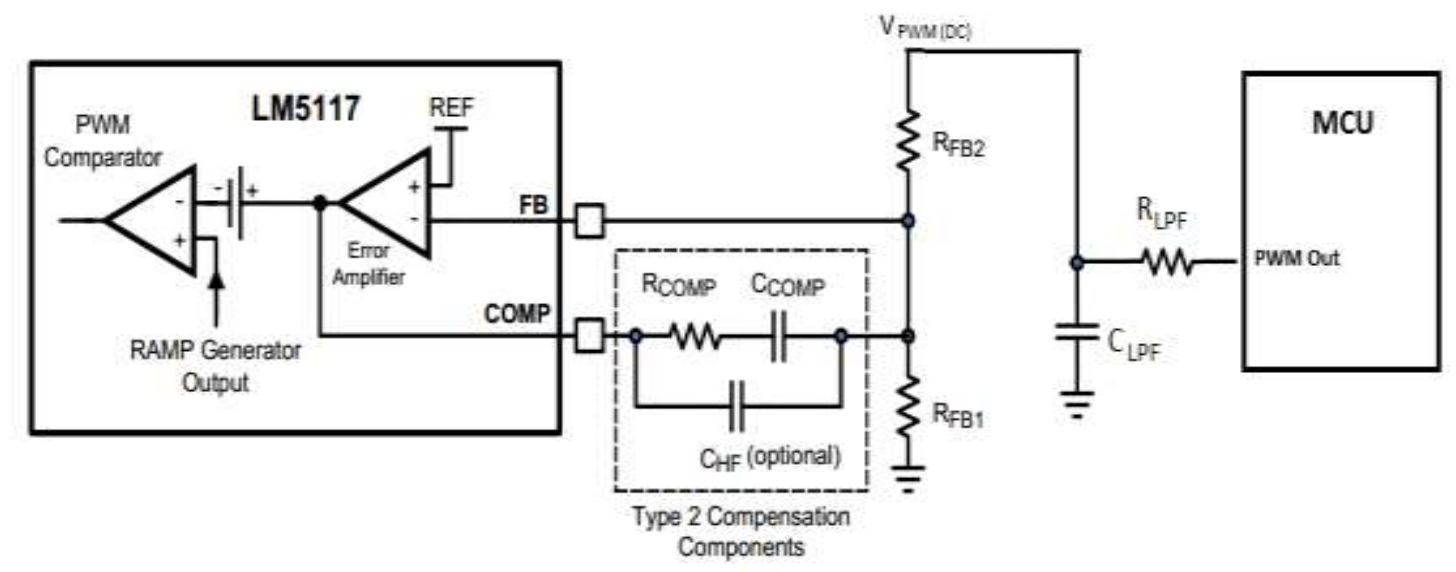

Figure 24: Output control system diagram

The PWM output signal is set for a frequency of $200 \mathrm{kHz}$ to match the switching frequency of the LM5117. The RLPF and CLPF convert the digital switching signal to a DC voltage and set the voltage ripple, settling time, and cutoff frequency. This voltage divides down using RFB2 and RFB1 to create $0.8 \mathrm{~V}$ at the FB pin ideally when the duty cycle is $50 \%$. This allows room to increase or decrease the PWM duty cycle in order to change the FB pin with respect to the error amplifier reference voltage of $0.8 \mathrm{~V}$. The design chooses the RLPF resistor to maximize the current sourcing capability of the MCU. The MCU PWM has a voltage range from $0 \mathrm{~V}$ to $3.3 \mathrm{~V}$ and the maximum high-level output source current for all GPIO/AIO pins is $4 \mathrm{~mA}$. Choosing a $1 \mathrm{k} \Omega$ resistor for RLPF produces $3.3 \mathrm{~mA}$ when the output voltage of the PWM is $3.3 \mathrm{~V}$. The design chooses the RFB2 resistor value to be 10x larger than RLPF to prevent loading, which leads to $10 \mathrm{k} \Omega$.

\subsubsection{Analysis}

The LM5117 internal error amplifier is set for a fixed dc gain and dynamic range to interface with the microcontroller output. Figure 25 shows the switching model created in SIMPLIS to simulate the DC voltage coming from the PWM and feeding into the feedback node of the LM5117. This simulation provides a starting point to controlling the LM5117 Buck 
Controller with an external PWM signal. Figure 26 shows how the LM5117 Buck Controller responds to the varying PWM voltage inserted into its feedback node.

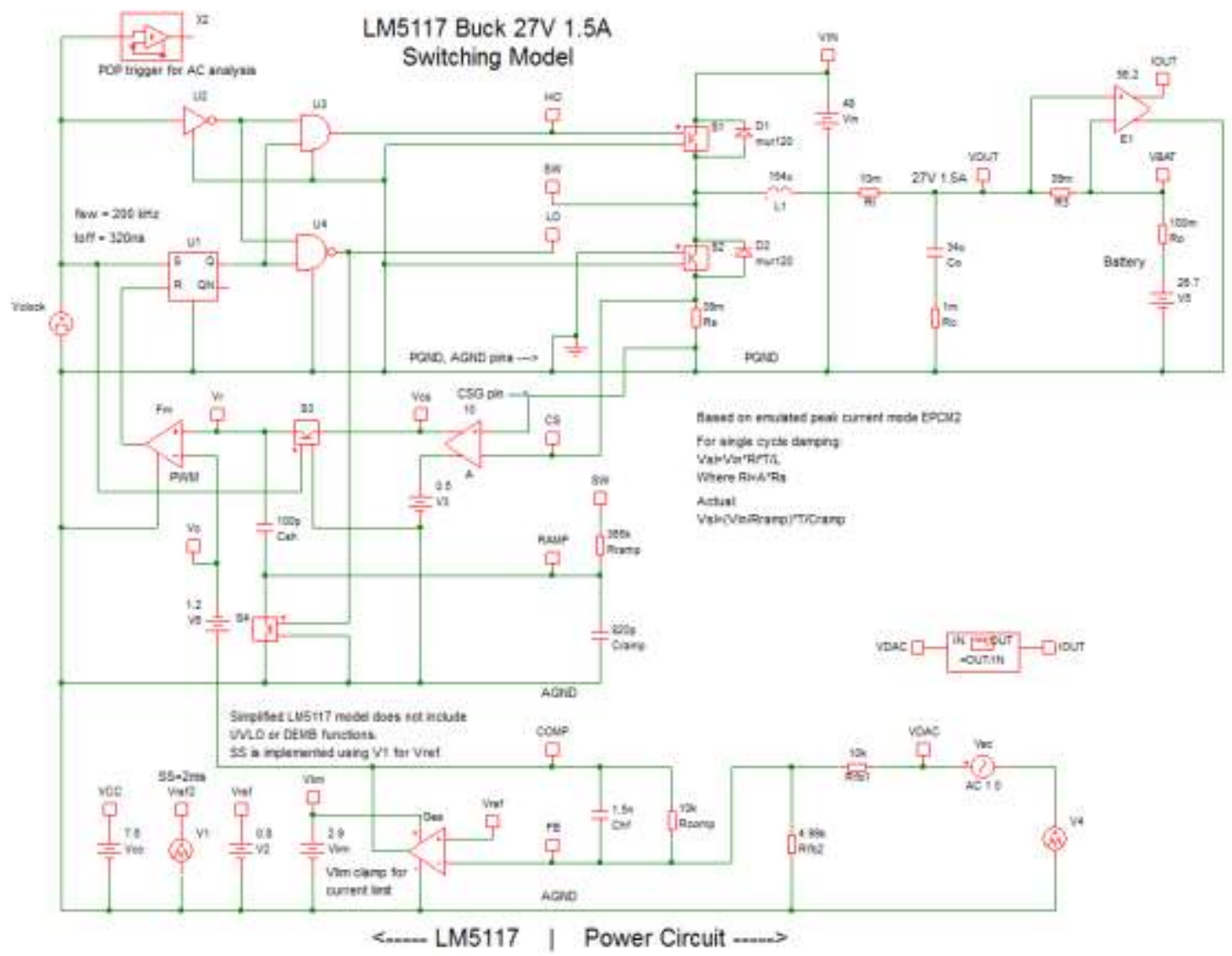

Figure 25: SIMPLIS switching model used to simulate DC analysis of PWM to LM5117 interface 


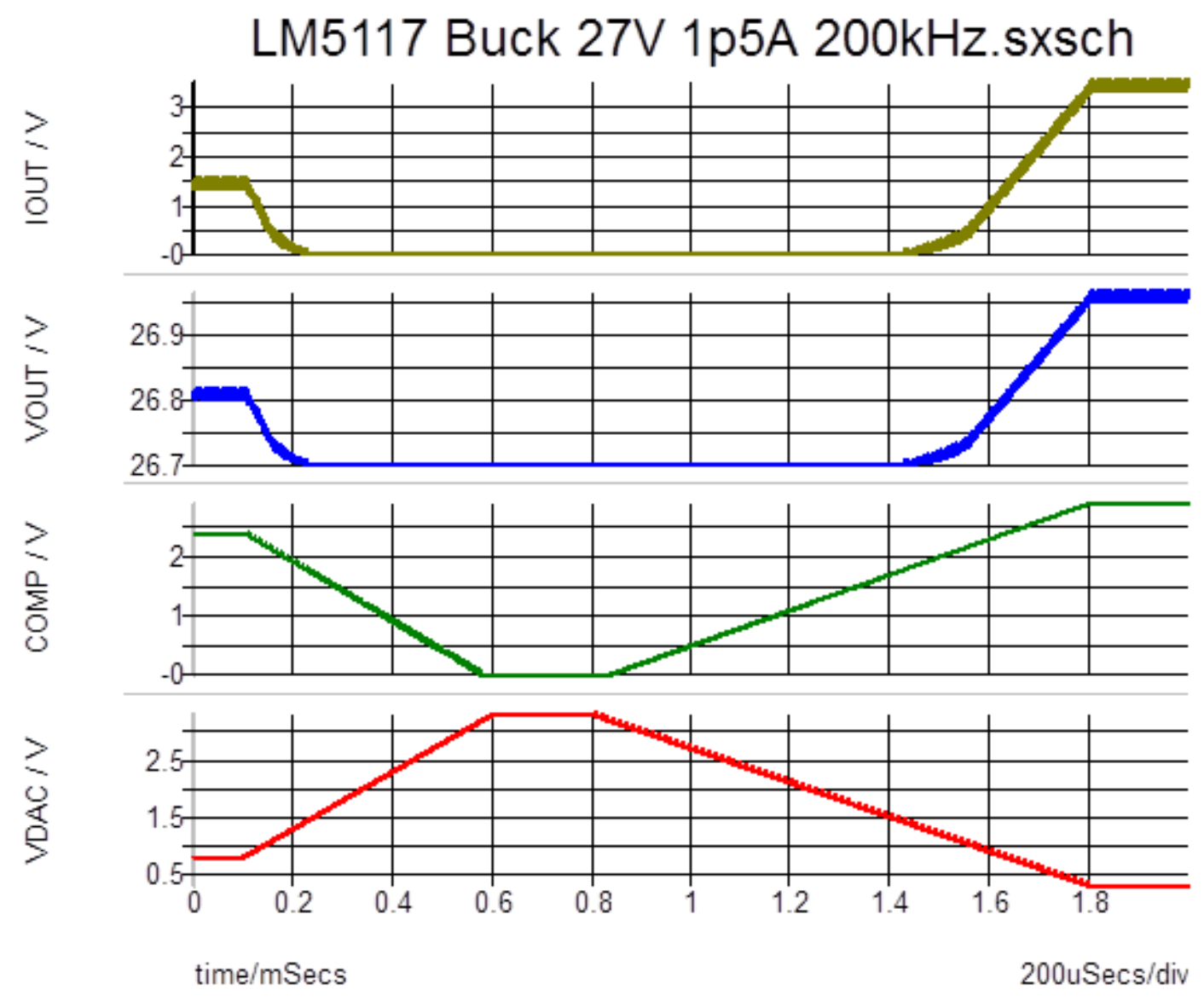

Figure 26: PWM to LM5117 interface DC simulation

For maximum resolution when using the PWM to control the output, the amplifier output must go to its maximum when $\mathrm{Vpwm}=0 \mathrm{~V}$ and its minimum when $\mathrm{Vpwm}=3.3 \mathrm{~V}$. This is centered around the internal reference of $0.8 \mathrm{~V}$. Since Figure 26 shows a linear region of operation for the LM5117 Buck Controller with linearly varying PWM voltage, the design at this point seems possible. If, however, the LM5117 Buck Controller showed only maximum and minimum output for a linearly varying PWM voltage, the design would need modification.

\subsection{Stability Analysis}

This section provides insight to the control theory and frequency analysis of the closed loop system to help predict the stability of the system for both the charge current loop and battery voltage loop. 


\subsubsection{LM5117 Controller with Buck Converter}

The actual system has both a current loop for battery current control and a voltage loop for battery voltage control, which both need separate stability analysis. The load also needs stability analysis, since a battery has a very large capacitance and varying resistance. The frequency analysis for this system requires accurate modeling to help predict system stability.

The Current-Mode Modeling Reference Guide [16] provides a linear solution for current mode control with equations that the voltage control-loop design can use. This reference guide models the buck current control-loop and the buck voltage control-loop and derives the sampling gain pole. The SIMPLIS switching model, used to approximate the frequency response of the complete system, models the actual physical circuit in that the LM5117 model acts just like the controller in reality. The SIMPLIS averaged model comes from state-space analysis done by Steven Sandler in his SPICE Circuit Handbook. See Robert Sheehan's Current Mode Reference Guide for more information on averaged modeling of current mode controllers [16].

Figure 27 shows the full simulation schematic. This SIMPLIS switching model has all the functions required to produce accurate frequency response for the complete system comprised of the LM5117 Buck controller, buck converter, analog versions of the MCU voltage loop and current loop compensators, and PWM output filtering. 


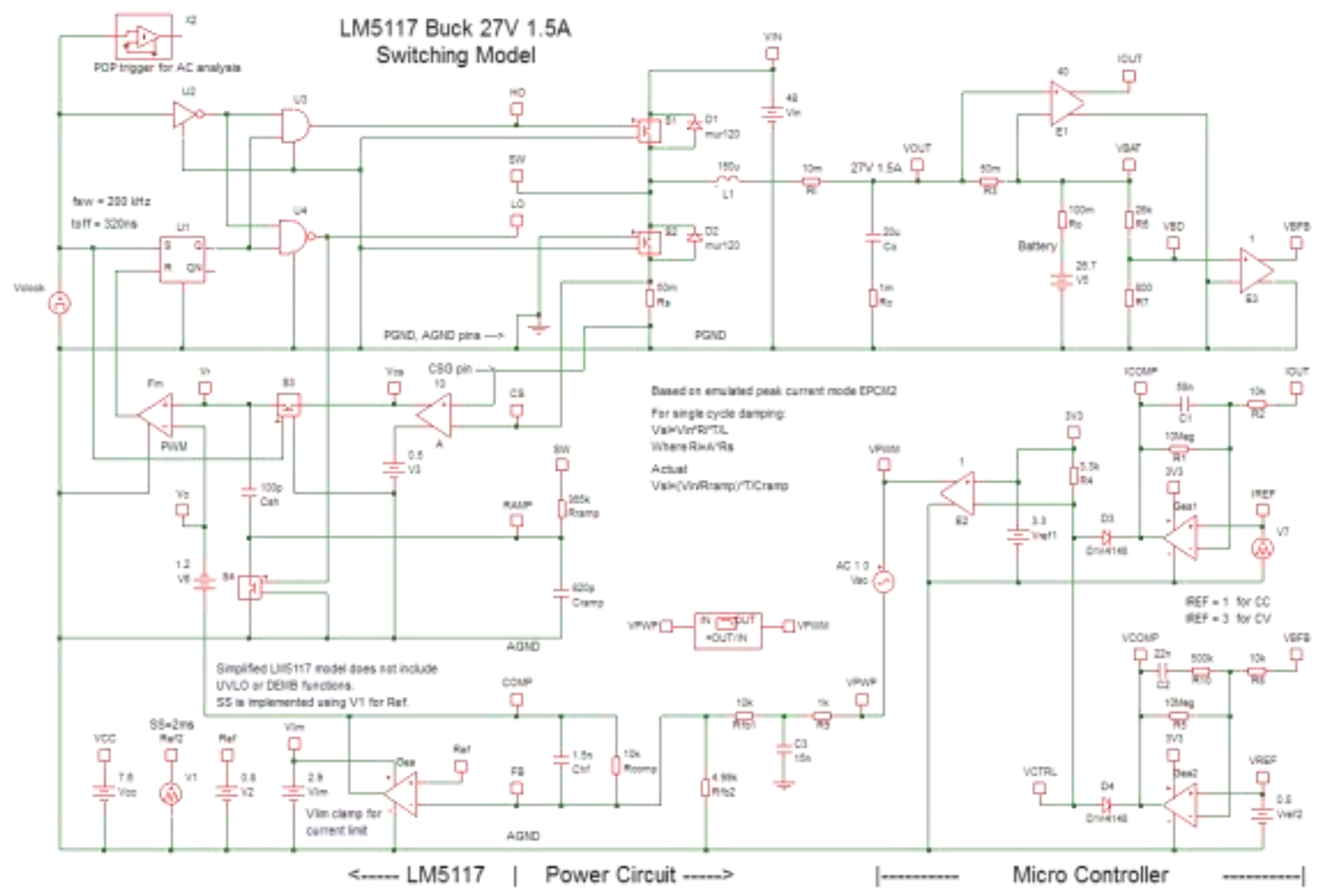

Figure 27: SIMPLIS switching model for Vout $=27 \mathrm{~V}$ and Iout $=1.5 \mathrm{~A}$

The design requires the microcontroller portion since the voltage loop and current loop need different compensation values. The simulation model incorporates the $10 \mathrm{kHz}$ lowpass filters required for PWM filtering to provide accurate stability analysis. The design adjusts the compensation values in the microcontroller portion to the bandwidth of both the current and voltage loops. In order to run the simulation for frequency analysis using the demo/intro version of SIMPLIS, an average model, shown in Figure 28, is created based on linear modeling of current-mode controllers. 


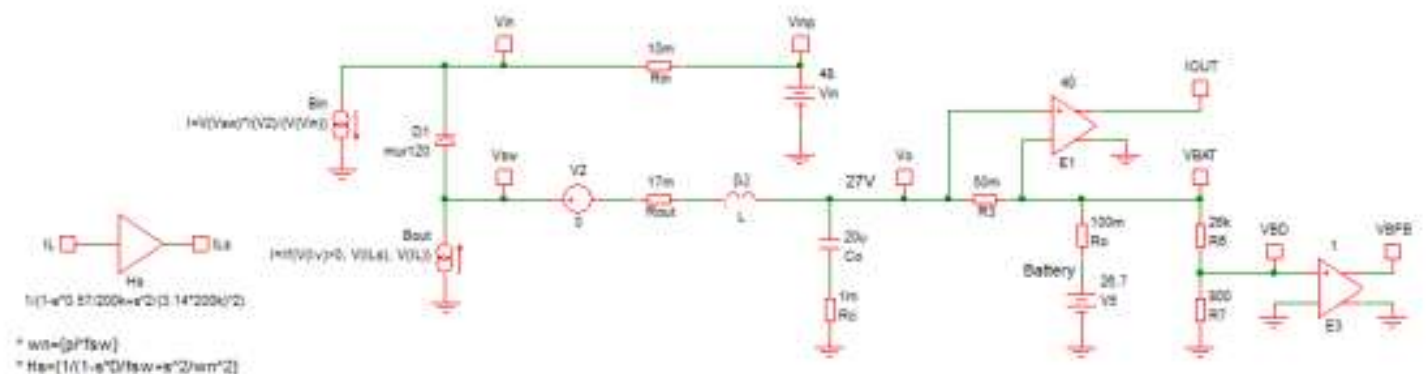

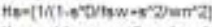

His mast be manady entered a 5 Matix - nunierical forna

"Cakculate 4 enter a new value of 0 wten changing Vh

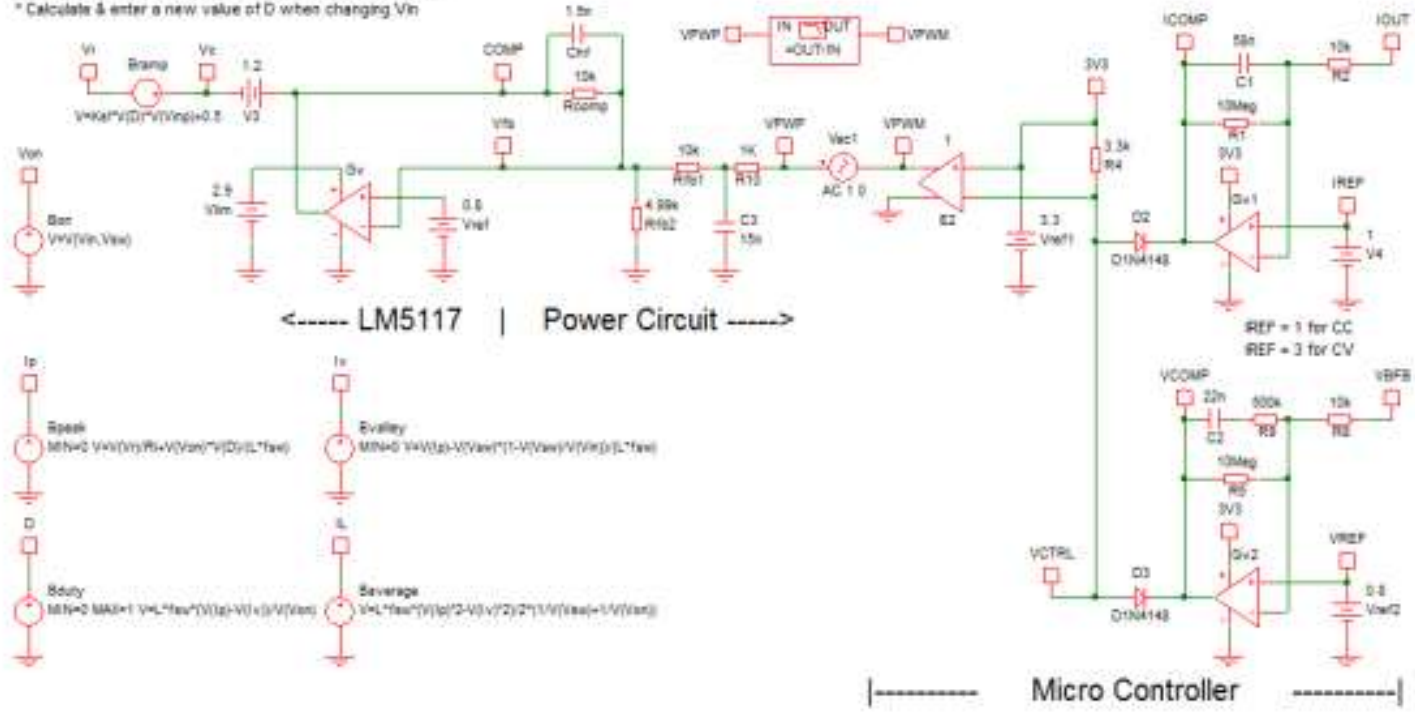

Figure 28: SIMPLIS average linear model based on switching model for $\mathrm{Vout}=27 \mathrm{~V}$ and Iout $=1.5 \mathrm{~A}$

The linear model accurately represents the switching model up to half the switching frequency [16]. This means the linear model accurately represents this system up to $100 \mathrm{kHz}$, which is more than required for observing the frequency response of the $1 \mathrm{kHz}$ current and voltage loop bandwidths. To see how to derive the linear model from the switching model or verification of linear model accuracy, refer to Current Mode Reference Guide written by Robert Sheehan [16].

\subsubsection{Current Loop}

The overall bandwidth of the charge current loop is $1 \mathrm{kHz}$. The charge current loop uses a single pole compensator. The compensator dc gain, set by the resistor ratio $10 \mathrm{Meg} / 10 \mathrm{k}$, is 1000 (or in $\mathrm{dB}: 20 \log (10 \mathrm{Meg} / 10 \mathrm{k})=60 \mathrm{~dB})$ with a transfer function of 
$G_{C-\text { current }}=\frac{10 \mathrm{Meg}}{10 \mathrm{~K}} \frac{1}{1+(58 \mathrm{n} * 10 \mathrm{Meg}) \mathrm{S}}$

The design adjusts the capacitor to give $1 \mathrm{kHz}$ loop bandwidth after adjusting the gain to $1000(60 \mathrm{~dB})$. The high gain provides good DC regulation resulting in the MCU set point accuracy to within $0.001 \%$. The system requires high gain, usually at least 100 (40 dB), to converge to the set point in steady state, but having too high of gain prevents access to the linear region of operation. Figure 29 shows the SIMPLIS current loop simulation frequency analysis for an output current of $500 \mathrm{~mA}$.

Current Control Loop

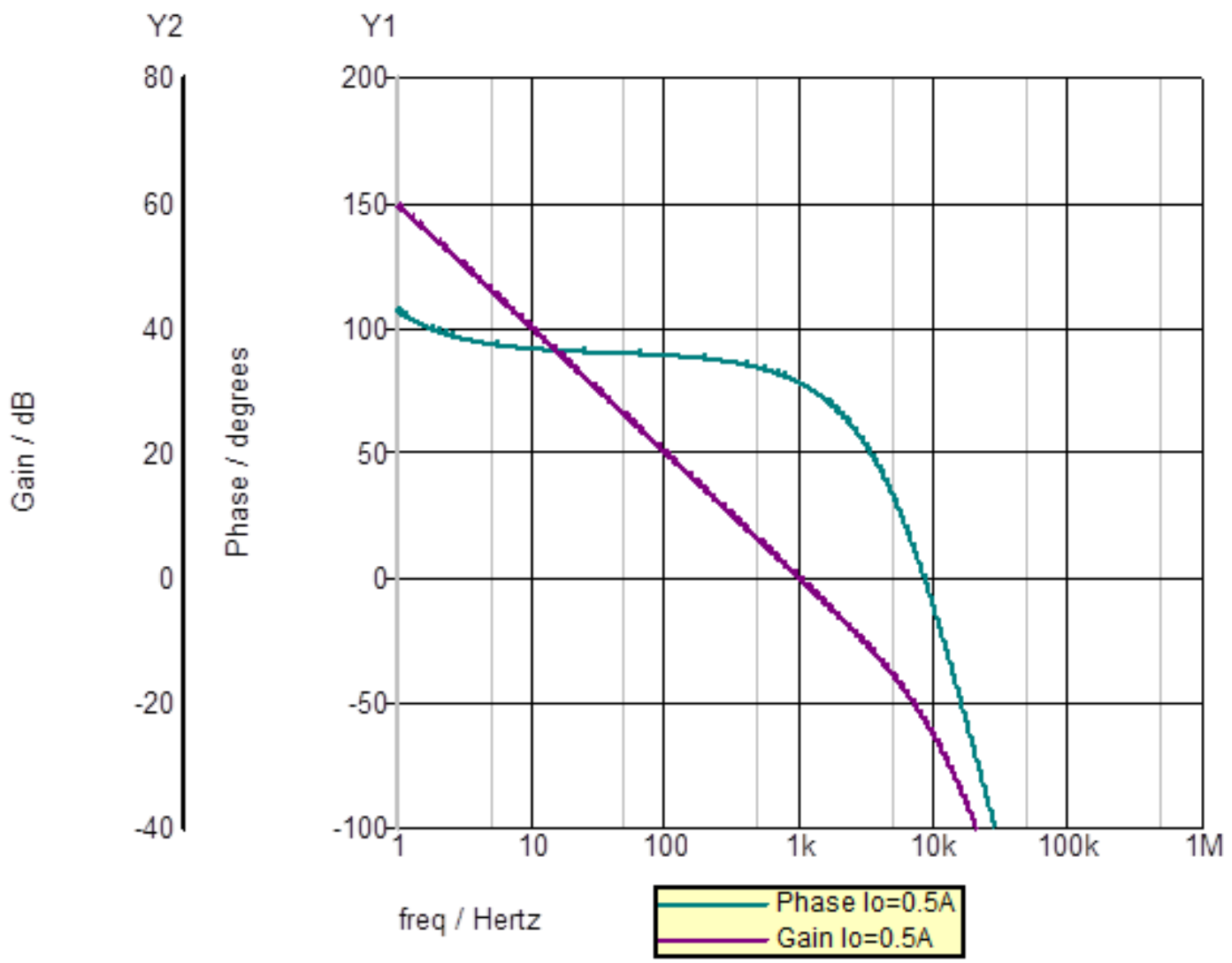

Figure 29: Current control loop magnitude and phase Bode plot from SIMPLIS linear model simulation 


\subsubsection{Voltage Loop}

The output voltage control-loop bandwidth is also around $1 \mathrm{kHz}$ with the battery

disconnected. The voltage loop uses a pole-zero compensator. The compensator dc gain, set by the resistor ratio $10 \mathrm{Meg} / 10 \mathrm{k}$, is 1000 (or in $\mathrm{dB}: 20 \log (10 \mathrm{Meg} / 10 \mathrm{k})=60 \mathrm{~dB}$ ) with a transfer function:

$G_{C-\text { voltage }}=-\frac{10 M e g}{10 K} * \frac{1+(22 n * 500 K) s}{1+(22 n *(10 M e g+500 K)) s}$

When the battery is connected, the gain drops to around $18(25 \mathrm{~dB})$ due to the lower resistance resulting in a bandwidth of around $6 \mathrm{~Hz}$. Figure 30 shows the SIMPLIS voltage loop simulation frequency analysis.

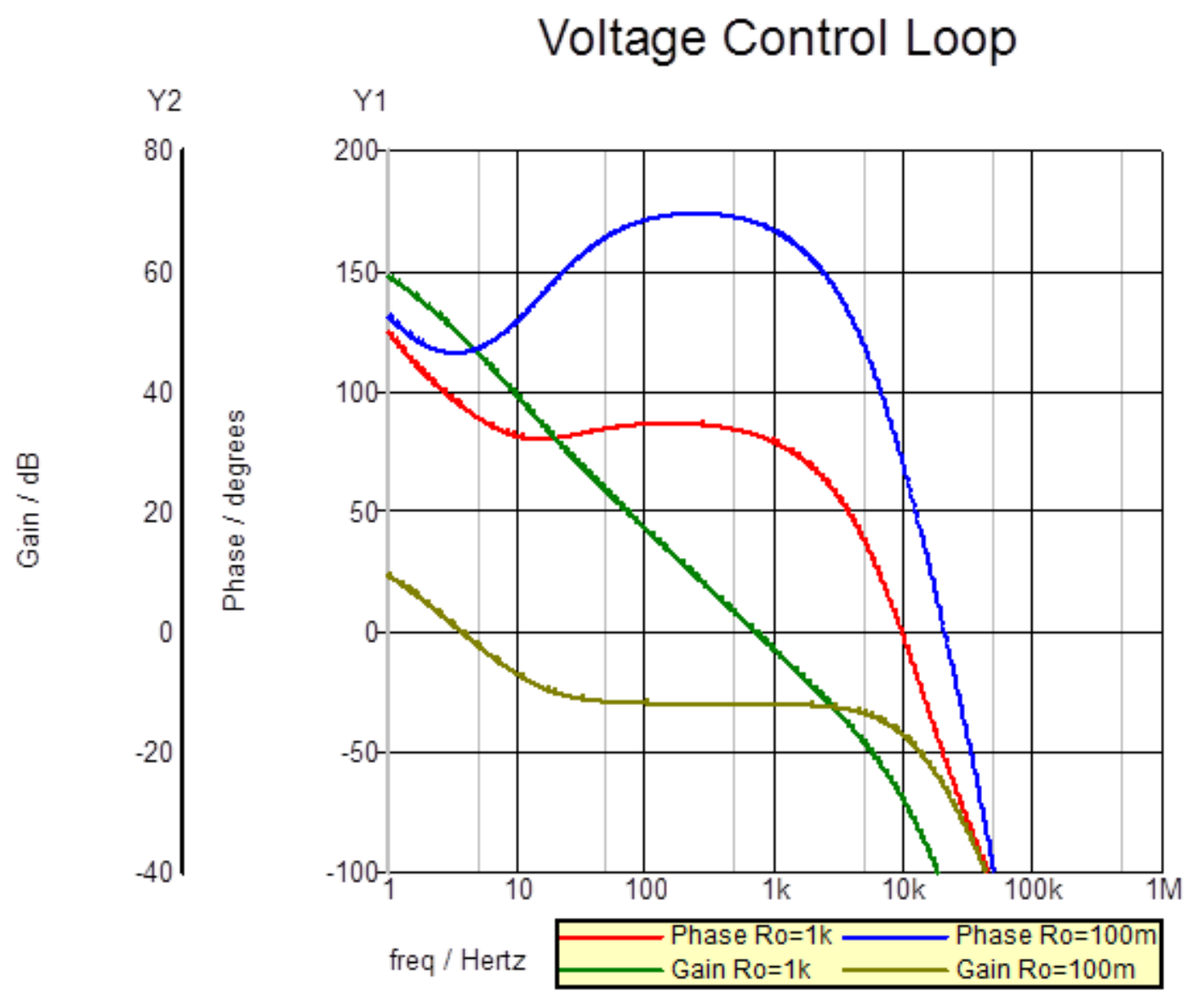

Figure 30: Voltage control loop magnitude and phase Bode plot with battery disconnected $($ Ro $=$ $1 \mathrm{k} \Omega)$ and single battery connected $(\operatorname{Ro}=100 \mathrm{~m} \Omega)$ from SIMPLIS linear model simulation 


\subsubsection{INA169 Current Shunt Monitor}

The current sense monitor only affects the frequency analysis of the closed loop system if an output capacitor is used since it would create a pole at the $-3 \mathrm{~dB}$ frequency shown in Figure 31.

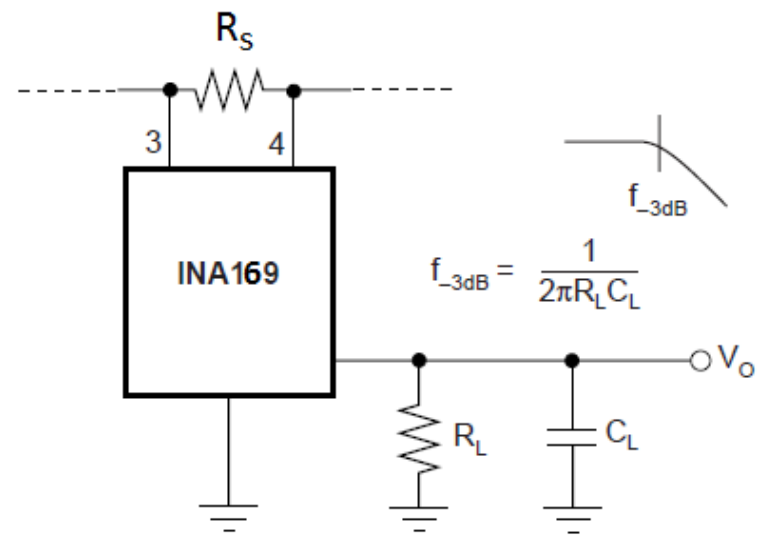

Figure 31: INA169 current shunt monitor -3dB frequency [15]

The design does not use an output capacitor in the external current sense circuit, so the INA169 has no impact on the stability analysis. The bandwidth of the INA169 is much larger than the bandwidth of either the current or voltage loops of the battery charger as the frequency response in Figure 32 shows.

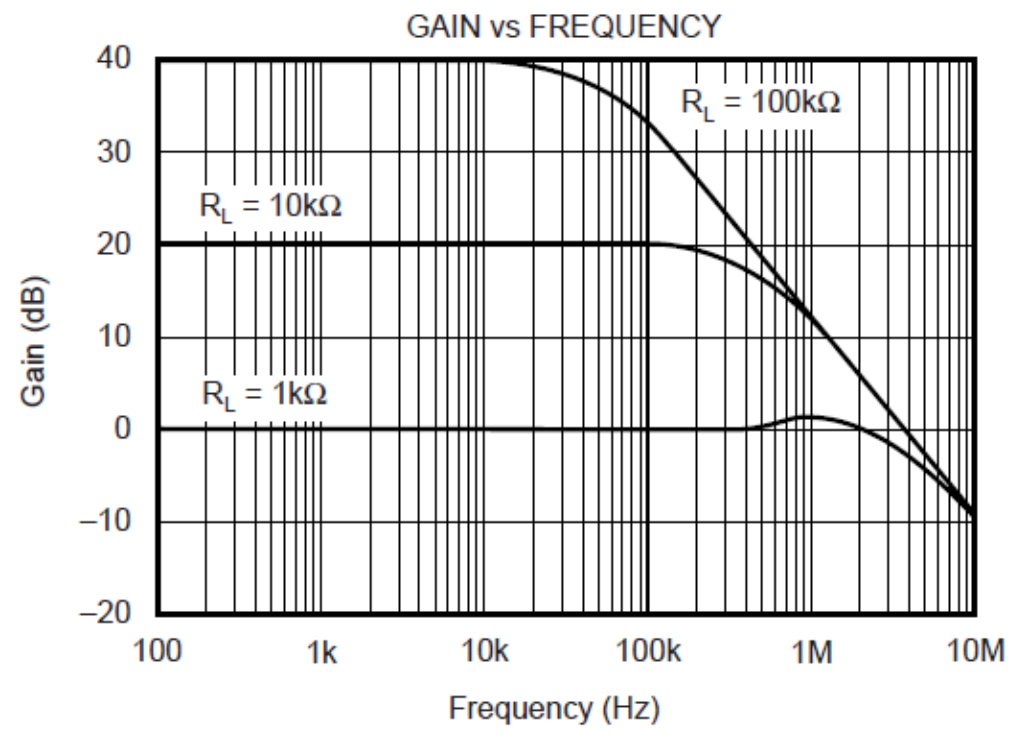

Figure 32: Frequency response of INA169 current shunt monitor [15] 


\subsubsection{ADC}

The ADC from the MCU affects the frequency analysis because of the input impedance that needs to be accounted for. See input model in Figure 33.

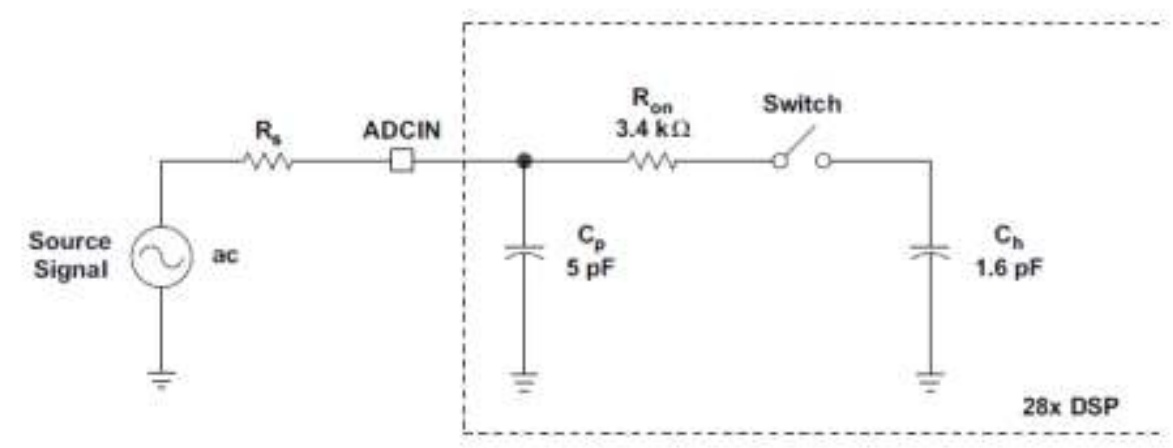

Typical Values of the Input Circuit Components:

Switch Resistance $\left(\mathbf{R}_{\mathrm{on}}\right): 3.4 \mathrm{k} \Omega$

Sampling Capacitor $\left(\mathrm{C}_{h}\right): 1.6 \mathrm{pF}$

Parasitic Capacitance $\left(\mathrm{C}_{\mathrm{p}}\right): 5 \mathrm{pF}$

Source Resistance $\left(R_{f}\right): 50 \Omega$

Figure 33: ADC input impedance model [14]

The input capacitance is so small that the delay caused by the ADC input filters can be ignored. Next is to account for the delay caused by ADC sampling. In general selecting a small sampling period allows the continuous system to transform to the z-domain more accurately. A good guideline sets the sample period to:

$T_{\text {sample }}=\frac{1}{10 f_{b}}$ or in terms of sample frequency, $f_{\text {sample }}=10 f_{b}$,

where fb represents the frequency bandwidth of the closed-loop continuous system [14]. For both the current and voltage loops, the bandwidth is $1 \mathrm{kHz}$. Setting the sample rate to $10 \mathrm{kHz}$ means the sample period is $100 \mu \mathrm{s}$, which is a tenth of the period of both the voltage and current loops. If the current loop represents a full $360^{\circ}$ cycle, the phase shift caused by that sample rate is a tenth of the full cycle so $36^{\circ}$. When this phase shift adds to the phase margin of the current and voltage loops shown in Figure 29 and Figure 30, the system remains stable since the total phase remains less than $180^{\circ}$. So further increasing the sample rate would further reduce the phase shift 
caused by sampling, which increases the phase margin. The design sets the sample rate to 198 $\mathrm{kHz}$, which is much higher than the $10 \mathrm{kHz}$ example previously mentioned, to allow digital filtering and prevent noise interference caused by the LM5117 switching at $200 \mathrm{kHz}$.

\subsubsection{Processing Delay [17]}

The time for the MCU to process the input ADC data and make the necessary changes to the PWM affects stability as this processing delay adds a pure time delay in the system.

A pure time delay without attenuation has the following transfer function:

$G_{d}(s)=e^{-s T}$ or for frequency response analysis $G_{d}(s)=e^{-j \omega T}$

where $\mathrm{T}$ represents the time delay. A time delay does not add any additional poles or zeros to the system nor does it alter the magnitude. It does, however, add a phase shift to the frequency response given by:

$\Phi(\omega)=-\omega T$ in radians or $\Phi\left(\frac{\pi}{180}\right)=-2 \pi f T$ in degrees.

For this system, the amount of time delay before the system becomes unstable is calculated as follows:

$T_{\text {delay }}=\frac{\Phi_{\text {unstability }}\left(\text { Phase } \text { margin }^{\circ} * \pi / 180\right)}{-2 \pi f_{\text {cutoff }}}$,

where phase margin for the current loop is approximately $66^{\circ}$ when using the simulation approximation after taking into account phase shift from sampling and the cutoff frequency is approximately $1 \mathrm{kHz}$. This means a delay of $183 \mu$ s or greater causes the system to become unstable due to the resulting phase shift. The time delay required for instability for the voltage loop uses similar calculation. When the battery is disconnected, roughly the same delay as the current loop is required before the system becomes unstable. When the battery is connected, the phase margin becomes approximately $24^{\circ}$ and the cutoff frequency changes to approximately $6 \mathrm{~Hz}$ due to the drop in gain caused by the change in load resistance and capacitance inherent to the battery. The time delay required for the system to become unstable is $295 \mu$ s meaning the system becomes more stable when the battery is connected. 
From the addition of the delay, the resulting phase shift adds to the phase shift from the rest of the system, which allows for stability analysis. Because time delays introduce additional phase lag, they result in a less stable system. Reducing the loop gain may be required to obtain a stable response but this also results in larger steady state error.

The MCU has an operating frequency of $90 \mathrm{MHz}$ with a clock period of approximately $11 \mathrm{~ns}$. When taking into account the total conversion time required by the ADC of approximately $489 \mathrm{~ns}$ along with the period of each clock cycle, there would need to be over 16,000 instructions and thus over 16,000 clock cycles to cause enough delay for the system to become unstable. Because the delay caused by the ADC and MCU processing is much less than the delay required to cause instability in the system, the system remains stable given the system's processing delay. The MCU takes an ADC sample, computes the new PWM setting, and updates the PWM in much less time than the sample time of $100 \mu \mathrm{s}$, which further ensures that the MCU computation time is acceptable for stability.

\subsubsection{PWM}

The PWM signal from the MCU filters through a low pass RC filter then scales by a voltage divider then enters an error amplifier in the LM5117 with a single pole compensator as shown in Figure 34. The double pole combination attenuates the square wave PWM signal to provide a DC signal to the error amplifier but also causes a phase shift due to the poles. 


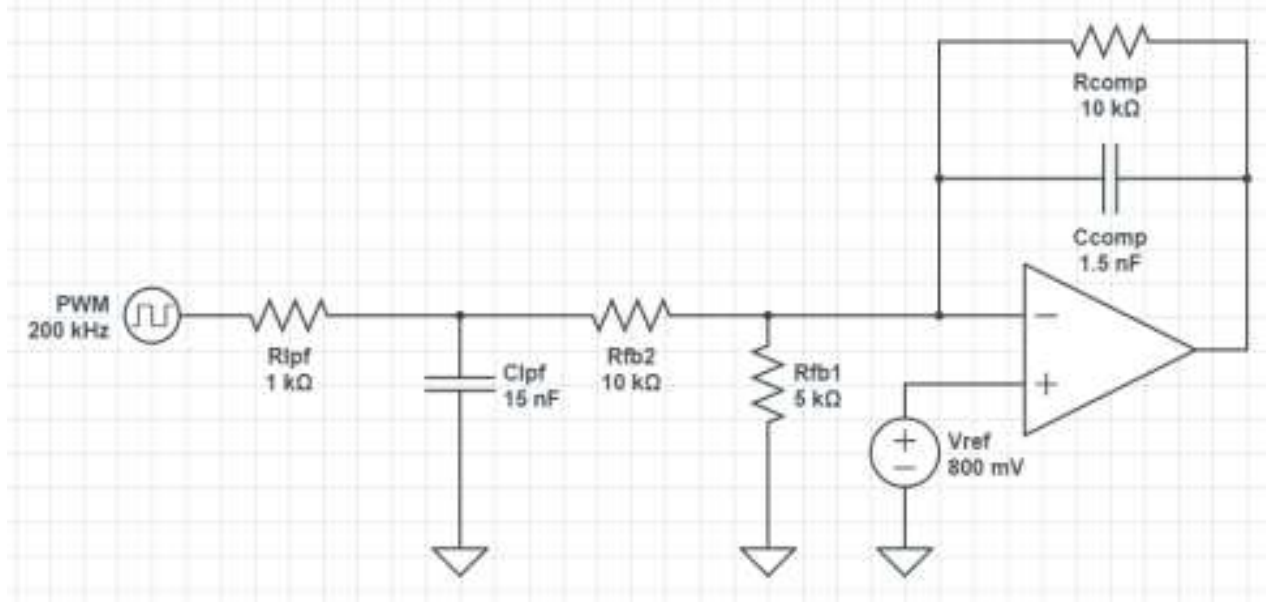

Figure 34: PWM signal to LM5117 error amplifier

The phase shift calculation follows:

Phase shift $=-\arctan (2 \pi f * R r c * C r c)-\arctan (2 \pi f * R f * C f)$

Phase shift $=-\arctan (2 \pi * 1 k H z * 1 k \Omega * 15 n f)-\arctan (2 \pi * 1 k H z * 10 k \Omega * 1.5 n f)$

Phase shift $\approx-11^{\circ}$

The system remains stable when accounting for filtering the PWM signal as shown in the simulation for the current and voltage loops.

\subsection{Troubleshooting}

Many problems arose during the design of this system. The first major problem resulted from improper configuration of the output voltage divider preventing the PWM to control the LM5117 Buck controller output. The next major problem resulted from too high of DC gain for the LM5117 Buck Controller due to improper configuration of the feedback compensation network. After fixing this, the next task was to stabilize the system by adding averaging digital lowpass filters, delays, and decoupling capacitors. Finally, the system required calibration so values set in software correspond to the desired behavior. Appendix E provides the troubleshooting details and Appendix F provides the calibration details. The next section shows the complete final battery charger design before discussing the performance. 


\subsection{Battery Charger Design}

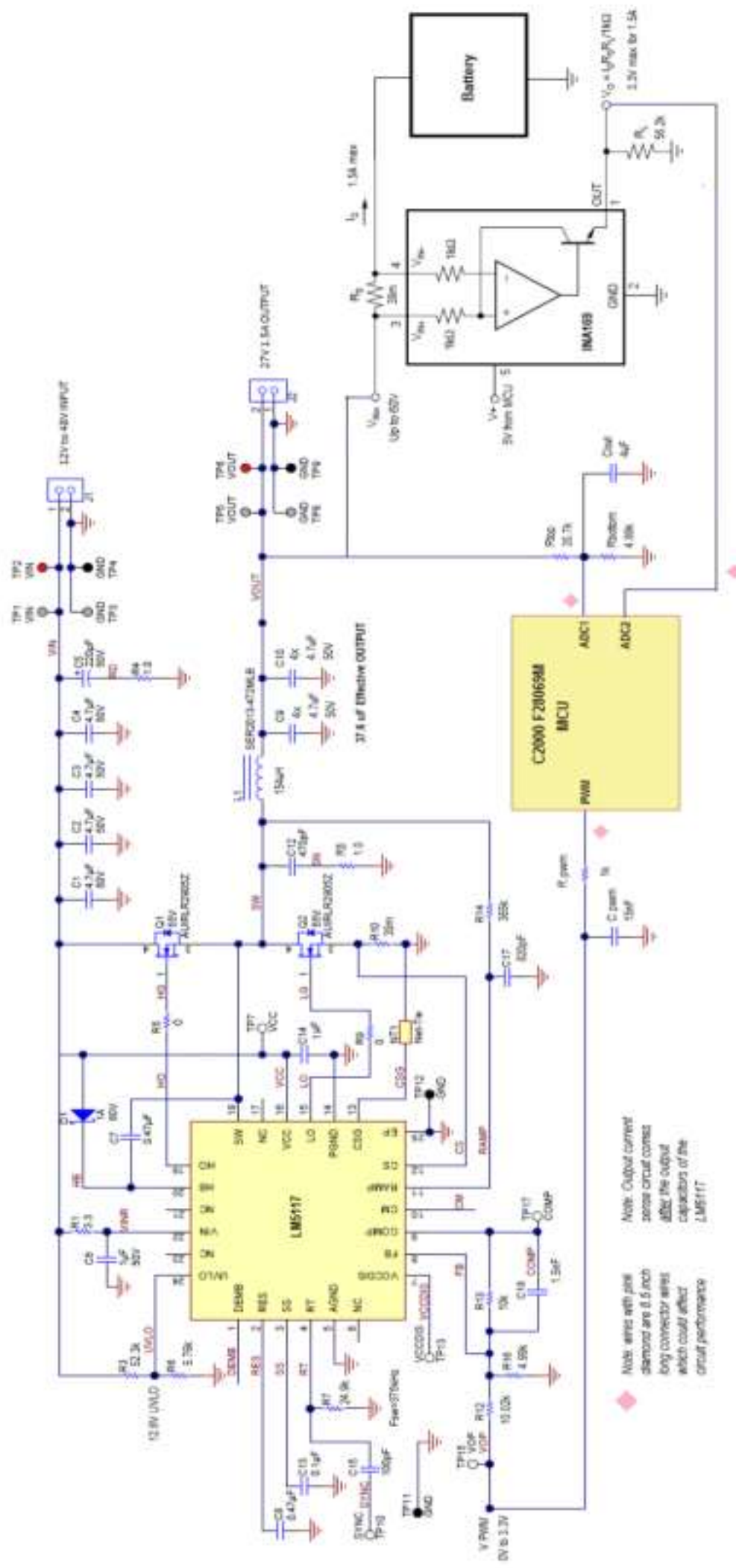

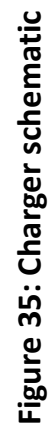




\subsection{Charger Performance}

Charger testing occurs with a Panasonic Lithium Ion NCR18650 as described in Table X. The charger implements the Rapid and Quick Rapid charge modes described in Table XIII by using the charge algorithms shown in Figure 53 and Figure 54. Figure 36 shows the block diagram of the charger test setup. The Agilent 34972A LXI Data Acquisition/Switch Unit captures the battery voltage, current sense voltage, and battery temperature once every second then sends the data to a computer via USB.
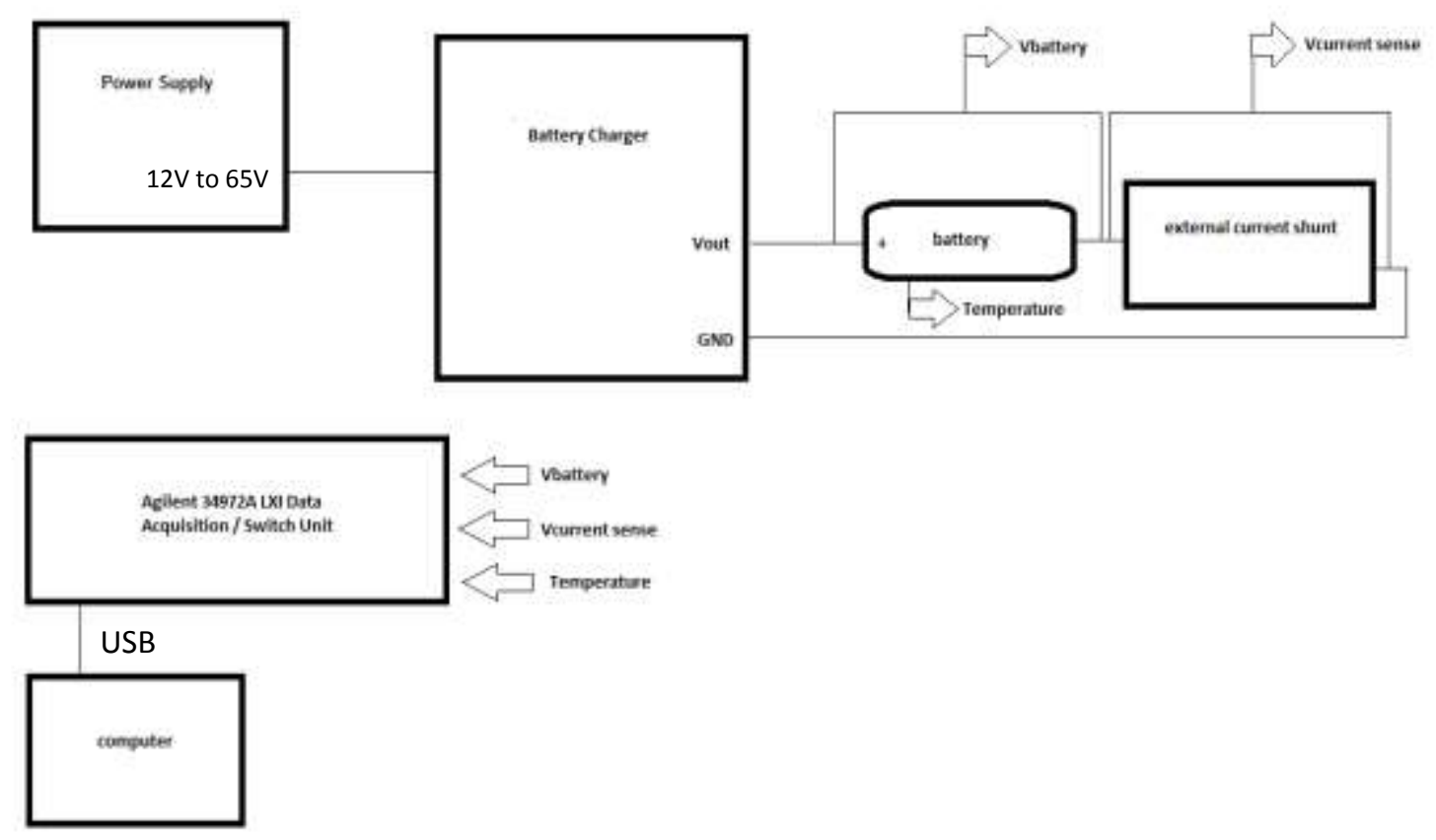

Figure 36: Battery charger test setup block diagram

Figure 37 shows the actual test setup in reality. Note this charger uses wires to connect the LM5117 Buck Controller, MCU, and INA169 Current Shunt Monitor. If the system is created on a PCB, the losses in the wires would decrease and the efficiency of the system would increase. 


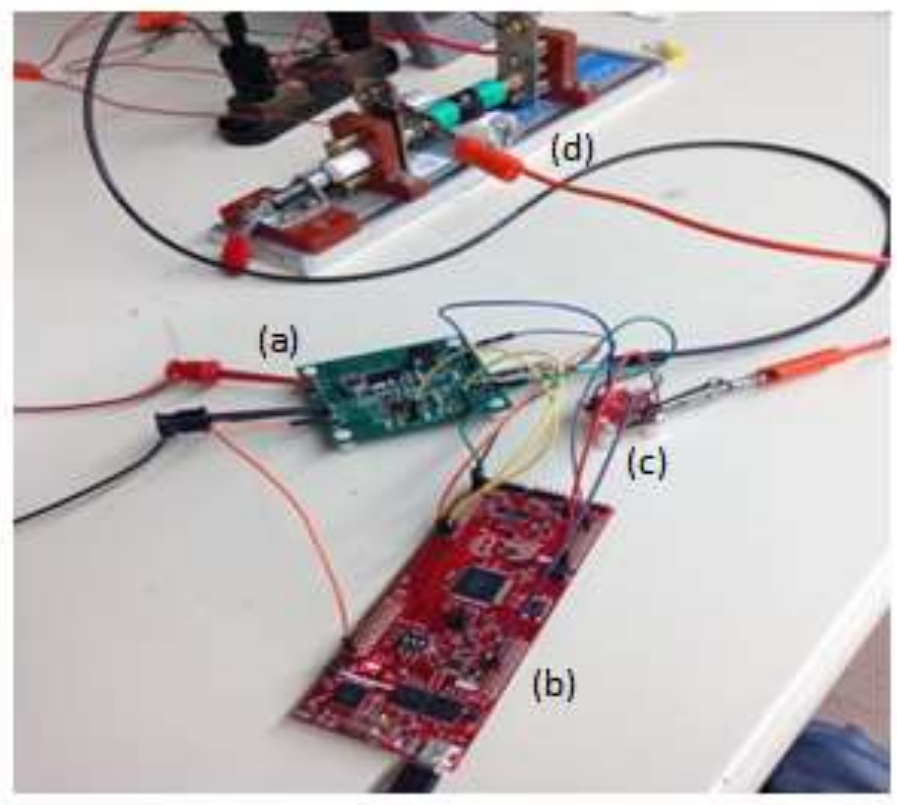

Figure 37: Picture of battery charger test setup consisting of the power stage LM5117 (a), the MCU (b), the current sense circuit (c), and the battery (d)

\subsubsection{Charge Profiles}

3.7.1.1 Rapid Charge Mode

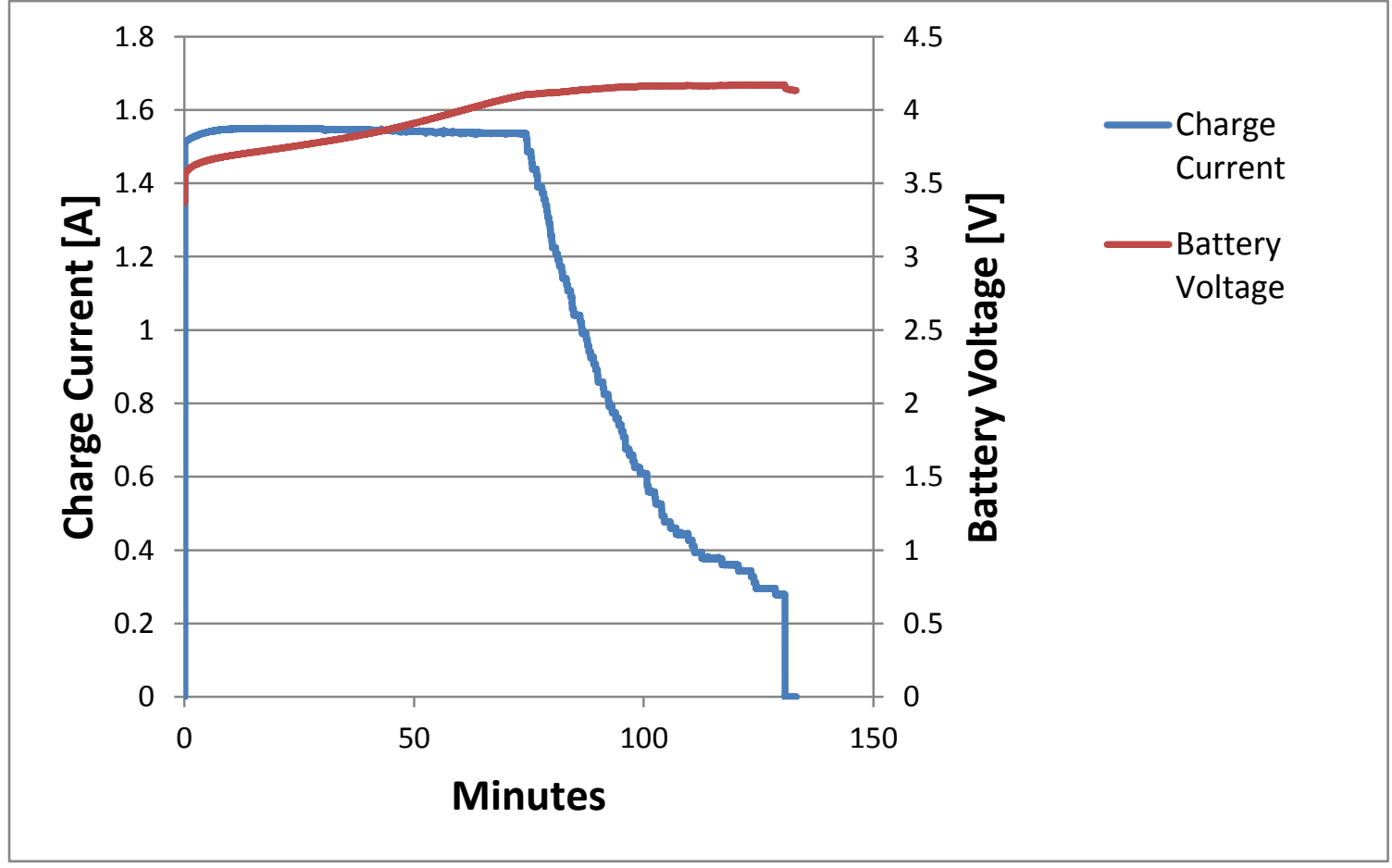

Figure 38: Rapid charge mode profile 
The Rapid charge mode profile, shown in Figure 38, sets the charger current to $0.5 \mathrm{C}$ and maintains constant current until the charge voltage measures $4.2 \mathrm{~V}$. Then the charger maintains the charge voltage while decreasing the charge current. Once the charger measures the charge voltage with the charge current less than the taper current of $0.1 \mathrm{C}$ or $300 \mathrm{~mA}$, the charger then terminates the charge and waits until the battery voltage drops below nominal voltage before charging again. The advantage of this mode is the charge rate of $0.5 \mathrm{C}$ offers an intermediate tradeoff between charge speed and stress on the battery. This mode also charges the battery to near $100 \%$ state of charge due to the constant voltage current taper portion of the charge profile.

The disadvantage is that quicker charge modes exist since a $1 \mathrm{C}$ charge rate would charge the battery faster.

\subsubsection{Quick-Rapid Charge Mode}

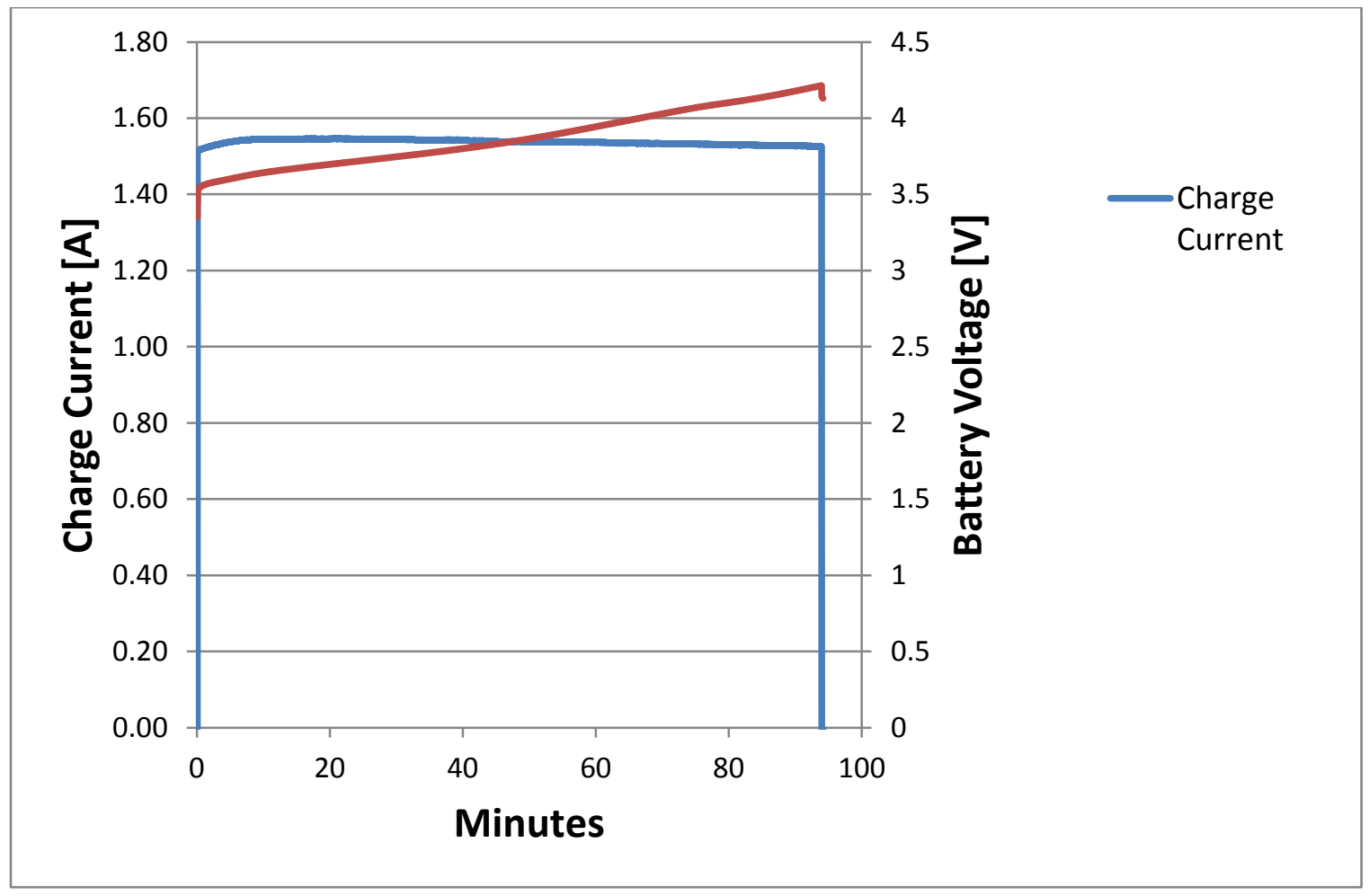

Figure 39: Quick-Rapid charge mode profile 
The Quick-Rapid charge mode profile, shown in Figure 39, starts the same as the Rapid charge mode. The charge current is set to $0.5 \mathrm{C}$ and maintains constant current until the charge voltage measures $4.2 \mathrm{~V}$. This signifies roughly $70 \%$ state of charge so at this point the charger terminates the charge current and the charging is complete. The advantage of this charge mode is speed in terms of finishing the charge and results in less stress on the battery since the battery never reaches maximum capacity. The disadvantage is that with only $70 \%$ state of charge, the runtime of the battery suffers, as the battery does not have as much capacity as with a full charge.

\subsection{Charger Efficiency}

\subsubsection{LM5117 Buck Converter Efficiency}

Efficiency is defined as power output per power input and measures how wasteful a system is. This battery charger offers charge efficiency above 90\%. The LM5117 Buck Controller uses a Synchronous Buck Converter to minimize switching losses. Other chargers use diodes or have Buck-Boost Converters that do not provide efficiency greater than $80 \%$. Figure 40 shows a simulation of the converter efficiency.

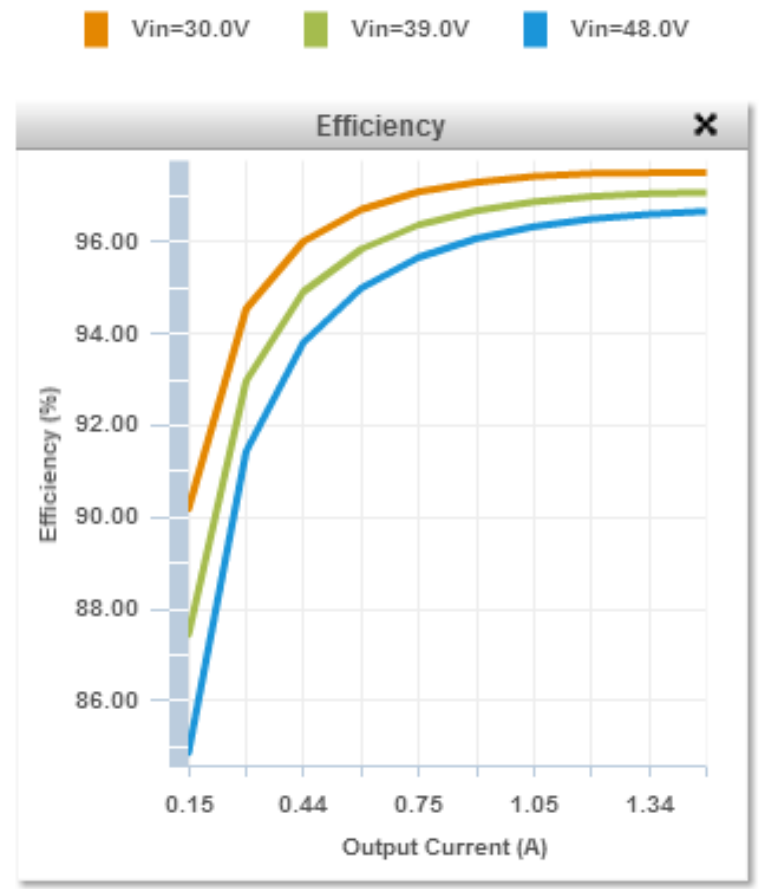

Figure 40: LM5117 efficiency simulation up to 1.5A 


\subsubsection{Charge Efficiency}

Battery University states that for the first $70 \%$ of the state of charge, the charge efficiency is close to $100 \%$ as the battery absorbs nearly all of the energy and remains cool. A fast charge however, has a higher charge efficiency than a slow charge. For example, a standard NiCd battery has charge efficiency around $91 \%$ when charged at $1 \mathrm{C}$ but around $71 \%$ when charged at $0.1 \mathrm{C}[1]$.

The actual charger efficiency is calculated by measuring the input power from the power supply and dividing by the measured output power measured with the Agilent 34972A LXI Data Acquisition/Switch Unit. Figure 41 shows the efficiency measured during the PWM linear test. In this test, the PWM is decremented from a value of 285 , which corresponds to a current of $9.91 \mathrm{~mA}$ to a value of 174 , which corresponds to $1.816 \mathrm{~A}$. As the current increases, the efficiency increases since power output is increasing. The battery charges from $3.3322 \mathrm{~V}$ to $3.53 \mathrm{~V}$ during this test so battery voltage does not influence output power much but as the battery charges up the output power increases, which increases the efficiency even more.

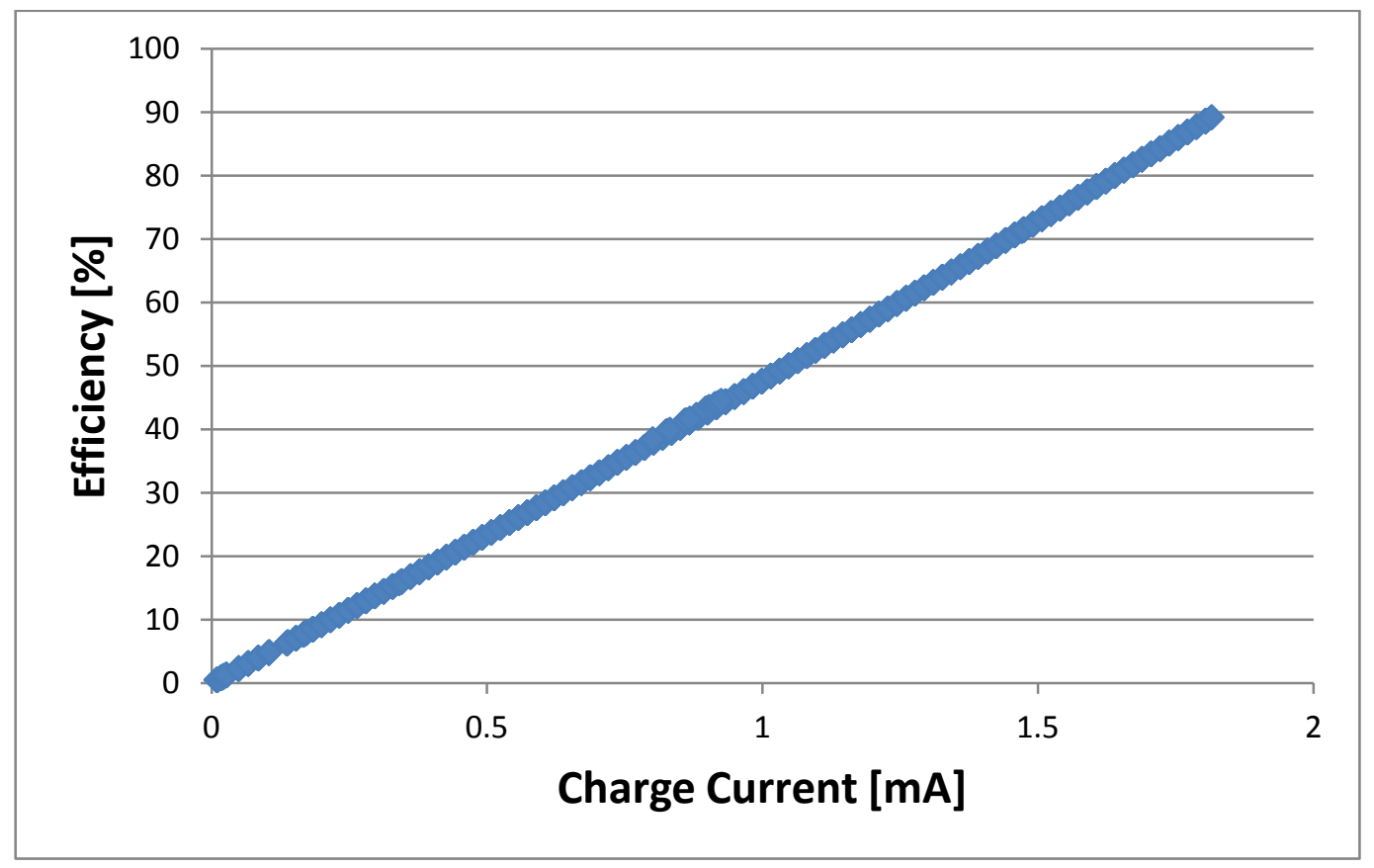

Figure 41: Efficiency measured during PWM Linear Test 
Figure 42 shows the efficiency for the Rapid charge mode. The efficiency directly corresponds to the charge current and slowly increases as the output voltage increases due to the battery charging.

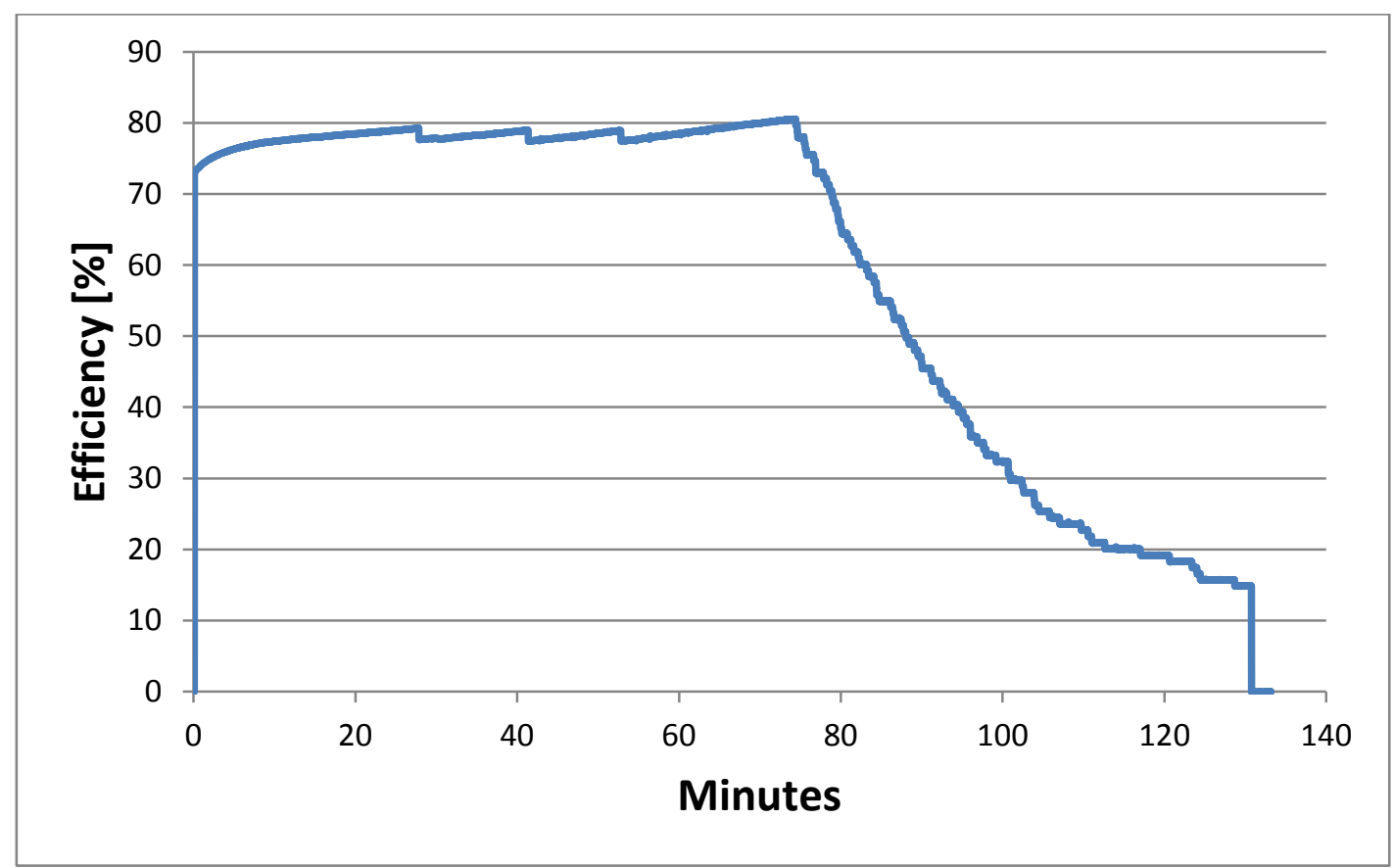

Figure 42: Efficiency measured during rapid charge mode with $\mathrm{Vin}=15.05 \mathrm{~V}$ and Iin $=0.49 \mathrm{~A}$ to $0.52 \mathrm{~A}$ 


\section{BATTERY MANAGEMENT SYSTEM}

This chapter explains the design of the BMS by describing each of the components and their function. The reader should note that the BMS is only designed for Li-Ion batteries since this chemistry is the most sensitive to improper charging and management. This BMS offers many more features that those currently implemented and the user can add create additional software if desired. Chapter 5 explains the connections between the different components and the BMS software program.

\subsection{Hardware}

The BMS consists of the modules shown below in Figure 43. Refer to Tables XVI, XVII, and XVIII in Chapter 5 for component connections.

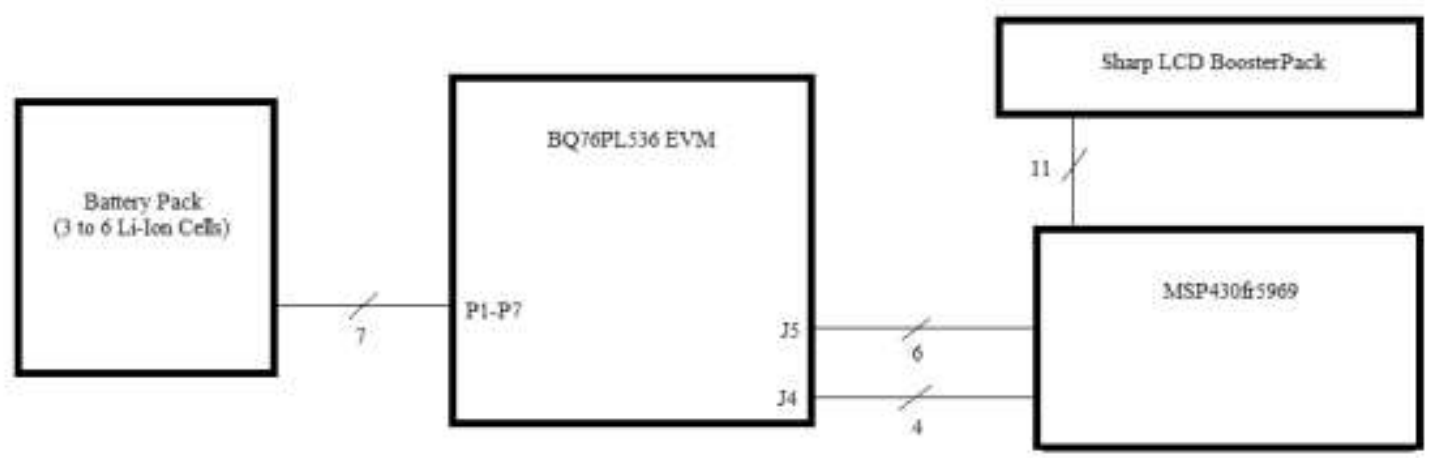

Figure 43: BMS block diagram

\subsubsection{Battery Pack}

The battery pack, shown in Figure 44, contains between three and six Lithium Ion cells. The minimum allowed voltage for each cell is $1 \mathrm{~V}$, and max voltage is $4.5 \mathrm{~V}$. The batteries connect in series with the negative terminal of the first cell connecting to P7 and the negative terminal of the next cell connecting to P6 and so on until the positive terminal of the last cell connects to P1. Another pack of three to six cells can connect to the other two plugs, but this project only uses one pack. The pack connects to the EVM at the Port 1 plug. The batteries must remain secure and the user must secure the lines from the battery pack into the plug with the metal screws before 
connecting to the EVM. The negative of the bottom cell connects to P1. For more information on the specific cells used see the 18650 datasheet [6]. This battery pack uses Arbin Instruments high power cell holders for cylindrical cells.

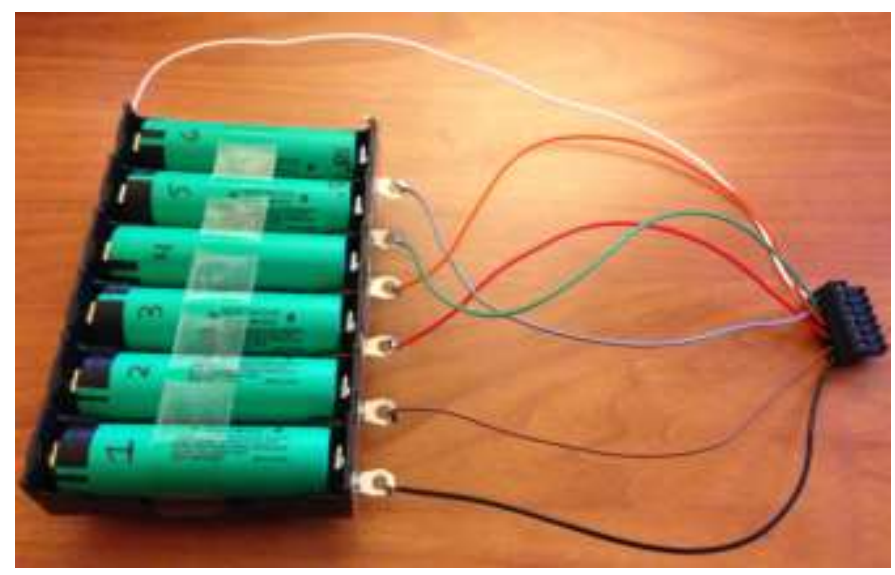

Figure 44: Battery pack containing 6 Li-Ion 18650s

\subsubsection{BQ76PL536 EVM [19]}

The EVM shown in Figure 46 has three BQ76PL536 BMS ICs shown in Figure 45 that monitor the battery packs. Note that this project only uses one BMS chip, since it only uses one battery pack. The BMS chip connects to cell balance circuitry as shown in Figure 51, which then connects to the cells. The EVM has an isolated communication interface that allows SPI communication with a host device. The BMS chips receive power from the battery pack itself requiring a supply voltage between $7.2 \mathrm{~V}$ and $27 \mathrm{~V}$. The communication portion of the BQ76PL536 receives power from a 5V output of the MSP430FR5969. Find more information related to the BMS chip including the cell monitoring and cell balancing in the BQ76PL536 datasheet [18]. Find information regarding the setup of the EVM and the operation of the GUI it comes with in the EVM Start Up Guide [19]. 


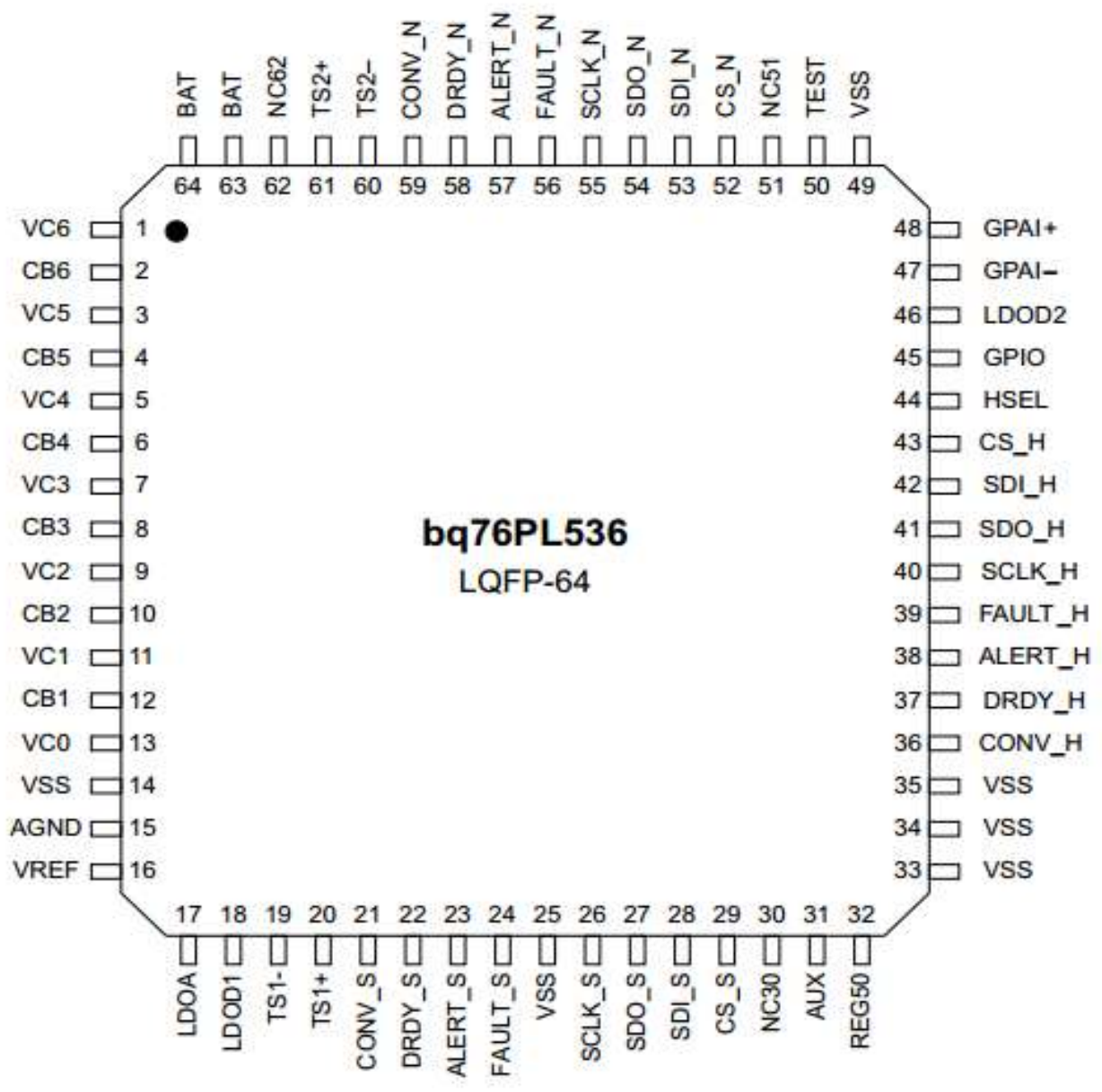

Figure 45: BQ76PL536 BMS IC pinout [18]

Figure 45 shows the functionality of the BMS ICs. They offer battery cell monitoring up to six cells in addition to pack voltage monitoring. They offer two temperature sensors along with multiple fault and alert pins that allow programming to create a BMS that provides cell and user safety. 


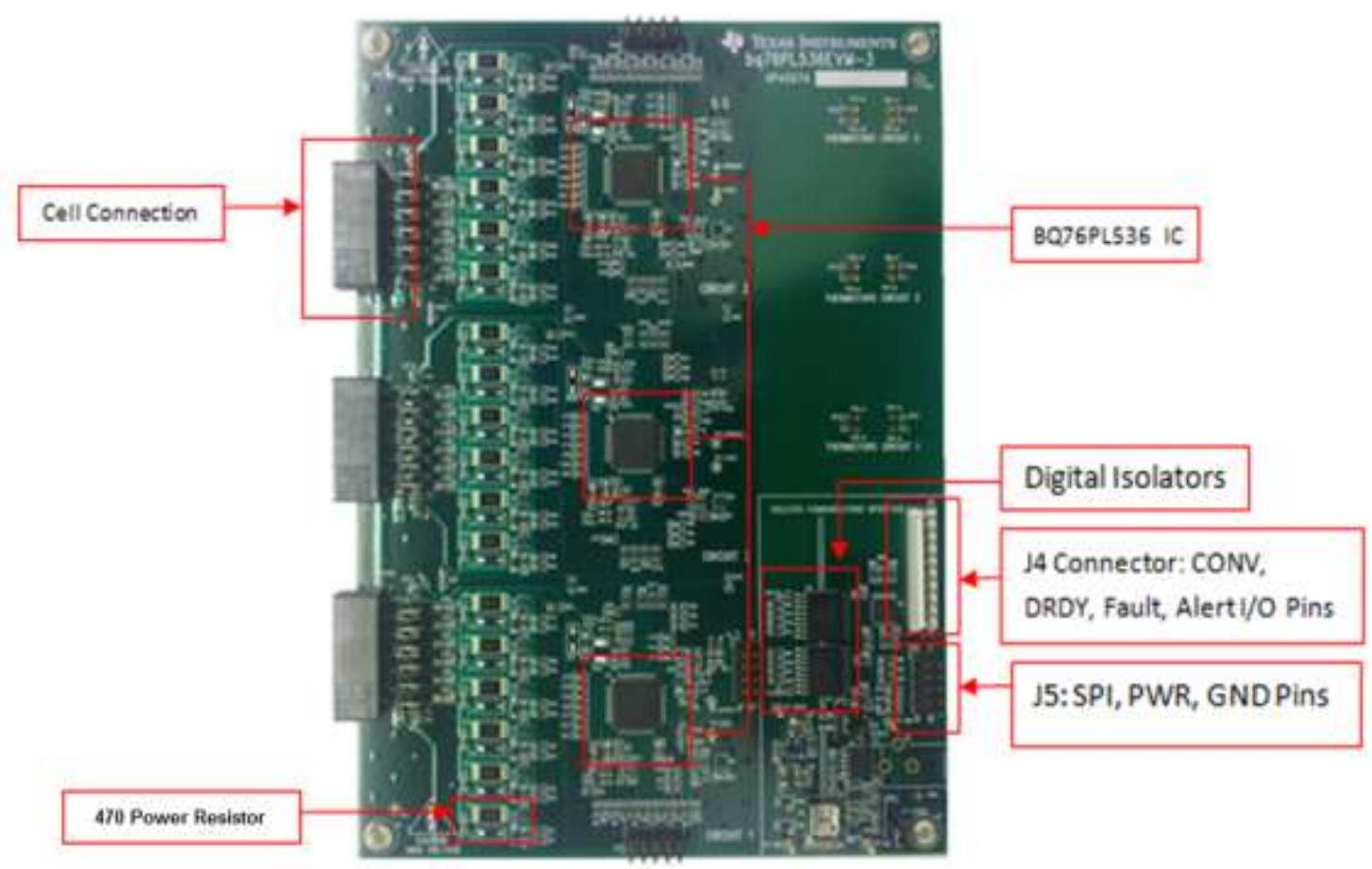

Figure 46: BQ76PL536 EVM

\subsubsection{MSP430FR5969 MCU (host device) [20-22]}

The MCU, shown in Figure 47, communicates to the EVM through SPI. The MCU reads in important data from the BMS chips and then uses an LCD screen to display the information to the user. The MCU reads cell voltage, pack voltage, and two pack temperatures. The MCU also calculates and displays the state of charge of the cells. The MCU has control over the cell balance circuitry and can make the EVM detect if cells are out of balance and start balancing them if needed. The MCU has an option select button (right button) and a menu button (left button), which helps the user navigate through the menus on the LCD screen. Find more information in the MSP430FR5969 Datasheet [20], MSP430fr59xx Family User's Guide [21], and MSPEXP430FR5969 LaunchPad User's Guide [22]. 


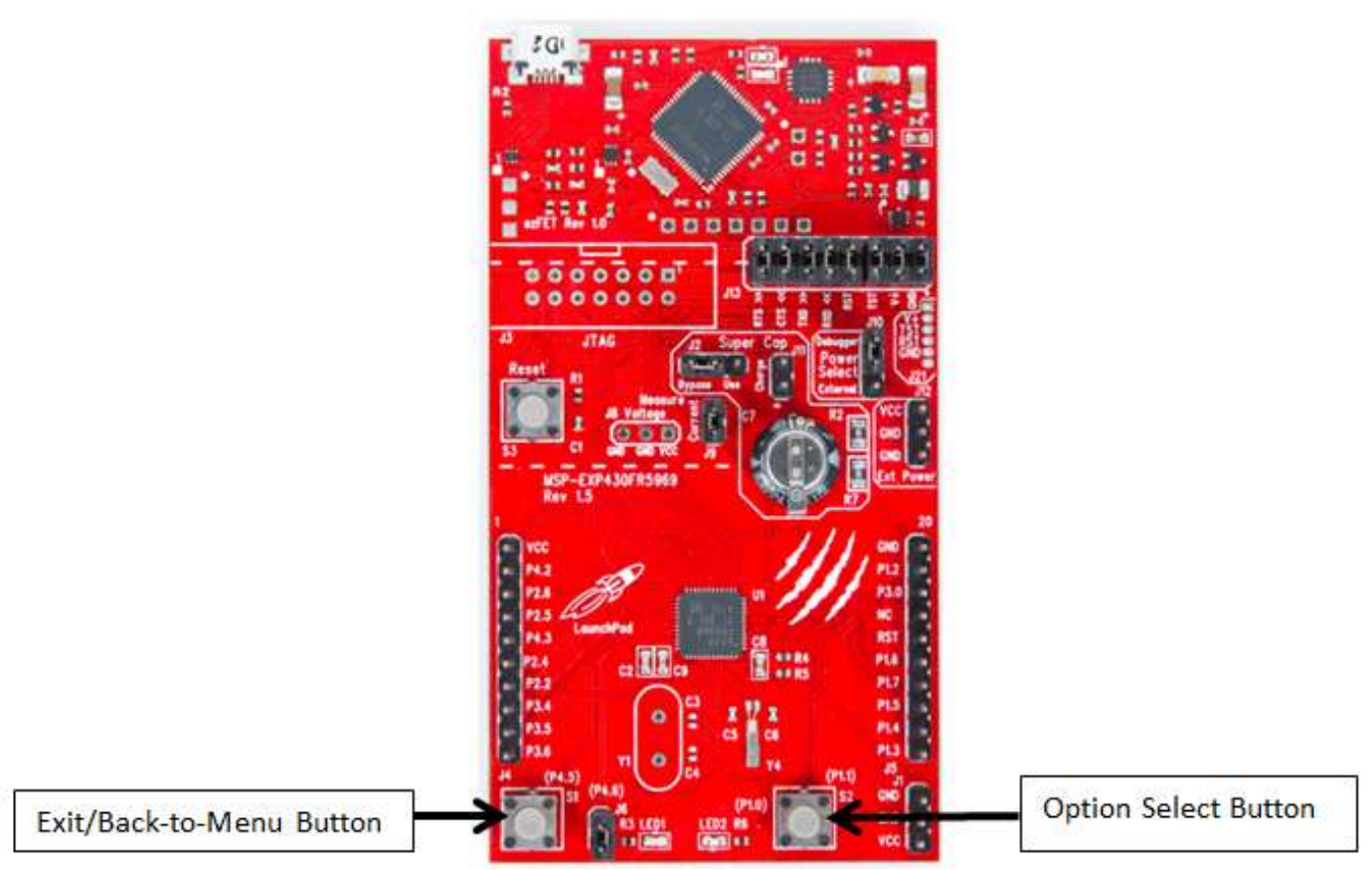

Figure 47: MSP430FR5969 MCU LaunchPad [22]

The MSP430FR5969 offers two separate SPI ports, which allows communication between both the EVM and the Sharp LCD BoosterPack. The MCU comes with two buttons that allow user interaction with the BMS in addition to easy interfacing with the Sharp LCD BoosterPack. Sharp LCD BoosterPack (user interface) [23]

The Sharp LCD BoosterPack, shown in Figure 48, connects to the MCU through SPI and controls both the BMS and the battery charger in addition to displaying important measurements. The measurements from the EVM display on the LCD through different menus and the capacitive touch sliders allow the user to change measurement and cell selection. Note that the design only uses the left capacitive touch slider. Find more information in the Sharp LCD BoosterPack User's Guide [23]. 


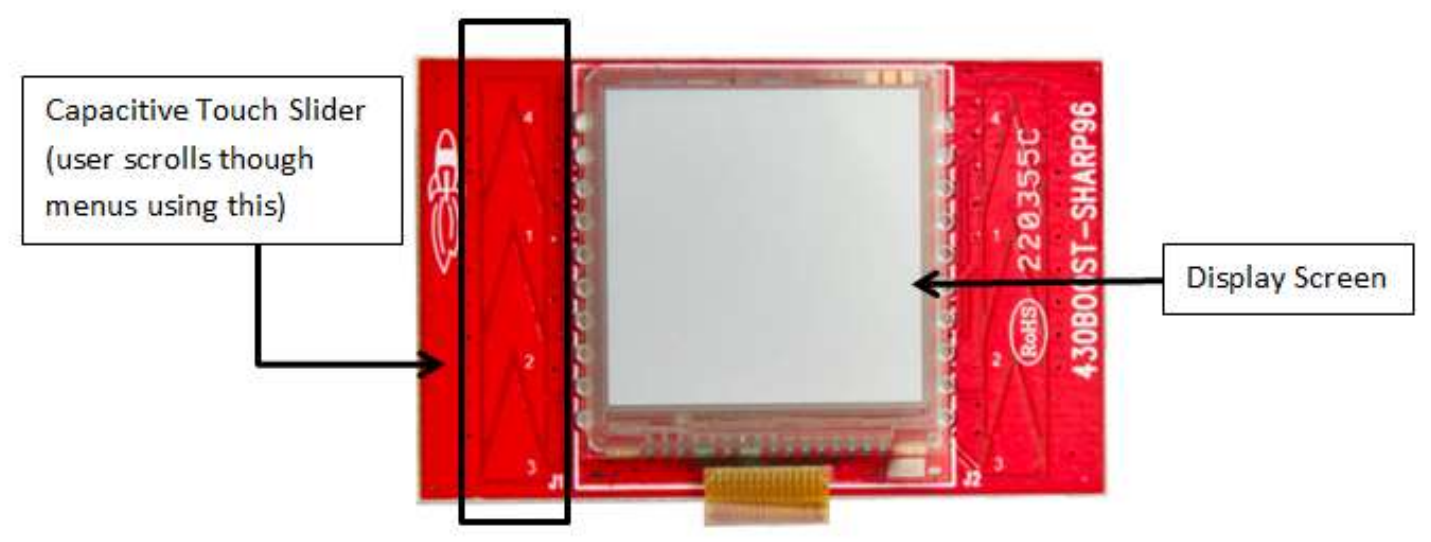

Figure 48: Sharp LCD BoosterPack [21]

The Sharp LCD BoosterPack connects directly to the MCU as shown in Figure 49 and can be programed without modification. It features a 1.3-inch screen of 96 x 96 pixels providing high-contrast images or text. Other features include low power consumption and software enabled by TI's software libraries.

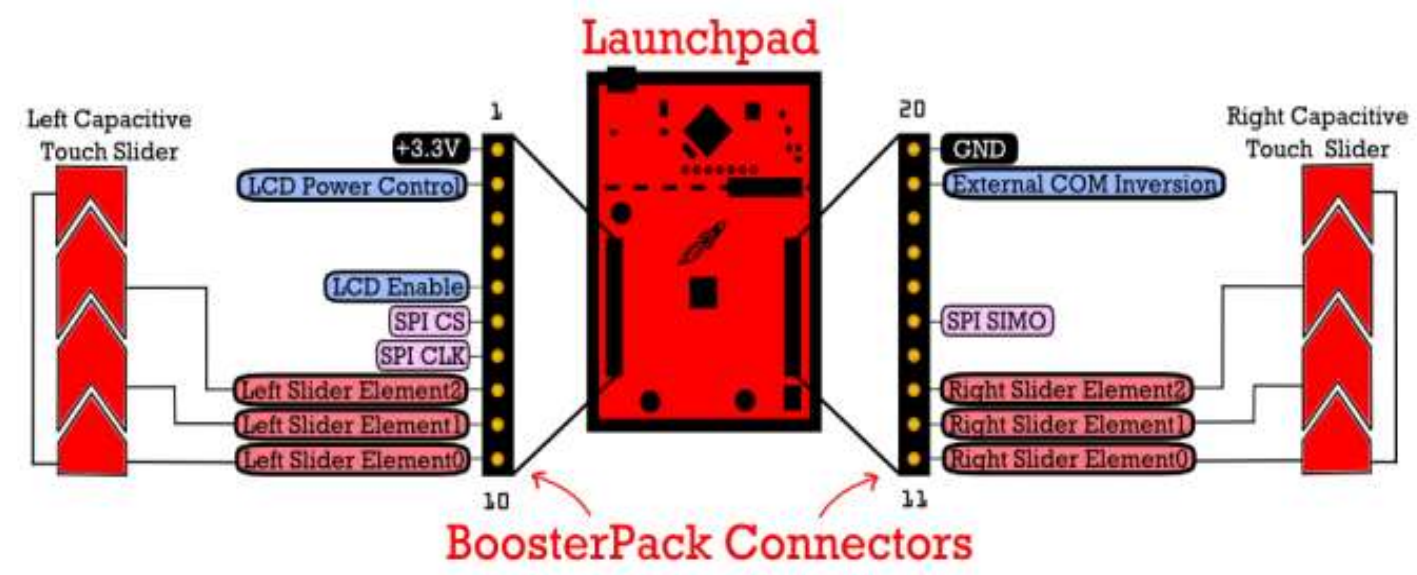

Figure 49: Sharp LCD BoosterPack connection to MCU [23]

\subsection{Battery Balancing}

Battery balancing comprises an essential component to any BMS because having batteries that differ in voltage in a battery pack causes the pack performance to degrade along with the possibility of damaging the individual cells. 
This system only balances Li-Ion cells due to their higher energy densities compared to the other chemistries. Overcharging Li-Ion cells can result in pressure build-up, which can lead to gas leaks and explosions. Other chemistries exhibit much more tolerance to overcharging in the form of very low currents sometime called trickle charge of approximately $0.1 \mathrm{C}$. This results from their lower energy densities and higher thermal capacity requiring higher temperatures for thermal runaway.

This project uses a BQ76PL536 EVM, which has a passive battery-balancing scheme developed by Texas Instruments as shown in Figure 50. The balancing circuitry, schematic as shown in Figure 51, uses switches to draw current through power resistors to dissipate power supplied by the battery that has more charge compared to the other cells. If the cells differ by more than $50 \mathrm{mV}$, the balancing circuitry can be enabled through the main menu as shown in the BMS application in Figure 55. If the cells differ by less than 50mV, the BMS displays that the cells are balanced if the user attempts balancing. The next chapter describes the software this system utilizes. The battery charger and BMS both have MCUs that require programming but provide endless flexibility in terms of charging and managing batteries. 


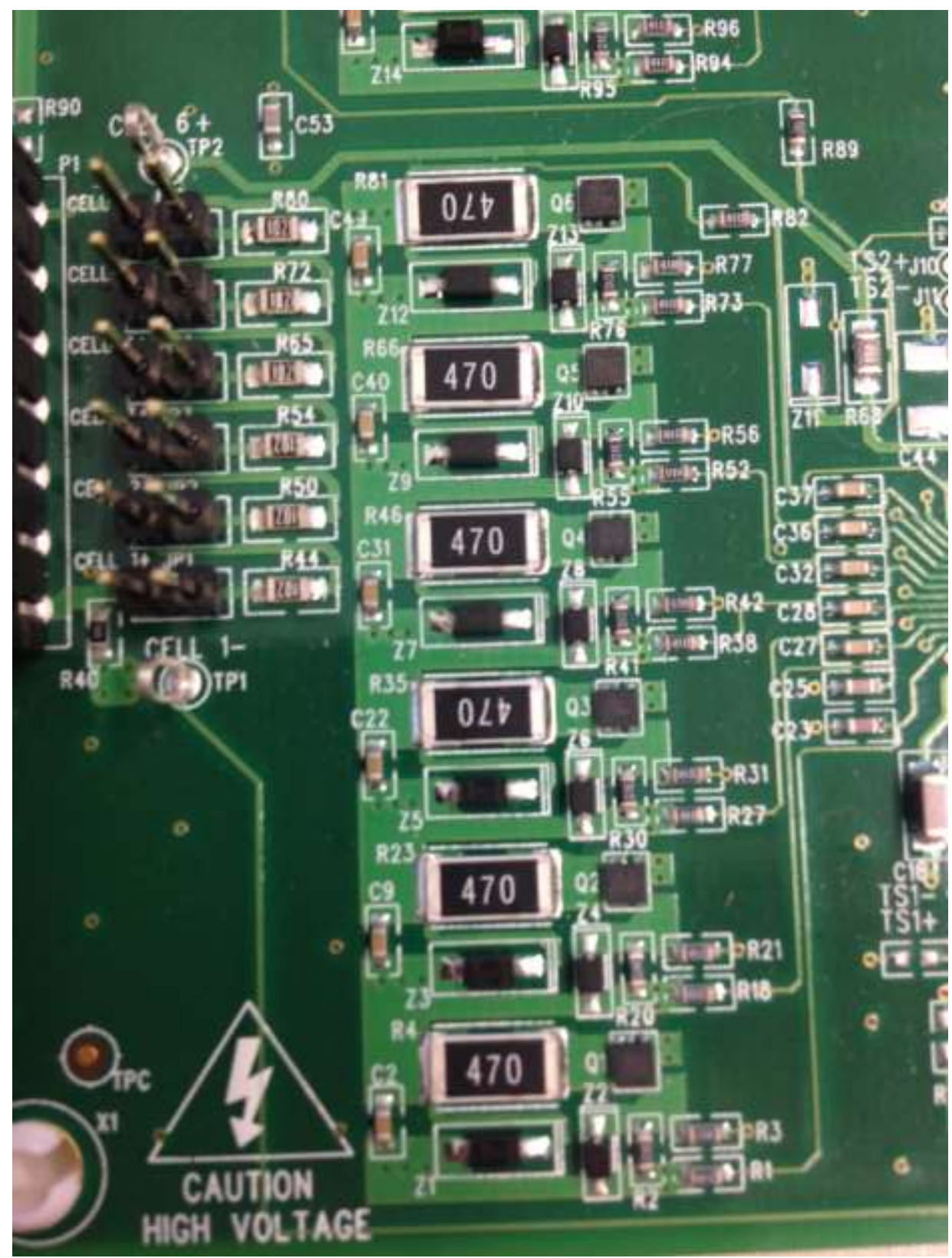

Figure 50: Balance circuity from BQ76PL536 EVM developed by Texas Instruments 


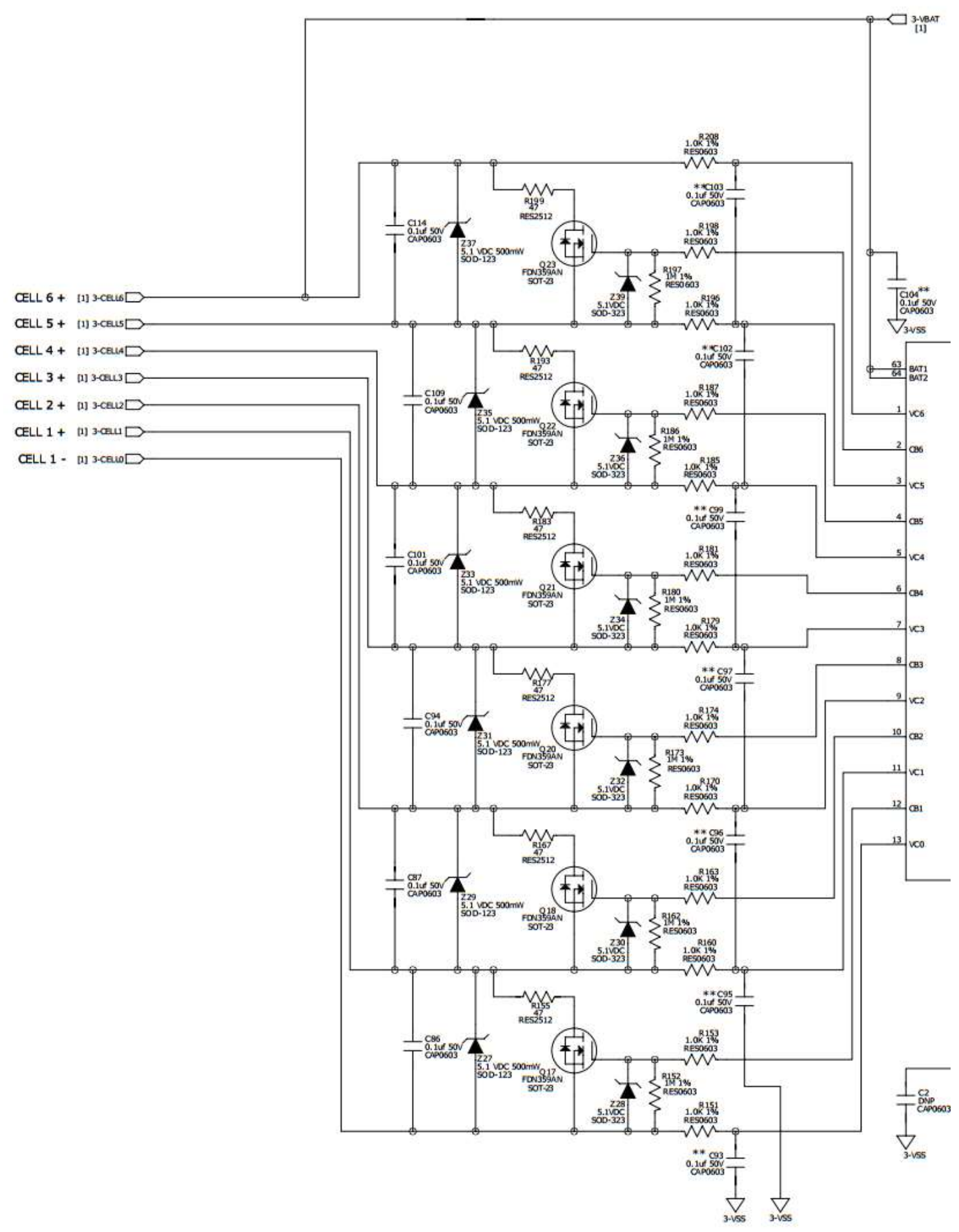

Figure 51: Cell balance schematic from BQ76PL536 EVM developed by Texas Instruments [18] 


\section{SOFTWARE}

This chapter discusses the software that operates the battery charger and BMS. This chapter starts by providing state diagrams to help the reader understand the flow of the battery charger and BMS programs. Then, this chapter provides the charge algorithms to show the battery charger functionality and to help reader grasp the endless charge possibilities.

\subsection{Universal Programmable Battery Charger}

In order to charge batteries, the user must configure the charger to the batteries that need charging. The user determines the charge current, charge voltage, and termination taper current. Future improvements would allow the user to choose cell chemistry type, charge mode, and number of cells using the left capacitive touch slider and the option select button. Figure 52 shows the configuration state diagram of the battery charger to illustrate the flow of the program.

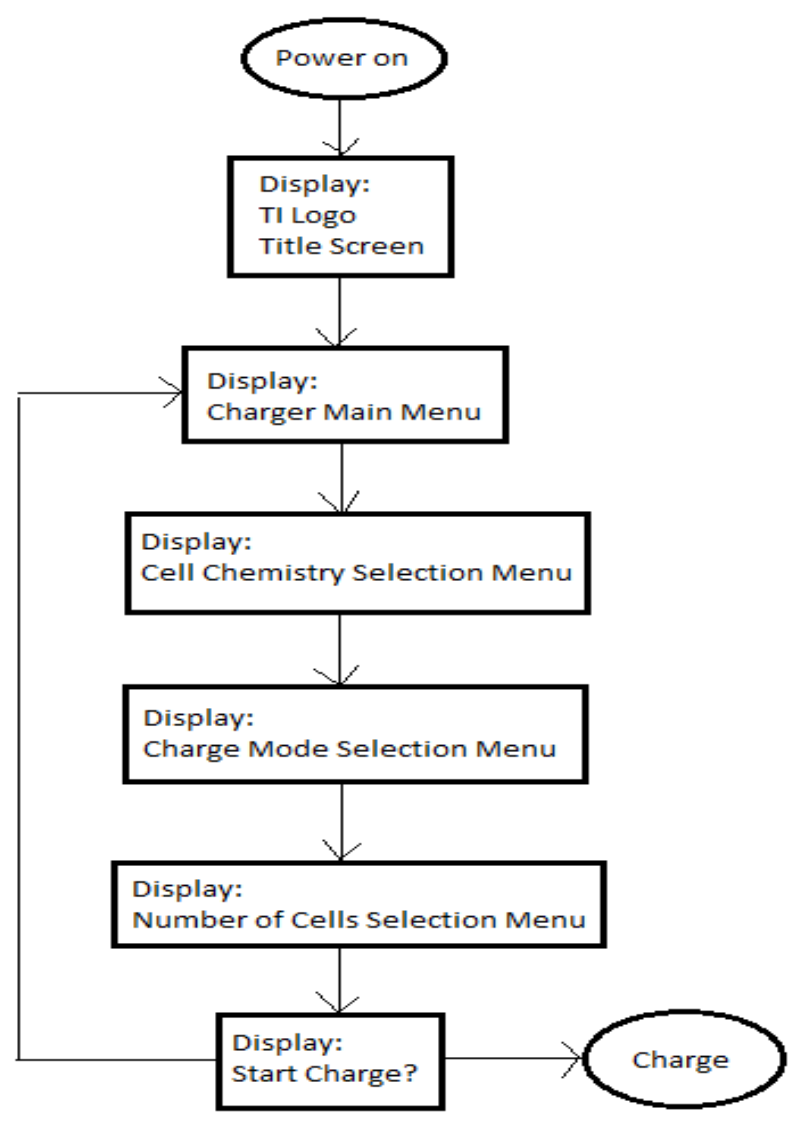

Figure 52: Charger configuration state diagram 


\subsubsection{Charge Mode Software}

Once the user configures the charger as desired, the charger begins charging. Each chemistry has a unique charge algorithm with different algorithms for the charge mode selected. Figure 53 below shows an example of Rapid charge mode for Lithium Ion Cobalt chemistry designed for Panasonic 18650 [6]. The algorithm uses a constant current (CC)/constant voltage (CV) charging algorithm, which is the recommended way to charge this type of battery [1-5] at a max recommended charge rate of $0.5 \mathrm{C}[6]$. Chapter 1 provides the details for charging various types of batteries used to create these charge modes.

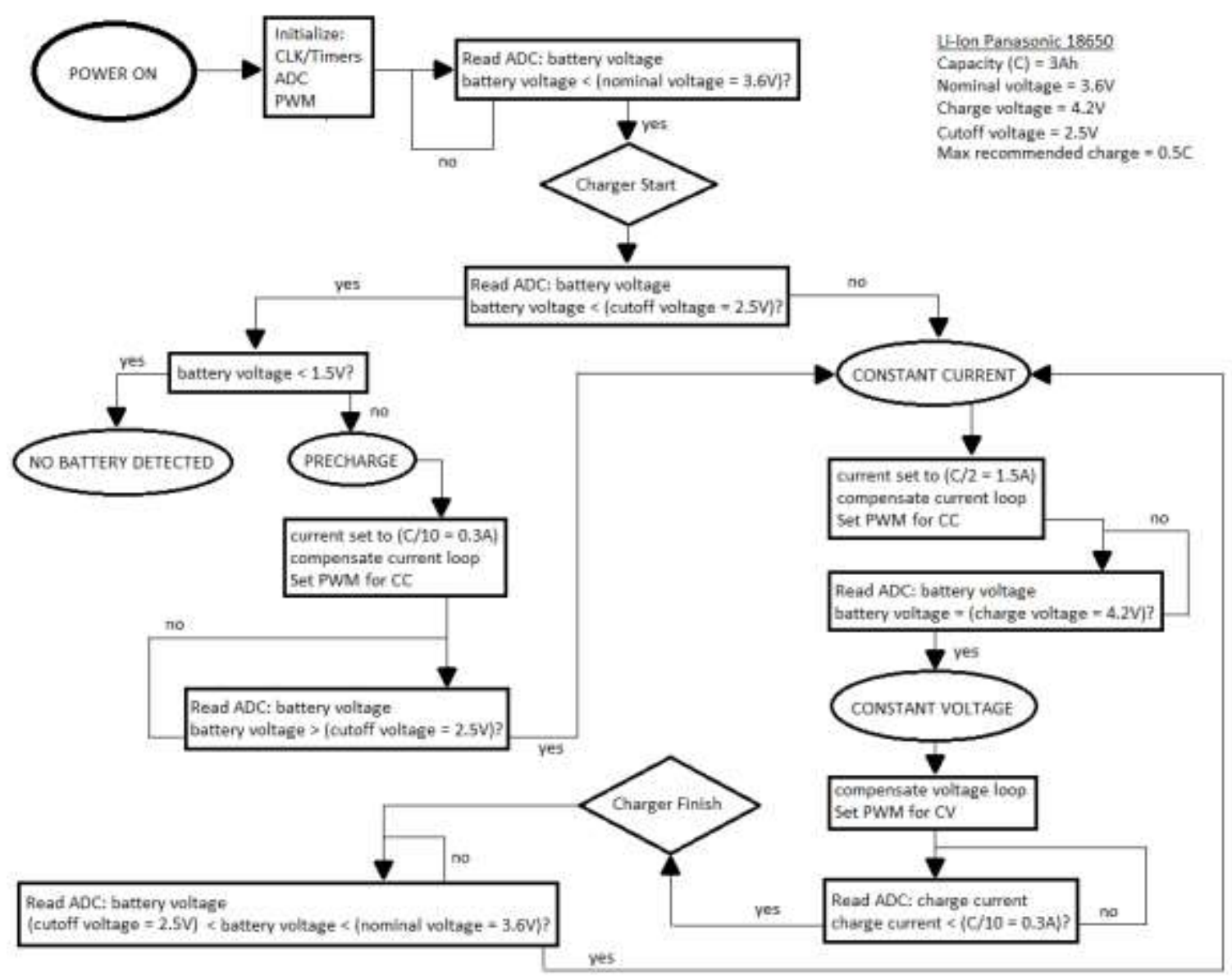

Figure 53: Lithium Ion chemistry Rapid charge mode designed for a Panasonic 18650 
Figure 54 shows an example of the Quick Rapid charge mode for the Li-Co chemistry designed for the same battery. The algorithm uses a constant current (CC) charging algorithm similar to the Rapid charge mode but terminates charge once the cell voltage reaches the charge voltage of $4.2 \mathrm{~V}$, which eliminates the constant voltage $(\mathrm{CV})$ stage essentially charging the battery to $70 \%$ SOC. The advantage of charging to $70 \%$ SOC is that the battery finishes charging quicker, and the cycle lifetime of the battery extends due to less stress on the battery during charging. The disadvantage of charging to only $70 \%$ SOC is that the runtime of the battery shortens since the battery is not charged to the maximum $100 \%$ SOC as with Rapid charge mode.

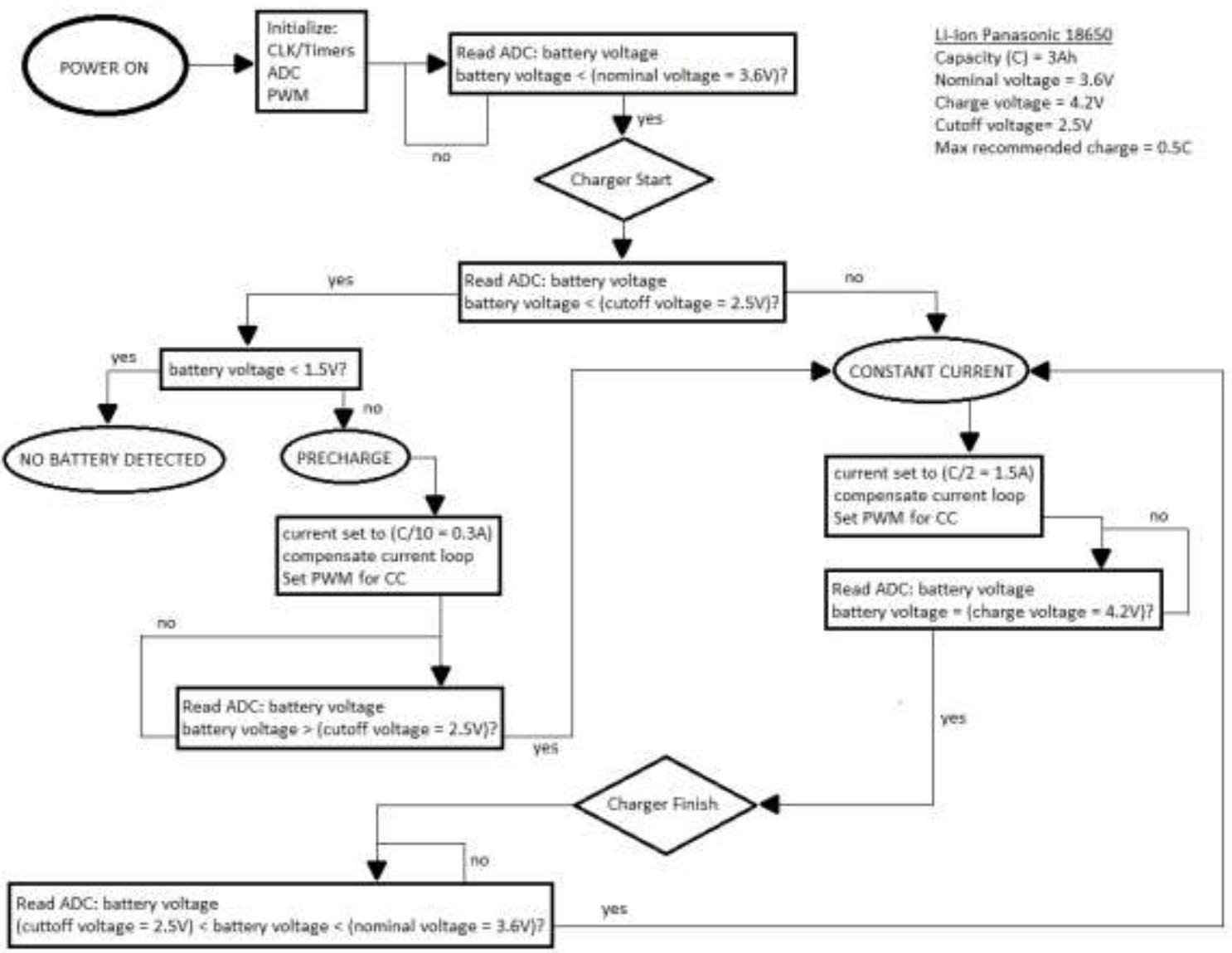

Figure 54: Lithium Ion chemistry Quick Rapid charge mode designed for a Panasonic 18650 


\subsection{Battery Management system}

Figure 55 shows the BMS application state diagram for user reference. The user should refer to this diagram when operating the BMS.

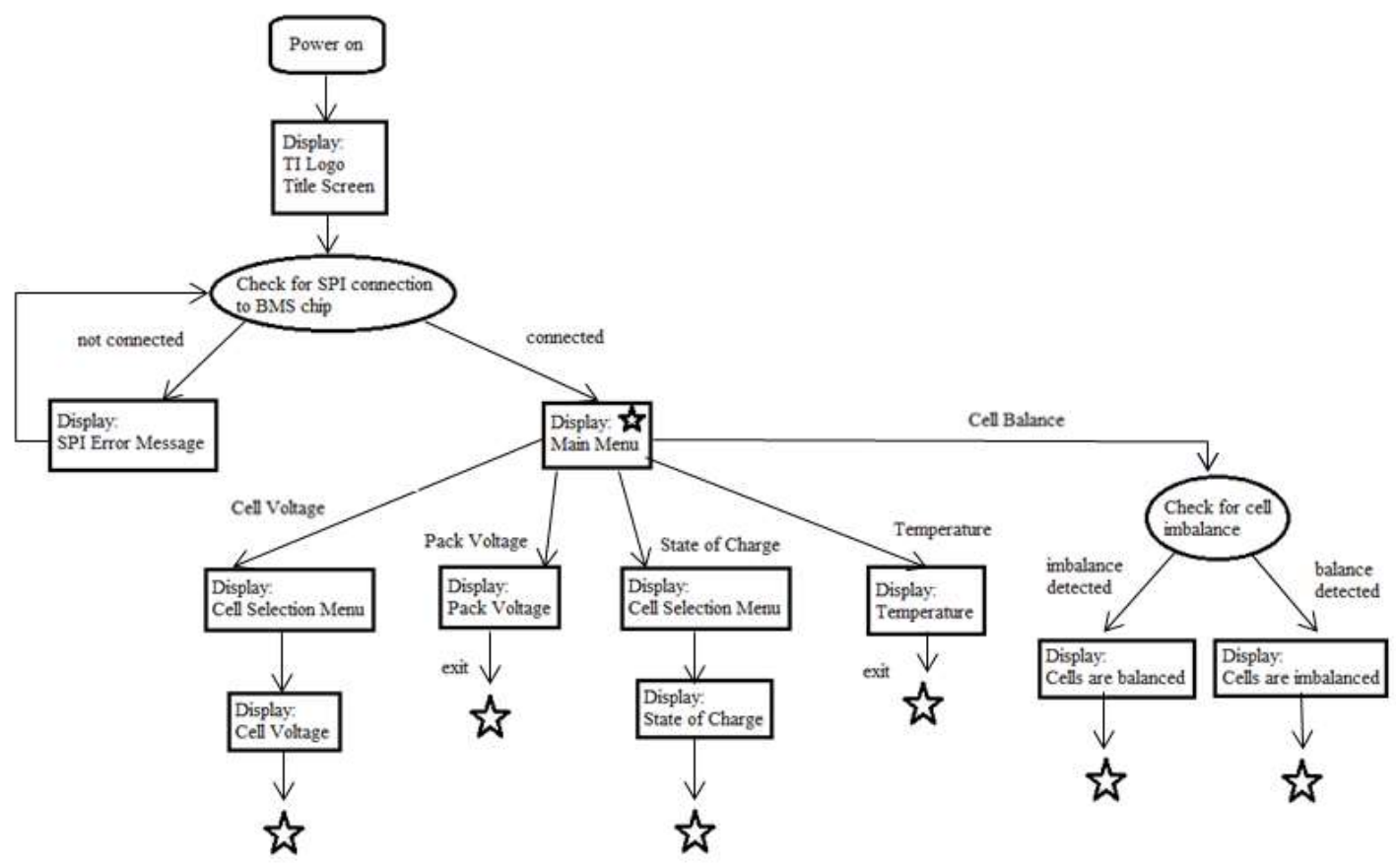

Figure 55: State diagram of BMS application

\subsubsection{SPI Error Message:}

If an SPI error message displays before the main menu displays, the BQ76PL536 device is not detected. There is most likely a problem with the SPI connection between the MSP430FR5969 and the EVM. Check the SPI lines along with the Power and Ground lines.

\subsubsection{Main Menu:}

The main menu displays the modes of the BMS. The user uses the option select button to select Cell Voltage, Pack Voltage, State of Charge, Temperature, or Cell Balance.

\subsubsection{Cell Voltage:}

Once the Cell Voltage mode is selected, the user then needs to select a cell using the option select button. The cell voltage of the selected cell displays in $\mathrm{mV}$. The cell voltage 
displays for 4 seconds then returns to the cell selection menu. Press the exit button to go back to the main menu.

\subsubsection{Pack Voltage:}

When the Pack Voltage mode is selected, the pack voltage for all connected cells displays in $\mathrm{mV}$. The user must press the exit button to return to the main menu.

\subsubsection{State of Charge:}

Once the State of Charge mode is selected, the user then needs to select a cell using the option select button. The state of charge of the selected cell displays by showing a battery with the approximate remaining charge. See Table XV below for charge remaining approximation information.

\section{Table XV: Voltage to state of charge conversion}

\begin{tabular}{|c|c|}
\hline Voltage of Cell [V] & Bars of Charge Remaining (State of Charge) \\
\hline$<3.3$ & 1 \\
\hline 3.3 to 3.4 & 2 \\
\hline 3.4 to 3.5 & 3 \\
\hline 3.5 to 3.6 & 4 \\
\hline 3.6 to 3.7 & 5 \\
\hline 3.7 to 3.8 & 6 \\
\hline 3.8 to 3.9 & 7 \\
\hline$>4.0$ & 8 \\
\hline
\end{tabular}

\subsubsection{Temperature:}

When the user selects the Temperature mode, two different pack temperatures at two separate locations in the battery pack display to the screen in degrees Celsius. The user must press the exit button to return to the main menu.

\subsubsection{Cell Balance:}

When the user selects the cell Balance mode, the system checks to see if the cells are imbalanced. The cell imbalance threshold is programmed to $50 \mathrm{mV}$. This means that if the highest cell voltage differs from the lowest cell voltage by more than $50 \mathrm{mV}$, the cells are considered imbalanced and the Cell Imbalance screen displays. If the cells are already balanced, the Cell 
Balance screen displays. The system can control the cell balance circuitry shown in Figure 50 and Figure 51 but it is recommended to enable cell balancing only if the system is connected to a charger since the higher cells drain until reaching the lowest cell voltage.

\subsubsection{BMS Connections}

\subsubsection{Between battery pack and EVM}

Table XVI: Connection from battery pack to EVM

\begin{tabular}{|c|c|}
\hline Battery Pack & BQ76PL536 EVM \\
\hline Cell 6 Positive & P1 \\
\hline Cell 6 Negative & P2 \\
\hline Cell 5 Negative & P3 \\
\hline Cell 4 Negative & P4 \\
\hline Cell 3 Negative & P5 \\
\hline Cell 2 Negative & P6 \\
\hline Cell 1 Negative & P7 \\
\hline
\end{tabular}

The cells connect in series and wires connect each cell in the battery pack to a port on the EVM allowing for individual cell monitoring in addition to pack monitoring.

\subsubsection{Between EVM and MCU}

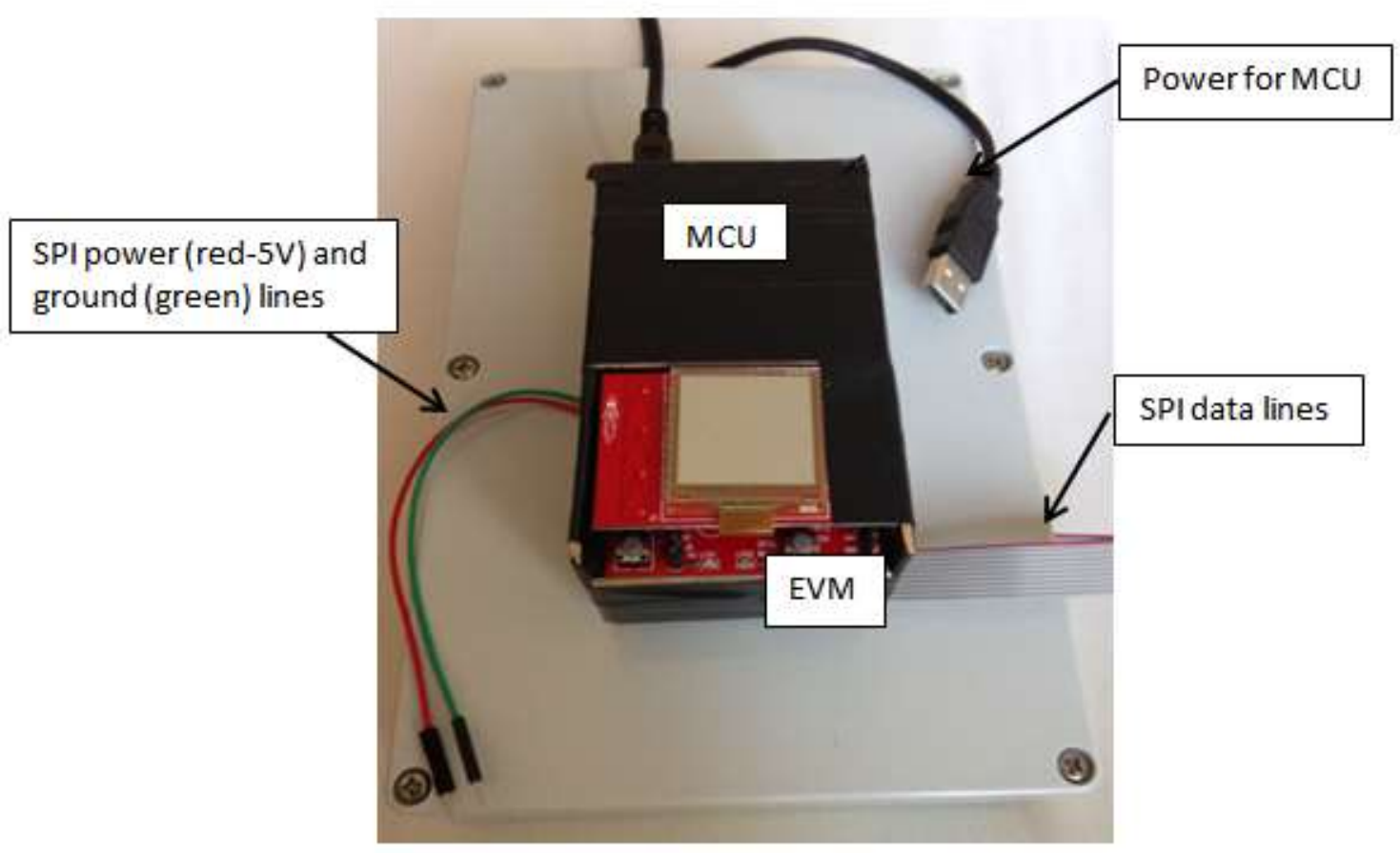

Figure 56: MCU on top of EVM 
The MCU communicates with the BMS chips via SPI. Figure 56 shows the MCU used for the BMS for user reference.

Table XVII: Connection from EVM to MCU

\begin{tabular}{|c|c|c|}
\hline BQ76PL536 Pin Name & EVM Pin \# (Port) & MSP430FR5969 Pin \\
\hline VCC (SPI Power) & 6 (P5) & VCC \\
\hline GND & 2 or 10 (P5) & GND \\
\hline CS_H & $9(\mathrm{P} 5)$ & P3.0 (GPIO) \\
\hline CLK_H & $7(\mathrm{P} 5)$ & P2.2 (UCSIB0CLK) \\
\hline SDI_H & $8(\mathrm{P} 5)$ & P1.6 (USCIB0SIMO) \\
\hline SDO_H & $5(\mathrm{P} 5)$ & P1.7 (UCSIB0SOMI) \\
\hline CONV_H & $5(\mathrm{P} 4)$ & not connected* \\
\hline DRDY_H & $4(\mathrm{P} 4)$ & not connected* \\
\hline ALERT_H & $3(\mathrm{P} 4)$ & not connected* \\
\hline FAULT_H & $2(\mathrm{P} 4)$ & not connected* \\
\hline
\end{tabular}

*These pins are disconnected due to limited number of pins available on the MSP430FR5969. The code that relates to these functions is disabled.

\subsubsection{Between MCU and BoosterPack}

Table XVIII: Connection from MCU to LCD Screen

\begin{tabular}{|c|c|}
\hline MSP430FR5969 MCU & Sharp LCD BoosterPack \\
\hline VCC & VCC \\
\hline GND & GND \\
\hline LCD Power Control & P4.2 \\
\hline LCD Enable & P4.3 \\
\hline SPI CS & P2.4 \\
\hline SPI CLK & P2.2(UCSIB0CLK) \\
\hline SPI SIMO & P1.6 (UCSIB0SIMO) \\
\hline External COM Inversion & P1.2 \\
\hline Left Slider 2 & P3.4 \\
\hline Left Slider 1 & P3.5 \\
\hline Left Slider 0 & P3.6 \\
\hline
\end{tabular}

The Sharp LCD BoosterPack is designed to fit directly into the socket located on the MSP430FR5969 MCU so no additional wires or hardware is required. 


\subsubsection{Final BMS product}

Figure 57 shows the complete BMS product.

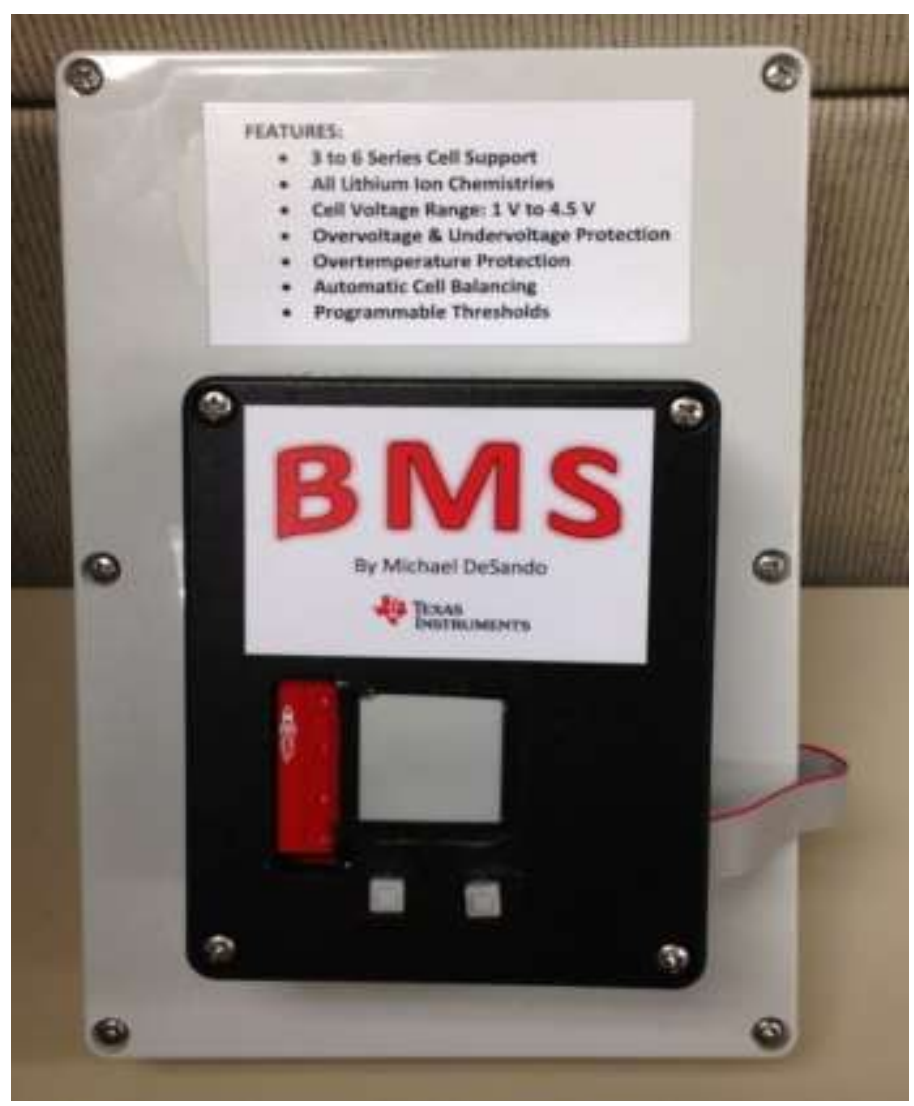

Figure 57: Final BMS product 


\section{FINAL THOUGHTS}

This chapter discusses the final thoughts the reader should know relating to the system designed in this report. The first section briefly discusses possible connector options to connect the system to different batteries and other devices. The next section discusses future improvements that can be added by the user if desired. Then a conclusion section summarizes the achievement this system makes in the field of battery chargers and management systems.

\subsection{Connectors}

Unfortunately, every brand offers devices with different chargers thus creating almost as many connectors. Even devices made by the same company may have different connectors depending on the generation of the device or device power requirements. This project does not focus as much on how to connect the charger to a given battery or device, but options on the market help solve this problem. Tenergy sells an "Octopus" multiple charging harness adaptor, shown in Figure 58, that supports the following connector types:

- Tamiya

- Mini Tamiya (for Airsoft packs)

- JST

- Hitec

- $\quad \mathrm{EC} 3$

- Deans

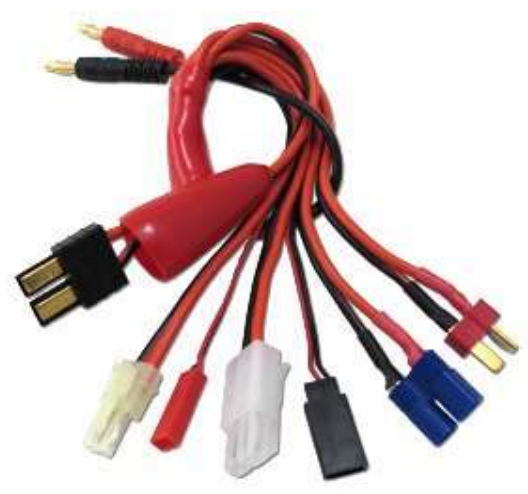

Figure 58: Multiple charging harnesses "Octopus" adaptor 
A simple internet search allows the user to find an adaptor for nearly any phone, laptop, or any other electronic device providing the ability to use this system to charge or power countless batteries or devices. The system design uses standard female Banana Jack Connectors at the output of the battery charger so the user can customize the adaptor needed to interface with those output connectors.

\subsection{Future Improvements}

\subsubsection{Additional Features}

Additional safety features including temperature sensing, pressure sensing, and alarms that visually and verbally alert the user could be added to improve user safety along with preventing damage to the system or the batteries. A display that allows the user to receive realtime feedback for charger status could also be added.

\subsubsection{Additional Programming}

This project has only two charge modes for one of the chemistries described in Chapter 1 currently programmed. Additional software is all that is required to create more charge modes for more chemistries or unique charge profiles. Additional software could also be added to track battery health such as total Coulomb count for measuring total amount of charge in battery lifetime, time since last full charge, approximate capacity of the battery, approximately cycle life remaining in the battery, average charge rate for a given battery, average SOC for a given battery, etc.

\subsubsection{Power Supply Mode}

\subsubsection{Introduction}

A power supply is a device that allows a user to change the output current and voltage to supply a set power within a defined range set by the system design. Power supplies have a constant voltage and constant current mode to accomplish this. This project demonstrates power supply capabilities in that the user selects different chemistries and charge modes to output specific current and voltage depending on the requirements to charge a given battery. This system 
can be designed to output any constant current or constant voltage within the designed specifications, essentially creating a power supply.

\subsubsection{Applications}

All electronic device chargers that plug into the wall to charge a battery internal to the device are nothing more than $\mathrm{AC} / \mathrm{DC}$ converters that supply a specific power to the battery in the device. The actual battery charger circuitry is internal to the device and located with the battery. This means that an intelligent power supply that knows when to charge, how much power to deliver while charging, and when to terminate charge is all that is required to charge these electronic devices. This project demonstrates the ability for a user to choose a charge mode to charge any battery as desired. This project can allow a user to choose a charge voltage and charge current to deliver the required power to charge (or power) a given electronic device. Ideally, the system could act as any of the power supplies shown in Table XXXII just by modifying the software.

Table XIX: Power requirements to charge (or power) various electronic devices

\begin{tabular}{|c|c|c|}
\hline Device & Voltage [V] & Current [A] \\
\hline Iphone5 & 5 & 1 \\
\hline MacBook Pro & 16.5 & 3.65 \\
\hline Toshiba Satellite P75-A7200 & 19 & 4.74 \\
\hline Samsung Galaxy Tab 10.1 & 5 & 2 \\
\hline Homedics alarm clock & 5 & 1.5 \\
\hline Remington electric shaver & 3.6 & 0.1 \\
\hline
\end{tabular}

\subsection{Conclusion}

This report provides the knowledge to charge and manage a variety of batteries and the design of a system that accomplishes that. By comparing my system to the systems currently available, it has three main advantages: First, using a synchronous Buck Converter topology improves charge efficiency to above $90 \%$ as compared to the current systems limited to $80 \%$ with an asynchronous Buck-Boost Converter topology. Second, by using a PWM to control a Current-Mode Buck Controller, the user has linear control of the output charge current, which allows charge currents 
as low as $10 \mathrm{~mA}$ compared to the $100 \mathrm{~mA}$ of other universal battery chargers. Third, having linear control over the current allows the user maximum flexibility in terms of choosing the charge current, charge voltage, and termination taper current providing a tradeoff between charge time, state of charge, and battery lifetime. 


\section{BIBLIOGRAPHY}

[1] Buchmann, Isidor. Battery University. Cadex Electronics Inc. 2014. Web. $<$ http://batteryuniversity.com>

[2] Lawson, Barry. Electropaedia. Woodbank Communications Ltd. 2014. Web. $<$ http://www.mpoweruk.com/>

[3] Simpson, Chester. LM2576, LM3420, LP2951, LP2952 Battery Charging. Texas Instruments. 2011. [Online article] < http://www.ti.com/lit/an/snva557/snva557.pdf>

[4] Designing a multichemistry battery charger. Texas Instruments. 2009. [Online article] <http://www.ti.com/lit/an/slyt357/slyt357.pdf>

[5] Grewal, Harman. Li-Ion Battery Charger solution using the MSP430. Texas Instruments. Dec 2005. [Application Report] < http://www.ti.com/lit/an/slaa287/slaa287.pdf>

[6] NCR18650 Datasheet. Panasonic. Feb 2010. [Datasheet] <http://industrial.panasonic.com/wwwdata/pdf2/ACA4000/ACA4000CE240.pdf>

[7] Tenergy TB6AC: Intelligent digital balance charger. 2010. [Operating manual] <http://www.all-battery.com/datasheet/TENERGY\%20TB6AC\%20Manual.pdf>

[8] Bantam e-Station BC6 Operating Manual. Bantam, Inc. [Operating manual] <http://www.ircha.org/sites/default/files/Digital\%20Library/Bantam\%20BC6.pdf>

[9] Cadex Electronics. Cadex Electronics, Inc. 2014. Web. < http://www.cadex.com/en>

[10] LM5117 Datasheet. "Wide Input Range Synchronous Buck Controller with Analog Current Monitor." Texas Instruments. March 2013. [Datasheet] <http://www.ti.com/lit/ds/symlink/lm5117.pdf>

[11] LAUNCHXL-F28069M Overview: User's Guide. Texas Instruments. Jan 2015. [User Guide] < http://www.ti.com/lit/ug/sprui11/sprui11.pdf>

[12] TMS320F2069M LaunchPad Development Kit Quick Start Guide. Texas Instruments. 2 Dec 2014. [Quick start guide] < http://www.ti.com/lit/ml/sprui02/sprui02.pdf>

[13] TMS320F2806x Piccolo Microcontrollers. Texas Instruments. July 2014. [Datasheet] <http://www.ti.com/lit/ds/symlink/tms320f28068m.pdf>

[14] TMS320x2806x Piccolo Technical Reference Manual. Texas Instruments. Mar 2014. [Reference Guide] < http://www.ti.com/lit/ug/spruh18e/spruh18e.pdf>

[15] INA169 High-Side Measurement Current Shunt Monitor. Texas Instruments. Nov 2005. [Datasheet] < http://www.ti.com/lit/ds/symlink/ina169.pdf>

[16] Robert Sheehan. "Current-mode modeling for peak, valley and emulated control methods." Current Mode Modeling - Reference Guide. Texas Instruments. 2011. [Reference Guide] < http://www.ti.com/lit/an/snva542/snva542.pdf> 
[17] Richard C. Dorf and Robert H. Bishop. "Modern Control Systems." $12^{\text {th }}$ Ed. Prentice Hall. Pearson Education, Inc. 2011. [Book]

[18] BQ76PL536 Datasheet. Texas Instruments. July 2010. [Datasheet] <http://www.ti.com.cn/cn/lit/ds/symlink/bq76pl536.pdf>

[19] BQ76PL536 EVM Quick Start Guide. Texas Instruments. May 2011. [Quick Start Guide] <http://www.ti.com/lit/ug/sluu437b/sluu437b.pdf>

[20] MSP430fr59xx Mixed-Signal Microcontroller. Texas Instruments. May 2014. [Datasheet] <http://www.ti.com/lit/ds/symlink/msp430fr5969.pdf>

[21] MSP430fr59 Family User's Guide. Texas Instruments. May 2014. [User Guide] <http://www.ti.com/lit/ug/slau367c/slau367c.pdf>

[22] MSP-EXP430FR5969 LaunchPad User's Guide. Texas Instruments. Feb 2014. [User Guide] <http://www.ti.com/lit/ug/slau535/slau535.pdf>

[23] Sharp LCD BoosterPack User's Guide. Texas Instruments. Feb 2014. [User Guide] <http://www.ti.com/lit/ug/slau553/slau553.pdf>

[24] Multi-Cell Li-Ion Battery Management System using MSP430F5529 and bq76PL536. Dec 2010. [Application Report]. <http://www.ti.com/lit/an/slaa478/slaa478.pdf>

[25] Battery Management System. Wikipedia. Mar 2015. [Online article] <http://en.wikipedia.org/wiki/Battery_management_system>

[26] Serial Peripheral Interface Bus. Wikipedia. May 2015. [Online article] 〈http://en.wikipedia.org/wiki/Serial_Peripheral_Interface_Bus>

[27] Batter Management Solutions. Texas Instruments. 2014. [Application Note]. < http://www.ti.com/lit/sg/slyt420c/slyt420c.pdf >

[28] Multi-Cell Lithium Ion Battery Management System. Authors: Pramit Tamrakar, Jimmy Skadal, Matthew Schulte, Hao Wang. [Senior Project Report]. Submitted Oct 12, 2010.

[29] Aardvark Adapter User Manual. Total Phase, Inc. 2014. 2014. [User Manual] $<$ http://www.totalphase.com/support/articles/200468316-Aardvark-Adapter-UserManual\#s2.4> 


\section{APPENDIX A: COST ESTIMATE}

Table XX: Cost Estimates for BMS

\begin{tabular}{|c|c|c|c|c|}
\hline Component & Function & $\begin{array}{c}\text { Cost per } \\
\text { Unit }\end{array}$ & $\begin{array}{c}\text { \# of } \\
\text { units }\end{array}$ & $\begin{array}{c}\text { Total } \\
\text { Cost }\end{array}$ \\
\hline BQ76PL536 EVM & $\begin{array}{c}\text { Required for battery } \\
\text { management. }\end{array}$ & $\$ 400.00$ & 1 & $\$ 400.00$ \\
\hline $\begin{array}{c}\text { MSP430FR5969 MCU } \\
\text { LaunchPad }\end{array}$ & $\begin{array}{c}\text { Required for data processing and } \\
\text { communication to the EVM. }\end{array}$ & $\$ 20.00$ & 1 & $\$ 20.00$ \\
\hline $\begin{array}{c}\text { Sharp LCD } \\
\text { BoosterPack }\end{array}$ & $\begin{array}{c}\text { Required for displaying data to } \\
\text { the user. }\end{array}$ & $\$ 10.00$ & 1 & $\$ 10.00$ \\
\hline 5V 2A Power Adaptor & Required to power the MSP430. & $\$ 10.00$ & 1 & $\$ 10.00$ \\
\hline Wire & Required for connecting devices. & $\$ 3.00$ & 1 & $\$ 3.00$ \\
\hline Buttons & Required for user selection. & $\$ 1.00$ & 2 & $\$ 2.00$ \\
\hline Casing & $\begin{array}{c}\text { Required to enclose devices. } \\
\text { This is optional. }\end{array}$ & $\$ 10.00$ & 1 & $\$ 10.00$ \\
\hline Total & \multicolumn{2}{|l}{} & & $\$ 530.50$ \\
\hline
\end{tabular}

Table XXI: Cost Estimates for charger

\begin{tabular}{|c|c|c|c|c|}
\hline Component & Function & $\begin{array}{c}\text { Cost per } \\
\text { Unit }\end{array}$ & $\begin{array}{c}\text { \# of } \\
\text { units }\end{array}$ & $\begin{array}{c}\text { Total } \\
\text { Cost }\end{array}$ \\
\hline LM5117 EVM & $\begin{array}{c}\text { Required for battery } \\
\text { charging. }\end{array}$ & $\$ 75.00$ & 1 & $\$ 75.00$ \\
\hline $\begin{array}{c}\text { C2000 F28069 MCU } \\
\text { LaunchPad }\end{array}$ & $\begin{array}{c}\text { Required for controlling } \\
\text { LM5117. }\end{array}$ & $\$ 23.00$ & 1 & $\$ 23.00$ \\
\hline $\begin{array}{c}\text { Current sense circuit } \\
\text { board }\end{array}$ & $\begin{array}{c}\text { Required to measure } \\
\text { current. }\end{array}$ & $\$ 8.00$ & 2 & $\$ 16.00$ \\
\hline $\begin{array}{c}\text { 48V 0.83A Power } \\
\text { Adaptor }\end{array}$ & $\begin{array}{c}\text { Required to power the } \\
\text { charger. }\end{array}$ & $\$ 10.00$ & 1 & $\$ 10.00$ \\
\hline Total & & & & $\$ 124.00$ \\
\hline
\end{tabular}

Table XXII: Cost Estimates for batteries used for testing

\begin{tabular}{|c|c|c|c|c|}
\hline Component & Function & $\begin{array}{c}\text { Cost per } \\
\text { Unit }\end{array}$ & $\begin{array}{c}\# \text { of } \\
\text { units }\end{array}$ & $\begin{array}{c}\text { Total } \\
\text { Cost }\end{array}$ \\
\hline Li-Ion Cells & Required for testing. & $\$ 10.00$ & 6 & $\$ 60.00$ \\
\hline $\begin{array}{c}\text { Battery } \\
\text { Holders }\end{array}$ & $\begin{array}{c}\text { Required to create battery pack used } \\
\text { for testing. }\end{array}$ & $\$ 2.75$ & 6 & $\$ 16.50$ \\
\hline Total & & & & $\$ 76.50$ \\
\hline
\end{tabular}

Note: This system is designed with EVMs and LaunchPads, which significantly increases the price of the system. If mass produced as one complete system, the price per system reduces significantly. The price if the entire system is designed on one circuit board and built on the component level is less than $\$ 100$. 


\section{APPENDIX B: BATTERY LIFECYCLE RESEARCH}

This research focuses on battery lifetime (cycle life) and how this relates to charge rate, state of charge (SOC), discharge rate, depth of discharge (DOD), internal resistance, temperature, number of cycles, and age.

\subsection{Introduction}

Batteries exist everywhere and charging batteries occurs every day by almost everyone. The global revenue from batteries in 2009 was $\$ 47.5$ billion and this market expects to grow to $\$ 74$ billion by 2015 [1]. Rechargeable batteries provide the most common way to power nearly all portable devices. These days we have phones, laptops, tablets, iPod or mp3 players, digital cameras, etc. that all have rechargeable batteries and we seem to prefer charging our devices in as little time as possible. But, does charging batteries quickly have an impact on the lifetime of the battery? How does the state of charge affect battery lifetime? How about the effect of rate and depth of discharge on battery lifetime? Does the age of the battery affect its lifetime even if the battery is not being used? Finding the answers to these questions can help determine the proper management of batteries and when a battery needs to be replaced. A manger of the Energy Storage Research Program at the Department of Energy said, "every year roughly one million usable lithium-ion batteries are sent in for recycling with most having a capacity of up to 80 percent" [1]. Knowing the state of a battery and how much life it has is a huge problem that most people are not aware of.

\subsection{Capacity Loss}

Capacity is defined as the availability to store charge. A battery starts (ideally) with $100 \%$ capacity, which means all of the space in the battery can store charge. Over time, the capacity decreases, which reduces the amount of space to store energy. See Figure 59 below. 


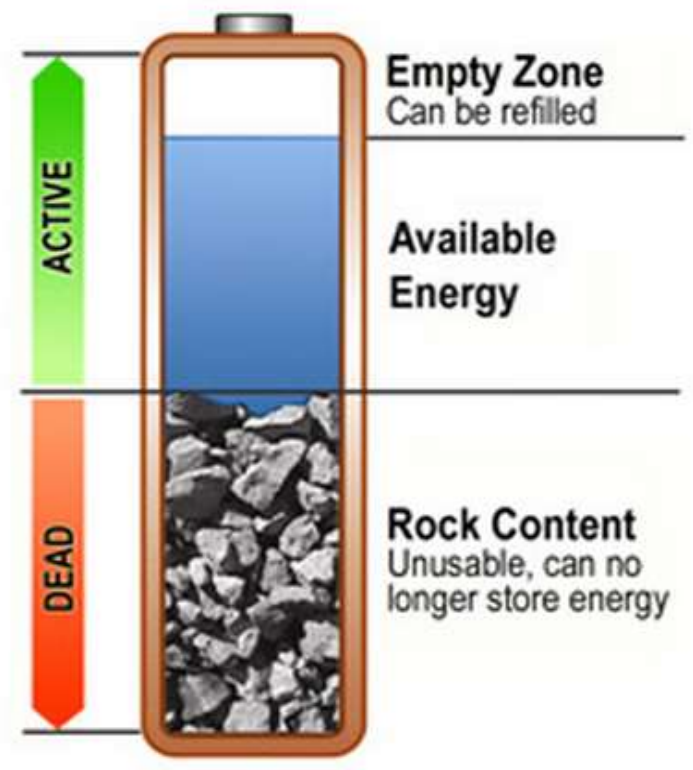

Figure 59: Battery with less than $100 \%$ capacity courtesy of Cadex [1]

From Figure 59, the "Rock Content" represents the decrease in capacity since this portion takes up space in the battery but cannot store charge.

\subsection{Battery Lifetime (cycle life)}

Battery lifetime is defined as the number of charge and discharge cycles a battery undergoes before its capacity, or the amount of energy it can store, drops to $80 \%$ of the rated capacity of the battery when it is brand new [2]. This percentage can vary however depending on the application and user preference. Every battery eventually become unusable in that it no longer accepts or stores charge above a certain capacity. Most new batteries gradually build up capacity in the first 100 to 200 cycles before reaching the maximum capacity of the battery. After this point, with each additional cycle, the capacity decreases. There is no specific timespan for how long a battery's capacity lasts for but most portable batteries deliver between 300 and 500 full charge cycles. The decreasing capacity depends on the makeup of the battery, environmental conditions, and how the user charges and uses (discharges) the battery [1]. This research focuses on the charging and discharging, specifically the rate of charge, the state of charge (SOC), and the depth of discharge (DOD), since these parameters are completely controlled by the user. 


\subsubsection{Li-Ion}

Li-ion batteries start at maximum capacity and begin to decline immediately. The end of a lithium ion battery occurs when the transfer of ions slows down due to cell oxidation. This process occurs naturally as the battery is used over time and is irreversible [1].

\subsubsection{Lead Acid}

The lead acid battery cycle lifetime has three stages called formatting, peak, and decline as shown in Figure 60. The formatting stage starts around 85\% capacity and increases to $100 \%$ after charging and discharging approximately 20 to 50 times. This occurs during normal use. The Peak stage last for approximately 100 to 200 cycles before gradually declining.

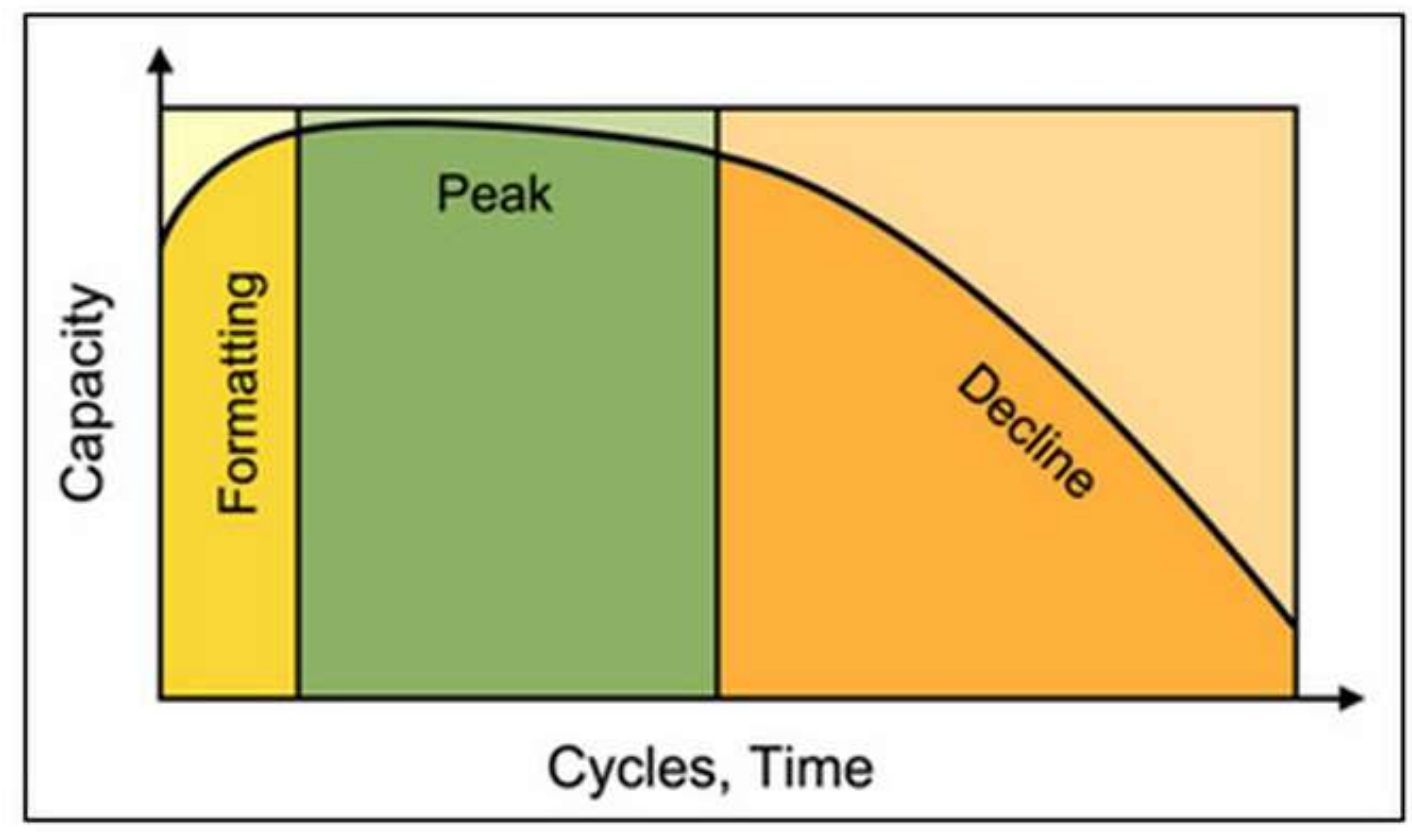

Figure 60: Three stages of lead acid cycle lifetime courtesy of Cadex [1]

The end of a lead acid battery results from sulfation or grid corrosion. Sulfation causes a thin layer to form on the negative cell plate if the battery remains in a low state of charge for a long period. Sulfation can be reversed if an equalization charge is applied before it becomes too damaged. Grid corrosion can be reduced if the battery is properly charged with correct float voltage [1]. 


\subsubsection{Nickel Based}

Nickel based batteries require priming similar to formatting of lead acid before reaching full capacity if the batteries are new or stored for a long period of time (six months or longer). Priming requires cycling the battery 5 to 7 times if it's a high quality battery or up to 50 cycles for other batteries. The end of nickel based batteries result from corrosion or crystalline formation. This crystalline formation can occur if the battery is not discharged enough due to an effect called memory [1].

\subsection{Battery Runtime}

Battery runtime is different from battery lifetime. The runtime is defined as the time the battery lasts on a full charge before dying and needing to be recharged. This is the time of one discharge cycle. Runtimes given by manufactures assume the capacity of the battery is $100 \%$, which gives a bad representation of the actual runtime since the capacity slowly decreases over time. This means that over time, the runtime of the battery reduces since space in the battery to store charge reduces as compared to when it was brand new.

\subsection{Factors that Reduce Battery Lifetime}

There are many factors that add stress to a battery, which result in a shorter lifetime.

\subsubsection{Number of Charge \& Discharge Cycles}

Each time the battery charges and discharges, the battery's capacity decreases slightly. The more the battery is used, the shorter the battery lasts as the battery's performance decreases as seen in Figure 61. 


\section{Cycle Life at Room Temperature}

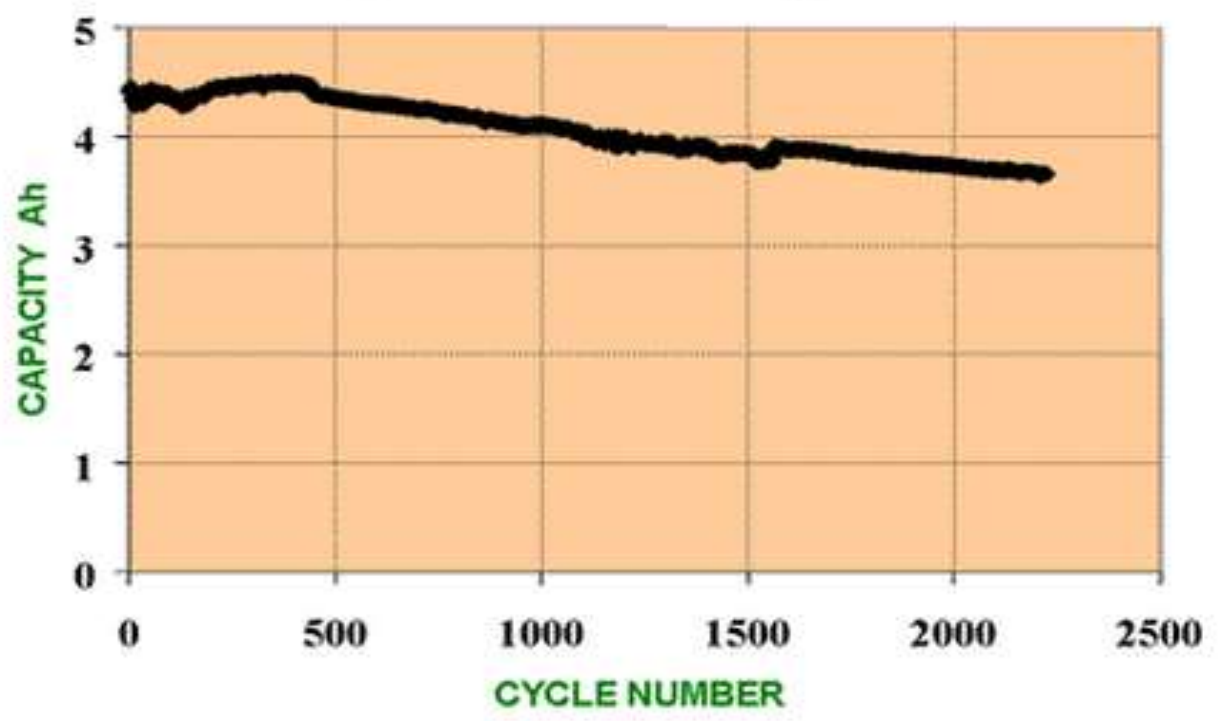

Figure 61: Capacity compared to the number of cycles [2]

\subsubsection{Charge \& Discharge Rate}

Figure 62 shows that faster rates of charge or discharge directly corresponds to shorter cycle lifetime of the battery [1].

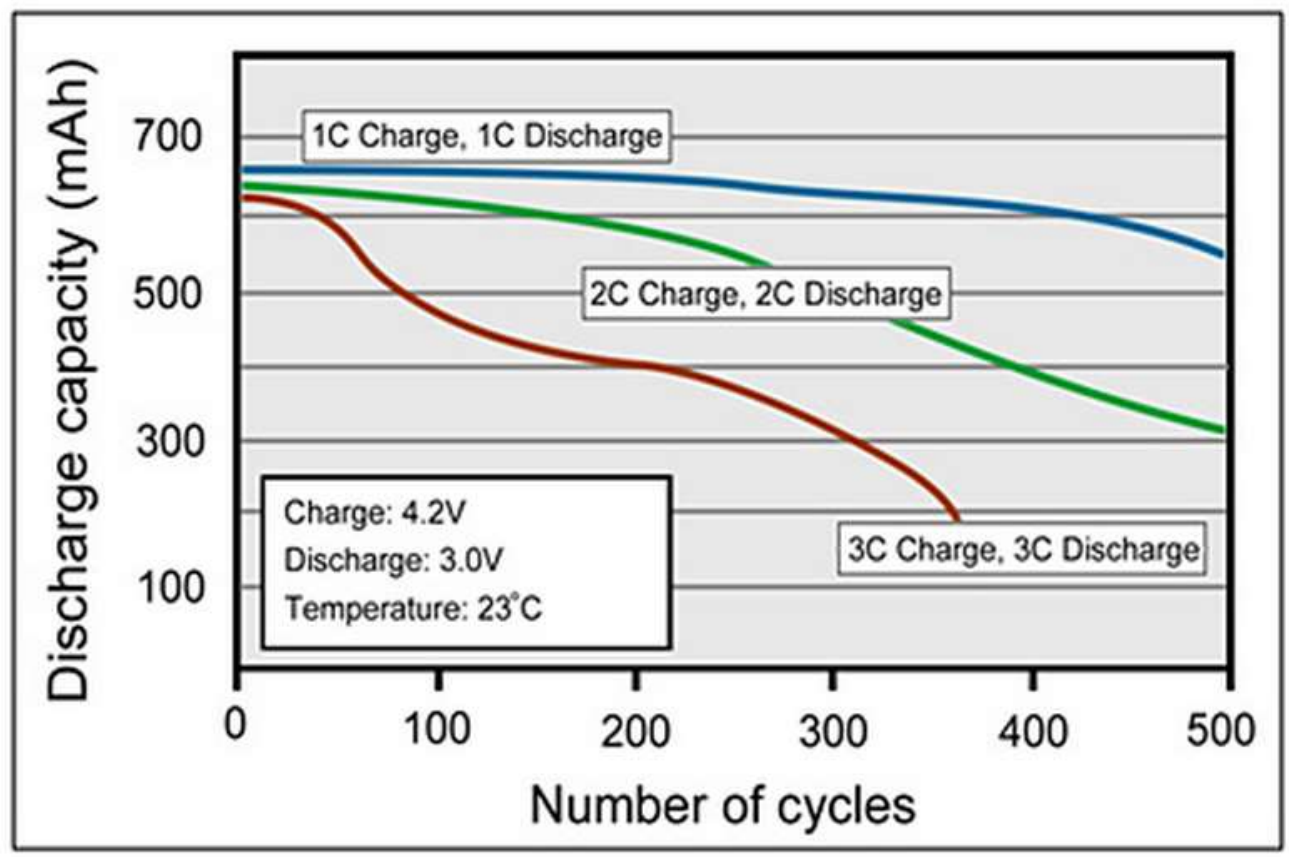

Figure 62: Charge and discharge rate for Li-Ion battery vs number of cycles courtesy of Cadex [1] 


\subsubsection{State of Charge \& Depth of Discharge}

When Li-ion batteries fully charge and then fully discharge, they do not last as long as batteries that charge and discharge partially. Charging a battery to $4.2 \mathrm{~V} /$ cell is considered fully charged. Discharging to $2.5 \mathrm{~V} /$ cell is considered fully discharged. See Table XXIII and Table XXIII below [1].

Table XXIII: State of charge compared to Li-Ion cycle lifetime courtesy of Cadex [1]

\begin{tabular}{|c|c|c|}
\hline $\begin{array}{c}\text { Charge level } \\
\text { (V/cell) }\end{array}$ & Discharge cycles & $\begin{array}{c}\text { Capacity at full } \\
\text { charge }\end{array}$ \\
\hline$[4.30]$ & {$[150-250]$} & $\sim[110 \%]$ \\
4.20 & $300-500$ & $100 \%$ \\
4.10 & $600-1,000$ & $\sim 90 \%$ \\
4.00 & $1,200-2,000$ & $\sim 80 \%$ \\
3.92 & $2,400-4,000$ & $\sim 75 \%$ \\
\hline
\end{tabular}

Table XXIV: Depth of discharge vs discharge cycles for Li-Ion courtesy of Cadex [1]

\begin{tabular}{|c|c|}
\hline Depth of discharge & Discharge cycles \\
\hline $100 \%$ DoD & $300-500$ \\
$50 \%$ DoD & $1,200-1,500$ \\
$25 \%$ DoD & $2,000-2,500$ \\
$10 \%$ DoD & $3,750-4,700$ \\
\hline
\end{tabular}

Figure 63 shows the state of charge's effect on cycle lifetime. The cycle life reduces significantly as the battery charges to higher SOC. 


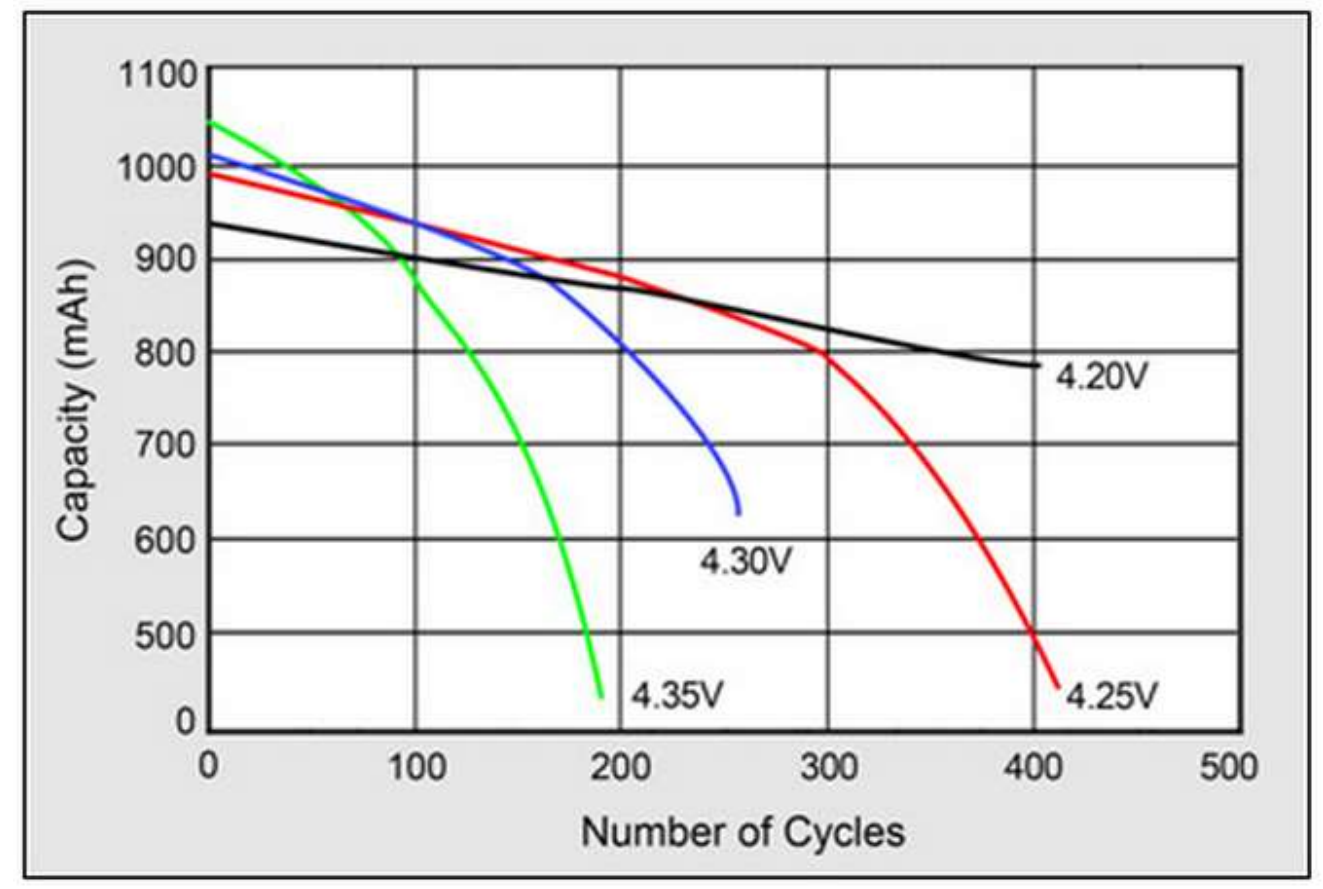

Figure 63: State of charge and capacity compared to Li-ion cycle lifetime courtesy of Cadex [1]

Lead acid batteries require an equalization charge, which charges the batteries $10 \%$ over the recommended voltage to bring the cells to similar levels. This is required every 1 to 3 months depending on use [1]. Nickel based batteries require complete discharge to prevent crystallization formation or the "memory" effect [1].

\subsubsection{Temperature}

Li-Ion batteries become stressed when exposed to temperatures higher than $30^{\circ} \mathrm{C}\left(86^{\circ} \mathrm{F}\right)$. See Table XXIV for temperature and capacity relationship at two different state of charges [1].

Table XXV: Temperature and state of charge compared to capacity courtesy of Cadex [1]

\begin{tabular}{|c|c|c|}
\hline Temperature & $40 \%$ charge & $100 \%$ charge \\
\hline $0^{\circ} \mathrm{C}$ & $98 \%$ & $94 \%$ \\
$25^{\circ} \mathrm{C}$ & $96 \%$ & $80 \%$ \\
$40^{\circ} \mathrm{C}$ & $85 \%$ & $65 \%$ \\
$60^{\circ} \mathrm{C}$ & $75 \%$ & $60 \%$ \\
& & (after 3 months) \\
\hline
\end{tabular}


A Sealed Lead Acid (SLA) battery's lifetime reduced by half for every $8^{\circ} \mathrm{C}\left(15^{\circ} \mathrm{F}\right)$ rise in temperature. For starter lead acid batteries, a $12^{\circ} \mathrm{C}\left(22^{\circ} \mathrm{F}\right)$ increase reduces the lifetime by roughly one year [1].

\subsubsection{Internal Resistance}

Internal resistances relate to the power output of the battery and the higher the resistance, the worse the performance. Internal resistance increases as temperature rises and time passes. See Figure 64 [2].

\section{Increasing Internal Resistance with Time and Temperature}

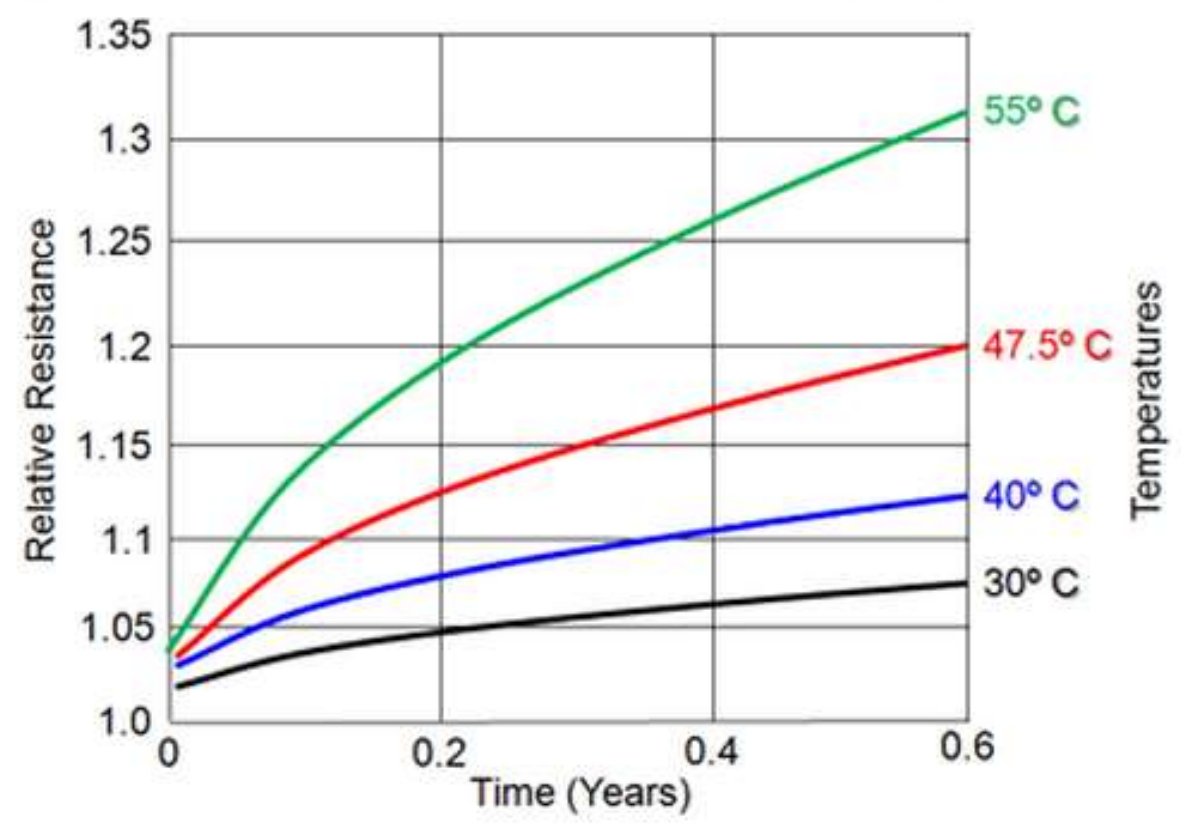

Figure 64: Internal resistance compared to temperature over time [2]

\subsubsection{Number of Cycles}

As the number of cycles increases, the capacity of the battery decreases. Counting cycles could be misleading since the depth of discharge may not be consistent if referring to real world battery usage. A Cadex Laboratory cycles $11 \mathrm{Li}$-polymer batteries to show how capacity reduces as batteries cycle. These cells charge at $1 \mathrm{C}$ to $4.2 \mathrm{~V} / \mathrm{cell}$ then allowed to saturate for a full complete charge. They then discharge to 3V/cell at 1C. This counts for one cycle [1]. See Figure 65 for the results. 


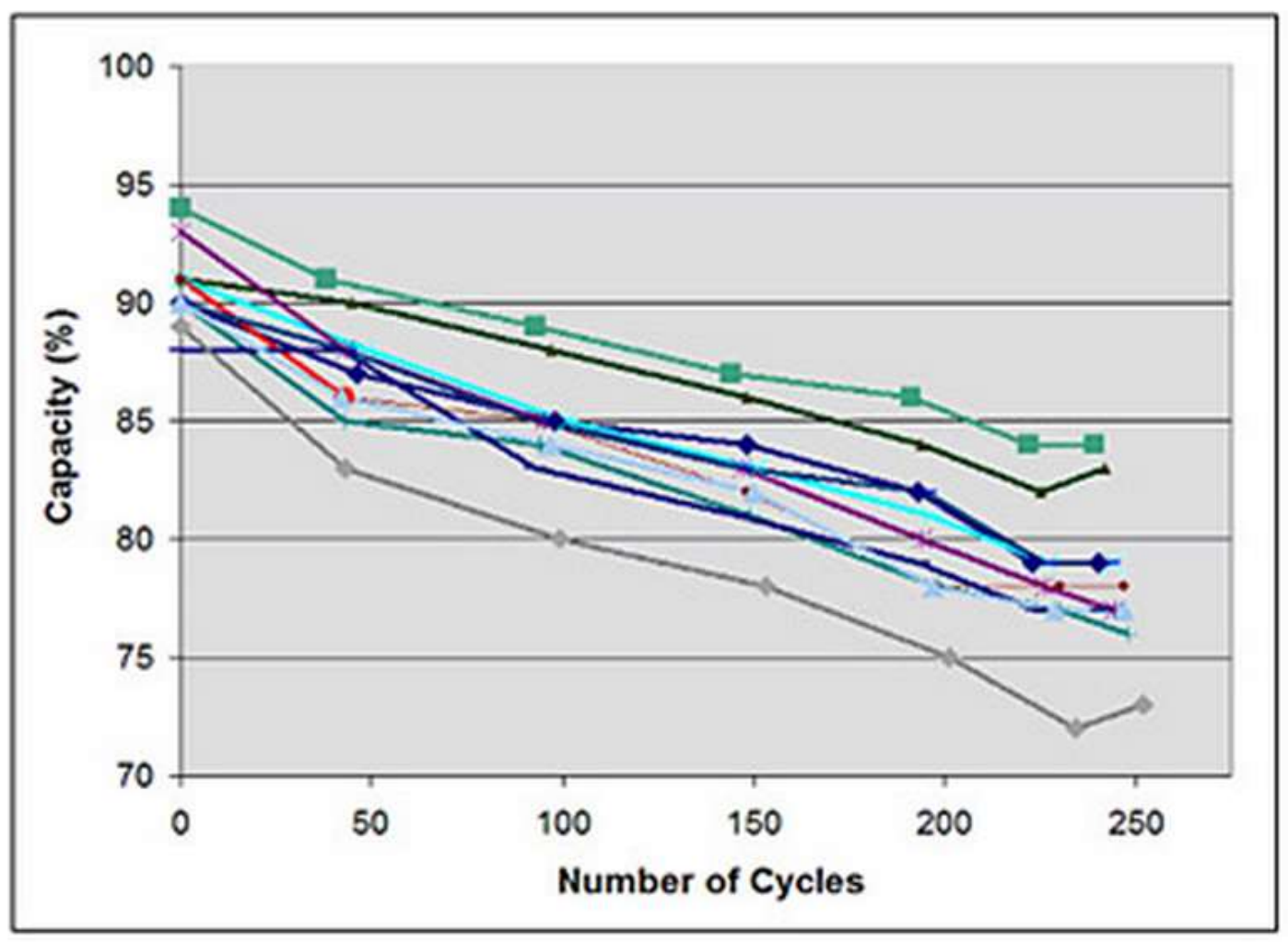

Figure 65: Capacity of 11 Li-polymer batteries during cycling courtesy of Cadex [1]

\subsubsection{Age}

Figure 66 shows that as batteries age, their capacity reduces [2].

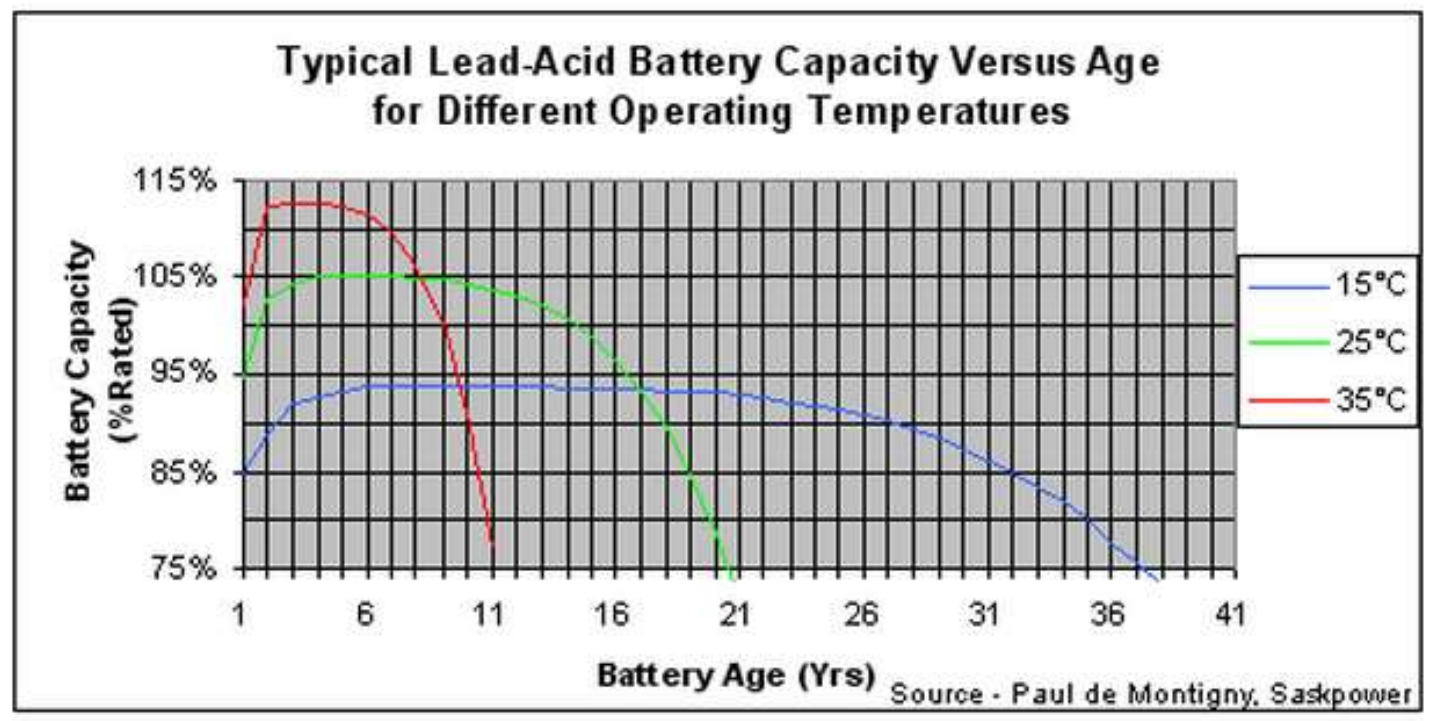

Figure 66: Capacity of lead acid Battery over time [2] 
Batteries also self-discharge over time and the amount of discharge depends on the battery type and chemistry as shown in Table XXV [1].

Table XXVI: Self-discharge over time for different battery types courtesy of Cadex [1]

\begin{tabular}{|l|l|}
\hline Battery System & Estimated Self-discharge \\
\hline Primary lithium-metal & $10 \%$ in 5 years \\
\hline Alkaline & $2-3 \%$ per year $(7-10$ years shelf life) \\
\hline Lead-acid & $5 \%$ per month \\
\hline Nickel-based & $10-15 \%$ in $24 \mathrm{~h}$, then $10-15 \%$ per month \\
\hline Lithium-ion & $5 \%$ in $24 \mathrm{~h}$, then $1-2 \%$ per month (plus $3 \%$ for safety circuit) \\
\hline
\end{tabular}

\subsection{Steps to Prolong Battery Lifetime}

\subsubsection{Li-Ion}

- Do not discharge Li-Ion too low, charge more often.

- A random or partial charge is fine. Li-Ion does not need a full charge.

- Limit the time the battery resides at $4.20 \mathrm{~V} /$ cell (full charge), especially if warm.

- Miderate the charge current to between $0.5 \mathrm{C}$ and $0.8 \mathrm{C}$ for Cobalt-based LithiumIon. Avoid ultra-fast charging and discharging.

- If the charger allows, lower the charge voltage to prolong battery life.

- Keep the battery cool. Move it away from heat-generating environments. Avoid hot cars and windowsills.

- High heat and full state-of-charge, not cycling, cause short battery life in laptops.

- Remove battery from laptop when used on the power grid. 


\section{APPENDIX C: MICROCONTROLLER DESIGN MATRIX}

\subsection{Design Iteration \#1 - MSP430FR5969 [20-22]}

The MSP430FR5969 used in the BMS was the original MCU chosen for the battery charger as well. This MCU is one of the less expensive MCUs and it comes with a handy Sharp LCD BoosterPack for display and user interaction. Table XXVI shows the specifications, which permits comparison with specifications with C2000 LAUNCHXL-F28069M.

Table XXVII: MSP430FR5969 specifications [20]

\begin{tabular}{|c|c|}
\hline & MSP43OFR5969 \\
\hline Frequency $(M 1-1 z)$ & 16 \\
\hline Flash (KB) & D \\
\hline FRAM (KB) & 64 \\
\hline SRAM (kB) & 2 \\
\hline GPIO & 40 \\
\hline $12 c$ & 1 \\
\hline SPI & 3 \\
\hline UART & 2 \\
\hline DMA & 3 \\
\hline$A D C$ & $A D C 12-16 c h$ \\
\hline Comparators & $1 E$ \\
\hline Timers-16-bit & 5 \\
\hline Timers-32-bit & o \\
\hline Multiplier & $32 \times 32$ \\
\hline AES & AES256 \\
\hline BSL & UART \\
\hline Min vec & 1.8 \\
\hline Max vec & 3.6 \\
\hline Active power (UA/MHz) & 101.25 \\
\hline Standby Power (LPM3-UA) & 0.5 \\
\hline Wakeup Time (us) & 7 \\
\hline Additional Features & $\begin{array}{l}\text { Real-Time Clock } \\
\text { Watchdog } \\
\text { Brown Out Reset } \\
\text { IrDA }\end{array}$ \\
\hline
\end{tabular}

\subsubsection{ADC Specifications}

The ADC reference selected is $2.5 \mathrm{~V}$ so the maximum analog input voltage for the MCU is $2.7 \mathrm{~V}$ as shown in the tables below from the MSP430FR5969 Datasheet [20]. 
Table XXVIII: ADC specifications for MSP430FR5969 [20]

\section{2-Bit ADC}

over recommended ranges of supply voltage and operating free-air temperature (unless otherwise noted)

\begin{tabular}{|c|c|c|c|c|c|c|}
\hline \multicolumn{2}{|r|}{ PARAMETER } & TEST CONDITIONS & MIN & NOM & MAX & UNIT \\
\hline$V_{(A x)}$ & Analog input voltage range ${ }^{(1)}$ & All ADC12 analog input pins $A x$ & 0 & & AVCC & V \\
\hline & Resolution & & & 12 & & bits \\
\hline & Data rate & & & & 200 & ksps \\
\hline$f_{A D C 120 S C}$ & Internal oscillator (2) & $\begin{array}{l}A D C 12 D \mid V=0, \\
f_{A D C 12 C L K}=f_{A D C 120 S C} \text { from MODOSC }\end{array}$ & 4.0 & 4.8 & 5.4 & $\mathrm{MHz}$ \\
\hline t'CONVERT & Conversion time & $\begin{array}{l}\text { REFON }=0 \text {, Internal oscillator, } \\
f_{A D C 12 C L K}=f_{A D C 120 S C} \text { from MODOSC }\end{array}$ & 2.6 & & 3.5 & US \\
\hline
\end{tabular}

(1) The analog input voltage range must be within the selected reference voltage range $V_{R_{+}}$to $V_{R}$. for valid conversion results.

(2) The ADC120SC is sourced directly from MODOSC inside the UCS.

\subsection{Design Iteration \#2 - C2000 LAUNCHXL-F28069M [11-14]}

\subsubsection{ADC Specifications}

Table XXIX: Specifications for C2000 LAUNCHXL-F28069M [14]

\begin{tabular}{|c|c|c|c|c|c|c|c|}
\hline \multicolumn{4}{|c|}{ PARAMETER } & MIN & TYP & MAX & UNIT \\
\hline \multicolumn{8}{|c|}{ DC SPECIFICATIONS } \\
\hline \multicolumn{3}{|l|}{ Resolution } & & 12 & & & Bits \\
\hline \multicolumn{3}{|l|}{ ADC clock } & 90-MHz device & 0.001 & & 45 & $\mathrm{MHz}$ \\
\hline \multicolumn{3}{|l|}{ Sample Window } & & 7 & & 64 & $\begin{array}{c}\text { ADC } \\
\text { Clocks }\end{array}$ \\
\hline \multicolumn{8}{|l|}{ ANALOG INPUT } \\
\hline \multicolumn{3}{|c|}{ Analog input voltage with intemal reference } & & 0 & & 3.3 & V \\
\hline \multirow{2}{*}{\multicolumn{2}{|c|}{ ADC clock }} & \multicolumn{2}{|c|}{ 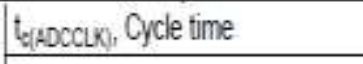 } & \multicolumn{2}{|c|}{22.22} & & ns \\
\hline & & \multicolumn{2}{|c|}{ Frequency } & & & 45 & $5 . \mathrm{MHz}$ \\
\hline MSPS & 3.46 & & & & & & \\
\hline Conversion Tme & $289 \mathrm{~ns}$ & & & & & & \\
\hline
\end{tabular}

The minimum ADC total operating time is $488.98 \mathrm{~ns}$ and results from a minimum sample window of 7 clock cycles + the conversion time +2 additional clock cycles for the ADC result to change. 


\subsection{Comparing MCUs}

The MCU samples battery current and voltage using ADCs and then outputs a voltage that feeds into the feedback node of the LM5117 Buck Controller using a PWM and RC filter. The design originally used the MSP430FR5969 because of low cost but was changed to C2000 LaunchXL-F28069M because of higher operating frequency and more available ADCs. The design matrix shown in Table XXIX, compares the MCUs using a rank between one, a low rating, and three, a high rating. The design matrix uses a weighted percentage so the total score for the worst possible reference equals one and the best possible reference equals three.

Table XXX: MCU design matrix comparison

\begin{tabular}{|c|c|c|c|c|c|}
\hline Specification & $\begin{array}{c}\text { MSP430FR5969 } \\
\text { LaunchPad }\end{array}$ & $\begin{array}{c}\text { C2000 LaunchXL- } \\
\text { F28069M }\end{array}$ & \multicolumn{2}{|c|}{ Rank (1-3) } & $\begin{array}{c}\text { Weight } \\
\text { \% }\end{array}$ \\
\hline $\begin{array}{c}\text { Operating } \\
\text { frequency }\end{array}$ & $16 \mathrm{MHz}$ & $90 \mathrm{MHz}$ & 1 & 3 & 30 \\
\hline ADC & 2 channel, $12-$ bit & 7 channel, 12-bit & 1 & 2 & 5 \\
\hline fADC & $5.4 \mathrm{MHz}$ & $45 \mathrm{MHz}$ & 1 & 3 & 10 \\
\hline tconv & $3 \mu \mathrm{s}(14$ cycles $)$ & $488.98 \mathrm{~ns}(22$ cycles) & 1 & 3 & 10 \\
\hline Data rate & $\approx 200 \mathrm{KSPS}$ & $\approx 3.46 \mathrm{MSPS}$ & 1 & 3 & 10 \\
\hline PWM/HRPWM & $16 \mathrm{MHz}, 0$ to $3.3 \mathrm{~V}$ & $90 \mathrm{MHz}, 0$ to $3.3 \mathrm{~V}$ & 1 & 3 & 30 \\
\hline Cost & $\$ 15.99$ & $\$ 24.99$ & 2 & 1 & 5 \\
\hline Total Score & $\mathbf{1 . 0 5}$ & $\mathbf{2 . 8 5}$ & & & \\
\hline
\end{tabular}

The C2000 LaunchXL-F28069M clearly outperforms the MSP430FR5969, which direct results from improved performance in ADC sampling, higher operating frequency for processing, and PWM output. 


\section{APPENDIX D: DESIGN ITERATIONS}

This Appendix describes the various design iterations to show the initial thinking for the battery charger system. The various options considered include the MCU, as previously mentioned in Appendix C, the output voltage divider, the current sense circuitry, and the feedback compensation network. Through research and learning more about each of the subsystems, the final design modifies the initial design decisions to create the system described in Chapter 3.

\subsection{Hardware}

This section describes the various hardware design iterations.

\subsubsection{Design Iteration \#1}

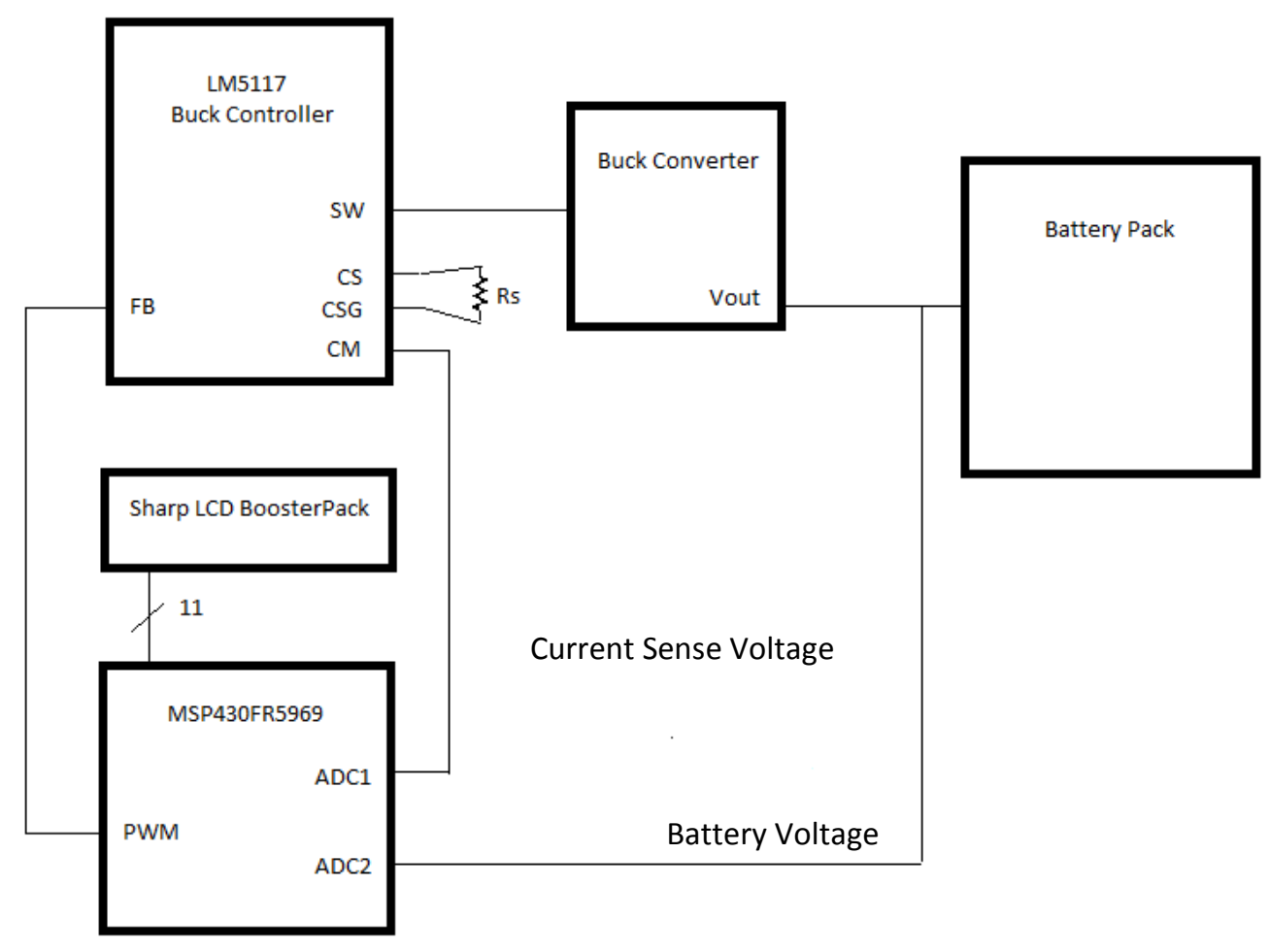

Figure 67: Battery charger block diagram iteration \#1 
Figure 67 shows the original battery charger block diagram. The original design uses the MSP430FR5969 MCU interfaced with the Sharp LCD BoosterPack. The final design uses the C2000 LaunchXL-F28069M because of increased performance resulting from higher operating frequency, higher resolution PWM, and more available ADCs for battery monitoring. Appendix $\mathrm{C}$ provides more detail on the MCU comparison. The original design also uses the internal current sense monitor provided by the LM5117. The final design uses the INA169 external current shunt monitor for sensing battery current because the external current shunt allows operation while the LM5117 runs in discontinuous conduction mode, which serves as a limitation for the internal current monitor in the LM5117. The INA169 external current shunt monitor also allows changing the gain by modifying the external gain resistor, which provides more design flexibility.

\subsubsection{Measuring Battery Voltage}

\subsubsection{Design Iteration \#1}

The battery pack voltage comes directly from the output node, which connects to the positive terminal of the battery pack. The battery pack voltage divides down using a voltage divider, shown in Figure 68, to allow a 0 to $27 \mathrm{~V}$ battery pack voltage to represent 0 to $2.7 \mathrm{~V}$ for ADC monitoring.

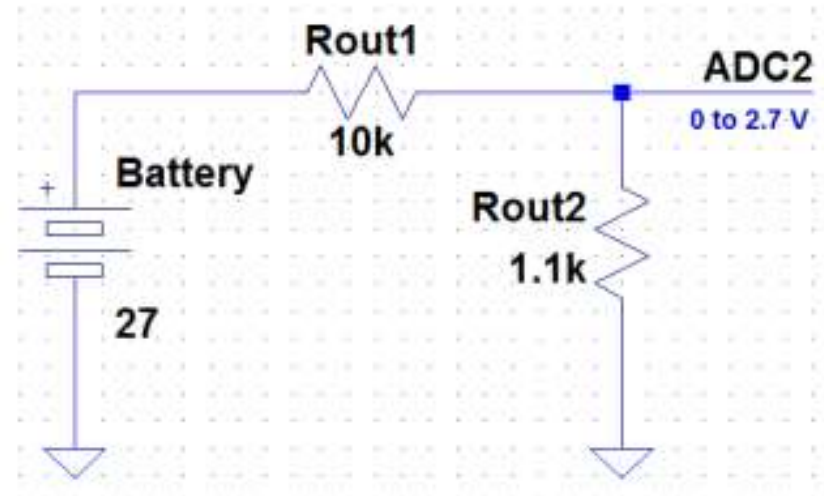

Figure 68: Output voltage divider for ADC monitoring of battery pack voltage 
This voltage divider is intended for the MSP430FR5969 MCU, since the ADC voltage ranges from $0 \mathrm{~V}$ to $2.7 \mathrm{~V}$. For the $\mathrm{C} 2000$ LaunchXL-F28069M MCU, the ADC voltage range is $0 \mathrm{~V}$ to $3.3 \mathrm{~V}$, so the final design requires a different voltage divider.

\subsubsection{Current Sense}

\subsubsection{Design Iteration \#1}

By measuring the voltage drop across the sense resistor, Rs, a current sense amplifier internal in the LM5117 senses the current flowing through QL, which is equivalent to the current through the inductor and the output charge current. The output of the current sense amplifier goes to a conditioner before going to a current monitor amplifier internal in the LM5117 before outputting on the current monitor pin labeled CM. See Figure 69 below to see the current sensing circuitry used to measure the battery current.

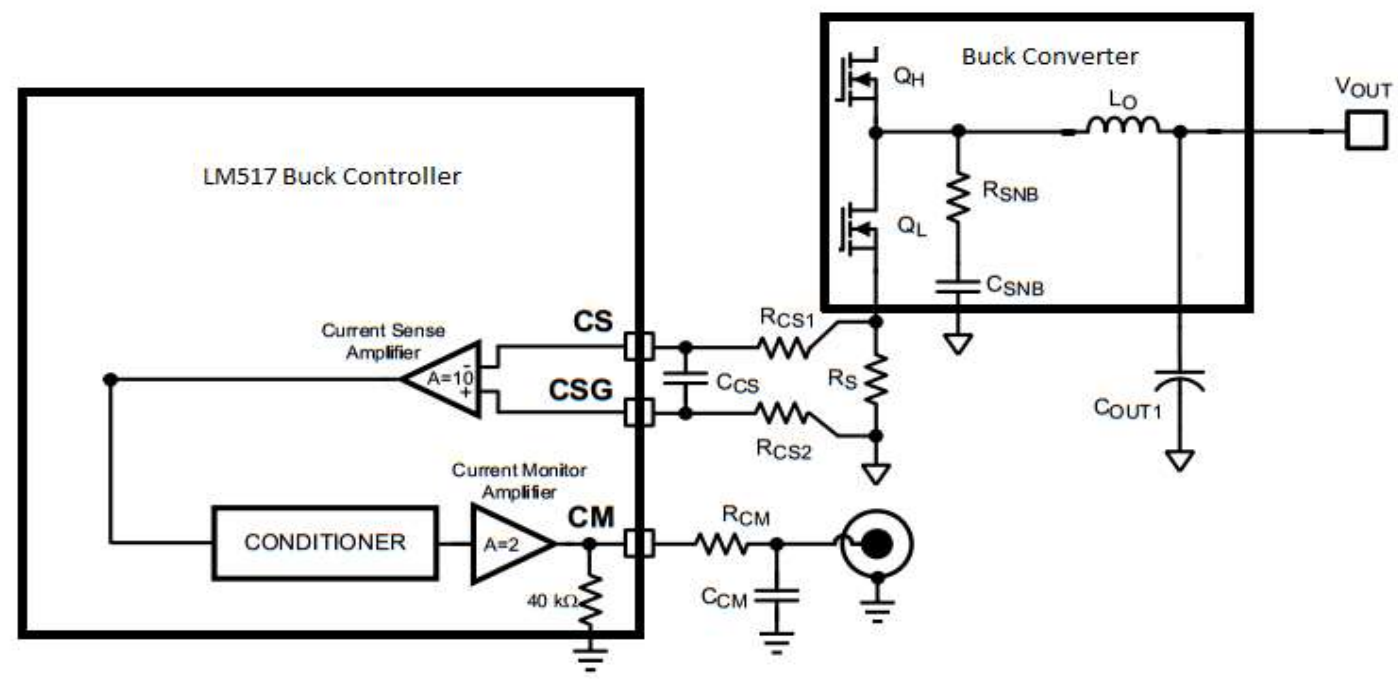

Figure 69: Current sense circuitry for battery current monitoring

The output of the CM pin is a voltage proportional to average inductor current of the Buck converter, which represents the output current. This analog voltage then goes to an ADC on the MCU, which allows reading the voltage value, converting to current, and then changing the system accordingly. 
This design changes in the final system because an external INA169 current shunt monitor allows accurate current measurements even if the converter operates in discontinuous conduction mode. In addition to accuracy, gain modification with an external resistor provides another advantage.

\subsubsection{Feedback Compensation}

\subsubsection{Design Iteration \#1}

The original design used the feedback compensation network shown in Figure 24 with Rcomp $=10 \mathrm{k} \Omega$, Ccomp $=0.1 \mu \mathrm{F}$, and CHF $=22 \mathrm{pF}$. The final design uses the feedback compensation network shown in Figure 34 to reduce the DC gain of the original design. Removing Ccomp allows the external resistor network to set the DC gain, rather than the gain of the internal error amplifier of the LM5117 Buck Controller. This gives the PWM control of the output of the LM5117 Buck Controller by outputting a PWM signal that accesses the linear region of the internal error amplifier when lowpass $\mathrm{RC}$ filtered. The next section discusses the troubleshooting steps that resulted in the various design iterations. 


\section{APPENDIX E: TROUBLESHOOTING}

\subsection{Discharge}

The first step in testing the battery charger requires discharging a battery to prepare it for charging. Figure 70 shows the discharge of a Panasonic Li-Ion 18650 from its nominal voltage of $3.6 \mathrm{~V}$ to its cutoff voltage of $2.5 \mathrm{~V}$.

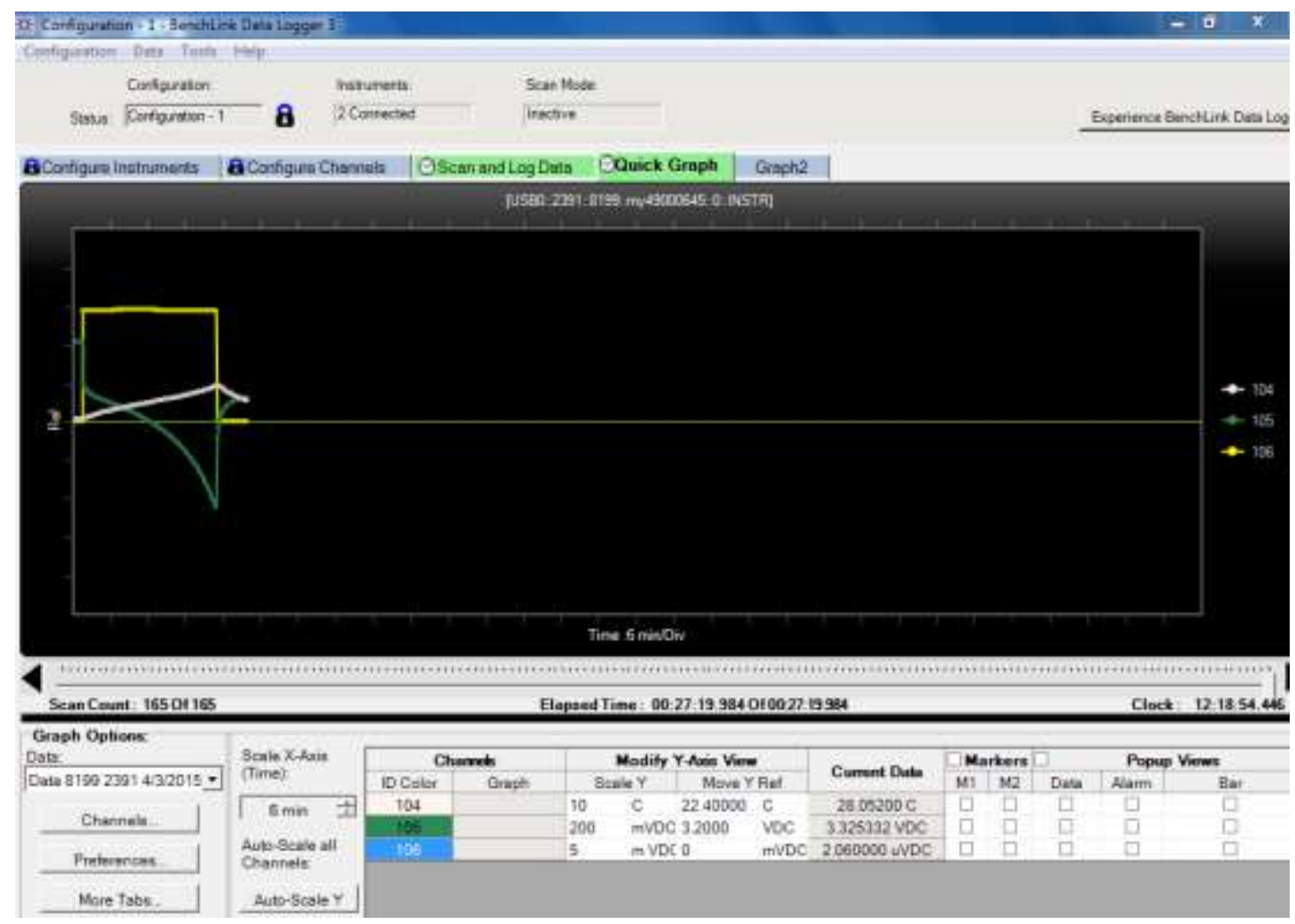

Figure 70: Panasonic Li-Ion 18650 discharge

\subsection{ADC Testing}

This section tests the ADC of the MCU to see if a known voltage produces the expected digital value that so the MCU can properly control the behavior of the charger. The first input voltage tested is $0 \mathrm{~V}$ (GND) shown in Figure 71. 


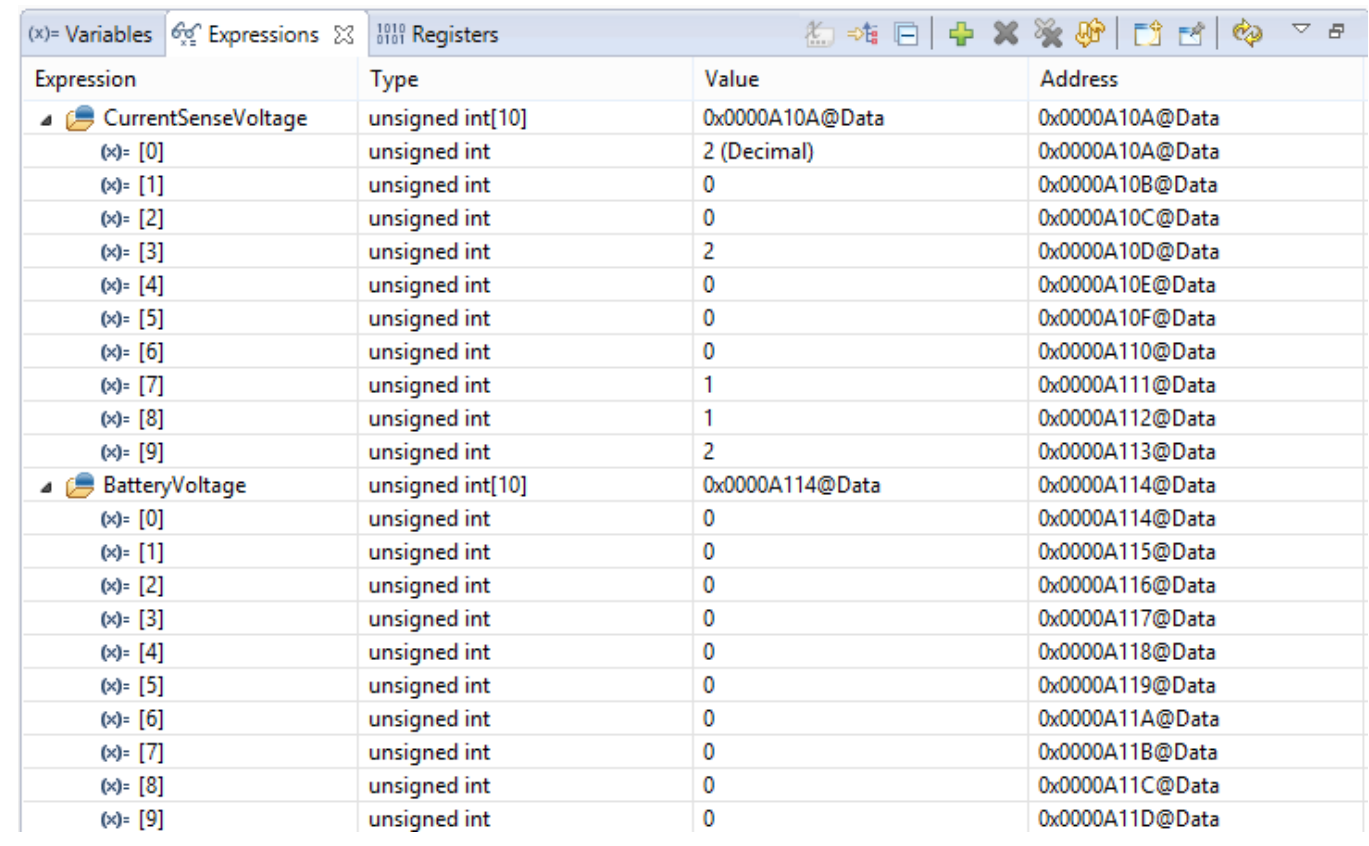

Figure 71: ADC test readings for $\mathrm{OV}$

The ADCINA2 channel used to measure current sense voltage reads 0 for ten consecutive readings when $0 \mathrm{~V}$ is applied. The ADCINA4 channel used to measure battery voltage reads nonzero for half of the readings with a maximum deviation of 2 . Next, a $3.3 \mathrm{~V}$, which corresponds to the max digital value of 4096, is applied to each ADC channel as shown in Figure 72.

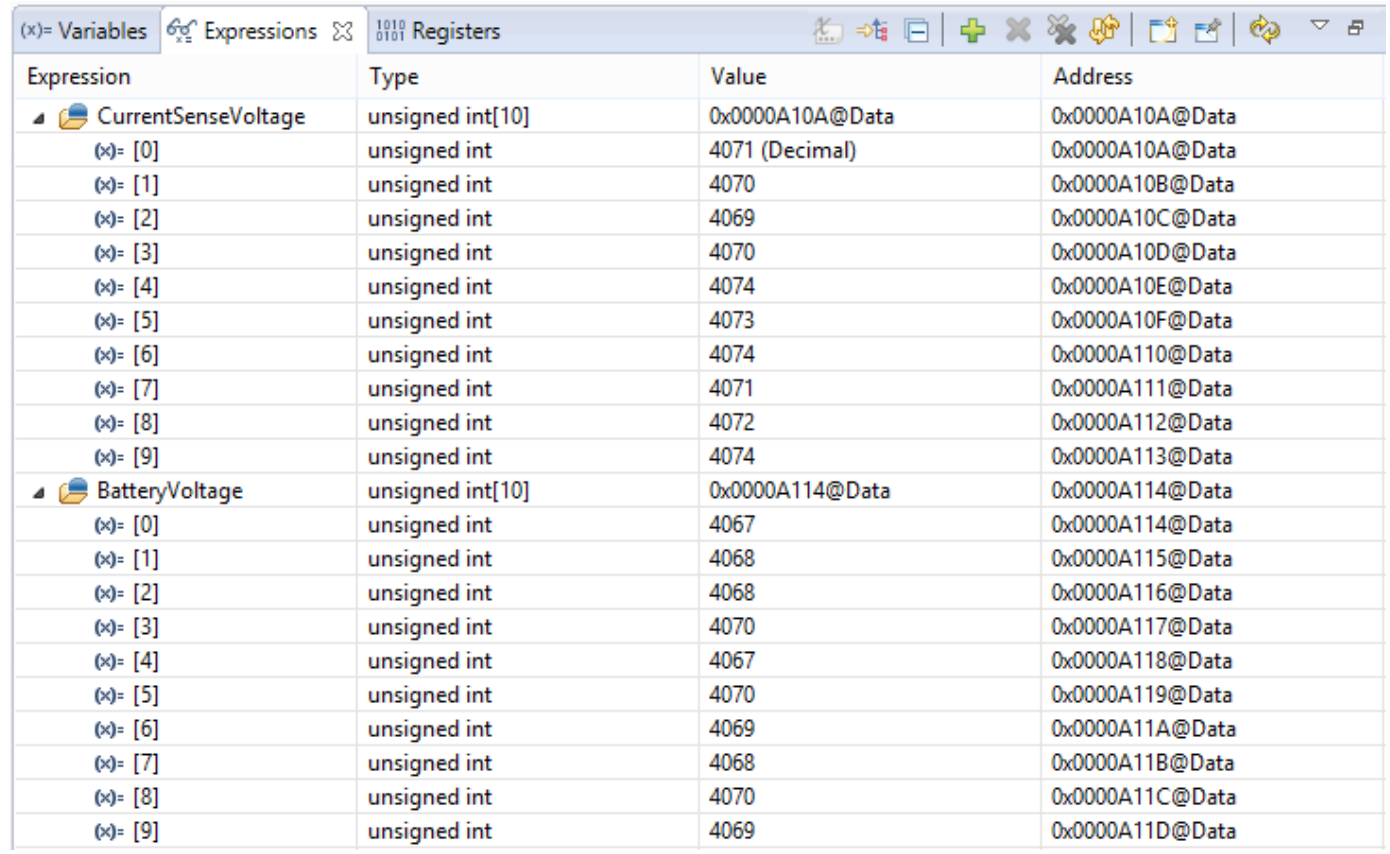

Figure 72: ADC test readings for 3.3V 
In this case, both channels differ from the expected digital value of 4096 in every ADC reading with the readings ranging from 4069 to 4074 for the battery voltage channel and 4067 to 4070 for the current sense voltage channel. These lower than expected values require calibration in software as described in Appendix F.

\subsection{PWM Testing}

This section tests the PWM functionality. The charger relies on using a PWM with varying duty cycle to feed into the feedback node of the LM5117 Buck controller in order to control the buck duty cycle to properly charge the battery. Figure 73 shows the PWM range works correctly from $0 \%$ duty cycle to very narrow $1 \%$ to very wide $99 \%$ to $100 \%$ duty cycle and anything in between. The PWM is set for $200 \mathrm{kHz}$ to match the switching frequency of the LM5117. The MCU has a system clock frequency of $90 \mathrm{MHz}$, which allows the PWM set value to be between and 450 providing a $0.22 \%$ step size.

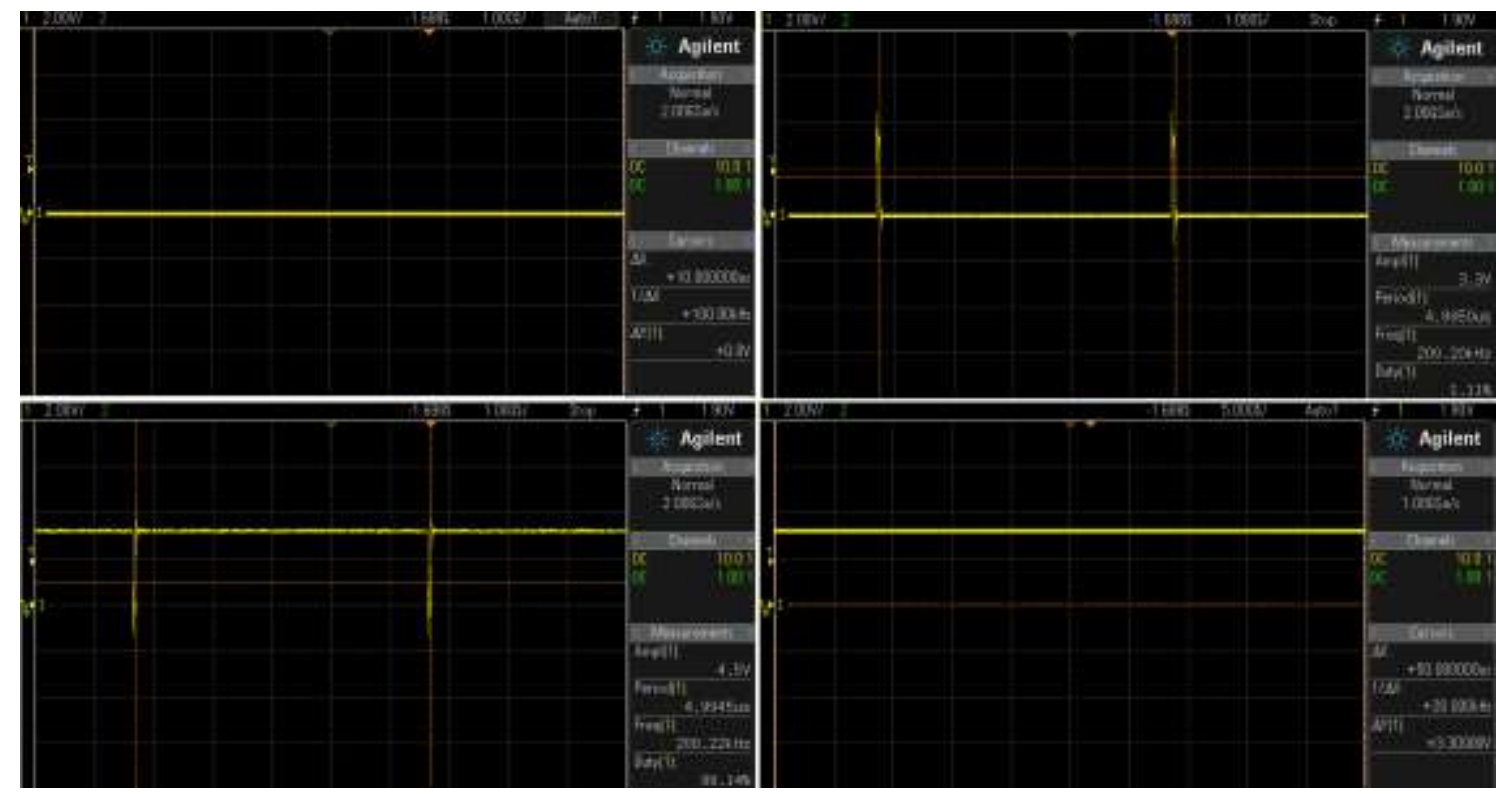

Figure 73: Example of PWM range from $0 \%$ to $1 \%$ to $99 \%$ to $100 \%$ duty cycle 


\subsection{Battery Charger System Testing}

This section tests the complete system.

\subsubsection{Charge Attempt \#1}

\subsubsection{Date: $4 / 9 / 15$}

\subsubsection{Procedure}

\section{Connect MCU to LM5117}

2. Connect battery into holder and close the circuit

3. Connect ground of battery current shunt to GND of LM5117

4. Connect positive of battery to V- of output current sense circuit

5. Plug in $\mathrm{MCU}$

6. Power up LM5117 by plugging power adapter into wall outlet

7. Download charger program

8. Start charger program

\subsubsection{Test Configuration}

Refer to Figure 36 for a block diagram that shows the test configuration. The battery connects in series with a current shunt of $5 \mathrm{~m} \Omega$ that measures $50 \mathrm{mV}$ for a $10 \mathrm{~A}$ current, which means a measurement of $5 \mathrm{mV}$ corresponds to a $1 \mathrm{~A}$ current. The current shunt measures the battery voltage across the positive and negative terminal of the battery. There is also a thermocouple temperature probe taped to the surface of the battery. An Agilent 34972A LXI Data Acquisition/Switch unit records each measurement every five seconds. The Y Reference is $22.4{ }^{\circ} \mathrm{C}$ for temperature (white trace \#104), 3.6VDC for battery voltage (green trace \#105), and OmVDC for current sense voltage (yellow trace \#106). The Y scale is $10^{\circ} \mathrm{C}$ for temperature, 200mVDC for battery voltage, and 0.5mVDC for current sense voltage. 


\subsubsection{Results}

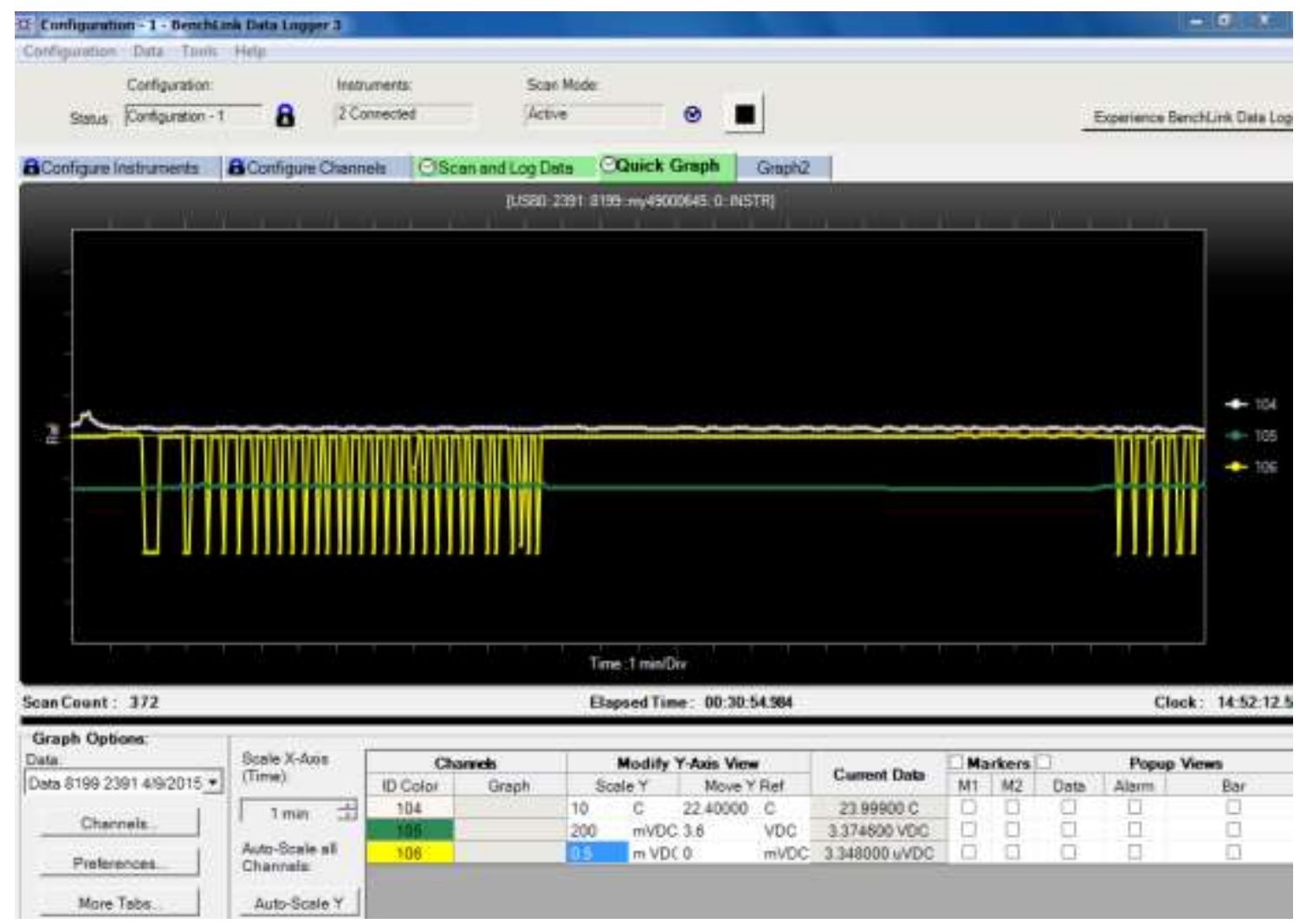

Figure 74: Charge attempt \#1

\subsubsection{Summary}

The battery charger switched between charging at 300mA and not charging (back to zero current) then charging again in an oscillatory manner. When the LM5117 was disconnected, the battery no longer charged, as shown in Figure 74 with the long period of zero current. During operation, the charger goes into FAULT mode, which means the charge current or battery voltage exceeds the software setting. When the FAULT mode is bypassed, the charger goes into CONSTANT_CURRENT mode, which sets a constant PWM setting for a constant current. Even when the PWM value is changed, the charger behavior remains unchanged, which suggests the PWM setting range is not properly driving the feedback node of the LM5117.

\subsubsection{Things to Check Before Next Charge}

- Feedback node voltage divider 


\subsubsection{Charge Attempt \#2}

\subsubsection{Date: $4 / 12 / 15$}

\subsubsection{Procedure}

\section{Connect MCU to LM5117}

2. Connect battery into holder and close the circuit

3. Connect ground of battery current shunt to GND of LM5117

4. Connect positive of battery to V- of output current sense circuit

5. Plug in $\mathrm{MCU}$

6. Power up LM5117 by plugging power adapter into wall outlet

7. Download charger program

8. Start charger program

\subsubsection{Test Configuration}

The test configuration is the same configuration as charge attempt \#1 except a change to the voltage divider. The voltage divider was previously set to $32 \mathrm{k} \Omega$ for the top resistor and $1 \mathrm{k} \Omega$ for the bottom resistor. The modification changed the voltage divider feedback resistors to $10 \mathrm{k} \Omega$ and $4.9 \mathrm{k} \Omega$ since the previous values were set for a $27 \mathrm{~V}$ output test to test the LM5117 buck controller by itself. The new resistor values are for driving the feedback node with the $3.3 \mathrm{~V}$ from the PWM. 


\subsubsection{Results}

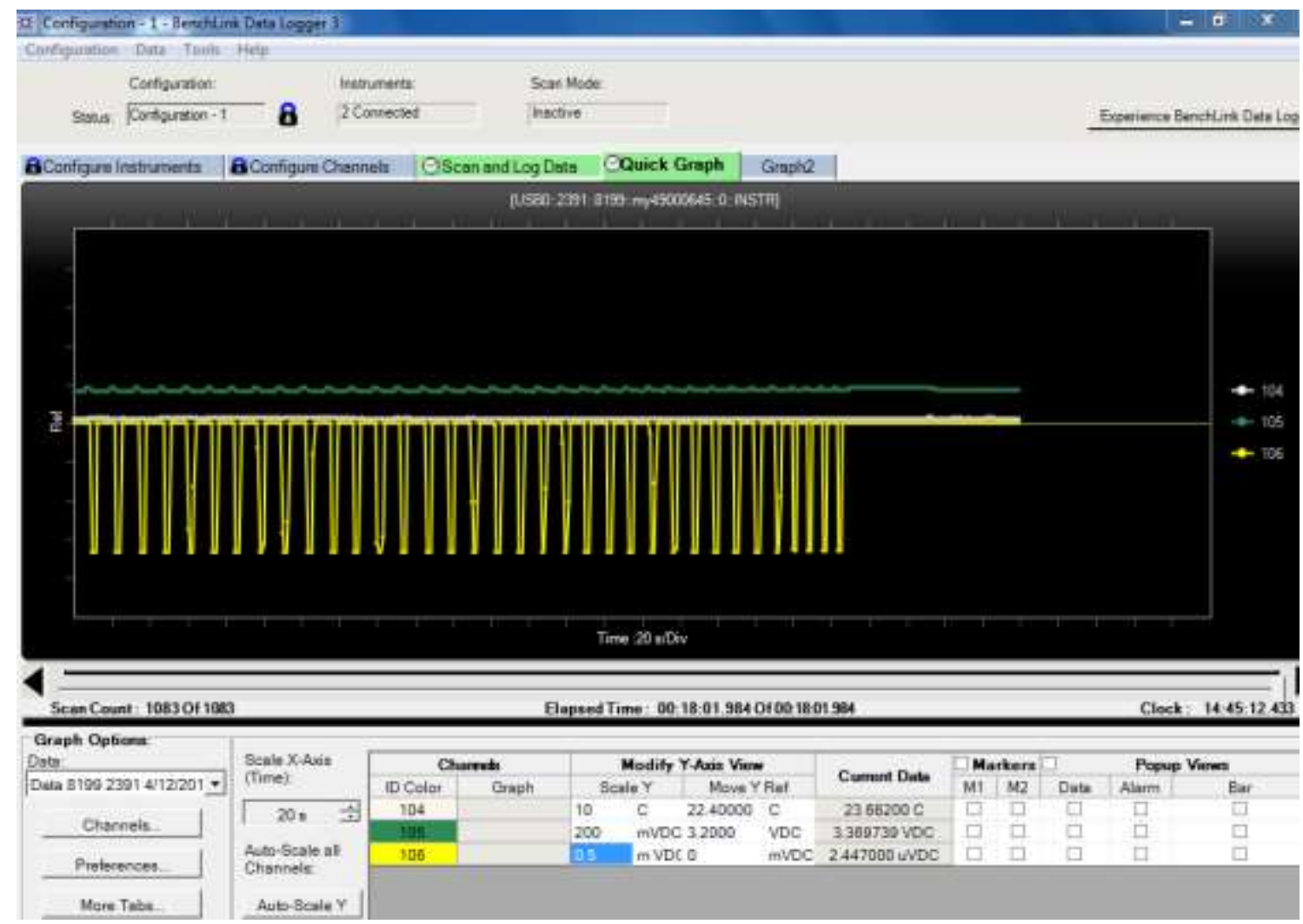

Figure 75: Charge attempt \#2

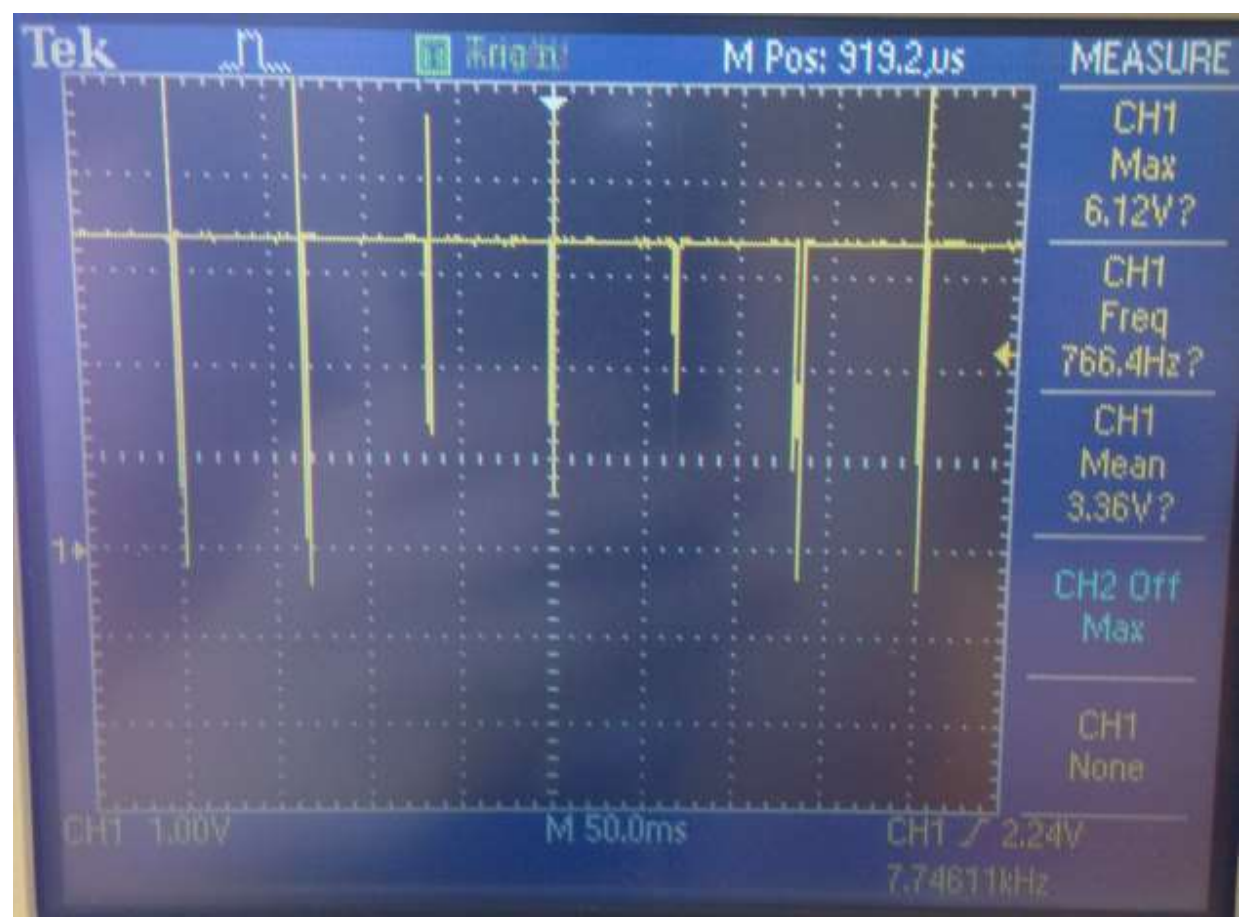

Figure 76: Switch node of LM5117 for charge \#2 


\subsubsection{Summary}

The test shows the current switching from $0 \mathrm{~A}$ to $300 \mathrm{~mA}$ at the output to the battery, which is the same result as before the voltage divider was changed. After checking the switch node of the buck converter in shown in Figure 76, it becomes clear that the buck is switching at maximum duty cycle, which suggests a low voltage being fed into the feedback node of the LM5117 since the feedback node is inverted. The switch node is also only switching to $3.3 \mathrm{~V}$, which is the voltage coming from the MCU rather than the power supply voltage of $48 \mathrm{~V}$, which suggests the LM5117 is not receiving the proper power. If the fault condition is left in software, the system goes into the fault mode, which means the output reaches an overvoltage condition, which is again evident by the LM5117 switching at max duty cycle. When the MCU is removed, the current output becomes zero which means the PWM is influencing the LM5117 switching but incorrectly.

\subsubsection{Things to Check Before Next Charge:}

- PWM signal integrity to the LM5117 feedback node

- $\quad$ Code that sets PWM

- PWM signal after the RC low-pass filter

\subsubsection{Charge Attempt \#3}

1.4.3.1 Date: $4 / 13 / 15$

\subsubsection{Procedure}

- $\quad$ Connect MCU to LM5117

- Connect battery into holder and close the circuit

- Connect ground of battery current shunt to GND of LM5117

- Connect positive of battery to V- of output current sense circuit

- Plug in MCU

- Download charger program 
- Start charger program

- Power up LM5117 by plugging power adapter into wall outlet

\subsubsection{Test Configuration}

Same configuration as charge attempt \#2 except the MCU receives power and the charger program starts before powering up the LM5117, which provides an initial PWM to the LM5117 feedback node upon receiving power. There is no digital filter implemented in software to compensate the MCU to maintain stability and the output no longer connects to the feedback node. The PWM is set directly to approximately $0.8 \mathrm{~V}$ to match the reference voltage of the feedback node. The charger now operates in open loop configuration with no feedback.

\subsubsection{Results}

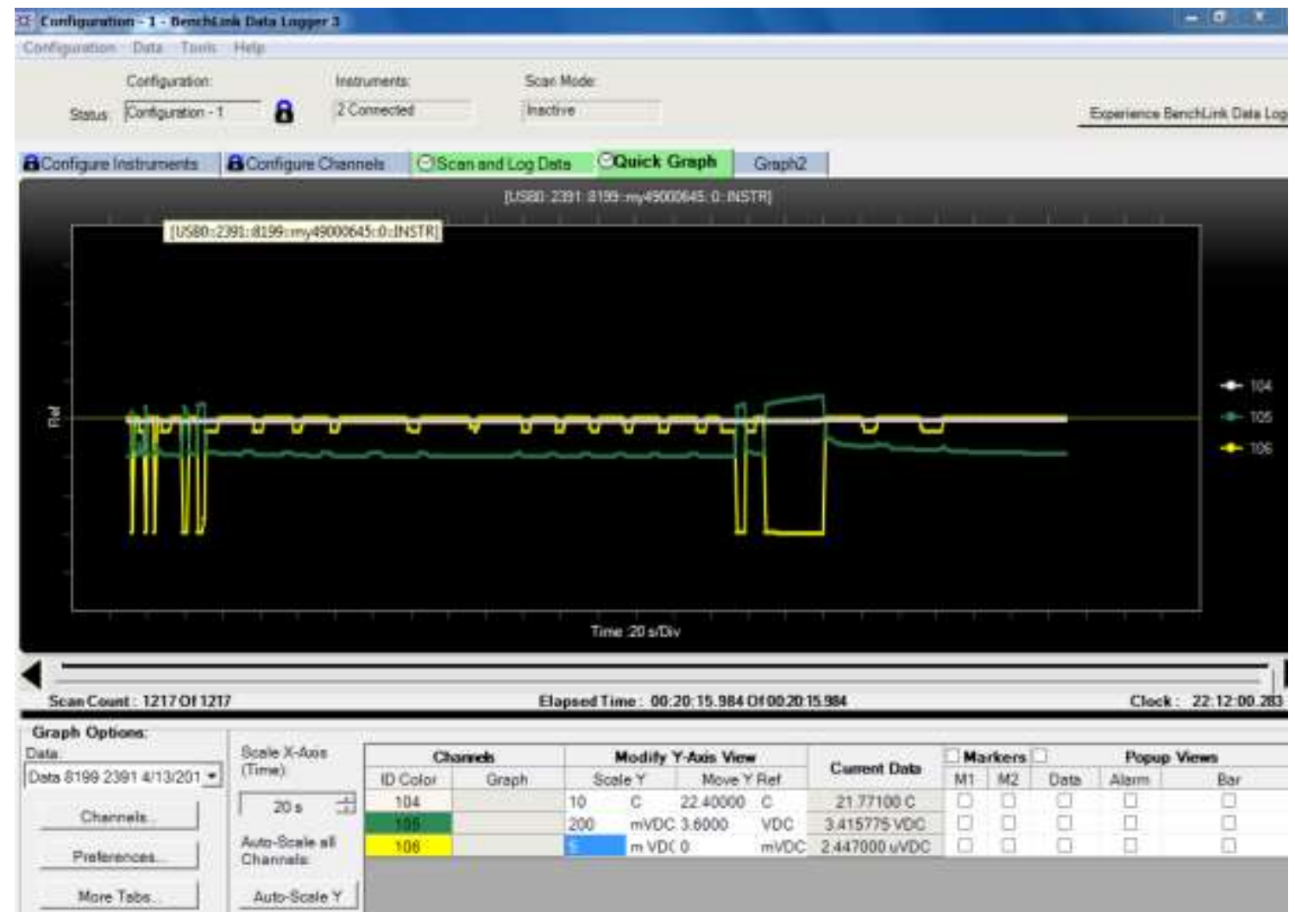

Figure 77: Charge attempt \#3 


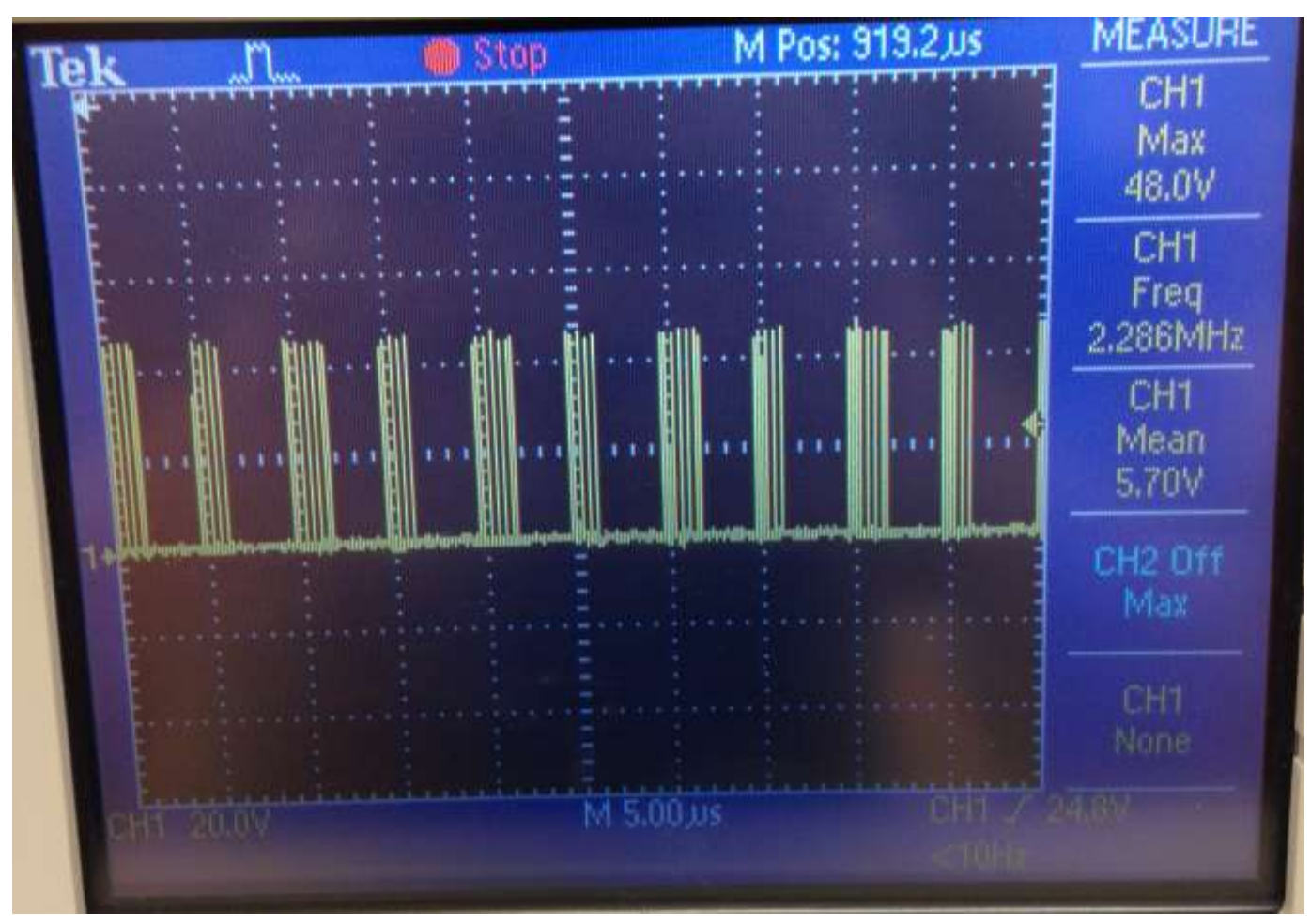

Figure 78: Switch node of LM5117 for charge attempt \#3

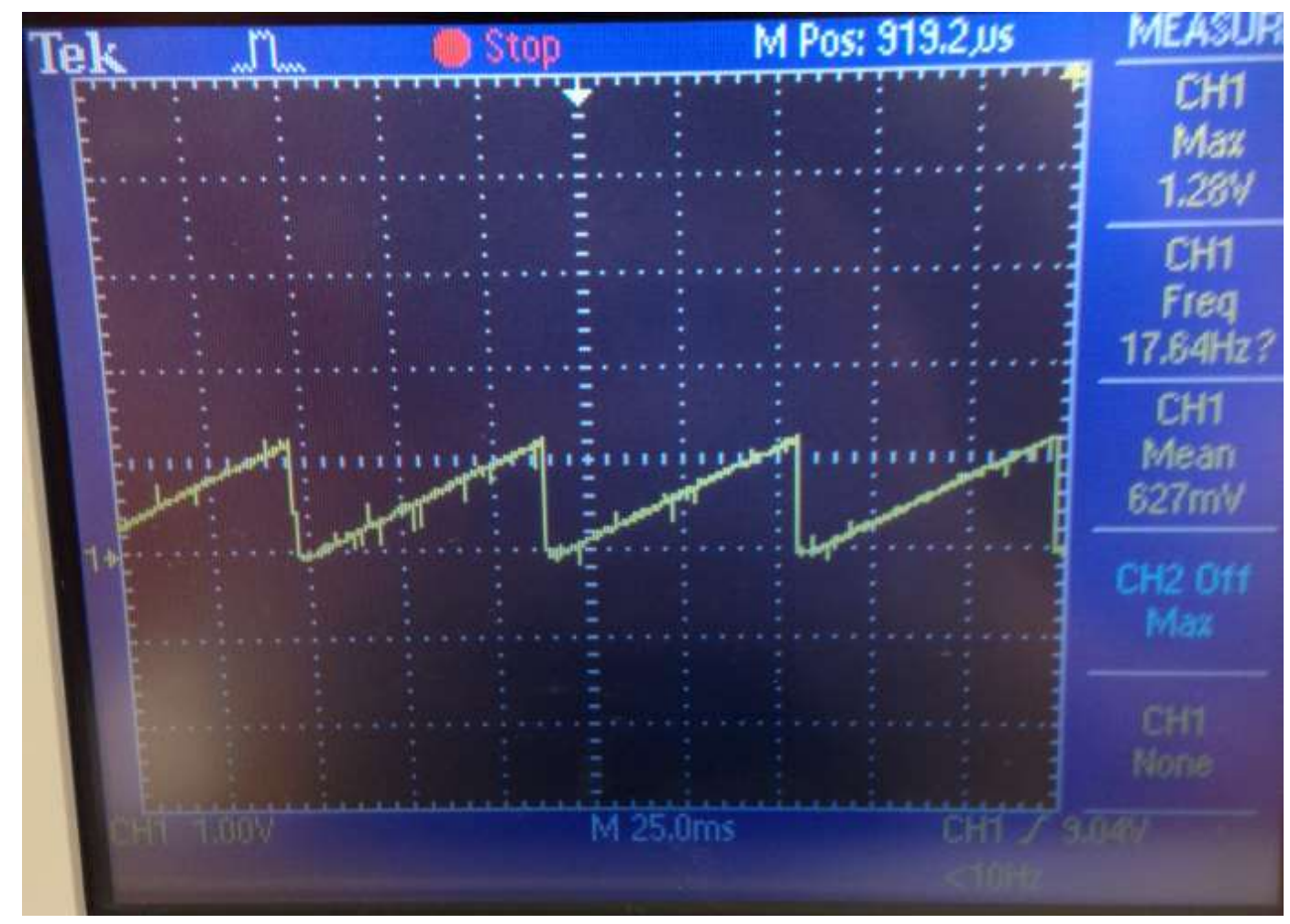

Figure 79: Reset pin on LM5117 for charge attempt \#3 


\subsubsection{Summary}

The test shows the charge current switching from $0 \mathrm{~A}$ to $3 \mathrm{~A}$ and the switch node switching from $0 \mathrm{~V}$ to $48 \mathrm{~V}$. The switch node, shown in Figure 78, would turn off for short periods suggesting the LM5117 is in current limit "hiccup" mode in which the LM5117 detects an overcurrent condition and shuts down the switching for a certain number of switch cycles before coming back on again. This was verified by checking the reset pin, shown in Figure 79, which was also triggering confirming the current limit (hiccup mode) for the LM5117. Since the PWM appears to have no control over the output current, testing needs to verify that there is actually a linear region of operation with the LM5117 that will allow PWM control of the output

\subsubsection{Things to Check Before Next Charge}

- $\quad$ Feedback compensation for LM5117

- PWM setting that causes current to remain constant in the linear region of operation

\subsection{Linear Region: Function Generator Test}

A function generator set to a $0 \mathrm{~V}$ to $3.3 \mathrm{~V}$ square wave emulates the capability of the PWM output from the MCU after the RC low-pass filter into the feedback node of the LM5117. This allows changing the duty cycle in fixed increments to replicate the PWM signal in order to find the linear region of operation for the LM5117. Figure 80 shows the switch node of the buck converter on the LM5117 when the function generator reaches $73.9 \%$ with a constant current electronic load set at 100mA on the output of the LM5117. 


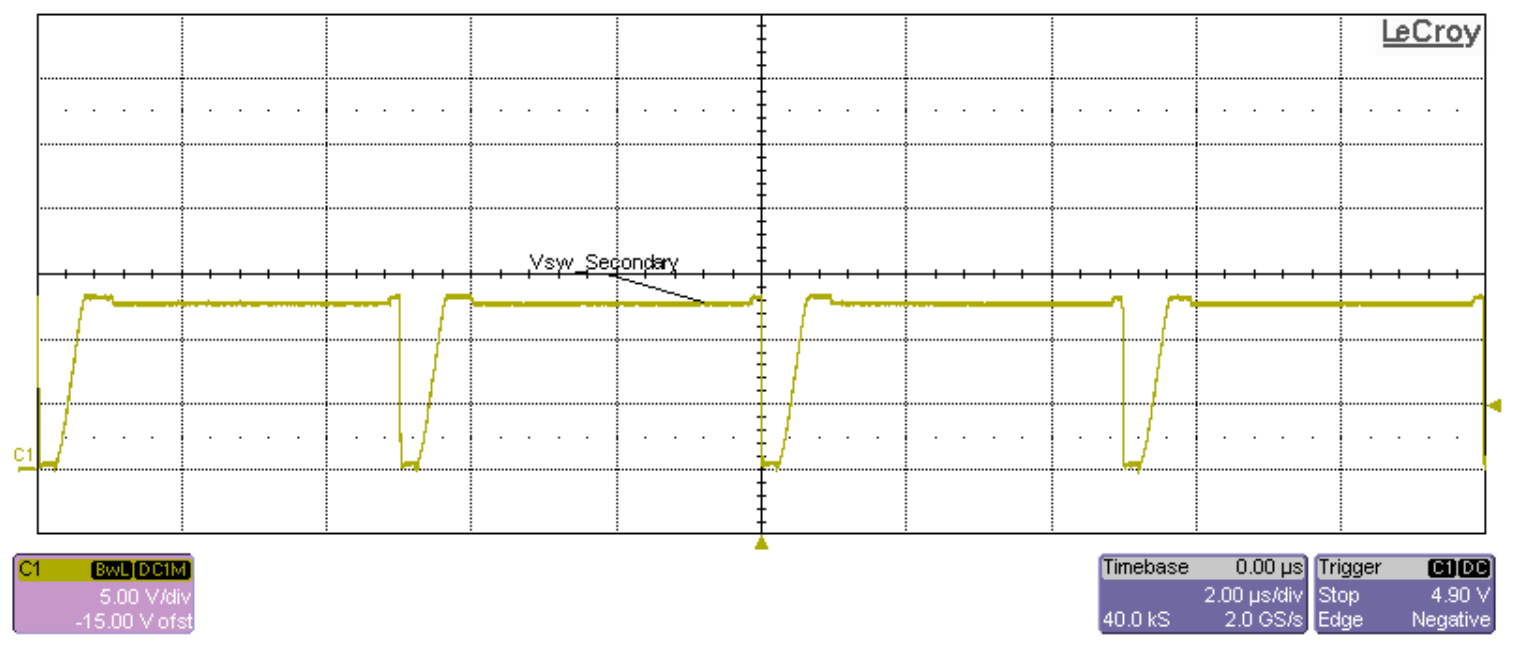

Figure 80: Switch node with function generator set to $73.9 \%$ and applied at feedback node of

\section{LM5117}

Figure 80 shows that at this function generator setting, the buck duty cycle is maximum.

Figure 81 shows the switch node of the buck converter on the LM5117 when the function generator is at $74.0 \%$ with a constant current electronic load set at $100 \mathrm{~mA}$ on the output of the LM5117.

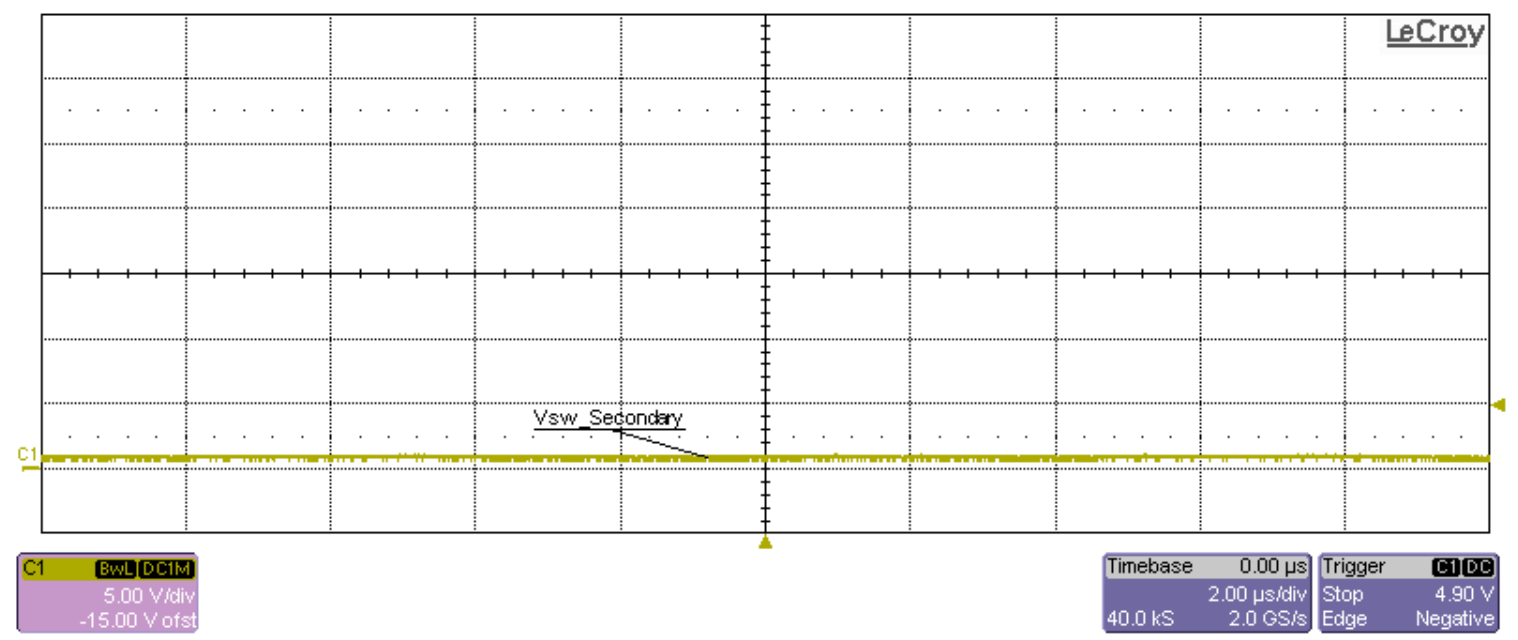

Figure 81: Switch node with function generator set to $74.0 \%$ and applied at feedback node of LM5117

Figure 81 shows that at $74 \%$, the buck duty cycle is minimum. Since the buck duty cycle is maximum at $73.9 \%$ and minimum at $74 \%$, it becomes clear that the DC gain of the feedback compensation on the LM5117 is too high because the slightest voltage variation causes the 
internal error amplifier to either rail high or rail low preventing access to the linear region. After checking the feedback configuration, it becomes clear that it is set for normal LM5117 operation with the feedback voltage feeding back into the feedback node but not set up for PWM injection operation. Figure 29 shows the original but incorrect type 2 compensation configuration that causes the DC gain to equal the internal error amplifier, which is much too high. Originally, Rcomp $=10 \mathrm{k} \Omega$, Ccomp $=0.1 \mu \mathrm{F}$, and $\mathrm{CHF}=22 \mathrm{pF}$. After modifying the feedback compensation to match Figure 34 and the simulation schematic in Figure 27, the function generator test is repeated and the linear region occurs between the function generator duty cycle of $58 \%$ and $64 \%$.

\subsection{Linear Region: PWM Test}

To find out what PWM values corresponds to what output charge current, the charger is set with the PWM at maximum duty cycle corresponding to a setting of 450 . Due to the inversion of the inverting internal error amplifier on the LM5117, maximum duty cycle on the PWM corresponds to minimum output current. The PWM decrements by one value every five seconds, and the Agilent 34972A LXI Data Acquisition/Switch Unit monitors the battery charger current every second. The test shows that at a PWM value of 285, the charge current becomes $9.91 \mathrm{~mA}$, which is the first PWM value that accesses the linear region of the LM5117. Each decrement on the PWM steps the circuit up approximately $16.12 \mathrm{~mA}$. The current continues to increase until the PWM value reaches 173, providing a max charge current of 1.81A. As the PWM value decreases from this point, the charge current decreases rapidly. When the PWM value is above 285 or below 169 , the charge current is actually negative, meaning the battery is providing approximately $500 \mu \mathrm{A}$. The PWM provides linear current control at a duty cycle between $68 \%$ and 38\%. See Figure 82 for a summary of the PWM value and corresponding charge current. 


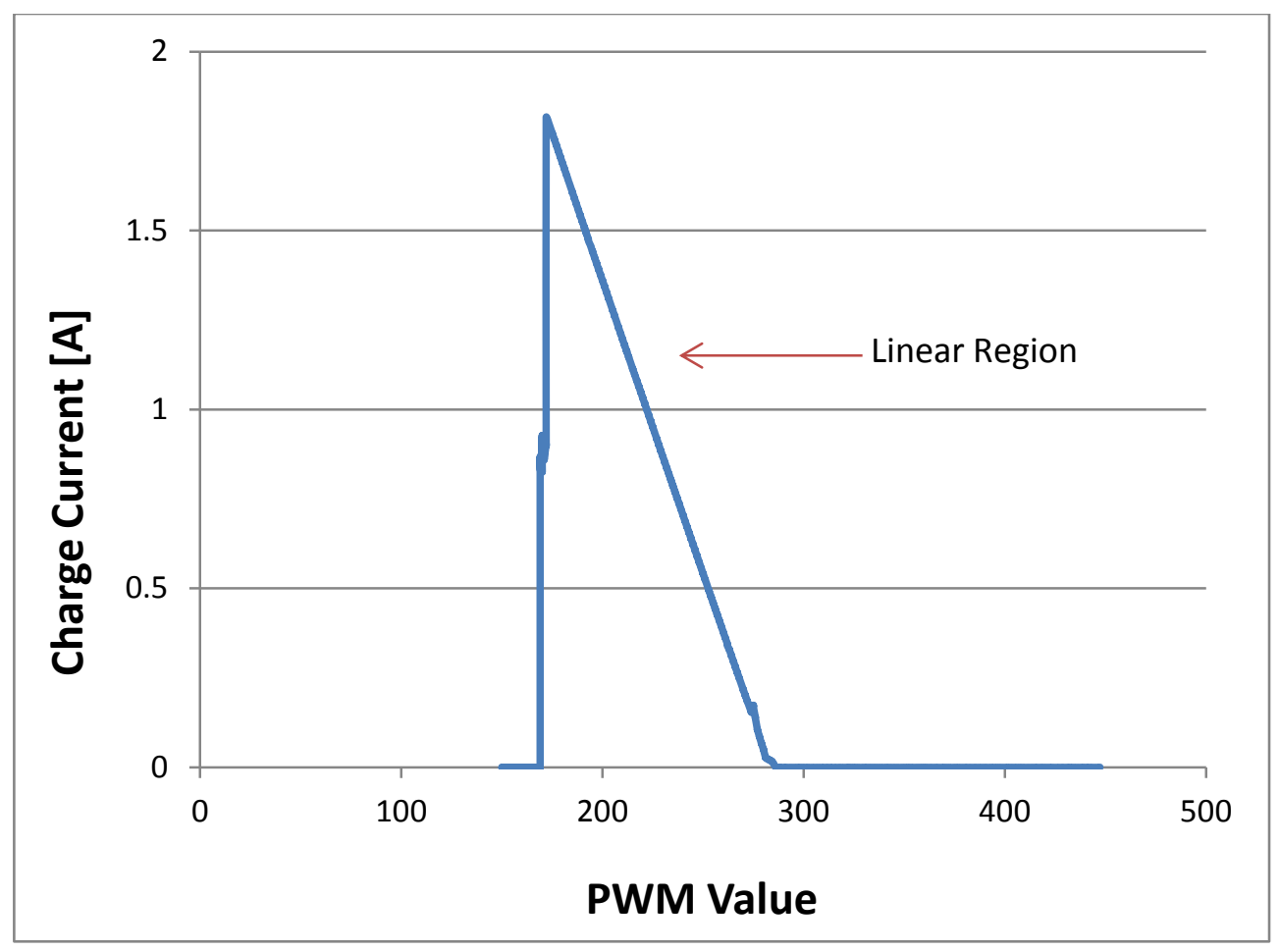

Figure 82: PWM value and corresponding charge current

Now that the MCU has full control over the output current by setting a specific PWM value, the charger algorithms shown in Figure 53 and Figure 54 can be implemented. Because the PWM value must be a whole integer value, the MCU filter from the simulation of Figure 27 becomes difficult to implement in software. Instead, the charger uses delays to emulate the functionality of the filters by setting the current loop and voltage loop bandwidths to $1 \mathrm{kHz}$. Through testing, it becomes clear that without delays, the charger updates the PWM values faster than they can settle due to the $10 \mathrm{kHz}$ cutoff frequency of the RC low-pass filter at the output of the PWM causing the output current to oscillate at an unintended set point. If the charger uses too much delay, the slow feedback of the battery voltage and current sense voltage causes an incorrect charge profile. Appendix F shows how to calibrate the ADC readings for battery voltage and current sense voltage to provide accurate feedback. The next section of troubleshooting shows how to prevent a nearly full-charged battery from prematurely triggering the constant voltage mode. 


\subsection{Adding Decoupling Capacitors}

During testing, it becomes clear that batteries at or above $3.9 \mathrm{~V}$ transition to the constant voltage mode immediately on starting the charger. This creates a problem because the charger should be in constant current mode until the set charge voltage threshold of $4.2 \mathrm{~V}$. The output node of the charger where the ADC measures the battery voltage shows voltage spikes in excess of $300 \mathrm{mV}$ as shown in Figure 83.

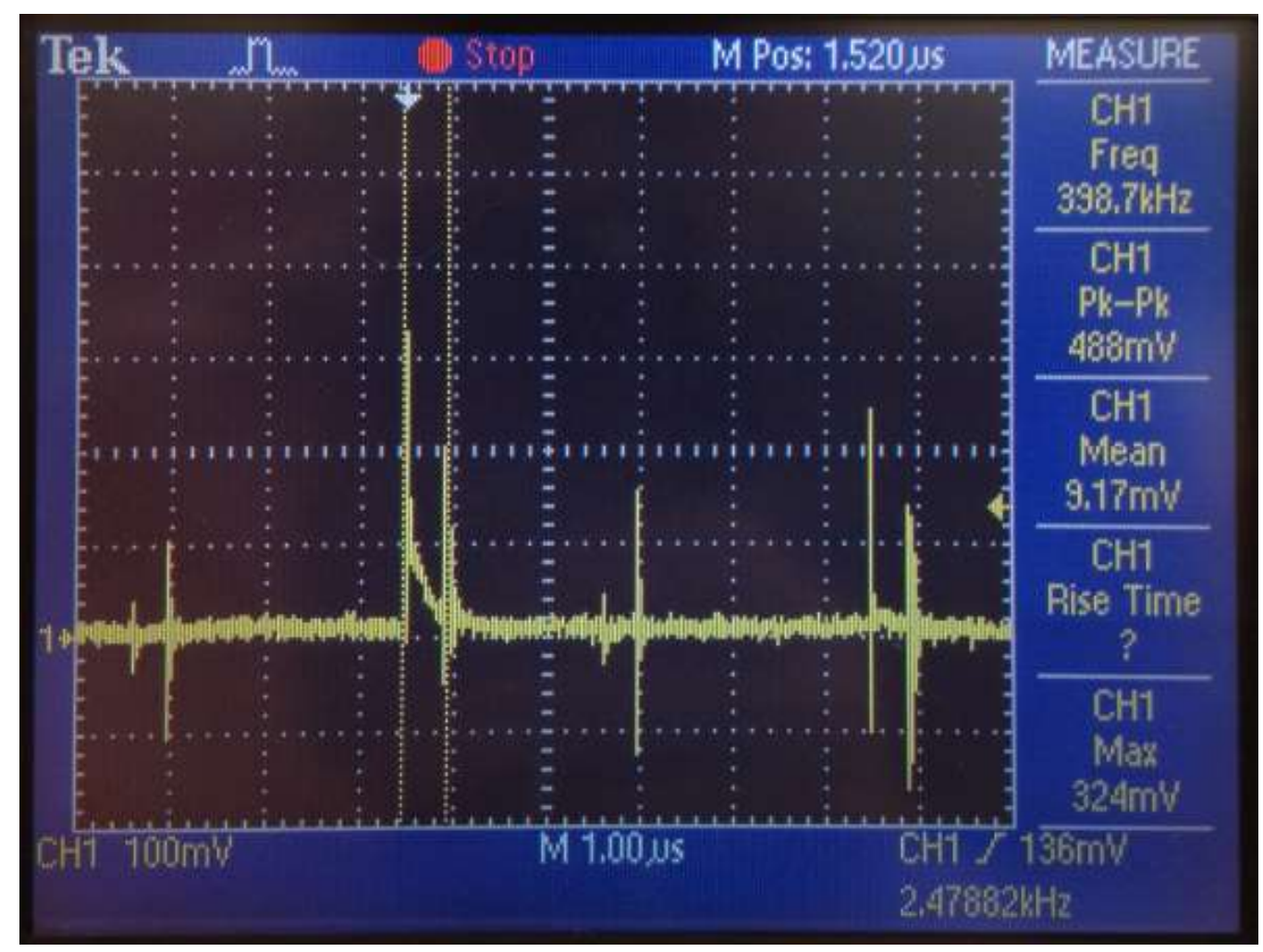

Figure 83: AC-coupled output voltage spikes of $300 \mathrm{~mA}$ while charging battery

The output node where these spikes occur inputs directly into the ADC that monitors battery voltage meaning the charger thinks the battery is at $4.2 \mathrm{~V}$ at as low as $3.9 \mathrm{~V}$. This causes the charger to start constant voltage mode prematurely, since it thinks the battery measures $4.2 \mathrm{~V}$. Adding two $2 \mu \mathrm{F}$ decoupling capacitors directly across the bottom resistor in the output voltage divider, labeled "Rbottom" in Figure 35, solves this problem. These capacitors help reduce the voltage spikes by preventing fast switching signals from changing the output node. See Figure 84 below to see how adding the decoupling capacitors improved the output voltage spikes. 


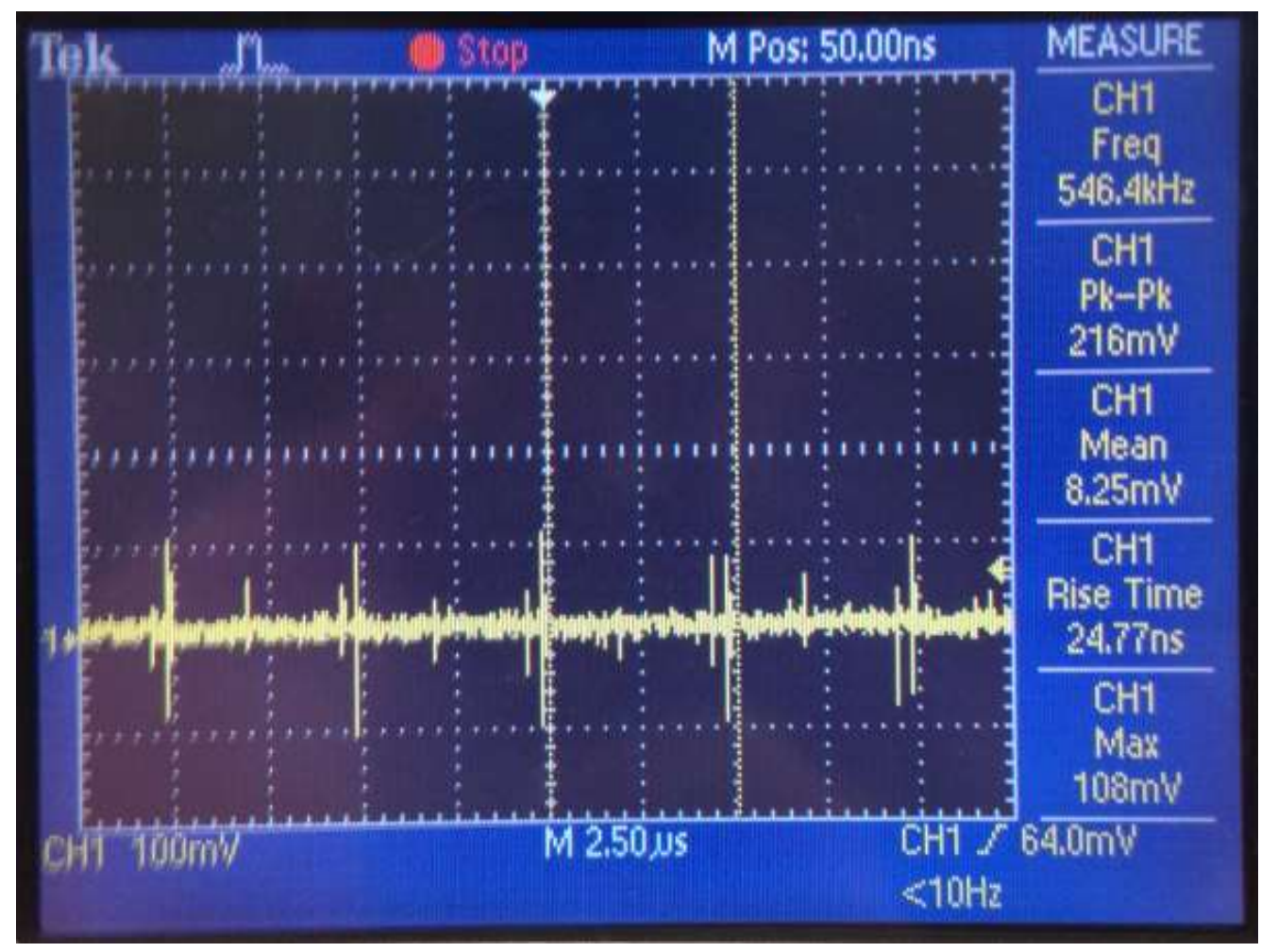

Figure 84: AC-coupled output voltage spikes reduced to $100 \mathrm{mV}$ with decoupling capacitors

With the addition of the decoupling capacitors, the output voltage spikes that the ADC measures for battery voltage reduce to $100 \mathrm{mV}$. These spikes occur roughly every $5 \mu \mathrm{s}$ corresponding to a $200 \mathrm{kHz}$ frequency. This is a direct result of the switching frequency of the LM5117 set to $200 \mathrm{kHz}$. The design sets the sampling frequency of the ADC to $198 \mathrm{kHz}$ so that the ADC never samples on a spike. With these improvements, the charger successfully charges batteries $4.1 \mathrm{~V}$ and below by charging in constant current mode up to $4.2 \mathrm{~V}$ before transitioning to constant voltage mode. 


\section{APPENDIX F: CALIBRATION}

After successfully controlling the output current of the LM5117 with the PWM, this section calibrates the ADC values so the feedback is accurate. The 12-bit ADCs measure battery voltage through a voltage divider and current sense voltage through the INA169 current shunt monitor circuit. Both of these measurements have losses in addition to potential noise on the wires that affect the actual value read by the MCU. The expected values are as follows:

\subsection{Calibrating ADC Readings}

\subsubsection{Battery Voltage}

$A D C$ value $=\frac{V i n * \frac{R_{\text {bottom }}}{R_{\text {top }} * R_{\text {bottom }}}}{3.3} * 4096$

Rbottom $=4.9705 \mathrm{k} \Omega(4.99 \mathrm{k} \Omega$ nominal $)$

Rtop $=24.838 \mathrm{k} \Omega 9(24.9 \mathrm{k} \Omega$ nominal $)$

Table XXXI: Expected and measured ADC values for battery voltage calibration

\begin{tabular}{|c|c|c|c|c|}
\hline & $\begin{array}{c}\text { Measured voltage } \\
{[\mathbf{V}]}\end{array}$ & $\begin{array}{c}\text { Expected } \\
\text { ADC }\end{array}$ & $\begin{array}{c}\text { Actual ADC at } \\
\mathbf{1 . 5} \mathbf{A}\end{array}$ & $\begin{array}{c}\text { Actual ADC at } \\
\text { 0A }\end{array}$ \\
\hline Charge Voltage & 4.2 & 869 & 988 & 888 \\
\hline $\begin{array}{c}\text { Nominal } \\
\text { Voltage }\end{array}$ & 3.6 & 745 & 883 & 773 \\
\hline
\end{tabular}

As Table XXXI shows, the expected ADC value varies significantly from the actual ADC reading while the circuit operates. The actual ADC reading also decreases as the current decreases, which is accounted for in the constant voltage mode algorithm.

\subsubsection{Current Sense Voltage}

$A D C$ value $=\frac{\frac{I_{\text {out }}}{1.5}}{3.2877} * 4096$ 
Table XXXII: Expected and measured ADC values for current sense voltage calibration

\begin{tabular}{|c|c|c|c|c|c|}
\hline & $\begin{array}{c}\text { Expected } \\
\text { current [A] }\end{array}$ & $\begin{array}{c}\text { Measured } \\
\text { current [A] }\end{array}$ & $\begin{array}{c}\text { Expected } \\
\text { ADC }\end{array}$ & Actual ADC & PWM value \\
\hline $\begin{array}{c}\text { Charge } \\
\text { Current } \\
(0.5 \mathrm{C})\end{array}$ & 1.5 & 1.5019 & 4080 & 3861 & 191 \\
\hline $\begin{array}{c}\text { Taper Current } \\
(0.1 \mathrm{C})\end{array}$ & 0.3 & 0.278 & 816 & 622 & 277 \\
\hline $\begin{array}{c}\text { Taper Current } \\
(0.033 \mathrm{C})\end{array}$ & 0.1 & 0.0946 & 272 & 383 & 279 \\
\hline
\end{tabular}

Similar to the ADC readings for the battery voltage, Table XXXII shows significant difference from the expected ADC readings and the actual ADC readings. This affects the charge profile, because they determine when the charger switches from constant current mode to constant voltage mode in addition to the charge current and the taper current. The algorithms in software use the calibrated "actual" ADC readings in order to achieve the desired charge profile.

\subsection{Digital Filtering}

Another way to improve accuracy is to use digital filters for averaging. Instead of using a single ADC reading for both current sense voltage and battery voltage monitoring, the final design increases the sample frequency and takes more readings. The MCU adds these readings and divides by the total number of readings for each $\mathrm{ADC}$ to provide a more precise average. By increasing the sample frequency proportional to the number of samples, the system keeps the bandwidth the same to maintain stability. For example, using a sampling frequency of $1 \mathrm{kHz}$ and taking one battery voltage reading and one current sense reading gives a bandwidth of $500 \mathrm{~Hz}$ but uses only one sample for both battery voltage and current sense voltage. Instead, the final design increases the sampling frequency to $198 \mathrm{kHz}$ and takes 100 battery voltage readings and 100 current sense voltage readings, adds them up, and divides by 100 to provide an average for both battery voltage and current sense voltage while maintaining the approximate $1 \mathrm{kHz}$ bandwidth. Note that the monitoring bandwidth is set for $1 \mathrm{kHz}$, and if the PWM updates, delays limit the actual voltage or current loop bandwidths to $1 \mathrm{kHz}$ as well to match the bandwidths from the simulation to maintain stability. 


\section{APPENDIX G: LIST OF EQUATIONS}

$\begin{array}{ll}\text { Equation } & \text { Page }\end{array}$

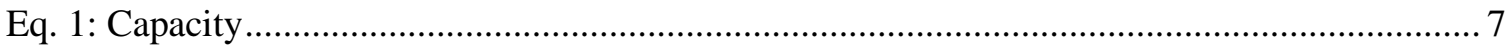

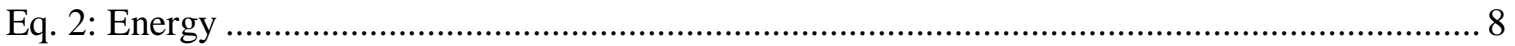

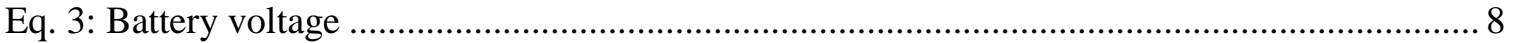

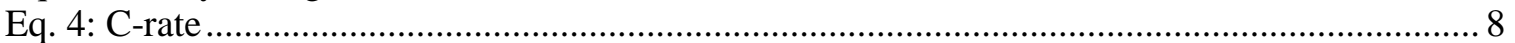

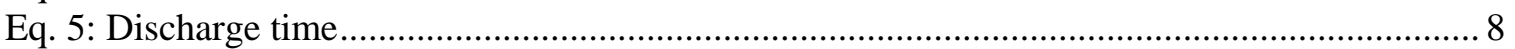

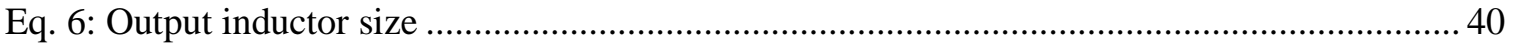

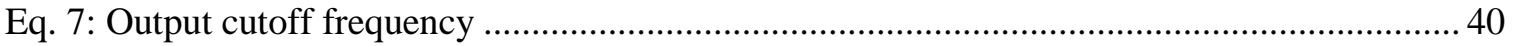

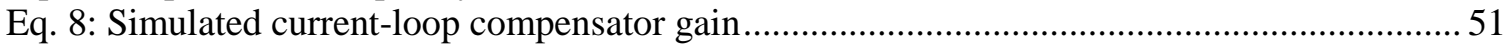

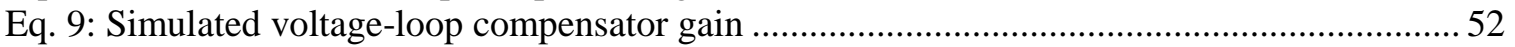

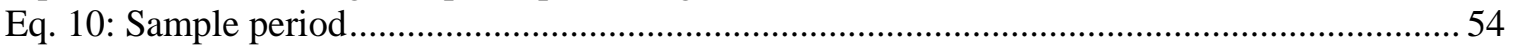

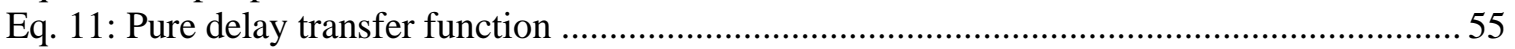

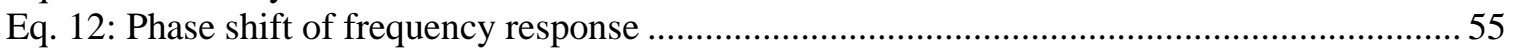

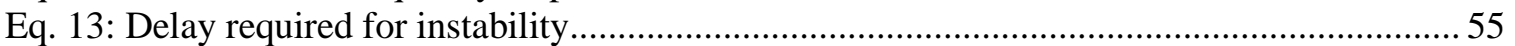

Eq. 14: Phase shift of 2nd order lowpass for LM5117 internal error amplifier.............................58

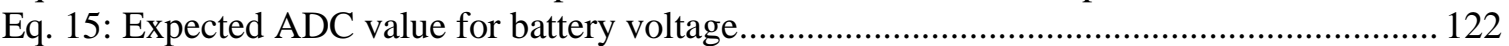

Eq. 16: Expected ADC value for current sense voltage .......................................................... 122 


\section{APPENDIX H: LIST OF ACRONYMS}

Acronym

ADC: Analog-to-digital converter

BMS: Battery Management system

DAC: Digital-to-analog converter

COV: Cell Overvoltage

CUV: Cell Undervoltage

EVM: Evaluation Module

IC: Integrated Circuit (chip)

LCD: Liquid crystal display

LED: Light emitting diode

Li-Ion: Lithium Ion

Li-Co: Li-Cobalt

Li-Mg: Li-Manganese

Li-P: Li-Phosphate

MCU: Microcontroller Unit

NDV: Negative Delta Voltage

NiCd: Nickel-Cadmium

NiMH: Nickel-Metal Hydride

$\mathrm{Pb}$ : Lead-acid

PCB: Printed circuit board

PWM: pulse-width modulation

SLA: Sealed Lead-Acid

SPI: Serial Peripheral Interface

SOC: State of Charge

USB: Universal Serial Bus 